Charged Porous Membrane Structures For Separation Of Biomolecules 
This work was financially supported by the Netherlands Organization for Scientific Research (NWO).

Graduation committee

Chairman

Prof. Dr. G. van der Steenhoven

University of Twente

Promotor

Prof. Dr.-Ing. M. Wessling

University of Twente

Assistant promotor

Dr. D. Stamatialis

University of Twente

Prof. Dr. Ir. R.G.H. Lammertink

University of Twente

Prof. Dr. J. Engbersen

University of Twente

Prof. Dr. G. Belfort

Rensselaer Polytechnic Institute,

USA

Dr. Dipl.-Ing. Bernd Krause

Gambro Dialysatoren GmbH, Germany

Charged porous membrane structures for separation of biomolecules Karina Kopeć, PhD Thesis, University of Twente, The Netherlands ISBN: 978-90-365-3146-7

Cover design by K. Kopeć, Pictures by K. Kopeć On the front cover: Cross-section of a PES/SPEEK blend hollow fiber membrane (C)2011 Karina Kopeć, Enschede, 2011

All rights reserved

Printed by Ipskamp Print Service 


\title{
CHARGED POROUS MEMBRANE STRUCTURES FOR SEPARATION OF BIOMOLECULES
}

\author{
DISSERTATION
}

\author{
to obtain \\ the degree of doctor at the University of Twente, \\ on the authority of the rector magnificus, \\ Prof. Dr. H. Brinksma,
} on the account of the decision of the graduation committee, to be publicly defended on Friday the $28^{\text {th }}$ of January 2011 at 16.45

by

Karina Katarzyna Kopeć

born on $13^{\text {th }}$ of October 1981 in Sosnowiec, Poland 
This dissertation has been approved by:

Prof. Dr.-Ing. M. Wessling - Promotor

Dr. D. Stamatialis

- Assistant Promotor 
If you can find a path with no obstacles, it probably does not lead anywhere...

For my parents

Thank you for supporting all my decisions

Dla moich rodziców

Dziękuję, że wspieraliście wszystkie moje decyzje 



\section{Table of Contents}

CHAPTER 1

INTRODUCTION............................................................................................................................................ 1

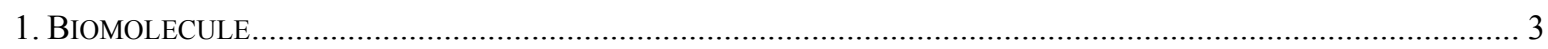

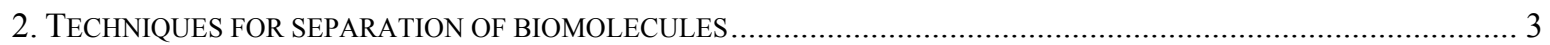

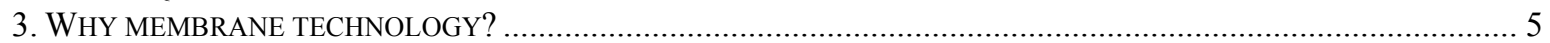

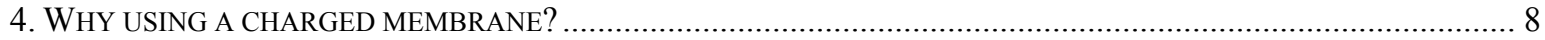

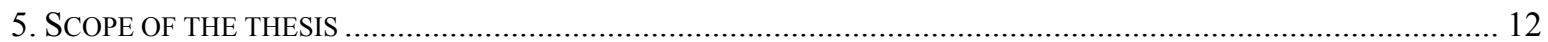

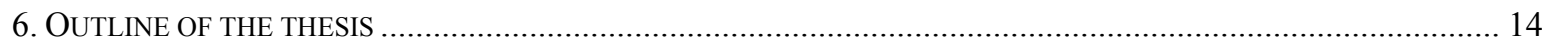

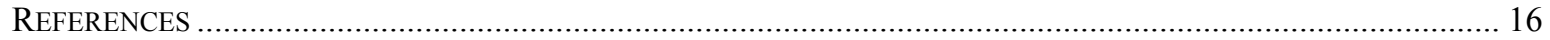

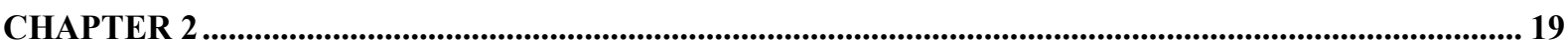

TAILORING THE SURFACE CHARGE OF AN ULTRAFILTRATION HOLLOW FIBER BY ADDITION OF A POLYANION TO THE COAGULATION BORE LIQUID ..................................... 19

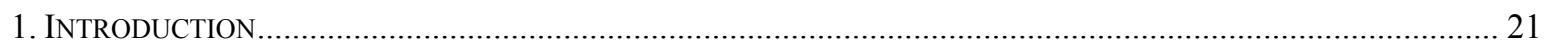

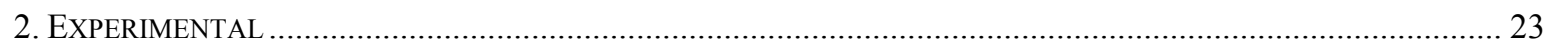

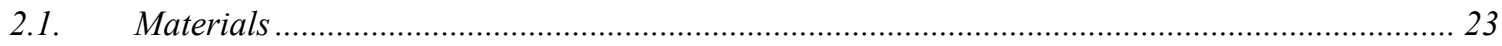

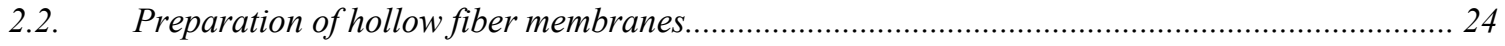

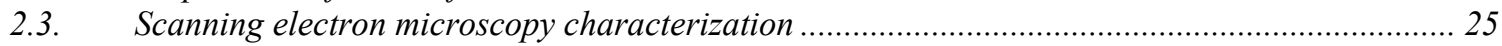

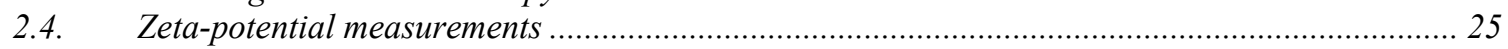

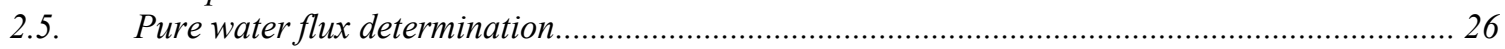

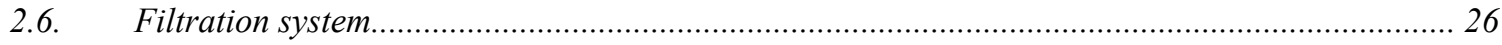

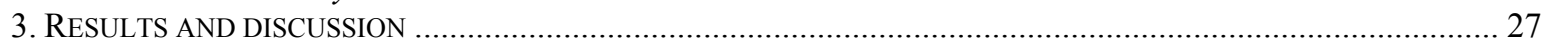

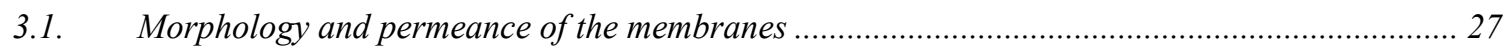

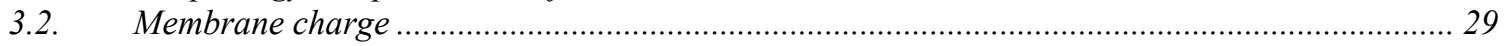

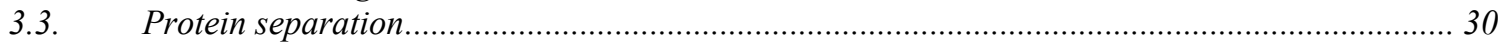

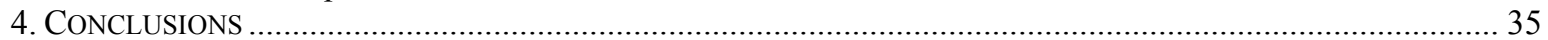

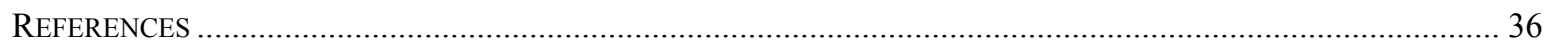

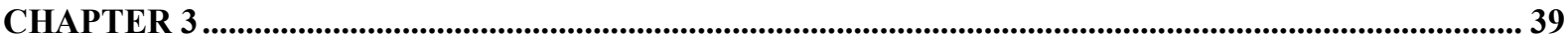

CHEMISTRY IN A SPINNERET - ON THE INTERPLAY OF CROSSLINKING AND PHASE INVERSION DURING SPINNING OF NOVEL HOLLOW FIBER MEMBRANES ............................... 39

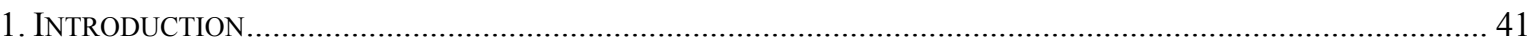

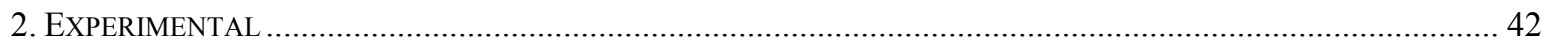

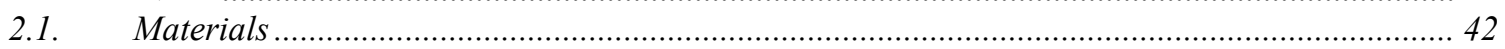

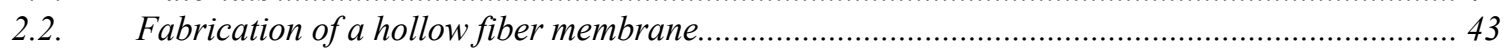

2.3. Attenuated Total Reflectance Fourier Transform Infrared Spectroscopy (ATR-FTIR)...............45

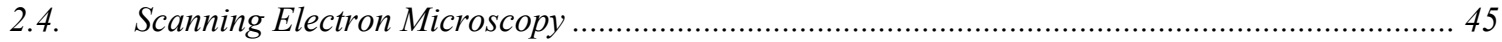

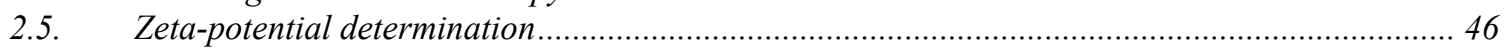

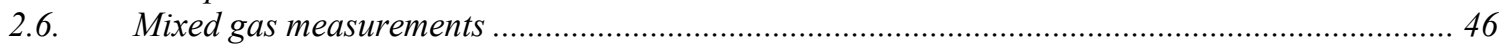

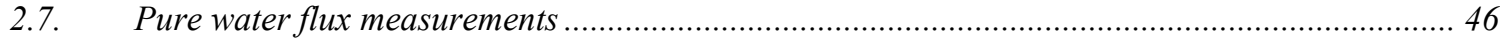

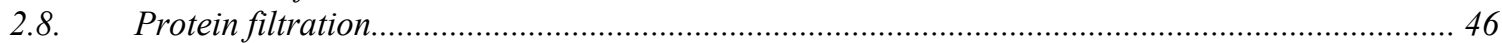

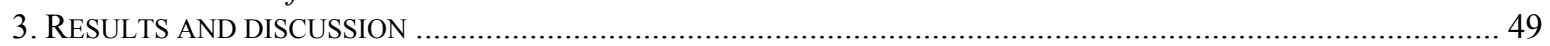

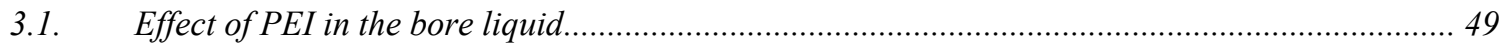

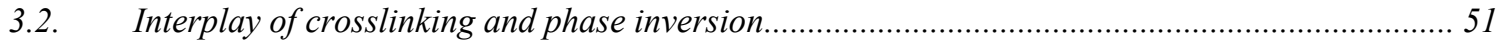

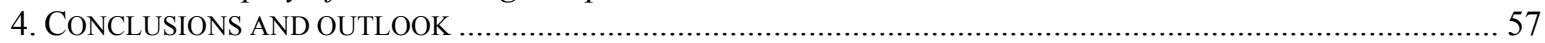

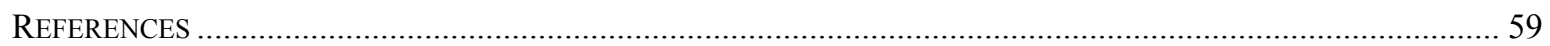


SOLVENT-RESISTANT MIXED MATRIX MEMBRANE ADSORBERS ............................................61

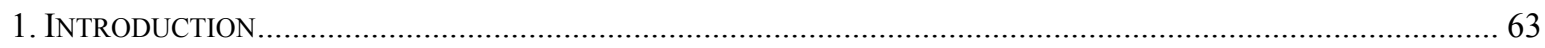

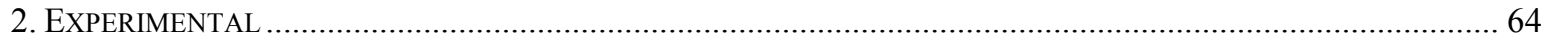

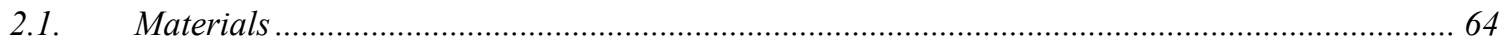

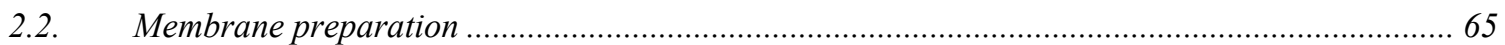

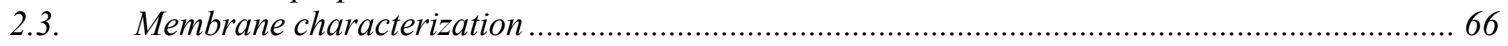

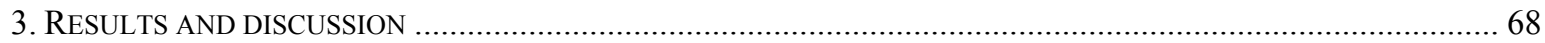

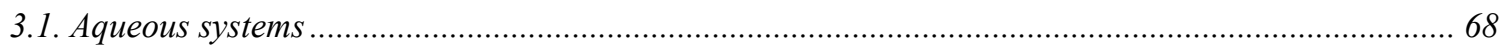

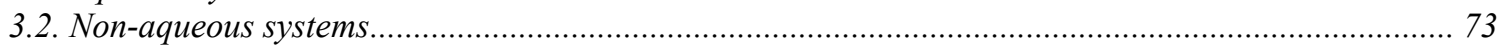

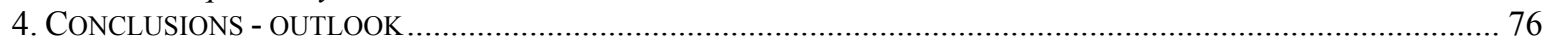

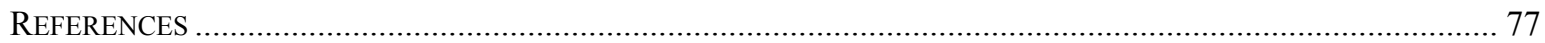

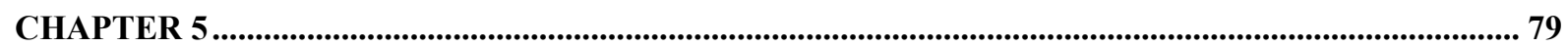

POROUS MEMBRANE STRUCTURES AS STATIONARY PHASE FOR CAPILLARY

ELECTROCHROMATOGRAPHY ..................................................................................................................79

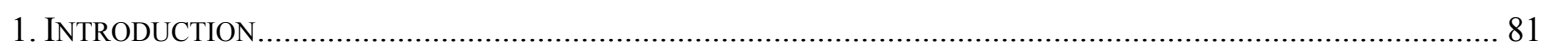

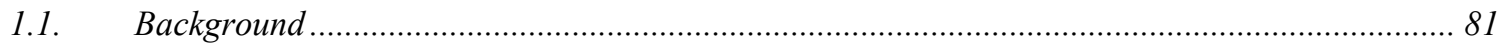

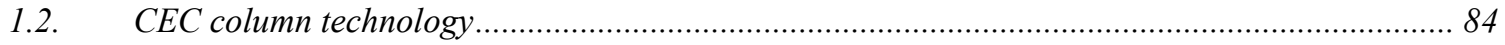

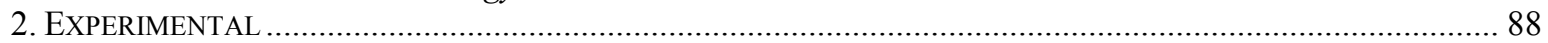

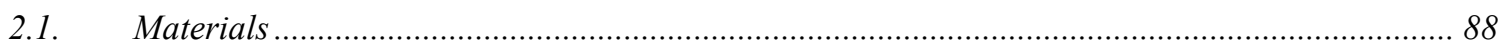

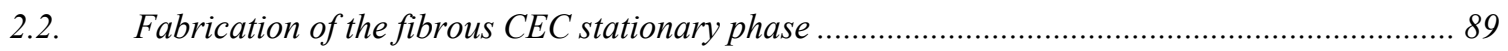

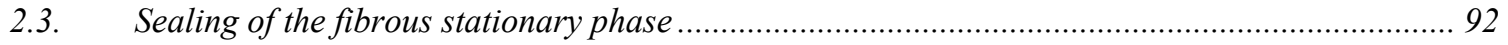

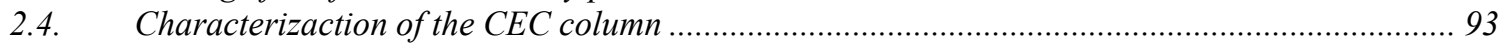

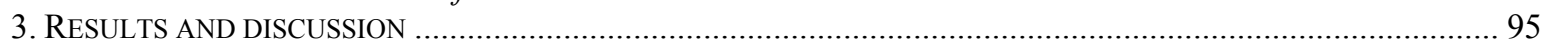

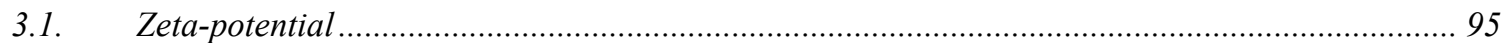

3.2. Morphology and separation performance of CEC columns............................................ 96

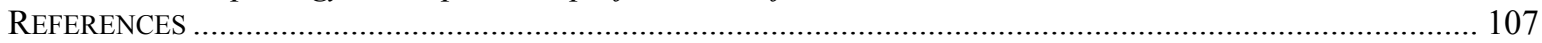

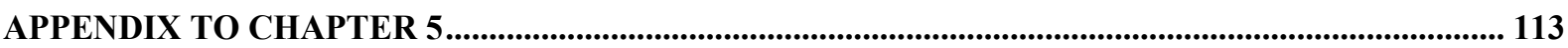

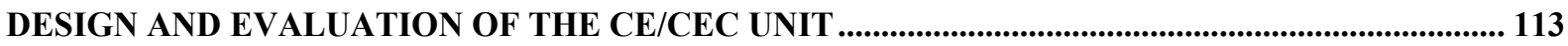

1. Design of the capillary electrophoresis/capillary electrochromatography unit................................. 114

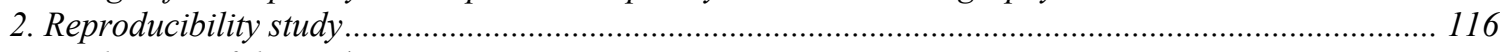

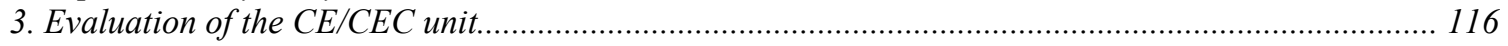

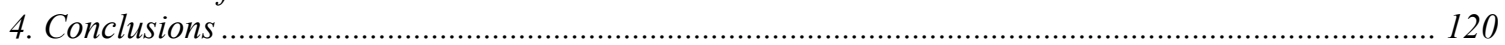

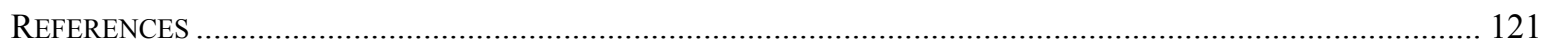

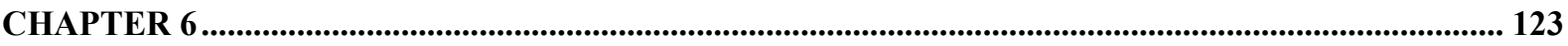

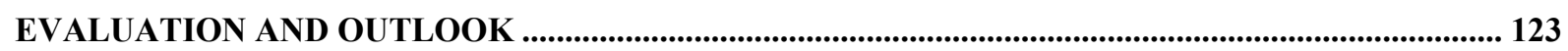

1. DEVELOPMENT OF CHARGED MEMBRANES FOR BIOMOLECULE SEPARATION ........................................... 125

1.1. Polyelectrolyte in the bore liquid ........................................................................................ 126

1.2. Polyelectrolyte/crosslinker in the bore liquid (gas and liquid/solute separation).......................... 126

1.3. Mixed matrix membranes (solid phase extraction) ..................................................................... 130

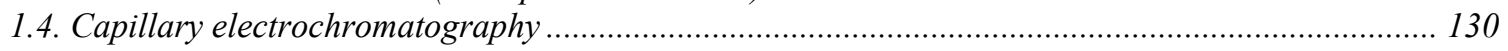

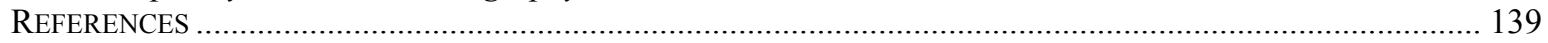

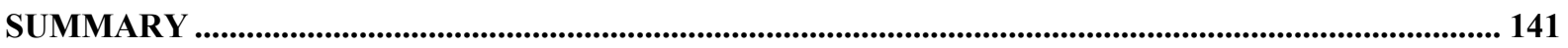

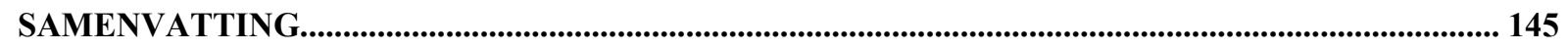

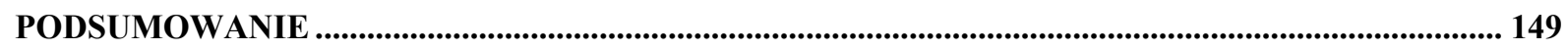

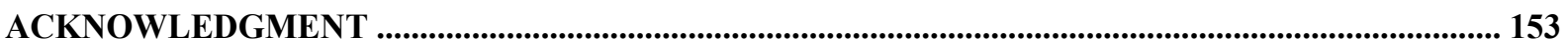




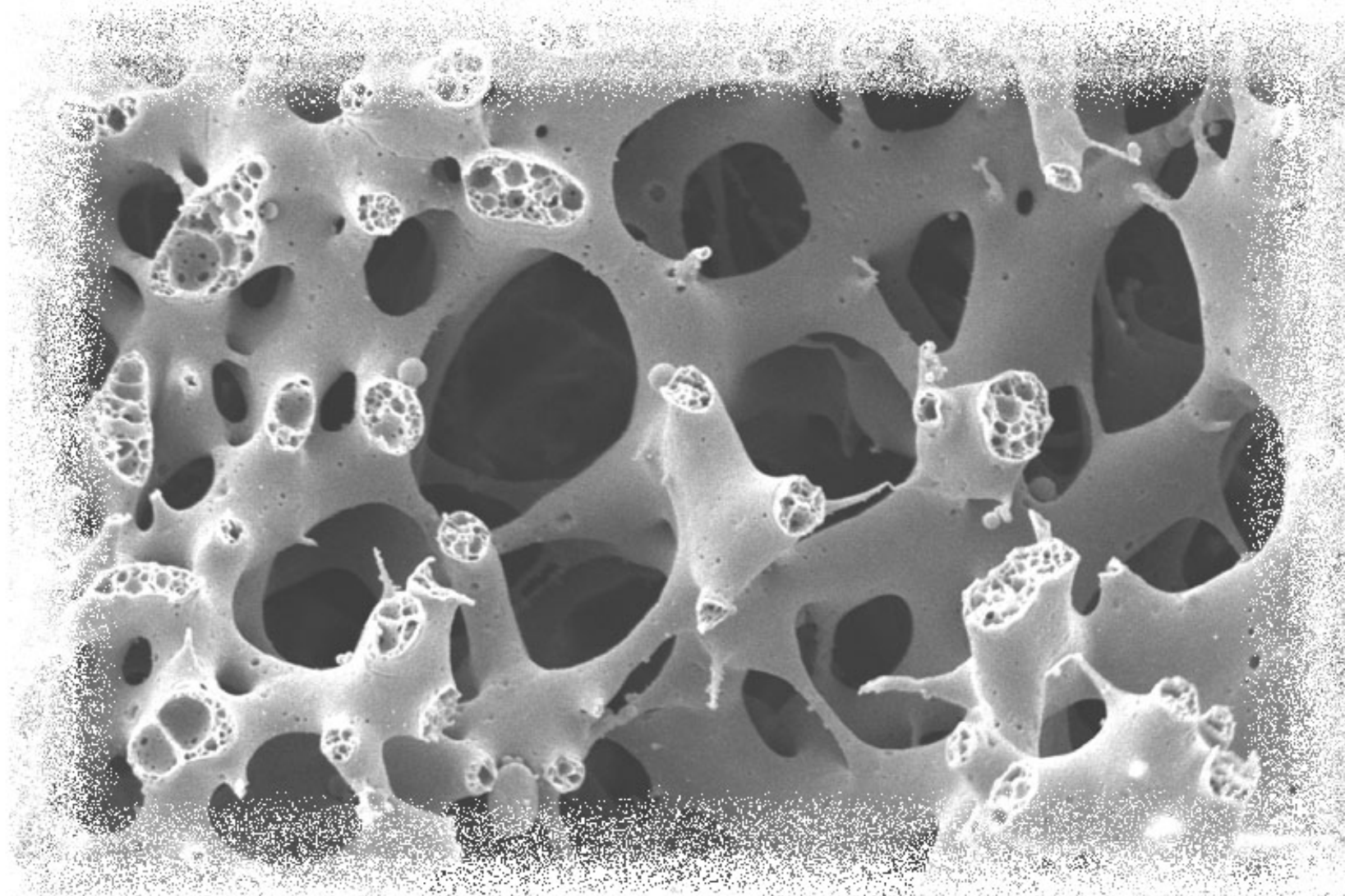

Chapter 1

Introduction 


\section{Biomolecule}

In modern biotechnology and biomedical engineering, the ability to identify and separate different biomolecules accurately and efficiently out of complex biological samples is of utmost importance. Proteomics, cancer diagnostics or understanding of biomolecular signatures involved in human diseases are the new challenges of science - science which makes biologist, physicians and chemical engineers work together. The eyes of the scientists are directed towards the mysterious Biomolecule...

The biomolecule is any organic molecule that is produced by a living organism. It can be also named a biogenic substance - a substance produced by life processes. Biomolecules are commonly categorized in three subgroups, with regard to their size [2, 3]:

a) small molecules, include lipids, phospholipids, glycolipids, sterols, glycerolipids, carbohydrates, sugars, vitamins, hormones, neurotransmitters, metabolites

b) monomers, like aminoacids, nucleotides, monosaccharides

c) polymers: peptides, oligopeptides, polypeptides, proteins, nucleic acids, DNA, RNA, plasmids, oligosaccharides, polysaccharides (e.g. cellulose), lignin, hemoglobin.

Table 1 presents characteristic magnitudes of some of the biomolecules together with cells, bacterias and viruses. The "particle size" of the desired product to be separated can range from a single molecule to particles of nearly a millimeter in diameter. Moreover, the viscosity of fluids can range over three orders of magnitude from $1 \mathrm{mPa}$ s to $1 \mathrm{~Pa}$; [4].

Table 1 Characteristic magnitudes of biomolecules, cells, bacterias and viruses [5]

\begin{tabular}{|c|c|c|c|c|}
\hline Entity & $\begin{array}{l}\text { Molecular } \\
\text { Weight }\end{array}$ & $\begin{array}{c}\text { Characteristic } \\
\text { Length }\end{array}$ & $\begin{array}{l}\text { Density, } \\
\mathrm{g} / \mathrm{cm}^{3}\end{array}$ & $\begin{array}{c}\text { Mass, } \\
\mathrm{g}\end{array}$ \\
\hline Mammalian cells & - & $10 \mu \mathrm{m}$ & & \\
\hline Escherichia coli & - & $1 \times 1 \times 3 \mu \mathrm{m}$ & 1.07 & $2.4 \cdot 10^{-12}$ \\
\hline Viruses & & $50 \mathrm{~nm}$ & & \\
\hline DNA & $10^{9}$ & & & \\
\hline RNA & $10^{6}$ & & & \\
\hline Plasmids & $3.3-13.2 \cdot 10^{6}$ & $150-250 \mathrm{~nm}$ & & \\
\hline Proteins & $10-3000 \mathrm{kDa}$ & $5 \mathrm{~nm}$ & 1.34 & $5.64 \cdot 10^{-20}$ \\
\hline
\end{tabular}

\section{Techniques for separation of biomolecules}

Bioseparation processes require different approaches than those used in traditional chemical industries. Most biological molecules, and particularly proteins, are destroyed by heat, cannot be evaporated or distilled, because they would change their specific structure which would lead to the loss of their function. Therefore biomolecules are processed by techniques that do not require heat or extreme $\mathrm{pH}$. Another difference between the 
biomolecules and chemicals is the produced amount. For example, in the pharmaceutical industry, only a few kilograms of a protein might be produced per year, but the total selling price can be in million of dollars [4]. The biomolecule, before it is received as a high purity substance, it is processed in a long way of sequential steps applied to bring it from its natural state as a component of a tissue, cell or fermentation broth, through progressive improvements in purity and concentration. Some biomolecules can be directly isolated from its natural source (and they can be directly taken to the downstream processing), others have to first be grown by bacterial or mammalian cell lines in bioreactors (so called upstream stage of the bioprocess) and afterwards moved to the downstream section.

All the bioseparations are then a part of the downstream processing which is a recovery and purification of the biomolecules. This essential step in the manufacturing of pharmaceuticals and food ingredients (usually considered a specialized field in biochemical engineering) can be broadly considered as consisting of four sequential steps $[1,3]$ :

a) removal of insolubles

b) isolation of the product

c) purification of the product

d) polishing of the product.

Removal of insolubles is the first step and involves the capture of the product as a solute in a particles-free liquid, for example the separation of cells from fermentation broth containing an antibiotic. Typical operations at this stage are filtration, centrifugation, sedimentation, flocculation, electroprecipitation.

Product isolation is the removal of the components whose properties differ to a large extent from the desired product. For most products, water is the main impurity and at this stage most of it is removed leading to the reduction of the product volume and its concentrating. The product isolation involves solvent extraction, adsorption, ultrafiltration and precipitation.

Product purification is the separation of those contaminants which physical and chemical properties are very similar to those of the final product. Consequently, this part of the downstream processing is the most time consuming and expensive to carry out requiring sensitive equipment. The product purification is usually accomplished by various chromatographic techniques, but crystallization or fractional precipitation are also used.

Product polishing is done as a final processing step and ends up in packaging of the product in a form that it is stable and easily transportable. The typical unit operations are crystallization, desiccation, lyophilization and spray drying. For some products this stage is finished with sterilization.

Certainly, the isolation and purification steps play the most important role in the downstream processing. The cost of the final product, independently of the purification technique, is dominated by its concentration in the initial feed (see Figure 1). The cost of recovering a pure component from a dilute mixture increases significantly with dilution $[1,5]$.

Bioseparations are generally difficult. The products of interest are labile and thus require mild processing conditions. They arrive at downstream processing contaminated with closely related species, and the required product purity is usually very high [5]. These demands dictate a large number of processing steps in series. 
Regulatory considerations state that the basic separation scheme must be fixed very early in the overall development process. Apart from the strict standards on the purity of a product, the Food and Drug Administration (FDA) requires validating the removal of various contaminants: host cell-related (DNA, endotoxin, protein, virus), product-related (oxidation, deamidation, acetylation, dimerization), and process-related (antibiotic, antiform, inducing agent) [5].

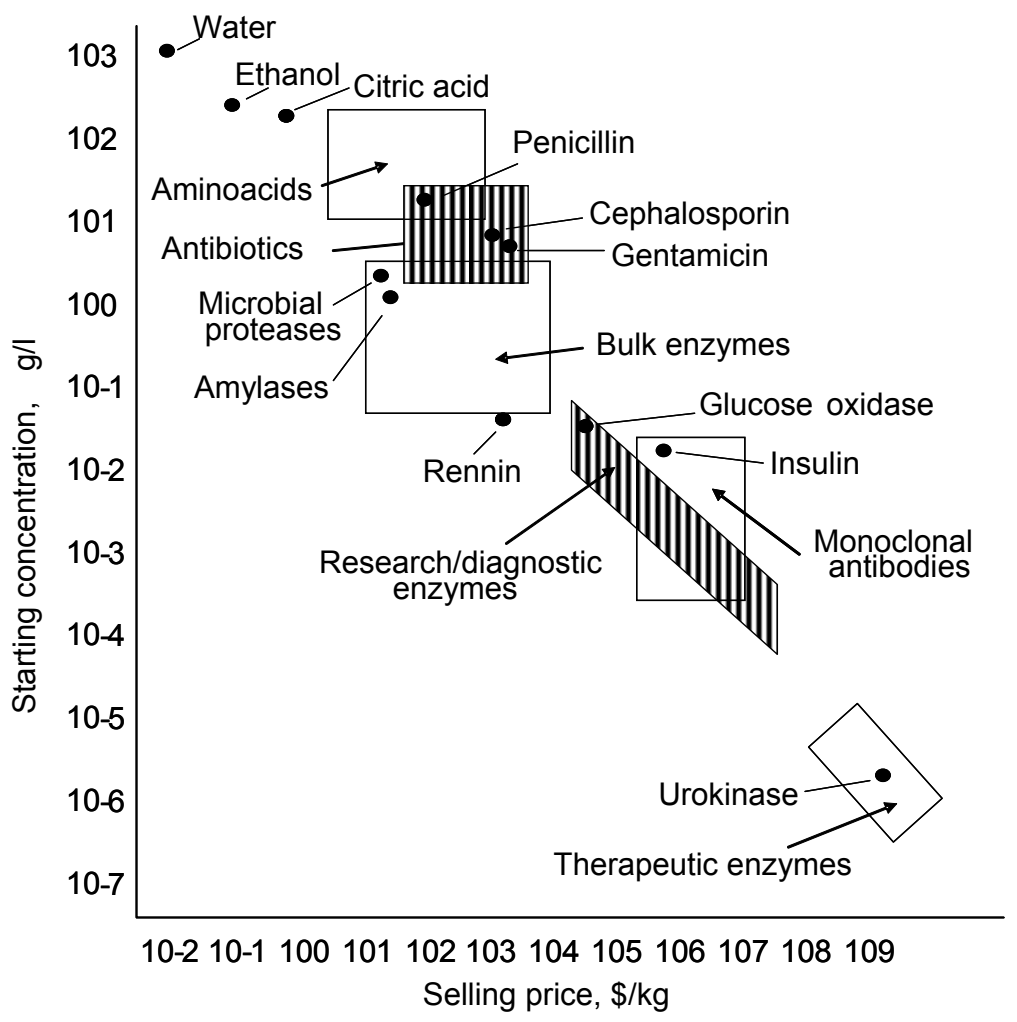

Figure 1 Relation of the initial product concentration and the cost [1]

\section{Why membrane technology?}

During the last three decades, membranes attracted the attention of chemists, chemical and biological engineers due to their unique separation principle, i.e. the selective transport and efficient separation comparing with other unit operations. Separations with membranes do not require any additives and they can be carried out at low temperatures with less energy consumption to other thermal separation processes. Due to these advantages of membrane processes, upscaling and downscaling of membrane separations as well as their integration into other separation or reaction processes are simple.

The first application of a membrane - a semipermeable barrier - for separation of biomolecules dates long back. In 1913 John J. Abel built the first artificial kidney which was supposed to clean the blood from metabolic toxins in case of end-stage kidney failure. Essential part of this unit was a membrane made of Collodion, a material based on cellulose [6]. Together with coworkers Abel performed the first hemodialysis on animals. The major 
breakthrough, however, in the treatment of patients with kidney disease was thanks to Willem Kolff, a Dutch physician who in 1945 performed the first successful hemodialysis on a human using a separation unit he designed [7, 8]. Kolff's rotating drum kidney used membranous tubes made of a new material known as cellophane that was actually used in the packaging of food (Figure 2). During the treatment, the blood-filled tubes were wrapped around a wooden drum that rotated through an electrolyte solution known as "dialysate". As the membranous tubes passed through the bath, the uremic toxins would diffuse into this rinsing-liquid.

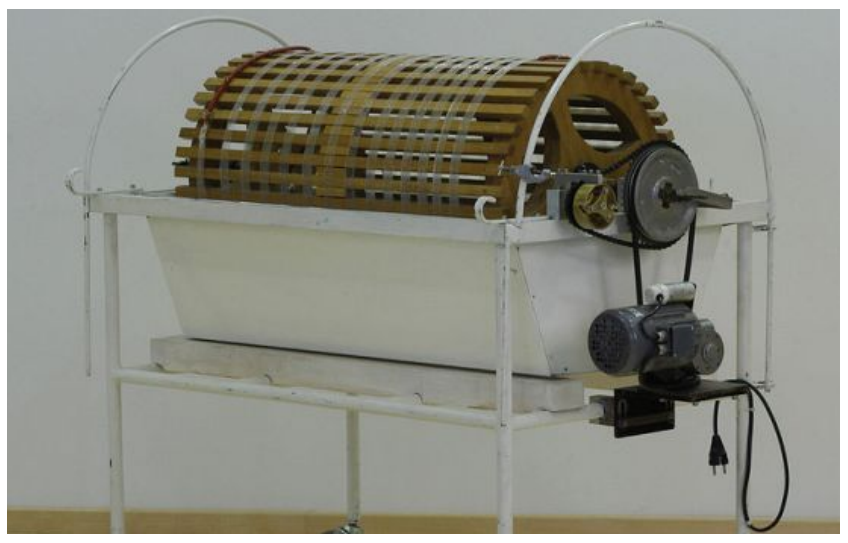

Figure 2 Kolff's artificial kidney

Nowadays, hemodialysis is the dominant therapeutic application of membranes with more than 46000 dialysis machines and about 150 million dialyzers sold in 2006 [9]. Table 2 presents different medical applications of membranes $[9,10]$.

Table 2 Medical application of membranes (UF = ultrafiltration, $\mathrm{GS}=$ gas separation, $\mathrm{NF}=$ nanofiltration, $\mathrm{MF}=$ microfiltration)

\begin{tabular}{lccc}
\hline Medical application & Membrane type & $\begin{array}{c}\text { Volume Devices/Year } \\
\text { (Million) }\end{array}$ & $\begin{array}{c}\text { Membrane Area } \\
\mathrm{m}^{2} / \text { Year (Million) }\end{array}$ \\
\hline Hemodialysis & UF, dialysis & $110\left(150^{*}\right)$ & $230\left(314^{*}\right)$ \\
Oxygenation & GS, NF, UF & 0.75 & 2 \\
Infusion & UF, MF & $1-2$ & $<1$ \\
Liver support & UF, MF & Unknown & Unknown \\
Pancreas & UF & Unknown & Unknown \\
Therapeutic apheresis & MF & 0.3 & $\sim 0.1$ \\
Plasma donation & MF & $<12$ & $<0.1$ \\
\hline
\end{tabular}

Data marked with (*) as for 2006 [9]; other data as for 2002 [10]

The next stage of bioseparations started in 1936 when John. D. Ferry described the use of membrane technology for enzyme concentration, analysis of bacteriophages and viruses, preparation of cell- and protein-free ultrafiltrates from biological solutions [11]. He mentioned, however, the system limitations due to the availability of membranes and modules. 
The first large-scale industrial application of membranes in bioseparations was in New Zealand in 1971 in a whey-processing unit [1]. Since then, membrane separation processes contributed widely in many sectors of bio-industry which could be divided into two groups:

(i) biotechnology, pharmacy, medicine

(ii) food and drink industry (beverages, dairy products, oils and fats, fruit and vegetables, meat and sugar).

Figure 3 compares the size of biomolecules with other molecules, microorganisms and particles showing membrane separation techniques applicable for each size.

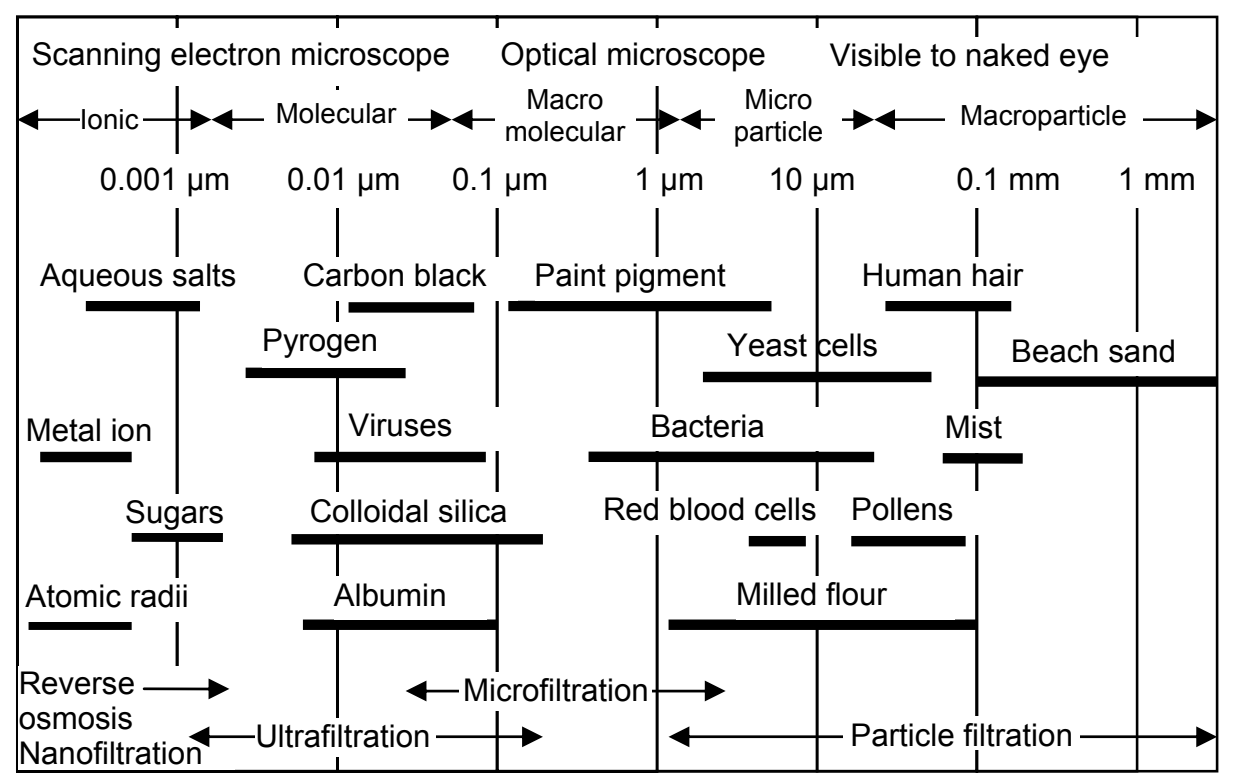

Figure 3 Classification of particles by size and applicable membrane processes

Membranes have been traditionally used for size-based separations with highthroughput, but low-resolution outcome. Current research and development of membrane processes in order to become techniques of choice for biotechnology, focuses on improvements in selectivity while maintaining the inherent high throughput characteristics of membrane [12].

Essentially, all the membrane processes are used nowadays for bioseparations, but the greatest interest is in the application of microfiltration, ultrafiltration, nanofiltration and membrane chromatography.

Membrane microfiltration competes with centrifugation, depth filtration and expanded-bed chromatography for the initial harvest of therapeutic products from mammalian, yeast and bacterial cell cultures and sterilizing liquids [2, 13]. In contrast to centrifugation, microfiltration when using $0.2 \mu \mathrm{m}$ pore size membranes results in a particle-free harvest solution which does not require any additional clarification. Microfiltration membranes are extensively used for sterile filtration of almost all biotherapeutics since the thermal stability of these molecules prohibits the use of alternative sterilization methods [14]. Sterile filters operate using normal flow filtration retaining bacteria, cell debris and insoluble aggregates. 
Membrane ultrafiltration largely replaced size-exclusion chromatography in protein concentration, buffer exchange and virus filtration [15]. Work has been demonstrated on the use of ultrafiltration for the purification of plasmid DNA [16] and virus-like particles [17]. Affinity separations of proteins were performed on ultrafiltration membranes with linked ligands $[18,19]$. Fractionation of dairy wastewater into lactose-enriched and protein enriched streams was also studied [13].

Membrane nanofiltration is used for separation of peptides, with the main application in treating cheese whey: enriching peptides with antibacterial properties and desalting the peptide fractions [20, 21].

Membrane chromatography uses membranes that contain functional ligands attached to the inner pore surface throughout the membrane structure providing highly selective separation via adsorption/binding interactions. The target biomolecules are adsorbed on these binding sites during the convective flow through the membrane pores. Ion exchange, affinity, reversed-phase, and hydrophobic interaction membranes have been developed [14, 22]. Although the equilibrium binding capacity is rather low, the convective flow through the pores reduces the mass transfer resistance compare to column (bed) chromatography $[12,14$, 23]. This offers great advantages for purification of large biomolecules that have significant diffusion limitations in conventional chromatographic media. Moreover, membrane chromatography has higher flow rates, lower pressure drop, shorter processing time and is less expensive than chromatography $[5,24,25]$. The pore size, membrane chemistry, membrane thickness and/or the number of membrane layers, however still need to be optimized to improve the binding capacities. Recently, particle loaded porous sheets and particle-embedded porous fibers (mixed matrix membrane adsorbers) were developed and optimized for separation of proteins [22, 25-31]. The incorporation of functional particles into porous polymeric matrix results in adsorptive structures, which can be applied to isolate peptides and proteins from complex mixtures, e.g. lysozyme from chicken egg white [30] or creatinine and endotoxin from blood [28]. The particles incorporated into polymeric matrix display rapid adsorption kinetics, high capacity and selectivity, and allow fast desorption of targeted molecules.

In most of the lab-scale and industrial-scale applications membranes are used in form of the hollow fiber membranes with a small field of flat sheets membranes. Hollow fiber membranes are made from a variety of polymers including polyethersulphone, polysulphone, polypropylene, polyacrylonitrile, polyvinylidene fluoride, regenerated cellulose, cellulose acetate $[13,14]$. These fibers typically have inner diameters of 0.2-1.8 $\mathrm{mm}$, they are self supporting and they do not need spacers or multiple sealing procedure [14]. The main advantage of using hollow fiber configuration is the high ratio of membrane surface area to its volume.

\section{Why using a charged membrane?}

Generally, in the membrane technology, charged membranes are applied in processes that can be divided into two groups. The first group are membrane processes that 
use pressure or concentration difference as a driving force and then, the electrical properties of the membrane are exploited at the interface membrane-solution or membrane-solute. In this type of separations (microfiltration, ultrafiltration, nanofiltration, reverse osmosis, dialysis, gas separation) the advantages of charged membranes are underlined as higher selectivity/retention or reduction of fouling phenomena. The other group are membrane processes which use external electrical field as driving force (electrodialysis, electrolysis, electrofiltration) [32].

As most of the biomolecules have their own charge, using charged membranes will provide additional flexibility to improve the selectivity of separation. A positively charged membrane will give higher retention of a positively charged biomolecule than will a negatively charged or neutral membrane of the same pore size [33]. The most applicable group of biomolecules to use with charged membranes are proteins and this thesis is focused on them.

Proteins are heterogeneous, amphoteric polymers of acidic, basic and neutral amino acids and carry both negatively and positively charged groups on their surface. Amino acids with basic and acidic side chains are almost always found on the outer surface of proteins dissolved in water since these side groups are highly polar. Amino acids with uncharged polar side chains are frequently also exposed to the outer protein surface because of their hydrophilic nature. The side chains of nonpolar amino acids are nearly always found inside because they tend to cluster together in a hydrophobic pocket [3]. The net charge of a protein is determined by the sum of positively and negatively charged amino acids residues on the protein surface, which is a function of the buffer $\mathrm{pH}$ in which the protein is dissolved. The isoelectric point $(\mathrm{pI})$ of a protein is the $\mathrm{pH}$ at which a protein has an equal number of positive and negative charges (the charge is zero) (structure b, see below). The isoelectric point is a specific characteristic of each protein and different proteins have different isoelectric point. Proteins in a solution at $\mathrm{pH}$ below their $\mathrm{pI}$ will have a net positive charge (structure a) and proteins above their $\mathrm{pI}$ will have a net negative charge (structure $\mathrm{c}$ ).

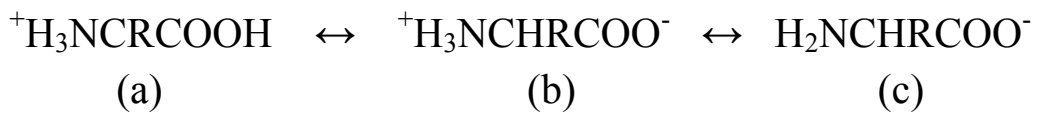

A solid surface, in this case a membrane surface, in contact with a solution of an electrolyte usually carries an electric charge. This charge gives rise to an electrical potential, $\psi$, which is the highest at the surface $\left(\psi_{0}\right)$ and decreases as we move through the liquid away from the surface, thus affecting the distribution of ions in the liquid. Ions from the liquid that have opposite charge to the charge of the membrane surface adsorb on the membrane and completely neutralize its charge (Figure 4). The ions immediately adjacent to the surface are nearly immobile, since the opposite charges are strongly interacting. These counterions form the so called Stern layer. [34]. Further from the solid surface, the electric attraction of the solid decreases and the ions are more mobile thus forming the diffuse layer which is composed of both co- and counterions. In bulk solution the ions of both signs are in a random motion. The Stern layer and diffuse layer are the principle of the electrical double layer model that describes the distribution of charges at the solid-liquid interface. Because of the 
a)

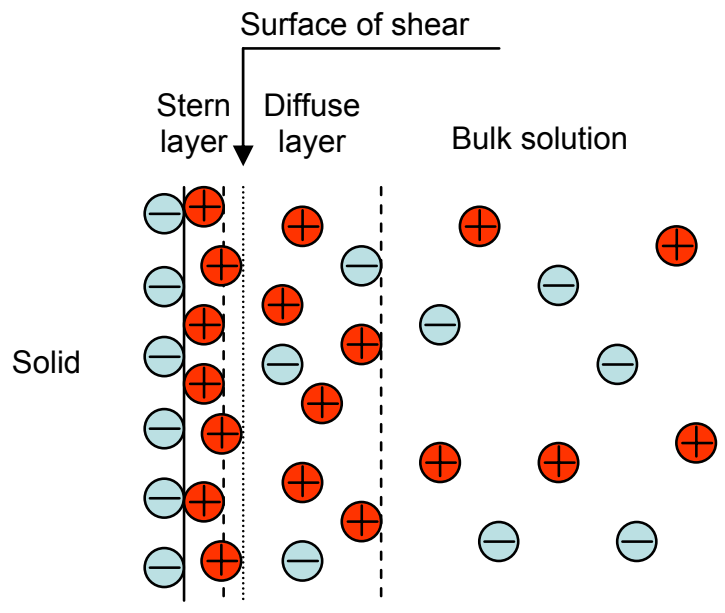

b)

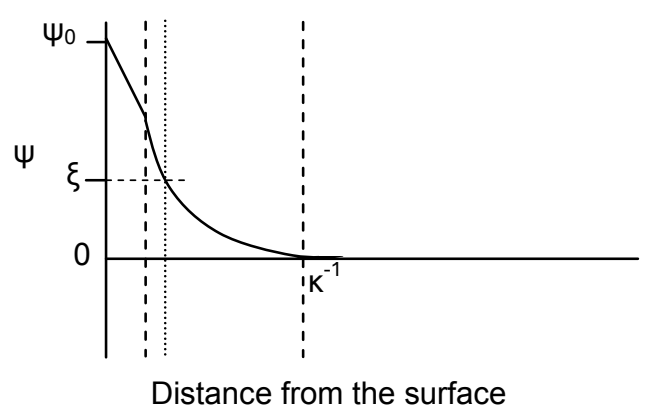

c)

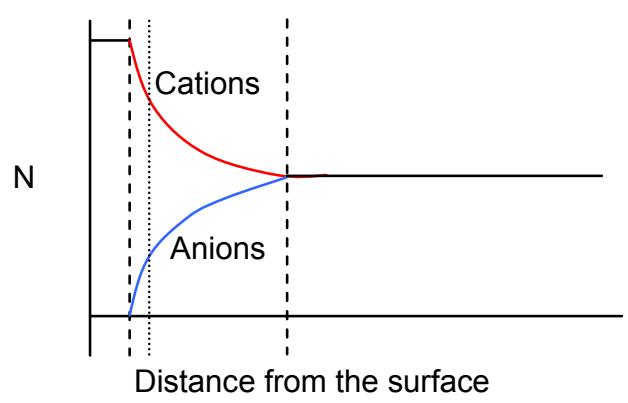

Figure 4 Schematic of the double layer at the charged solid-liquid interface: (a) the distribution of ions, (b) a graph of the electrical potential, (c) the concentration of ions

difference in charge between the diffuse layer and the solid surface, movement of one relative to the other will cause charge separation and generate a potential difference, or alternatively, application of an external electrical potential will cause movement of one relative to the other. This relative movement of the solid surface and the liquid occurs at the surface of shear and the potential at this surface of shear is known as zeta-potential, $\xi$. Its value can be determined by measurement of one of the electrokinetic phenomena listed in Table 3 . The importance of the $\xi$ potential comes from the postulate that the surface of shear is almost identical with the surface of the Stern layer. The zeta-potential gives the measure of the potential at the beginning of the diffuse layer and hence corresponds to $\psi_{0}$. It is a function of the solid surface charge, any adsorbed layer at the interface, and the nature and composition of the liquid electrolyte. The characteristic thickness of the double layer is the Debye length, $\kappa^{-1}$, which is 
reciprocally proportional to the square root of the ion concentration. In aqueous solution it is typically on the scale of a few nanometers and the thickness decreases with increasing concentration of the electrolyte.

Table 3 The electrokinetic phenomena

\begin{tabular}{lll}
\hline Stationary phase & Solid & Liquid \\
Mobile phase & Liquid & Small particles \\
\hline Movement by electric field & Electroosmosis & Electrophoresis \\
Mechanical movement & Streaming & Sedimentation \\
\hline
\end{tabular}

Charged membranes that carry exchangeable cations or anions are called ionexchangers. A cation exchanger has a negatively charged surface and replaces one positively charged cation with another. An anion exchanger is positively charged and exchanges negatively charged anions. The ion exchangers can be ionized over a small $\mathrm{pH}$ range (see Figure 5) and they are called weak ion-exchangers or can be charged over a broad $\mathrm{pH}$ range and then they are called strong cation-exchangers. Table 4 presents the common functional groups of ion exchangers.
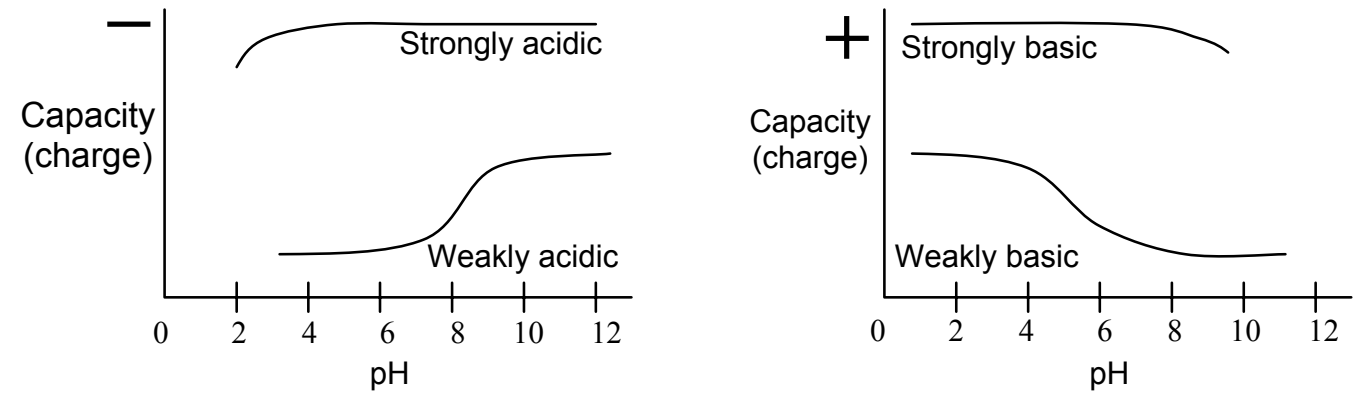

Figure 5 Charge of ion-exchange membranes vs. $\mathrm{pH}[3]$

Charged proteins can be fractionated based on their charge, even though they have similar sizes. It may be even possible to exploit electrostatic interactions for molecules with identical isoelectric point due to the different charge-pH profiles. The protein separation/fractionation will depend not only on the protein net charge, but also on the manner in which the charges are clustered on the protein's surface. Charged amino acids residues may be distributed uniformly on the surface forming regions of positive or negative charges. Hence the net charge of a protein can differ from its binding charge. Figure 6 shows the expected adsorption of a protein on a charged membrane depending on the $\mathrm{pH}$. The retention properties of membrane are difficult to predict, because while changing the $\mathrm{pH}$, both the protein net charge and the charge of the membrane will alter. In designing the separation of charged biomolecules with charged membranes, one must consider $\mathrm{pH}$, ionic strength of the buffer, and what influenced by these - the charge of membrane and the charge of protein. 
Table 4 Functional groups of ion exchanger membranes [3]

\begin{tabular}{clc}
\hline \multicolumn{1}{c}{ Type of ion exchangers } & \multicolumn{1}{c}{ Name } & $\mathrm{pK}$ \\
\hline Weak anion & Aminoethyl & \\
$-\mathrm{C}_{2} \mathrm{H}_{4} \mathrm{~N}^{+} \mathrm{H}_{3}$ & Diethylaminoethyl & $9.0-9.5$ \\
$-\mathrm{C}_{2} \mathrm{H}_{4} \mathrm{NH}^{+}\left(\mathrm{C}_{2} \mathrm{H}_{5}\right)_{2}$ & & \\
Weak cation & Carboxy & $3.5-4.0$ \\
$-\mathrm{COO}^{-}$ & Carboxymethyl & \\
$-\mathrm{CH}_{2} \mathrm{COO}^{-}$ & & \\
Strong anion & Trimethylaminoethyl & 9.5 \\
$-\mathrm{CH}_{2} \mathrm{~N}^{+}\left(\mathrm{CH}_{3}\right)_{3}$ & Triethylaminoethyl & \\
$-\mathrm{CH}_{2} \mathrm{H}_{4} \mathrm{~N}^{+}\left(\mathrm{C}_{2} \mathrm{H} 5\right)_{3}$ & Diethyl-2-hydroxypropyl-aminoethyl & \\
$-\mathrm{C}_{2} \mathrm{H}_{4} \mathrm{~N}^{+}\left(\mathrm{C}_{2} \mathrm{H}_{5}\right)_{2} \mathrm{CH}(\mathrm{OH}) \mathrm{CH}_{3}$ & & \\
Strong cation & Sulphonate & $\sim 2$ \\
$-\mathrm{SO}_{3}^{-}$ & Sulphomethyl & \\
$-\mathrm{CH}_{2} \mathrm{SO}_{3}^{-}$ & Sulphopropyl & $2.0-2.5$ \\
$-\mathrm{C}_{3} \mathrm{H}_{6} \mathrm{SO}_{3}^{-}$ & & \\
\hline
\end{tabular}

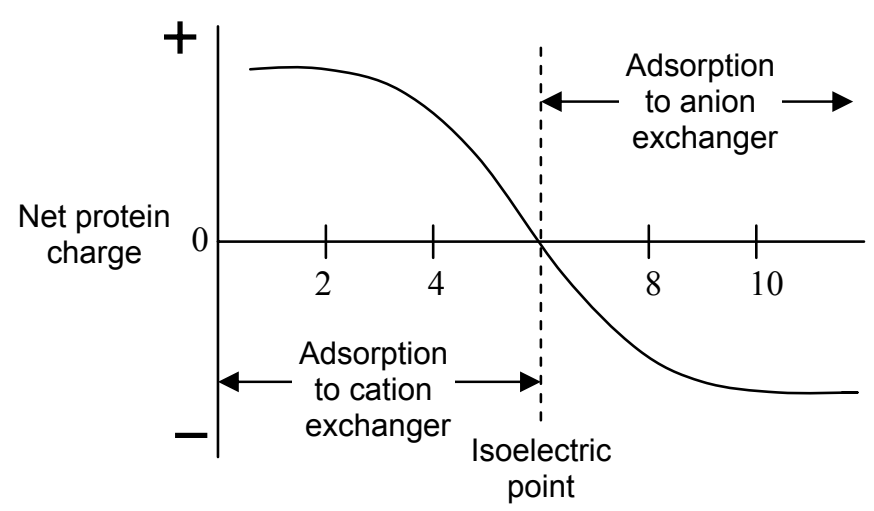

Figure 6 Protein charge vs. pH for protein [3]

\section{Scope of the thesis}

This thesis presents various membrane techniques for biomolecules separation. In all cases new charged membranes and new methods to introduce charge into the membranes are demonstrated. Table 4 presents "the summary of the thesis" and underlines the main subject matters of each chapter. In all chapters hollow fiber membranes were produced in the laboratory via the immersion precipitation dry-wet spinning [32, 35]. Figure 7 shows the schematic of the spinning procedure. The dope solution along with the bore liquid are pumped simultaneously by means of gear pumps $(2,4)$ through a double orifice spinneret $(5)$. The spinneret, shown in Figure 8, shapes the fiber - it determines its initial inner and outer diameter and the wall thickness. After a short residence time in the air (so called air gap) the still fluid-like fiber (6) is immersed in the coagulation bath containing nonsolvent, where the 


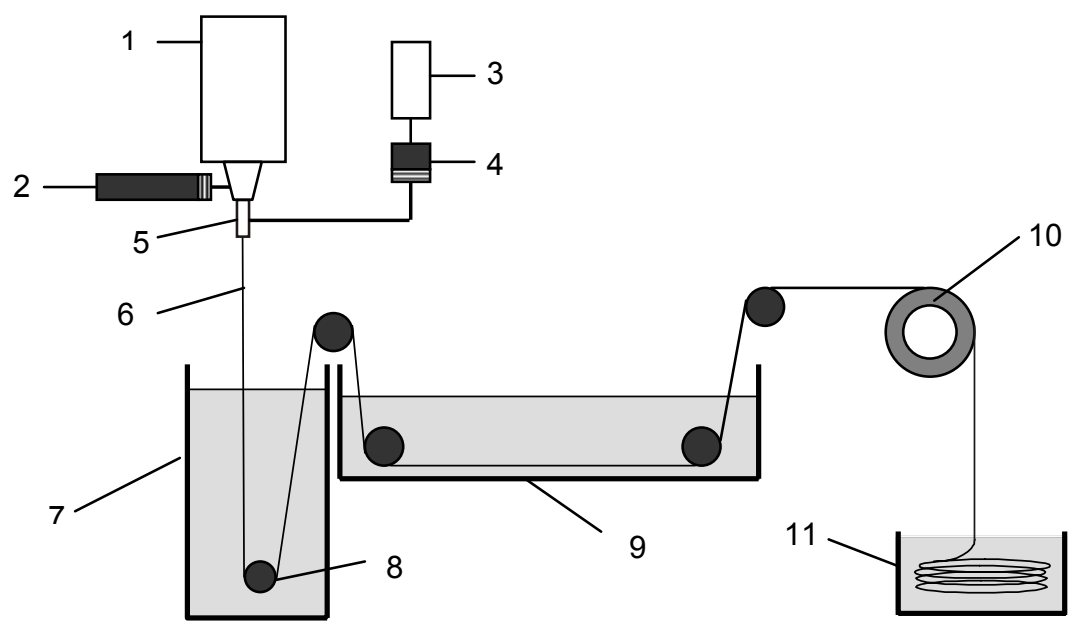

Figure 7 Schematic of the dry-wet spinning set-up. (1) tank with the polymer solution (2) gear pump for the polymer solution (3) tank with the bore liquid (4) gear pump for the bore liquid (5) spinneret (6) liquid fiber (7) coagulation bath with nonsolvent (8) guiding roll (9) rinsing bath (10) pulling wheel (11) collection bath.

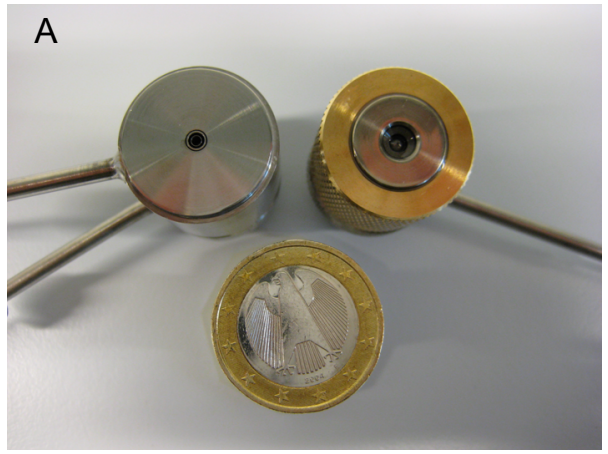

B

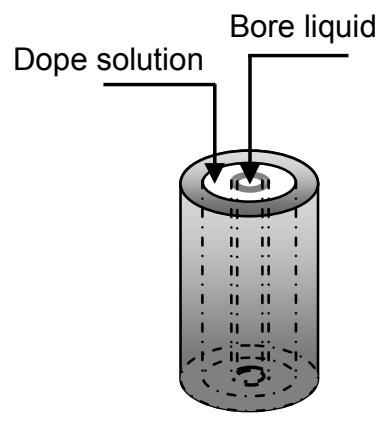

Figure 8 Spinneret; A: picture of 2 spinnerets with a 1Euro coin; B: schematic of the spinneret

solvent/nonsolvent exchange takes place and the precipitation occurs. The fiber being pulled by the wheel (10) at controlled speed is guided on the up-take rolls (8). In the second bath (9), the coagulation is completed and the fiber is collected in the final bath (11).

The main spinning parameters which determine the morphology of the fiber (average pore size, pore size distribution, porosity, pore tortuosity, thickness of the dense skin, inner and outer diameter) are: (i) extrusion rate of the polymer solution; (ii) bore liquid flow rate; (iii) pulling speed; (iv) residence time in the air gap; (v) temperature of the polymer solution; (vi) temperature of the coagulation bath; (vii) dimensions of the spinneret. The spinning parameters interfere with the membrane-forming factors such as the composition of the polymer solution, composition of the bore liquid and coagulation bath.

The spinning technique was not the only method of membrane production used in this work (although the leading one) as it can be seen in Table 5. The phase separation in-situ and polymer foaming were explored, too. A model protein or a model protein mixture was 
investigated in each chapter to give a proof of concept of the new method. Bovine serum albumin was used in all chapters as this protein is known of its stability, lack of effect in many biochemical reactions and low cost.

Table 5 Overview of the experimental work described in the thesis

\begin{tabular}{|c|c|c|c|c|}
\hline & Chapter 2 & Chapter 3 & Chapter 4 & Chapter 5 \\
\hline \multirow{2}{*}{$\begin{array}{l}\text { Model } \\
\text { biomolecule }\end{array}$} & \multirow{2}{*}{$\begin{array}{l}\text { Bovine serum } \\
\text { albumin } \\
\text { Hemoglobin }\end{array}$} & $\begin{array}{l}\text { Bovine serum } \\
\text { albumin }\end{array}$ & $\begin{array}{l}\text { Bovine serum albumin } \\
\text { Lysozyme }\end{array}$ & \multirow[t]{2}{*}{ Bovine serum albumin } \\
\hline & & Hemoglobin & Cholesterol & \\
\hline Technique & Ultrafiltration & Ultrafiltration & Adsorption & $\begin{array}{l}\text { Capillary } \\
\text { electrochromatography }\end{array}$ \\
\hline Membrane charge & Negative & Positive & Negative & Negative \\
\hline \multirow{3}{*}{$\begin{array}{l}\text { Membrane } \\
\text { configuration }\end{array}$} & \multirow{3}{*}{ Hollow fiber } & \multirow{3}{*}{ Hollow fiber } & \multirow{3}{*}{ Hollow fiber } & Hollow fiber \\
\hline & & & & Full fiber \\
\hline & & & & $\begin{array}{l}\text { Monolith (phase separation } \\
\text { in-situ) (Chapter 6) }\end{array}$ \\
\hline \multirow{3}{*}{$\begin{array}{l}\text { Technique of } \\
\text { charge } \\
\text { introduction into } \\
\text { the membrane }\end{array}$} & \multirow{3}{*}{$\begin{array}{l}\text { Polyelectrolyte } \\
\text { dissolved in } \\
\text { the bore liquid }\end{array}$} & \multirow{3}{*}{$\begin{array}{l}\text { Polyelectrolyte } \\
\text { dissolved in } \\
\text { the bore liquid }\end{array}$} & \multirow{3}{*}{$\begin{array}{l}\text { Charged particles } \\
\text { dispersed in matrix } \\
\text { polymer }\end{array}$} & $\begin{array}{l}\text { Polyelectrolyte dissolved in } \\
\text { the bore liquid }\end{array}$ \\
\hline & & & & $\begin{array}{l}\text { Polyelectrolyte blended } \\
\text { with the membrane } \\
\text { forming polymer }\end{array}$ \\
\hline & & & & $\begin{array}{l}\text { Charged particles dispersed } \\
\text { in matrix polymer }\end{array}$ \\
\hline
\end{tabular}

\section{Outline of the thesis}

Chapter 2 describes a new in-line method of introduction charge onto the bore surface of the hollow fiber membrane in a one-step spinning process. A negatively charged polyelectrolyte sulphonated poly(ether ether ketone) (SPEEK) is dissolved in the bore liquid and during the membrane formation deposited on the bore surface. The improved performance of such membrane is demonstrated by an ultrafiltration of binary mixture of proteins with similar molecular weights (bovine serum albumin and hemoglobin), which results in a very high selectivity.

Chapter 3 focuses also around the technique of dissolving a charged polymer in the bore liquid, but here, this polymer (polyethyleneimine, PEI) is at the same time a crosslinking agent for the membrane forming polymer. This chapter explores a new method of simultaneous membrane formation and chemical modification in a one-step spinning process. It is shown that two types of membranes: either a completely crosslinked and porous fiber (for ultrafiltration), or a porous fiber with crosslinked dense inner layer (for gas separation), can be produced via the same spinning procedure, only by changing the composition of the bore liquid and/or shell liquid and dope solution. The performance of this positively charged fiber is again proven by a separation of binary mixture of bovine serum albumin and hemoglobin. 
Chapter 4 explores application of mixed matrix membranes for adsorption of biomolecules. These membranes are produced by dispersion of negatively charged particles in the matrix polymer. The novelty of this work is that the membranes are crosslinked and for the first time applied for the adsorption of biomolecules (lysozyme and cholesterol) from organic solvents, rather than from aqueous solutions.

Chapter 5 introduces membrane technology in a completely new field, capillary elelectrochromatography (CEC) - a hybrid analytical separation technique. In this chapter, membrane fabrication methods described in previous chapters together with new methods are applied for preparation of novel stationary phases for CEC columns, which are tested in a laboratory-designed and laboratory-built CEC unit.

Ultimately, Chapter 6 summarizes this work and provides and outlook on the future of membrane bioseparations. 


\section{References}

[1] P.C. Singh, R.K. Singh, Choosing an appropriate bioseparation technique, Trends in Food Science \& Technology, 7 (1996) 49-58.

[2] H. Greisler, Biomolecules, in: WTEC Workshop on Tissues Engineering Research, Maryland, US, 2002.

[3] M.R. Ladisch, Bioseparations Engineering: Principles, Practice, and Economics, A John Wiley and Sons, Inc., 2001.

[4] K. Keller, T. Friedmann, A. Boxman, The bioseparation needs for tomorrow, Trends in Biotechnology, 19 (2001) 438-441.

[5] E.N. Lightfoot, J.S. Moscariello, Bioseparations, Biotechnology and Bioengineering, 87 (2004) 259-273.

[6] J.J. Abel, L.G. Rowntree, B.B. Turner, On the removal of diffusible substances from the circulating blood by means of dialysis, Transactions of the Association of American Physicians, 28 (1913) 50-54.

[7] W.J. Kolff, H.T.J. Berk, De kunstmatige nier: een dialysator met en groot oppenflak, Ned. Tijdschr. Geneeskd. , 87 (1943) 1684.

[8] W.J. Kolff, H.T.J. Berk, M.t. Welle, A.J.W. Ley, E.C.v. Dijk, J.v. Noordwijk, The artificial kidney: a dialyser with a great area, Acta Medica Scandinavica, 117 (1944).

[9] D.F. Stamatialis, B.J. Papenburg, M. Gironés, S. Saiful, S.N.M. Bettahalli, S. Schmitmeier, M. Wessling, Medical applications of membranes: Drug delivery, artificial organs and tissue engineering, Journal of Membrane Science, 308 (2008) 1-34.

[10] B. Krause, M. Storr, T. Ertl, R. Buck, H. Hildwein, R. Deppisch, H. Göhl, Polymeric Membranes for Medical Applications, Chemie Ingenieur Technik, 75 (2003) 1725-1732.

[11] J.D. Ferry, Ultrafilter Membranes and Ultrafiltration, Chemical Reviews, 18 (1936) 373455.

[12] R. van Reis, A. Zydney, Membrane separations in biotechnology, Current Opinion in Biotechnology, 12 (2001) 208-211.

[13] A. Saxena, B.P. Tripathi, M. Kumar, V.K. Shahi, Membrane-based techniques for the separation and purification of proteins: An overview, Advances in Colloid and Interface Science, 145 (2009) 1-22.

[14] R. van Reis, A. Zydney, Bioprocess membrane technology, Journal of Membrane Science, 297 (2007) 16-50.

[15] R.T. Kurnik, A.W. Yu, G.S. Blank, A.R. Burton, D. Smith, A.M. Athalye, R. van Reis, Buffer exchange using size exclusion chromatography, countercurrent dialysis, and tangential flow filtration: Models, development, and industrial application, Biotechnology and Bioengineering, 45 (1995) 149-157.

[16] P. Guerrero-Germán, D. Prazeres, R. Guzmán, R. Montesinos-Cisneros, A. TejedaMansir, Purification of plasmid DNA using tangential flow filtration and tandem anionexchange membrane chromatography, Bioprocess and Biosystems Engineering, 32 (2009) 615-623. 
[17] P.E. Cruz, C.C. Peixoto, K. Devos, J.L. Moreira, E. Saman, M.J.T. Carrondo, Characterization and downstream processing of HIV-1 core and virus-like-particles produced in serum free medium, Enzyme and Microbial Technology, 26 (2000) 61-70.

[18] J.H.T. Luong, A.L. Nguyen, K.B. Male, Recent developments in downstream processing based on affinity interactions, Trends in Biotechnology, 5 (1987) 281-286.

[19] K. Mondal, M.N. Gupta, The affinity concept in bioseparation: Evolving paradigms and expanding range of applications, Biomolecular Engineering, 23 (2006) 59-76.

[20] I. Recio, S. Visser, Antibacterial and binding characteristics of bovine, ovine and caprine lactoferrins: a comparative study, International Dairy Journal, 10 (2000) 597-605.

[21] J. Amiot, L. Germain, S. Turgeon, M. Lemay, C. Ory-Salam, F.A. Auger, Peptides from milk protein hydrolysates to improve the growth of human keratinocytes in culture, International Dairy Journal, 14 (2004) 619-626.

[22] Z. Borneman, Particle loaded membrane chromatography, PhD thesis, University of Twente, Enschede, 2006.

[23] T.M. Przybycien, N.S. Pujar, L.M. Steele, Alternative bioseparation operations: life beyond packed-bed chromatography, Current Opinion in Biotechnology, 15 (2004) 469478.

[24] J.X. Zhou, T. Tressel, Basic Concepts in Q Membrane Chromatography for Large-Scale Antibody Production, Biotechnology Progress, 22 (2006) 341-349.

[25] M.-E. Avramescu, M. Girončs, Z. Borneman, M. Wessling, Preparation of mixed matrix adsorber membranes for protein recovery, Journal of Membrane Science, 218 (2003) 219-233.

[26] M.-E. Avramescu, Z. Borneman, M. Wessling, Dynamic behavior of adsorber membranes for protein recovery, Biotechnology and Bioengineering, 84 (2003) 564572.

[27] M.-E. Avramescu, Z. Borneman, M. Wessling, Mixed-matrix membrane adsorbers for protein separation, Journal of Chromatography A, 1006 (2003) 171-183.

[28] Saiful, Mixed matrix membrane adsorbers for protein and blood purification, $\mathrm{PhD}$ Thesis, University of Twente, Enschede, 2007, pp. 162.

[29] Saiful, Z. Borneman, M. Wessling, Enzyme capturing and concentration with mixed matrix membrane adsorbers, Journal of Membrane Science, 280 (2006) 406-417.

[30] M.-E. Avramescu, Z. Borneman, M. Wessling, Particle-loaded hollow-fiber membrane adsorbers for lysozyme separation, Journal of Membrane Science, 322 (2008) 306-313.

[31] M.E. Avramescu, W.F.C. Sager, Z. Borneman, M. Wessling, Adsorptive membranes for bilirubin removal, Journal of Chromatography B, 803 (2004) 215-223.

[32] M. Mulder, Basic Principles of Membrane Technology, Second edition ed., Kluwer Academic Publisher, Dordrecht, The Netherlands 1997, 1996.

[33] A. Mehta, A.L. Zydney, Effect of Membrane Charge on Flow and Protein Transport during Ultrafiltration, Biotechnology Progress, 22 (2006) 484-492.

[34] G.T. Barnes, I.R. Gentle, Interfacial science: an introduction, Oxford University Press, 2005. 
[35] E. Roesink, Microfiltration: membrane development and module design, $\mathrm{PhD}$ Thesis, University of Twente, 1989. 


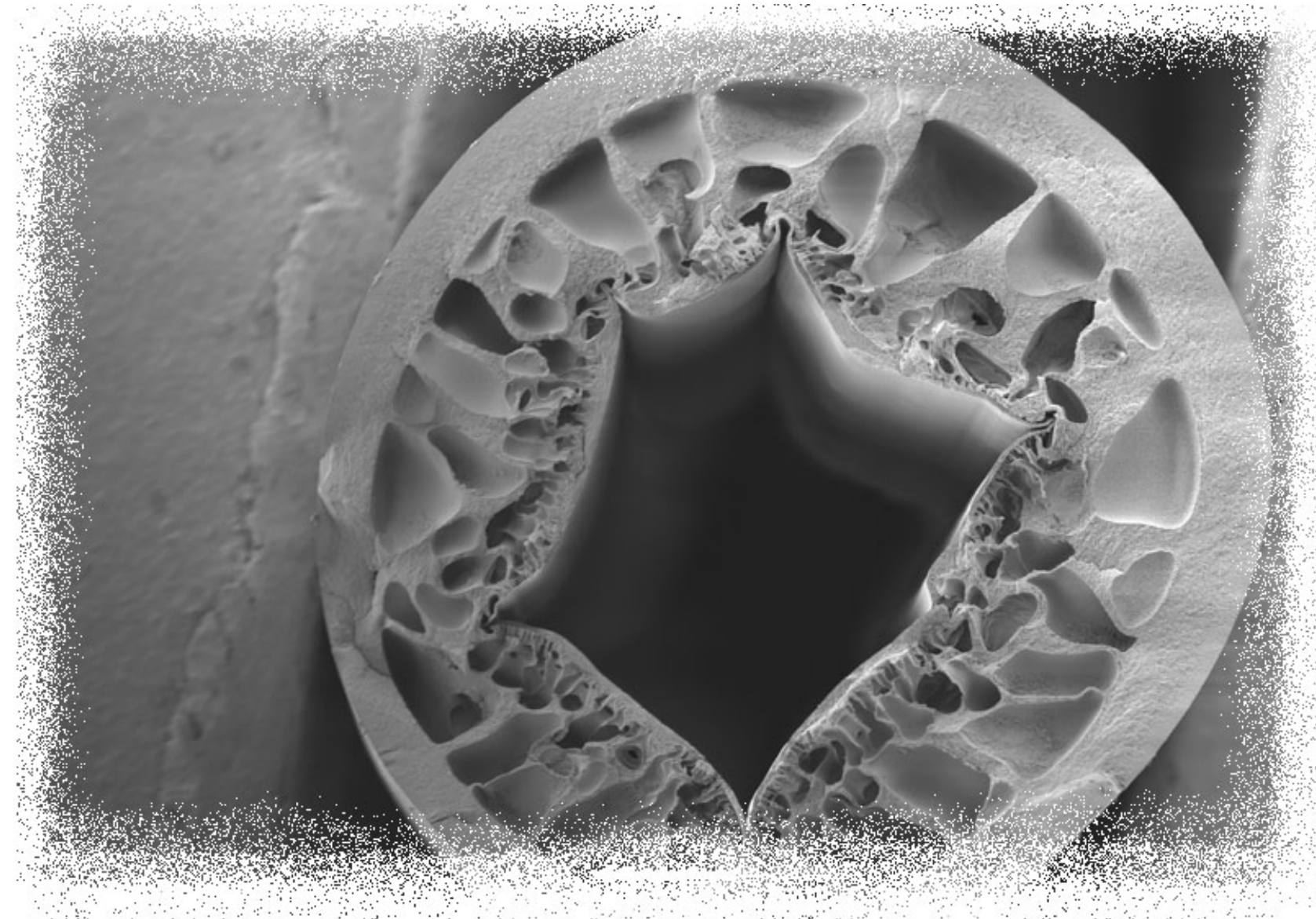

Chapter 2

Tailoring the surface charge of an ultrafiltration hollow fiber by addition of a polyanion to the coagulation bore liquid 


\begin{abstract}
In this chapter, we report a new in-line method to tailor the surface properties of porous ultrafiltration membranes in a one-step spinning process. A highly charged polyimide P84 hollow fiber membrane can be obtained by dissolving as less as $3 \%$ of sulphonated poly(ether ether ketone) (SPEEK) in the bore liquid. The zeta-potential of the lumen surface of this new P84/SPEEK membrane is independent of $\mathrm{pH}$ in the range 4.5 to 10 and around three times higher than for pure P84 hollow fiber membrane $(-58 \mathrm{mV}$ vs. $-21.5 \mathrm{mV})$. The P84/SPEEK membrane has uniform sponge-like structure and water permeance of 6.5 $1 /\left(\mathrm{m}^{2} \cdot \mathrm{h} \cdot\right.$ bar $)$.

Filtration of a mixture of proteins with similar molecular weights: Bovine Serum Albumin $(\mathrm{BSA}, \mathrm{MW} \approx 66.4 \mathrm{kDa})$ and Hemoglobin $(\mathrm{Hb}, \mathrm{MW} \approx 64.5 \mathrm{kDa})$, but differing in electrostatic properties, through the pure P84 and P84/SPEEK membranes demonstrates an improved separation performance of the P84/SPEEK hollow fiber. In fact, this membrane separates the binary mixture of BSA and $\mathrm{Hb}$ at the highest selectivity of around $\sim 200$ at $\mathrm{pH}$ 7.5. Moreover, at the same $\mathrm{pH}$ the flux decline for the P84/SPEEK membrane is significantly reduced in comparison to the pure P84 membrane.

Surprisingly, surface charge modifications can be introduced during the coagulation process by adding polyelectrolytes to bore liquid. This will offer new opportunities for in-line membrane modification during the spinning process.
\end{abstract}




\section{Introduction}

In recent years, modification of membranes by introduction of charge gained a lot of interest in the membrane field. Particularly, incorporation of negative charge became a focus point in many areas of membrane technology, with attention concentrated on sulphonated polymers. The sulphonation of materials is straightforward and effective method to enhance the negative charge and hydrophilicity of the membrane. The sulphonation degree can be easily tuned during the sulphonation reaction and materials with different ion exchange capacity (IEC) can be produced, which posses properties of strong cation exchangers. Polymers like polysulphone, polyethersulphone and poly(ether ether ketone) were successfully sulphonated and used in membrane formation [1-23].

Various techniques have been developed to introduce the polyelectrolyte into the membrane however blending is mostly used for both dense and porous membranes. Dense cation permeable membranes are mainly used for fuel cells and electrodialysis. Examples are blends of sulphonated poly(ether ether ketone) (SPEEK) with polyethersulphone [8] [14] [2] or polyimide [20,23]. Among porous membranes, a blend of SPEEK and polysulphone is used for nanofiltration for salt rejection [7], water purification [9, 10] as well as for nonaqueous nanofiltration of dyes from alcohol based feeds [17]. Lau et al. [21] investigated SPEEK blended with polyethersulphone as a nanofiltration membrane and presented theoretical study on the morphological and electrical properties of the membranes using different sulphonation degrees, while Arthanareeswaran et al.[22] showed a practical application of such blends for protein ultrafiltration. The blending properties of SPEEK with emphasis on the polyelectrolyte content was studied for other polymers, like polyetherimide [13], cellulose acetate [15] and poly(methyl methacrylate) [19]. Most of the membranes prepared from blends with polyelectrolyte suffer, unfortunately, from extensive swelling and compaction. Moreover, adding a second polymer, in this case, the polyelectrolyte to the first, membrane forming polymer, changes the miscibility of the membrane components. The kinetics of the demixing is altered and a modified membrane structure is obtained. Also, the added polymer is found throughout the whole membrane structure, a phenomenon that is highly undesirable when the polymer to be blended in is very expensive and difficult to synthesize.

Other methods to introduce the polyelectrolyte into the membrane include coating of a polyelectrolyte on an existing support membrane. For example, polyethersulphone support hollow fiber membrane was coated with sulphonated poly(ether ether ketone) (SPEEK) and applied for nanofiltration [18], flue gas dehydration and gas separation [24] whereas a polypropylene fiber coated with SPEEK was applied as a membrane contactor for olefin/paraffin separation [12] and polysulphone hollow fiber membrane coated with layer of SPEEK was used to stabilize a liquid membrane for metal ion transport [25]. Polyelectrolyte was also used for a bilayer membrane for fuel cell applications [23] by casting a layer of SPEEK solution on a polyimide membrane. Kochan et al.[26] explored the layer-by-layer (LbL) technique in which polyelectrolytes poly(ethylene imine) and poly(sodium 4-styrene 
sulphonate) are assembled by electrostatic adsorption directly onto the support polyethersulphone ultrafiltration membranes. As a result a thin dense polyelectrolyte film is created on the surface of the support membrane.

Efforts were also made to fabricate membranes with a porous layer of charged polymer in one step. Special triple orifice spinnerets were used for the co-extrusion of a dual layer hollow fiber composed of an inner layer of uncharged polymer of polysulphone for salt rejection [3] or polyethersulphone for protein ultrafiltration [4] and an outer layer of sulphonated polyethersulphone. Nevertheless, rather bad adhesion between the two layers hampered further development of these membranes.

The present study explores a novel approach to prepare in a one step process an integrally asymmetric highly charged hollow fiber membrane by dissolving the SPEEK polymer in the bore liquid. This in fact represents an in-line modification of the emerging membrane during the initial membrane formation steps. Polyimide P84 (Fig. 1), a polymer with high temperature stability up to $260^{\circ} \mathrm{C}$, chemical resistance to most organic solvents, acids, fats and fuels, high compressive and mechanical strength, is extruded through a spinneret. SPEEK (Fig. 1) is dissolved in a very small concentration in the bore liquid and pumped through the inner die of the spinneret.

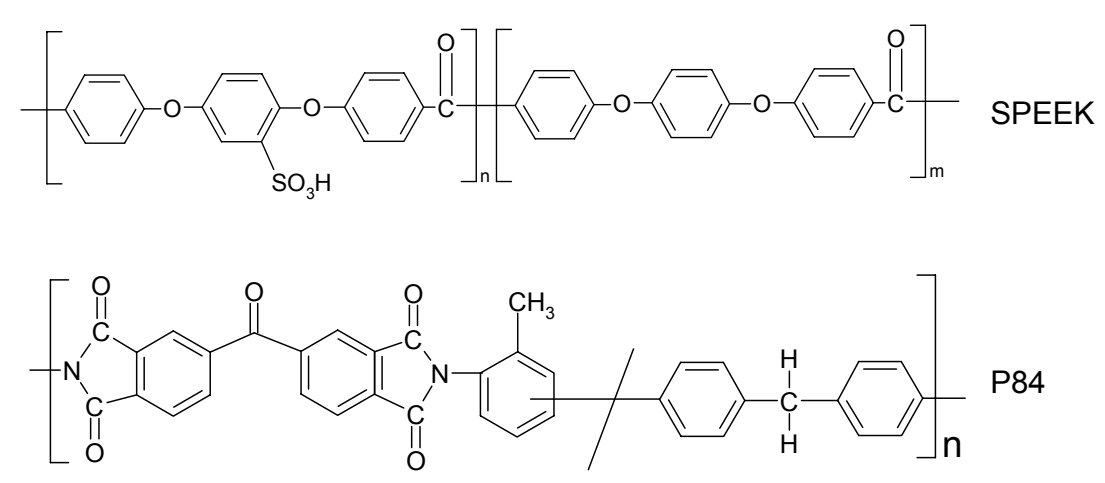

Figure 1 Chemical structure of P84 and SPEEK

To proof the effect of surface charge modification, a binary mixture of bovine serum albumin (BSA) with molecular weight (MW) of $66.4 \mathrm{kDa}$ and hemoglobin (Hb) with MW of $64.5 \mathrm{kDa}$ is chosen as the model solution (MW ratio of the proteins is 1.03 ) to investigate the membrane separation performance. The electrostatic interactions between charged protein molecules and charged membrane material play an important role in protein separation. It was documented [27] that the acceptable separation of proteins cannot be obtained based on the size-exclusion ultrafiltration unless the ratio of protein molecular weights MW is larger than 7. Hence, with a MW ratio of 1.03 effective separation during the filtration can only be achieved based on the electrostatic interactions between the proteins and the membrane. Proteins have zwitterionic character so that the same protein can carry positive or negative net charge depending on the $\mathrm{pH}$ of the medium in which it is dissolved. At the isoelectric point the protein net charge equals zero. Fig 2 presents the net charge of the two investigated 
proteins, BSA and $\mathrm{Hb}$, vs $\mathrm{pH}$ [28] [29]. The grey lines show the $\mathrm{pH}$ of the protein solution at which the produced membranes were investigated. At $\mathrm{pH} 4.8$, the adsorption of positively charged hemoglobin on the negatively charged membrane is expected, while the BSA should not interact electrostaticaly with the membrane, since it is at the isoelectric point. At pH 6.8, we anticipate the repulsion of negative BSA by negative membrane and no electrostatic interactions between neutral $\mathrm{Hb}$ and the negative membrane. At $\mathrm{pH} 7.5$ both proteins, as well as the membrane, carry negative charge and so the proteins should be repulsed by the membrane. The interactions between proteins and membranes and their effect on membrane transport properties are systematically investigated in the paper.

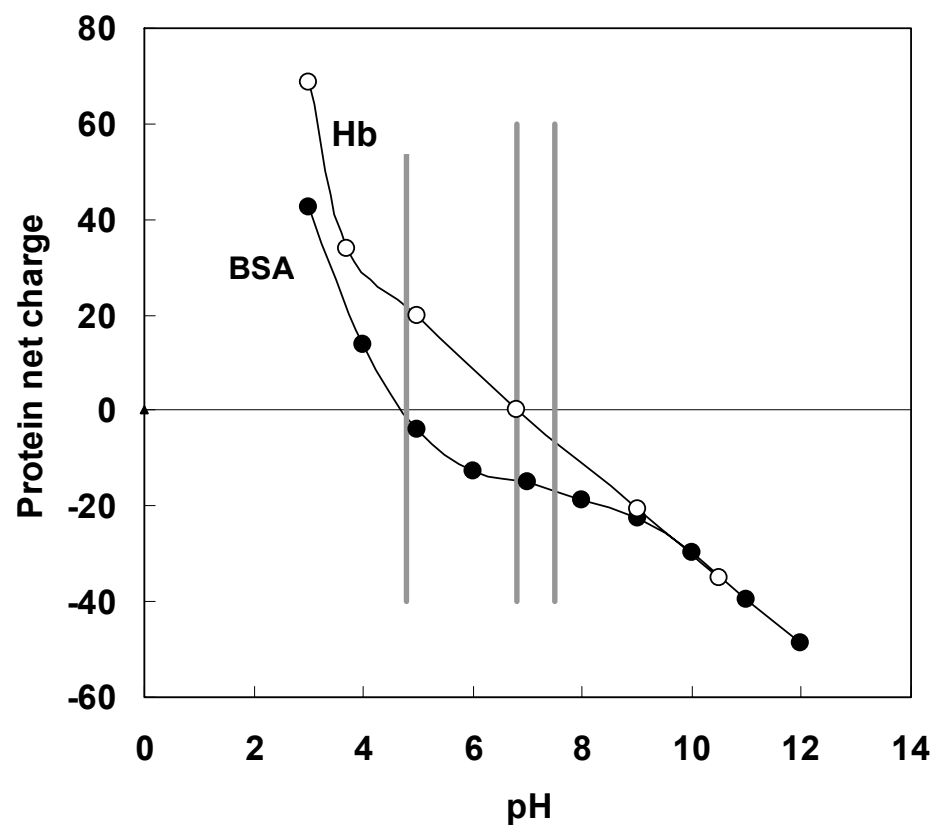

Figure 2 Zeta-potential of BSA and $\mathrm{Hb}$ as a function of $\mathrm{pH}$ plotted with data from Ref [28] and [29]. The grey vertical lines mark the $\mathrm{pH}$ at which the membranes were investigated

\section{Experimental}

\subsection{Materials}

Hollow fiber membrane and module preparation

Polyimide, type P84 was purchased from HP Polymer GmbH (325 mesh, STD). Poly(ether ether ketone) powder PEEK 450 PF was purchased from Victrex PLC. Glycerol, ethanol, both of analytical grade and concentrated sulphuric acid (96-98\%, extra pure) were obtained from Merck. 1-methyl-pyrrolidone (NMP), extra pure, was purchased from Across Organics. Two component polyurethane (PUR System, Rohm \& Haas) consisted of components $634 \mathrm{~A}$ and $725 \mathrm{~B}$ was used for making the modules for clean water flux measurements, filtration experiments and zeta-potential measurements. 


\section{Buffers and protein solutions}

The permeation of mixture of proteins through the membranes was studied using buffered solutions of BSA, fraction V from Fluka, and $\mathrm{Hb}$ from bovine blood, a lyophilized powder from Sigma Aldrich. The properties of these two proteins are listed in Table 1 [28, 30]. The experiments were carried out at three $\mathrm{pH}(4.8,6.8,7.5)$ with a binary mixture of BSA and $\mathrm{Hb}$ (concentration $0.5 \mathrm{~g} / 1$ each protein) in $10 \mathrm{mM}$ buffers. Their ionic strength was adjusted to $15 \mathrm{mM}$ with sodium chloride, 99.5\%, purchased from Across Organics. The protein solutions were filtered through the filtration paper (Rotilabo Faltenfilter, Roth) prior to use in the filtration set-up. For $\mathrm{pH} 4.8$ the acetate buffer was used and obtained by dissolving in water the acetic acid (glacial 100\%, anhydrous) from Merck and sodium acetate, anhydrous from Across Organics. For pH 6.8 and 7.5 phosphate buffers were used and prepared by dissolving in water monobasic sodium phosphate, monohydrate and dibasic sodium phosphate, anhydrous, both obtained from Across Organics. Potassium chloride, as well as, nitric acid $0.1 \mathrm{~mol} / \mathrm{L}$, volumetric solutions for the zeta-potential measurements were purchased from Fluka. Sodium hydroxide $0.1 \mathrm{~mol} / \mathrm{L}$ in ampoules (Titrisol) was obtained from Merck. All these chemicals were of analytical grade and used as received. Water for pure water flux experiments and for preparing the buffers was obtained from Millipore water purification unit.

Table 1 Characteristics of albumin (BSA) and hemoglobin (Hb) [28,30]

\begin{tabular}{lcc}
\hline Property & BSA & $\mathrm{Hb}$ \\
\hline Molecular Weight, kDa & 66.4 & 64.5 \\
Number of aminoacids & 583 & 574 \\
Ratio of aminoacids & $1: 1.27$ & $1: 0.80$ \\
Nonpolar contact area, $\AA^{2}$ & 1930 & 2300 \\
Isoelectric point & 4.8 & 6.8 \\
Total surface area, $\AA^{2}$ & 9500 & 9200 \\
Contact Area as \% of total surface area & 20 & 25 \\
Dimensions, $\AA$ & $140 \times 40 \times 40$ & $70 \times 55 \times 55$ \\
\hline
\end{tabular}

\subsection{Preparation of hollow fiber membranes}

PEEK was sulphonated in our laboratory according to the procedure described elsewhere [14]. The sulphonation degree (SD) of SPEEK was calculated [8, 14] to be $\sim 65 \%$ from the ion exchange capacity measurements (IEC) corresponding to the IEC of around 1.88 mequiv/g. The polymers (P84 and PEEK) were used as received after drying them in the vacuum oven at $30^{\circ} \mathrm{C}$ for 24 hours. The polymer dope solution (see composition in Table 2) was stirred at room temperature for 48 hours; next it was filtrated through a metal filter with a $25 \mu \mathrm{m}$ mesh and left for degassing for at least 24 hours. SPEEK was dissolved in a concentration of $3 \%(\mathrm{w} / \mathrm{w})$ in a mixture of NMP and water and left for degassing for 24 hours before it was used as a bore liquid in the spinning process.

All membranes were obtained by dry-wet immersion precipitation spinning. The dope solution along with the bore liquid were pumped simultaneously through a double 
orifice spinneret and after short residence time in the air, immersed into the water coagulation bath. Two different spinnerets (but of similar dimensions, see Table 2) were used due to the practical reasons. The take-up velocity of around $8 \mathrm{~m} / \mathrm{min}$ was controlled by a pulling wheel, which enabled also stretching the fiber. All prepared membranes were washed out for $48 \mathrm{~h}$ in water to remove the additives and solvents and afterwards impregnated with glycerol by placing in the $20 \%(\mathrm{w} / \mathrm{w})$ glycerol in water for $24 \mathrm{~h}$. Finally, the membranes were dried in the air. Two types of hollow fiber membranes were produced from the same dope solution, but with different bore liquid compositions: a membrane prepared without SPEEK in the bore liquid, will be referred as a P84 membrane, and the membrane prepared with SPEEK in the bore liquid will be referred as P84/SPEEK membrane in the following sections of this paper. Table 2 summarizes the spinning parameters of the two types of the investigated membranes.

Table 2 Spinning conditions of the investigated hollow fiber membranes

\begin{tabular}{|c|c|c|c|}
\hline \multicolumn{2}{|l|}{ Parameter } & P84/SPEEK & P84 \\
\hline \multirow[t]{3}{*}{ Dope composition, $\quad \%$} & P84 & 22 & 22 \\
\hline & NMP & 66 & 66 \\
\hline & Glycerol & 12 & 12 \\
\hline \multirow[t]{4}{*}{ Bore liquid composition, $\%$} & NMP & 87 & - \\
\hline & Water & 10 & - \\
\hline & SPEEK & 3 & - \\
\hline & Ethanol & - & 100 \\
\hline \multirow{2}{*}{$\begin{array}{l}\text { Dope flow rate, } \\
\text { Bore liquid flow rate, }\end{array}$} & $\mathrm{ml} / \mathrm{min}$ & 3.1 & 2.9 \\
\hline & $\mathrm{ml} / \mathrm{min}$ & 2.0 & 2.0 \\
\hline Air gap, & $\mathrm{cm}$ & 5.0 & 5.0 \\
\hline \multirow{2}{*}{\multicolumn{2}{|c|}{$\begin{array}{l}\text { External coagulant } \\
\text { Spinning temperature }\end{array}$}} & Water & Water \\
\hline & & $20^{\circ} \mathrm{C}$ & $20^{\circ} \mathrm{C}$ \\
\hline \multirow[t]{2}{*}{ Spinneret, } & $\mathrm{mm}$ & 0.8 & 0.6 \\
\hline & o.d. & 1.5 & 1.5 \\
\hline
\end{tabular}

\subsection{Scanning electron microscopy characterization}

Samples for scanning electron microscopy (SEM) were prepared by freezing the fresh wet fibers in liquid nitrogen and breaking them in order to expose the cross-sectional area. Samples were allowed to dry under vacuum at $30^{\circ} \mathrm{C}$ overnight and subsequently they were coated with a thin layer of gold using Balzer Union SCD 040 sputtering device. Membranes were examined using Jeol JSM-5600 LV Scanning Electron Microscope with Semaphore software for the determination of fiber dimensions.

\subsection{Zeta-potential measurements}

The zeta-potential of membranes was determined with a SurPAAS Electrokinetic Analyzer (Anton Paar GmbH, Austria) based on the measurement of streaming potential or streaming current. Modules were prepared with 1-3 fibers each, with length of around $4 \mathrm{~cm}$ and the space between the fibers completely filled with glue at the entire length of the module. $1 \mathrm{mM} \mathrm{KCl}$ was used as the electrolyte circulating through the measuring cell containing the membrane sample. The electrolyte was flowing through the lumen of the fiber 
and the zeta-potential of the lumen surface was determined assuming that the electrolyte flows only in one direction along the fiber without entering the porous structure. The $\mathrm{pH}$ was adjusted by automatic titration with $0.1 \mathrm{M}$ solution of nitric acid and $0.1 \mathrm{M}$ solution of sodium hydroxide in water. The electrolyte conductivity, temperature and $\mathrm{pH}$ value were measured simultaneously.

The zeta-potential was determined in the $\mathrm{pH}$ range 3-11 with taking into account the correction for the surface conductivity of the membrane [31]. When measuring the streaming potential of samples with significant surface conductivity (like in case of polyelectrolytes), the overall specific electrical conductivity is comprised of the conductivity of the bulk electrolyte and the surface conductivity of the membrane. In such case the zeta-potential is measured based on the streaming potential with a $100 \mathrm{M} \mathrm{KCl}$ solution. Due to the high electrical conductivity of such concentrated solution, the surface conductivity can be neglected and zeta-potential can be determined with known resistance of the measuring cell with $1 \mathrm{mM}$ and $100 \mathrm{mM} \mathrm{KCl}$. Alternatively, the zeta-potential can be determined by measurement of the streaming current which is insensitive to the surface conductivity measurements. Here, the measurements were done with the streaming current method.

\subsection{Pure water flux determination}

The modules for the pure water flux measurements consisted of one fiber with an effective length of around $16 \mathrm{~cm}$. The flux was determined using a dead-end ultrafiltration cell connected to a gas cylinder of compressed nitrogen to apply the feed pressure. The pure water flux $(\mathrm{J}), \mathrm{l} /\left(\mathrm{m}^{2} \cdot \mathrm{h}\right)$ was determined at different pressures up to 6 bar after the glycerol was removed from the membrane (by flushing the membrane with pure water) and steady state conditions were reached. The membrane permeance $(\mathrm{P})$ was obtained from the slope of the flux (J) vs. transmembrane pressure $(\Delta \mathrm{p})$.

\subsection{Filtration system}

The experimental set-up for protein separation is shown in Figure 3.

Three modules with hollow fiber membranes were tested at each $\mathrm{pH}$ at room temperature. The

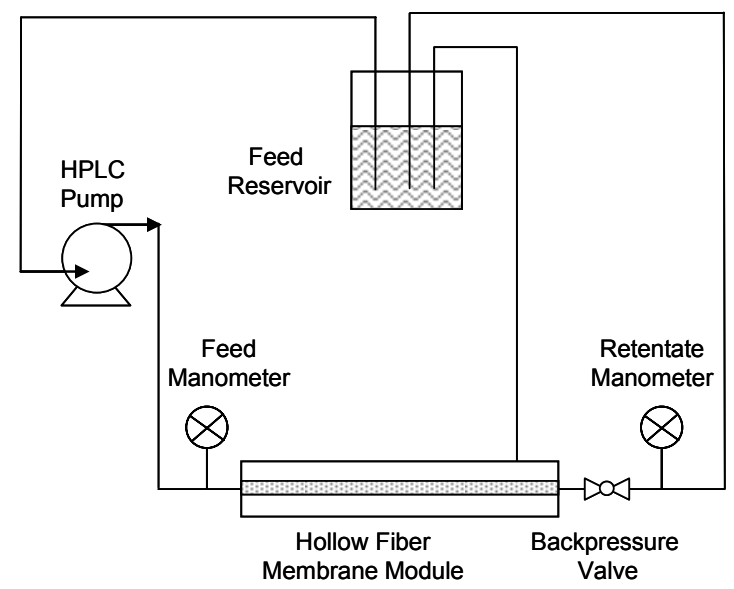

Figure 3 Schematic of the filtration set-up 
membrane modules were prepared in the same way as for the pure water flux determination. The membrane was conditioned by first flushing with pure water for $24 \mathrm{~h}$, and subsequently with the appropriate buffer for $2 \mathrm{~h}$. The feed of $500 \mathrm{~mL}$, composed of a binary mixture of $\mathrm{BSA}$ and $\mathrm{Hb}$ in the buffer, was pumped (Waters 590 Programmable HPLC Pump) into the lumen of the fiber, and the permeate solution exited from the shell (inside-out system), (crossflow filtration mode). Samples of feed, permeate and retentate were collected at various intervals for testing the concentration and flux. Both retentate and permeate were recycled back to the feed reservoir to keep the concentration of the feed solution constant during the whole experiment. Samples were taken every $30 \mathrm{~min}$ for $4 \mathrm{~h}$ in the volume of max. $3 \mathrm{~mL}$ per sample. The flow-rate of the feed was set at $9.0 \mathrm{~mL} / \mathrm{min}$ and the pressure was regulated manually by means of the ball valve at the retentate line to keep the feed pressure at $6.0 \pm 0.2$ bar. The transmembrane pressure was monitored by pressure manometers placed at the feed and retentate lines. Permeate and retentate fluxes were determined by measuring the volume collected in time. The protein concentration in feed, retentate and permeate was verified by an UV-Visible Spectrophotometer Cary 300 Scan (Varian). Hemoglobin solution displays 2 absorbance maxima at $280 \mathrm{~nm}$ and $406 \mathrm{~nm}$, whereas the BSA solution exhibits only one absorbance maximum at $280 \mathrm{~nm}$. Therefore, the $\mathrm{Hb}$ concentration in the protein mixture was calculated from the absorbance at $406 \mathrm{~nm}$ and the BSA concentration was assessed from the absorbance at $280 \mathrm{~nm}$ after subtracting the $\mathrm{Hb}$ contribution at this wavelength $[4,32]$. The permeation of each protein was expressed as sieving coefficient (SC):

$$
\mathrm{SC}=\frac{2 \mathrm{c}_{\mathrm{P}}}{\mathrm{c}_{\mathrm{R}}+\mathrm{c}_{\mathrm{F}}} \times 100 \%
$$

where $\mathrm{c}$ is the protein concentration $(\mathrm{g} / \mathrm{L})$ and the subscripts $\mathrm{P}, \mathrm{R}$ and $\mathrm{F}$ denote permeate, retentate and feed, respectively.

The separation performance of the membrane is expressed by the separation factor $\alpha_{\mathrm{BSA} / \mathrm{Hb}}$ :

$$
\alpha_{\mathrm{BSA} / \mathrm{Hb}}=\frac{\mathrm{SC}_{\mathrm{BSA}}}{\mathrm{SC}_{\mathrm{Hb}}}
$$

where $\mathrm{SC}_{\mathrm{BSA}}$ is the sieving coefficient of BSA and $\mathrm{SC}_{\mathrm{Hb}}$ is the sieving coefficient of $\mathrm{Hb}$.

\section{Results and discussion}

\subsection{Morphology and permeance of the membranes}

Figure 4 shows SEM images of the two types of spun hollow fiber membranes: pure P84 and P84/SPEEK. Both have a uniform sponge-like structure without macrovoids. The inner layer of the P84 membrane looks much denser than in case of the P84/SPEEK membrane. However, the P84 fiber has much higher pure water flux. The calculated permeance of P84 hollow fiber membrane, $P$, is $43.3 \mathrm{l} / \mathrm{m}^{2}$ hour bar) and of P84/SPEEK is 6.5 $1 /\left(\mathrm{m}^{2}\right.$ hourbar $)$. The measurements were carried out for at least $6 \mathrm{~h}$ at single pressure and through this time the flux was constant. Both membranes did not show any compaction within the studied transmembrane pressure range (Fig. 5). From the SEM images, it seems that the P84/SPEEK membrane has bigger pores than pure P84 membrane. However, the pure water 
flux through the P84 membrane is higher. Probably, it is the overall porosity and pore connectivity which determine the pure water flux. Besides, there is no visible, distinct layer of SPEEK on the lumen side of the P84/SPEEK fiber.
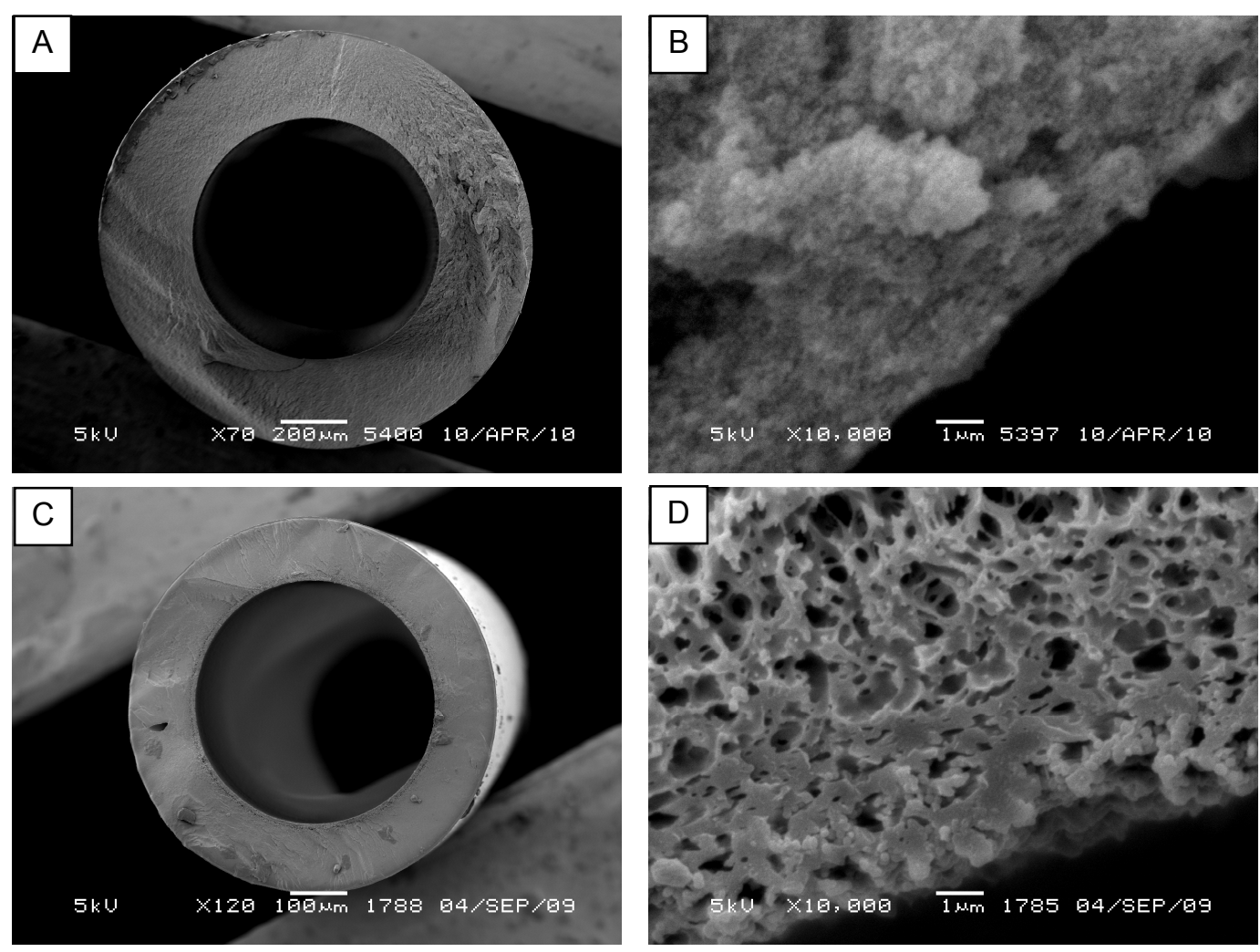

Figure 4 Cross-sections of the hollow fiber membranes prepared with (A, B) pure P84 and (C, D) P84/SPEEK; (B, D) show at higher magnification the bore side of the hollow fiber

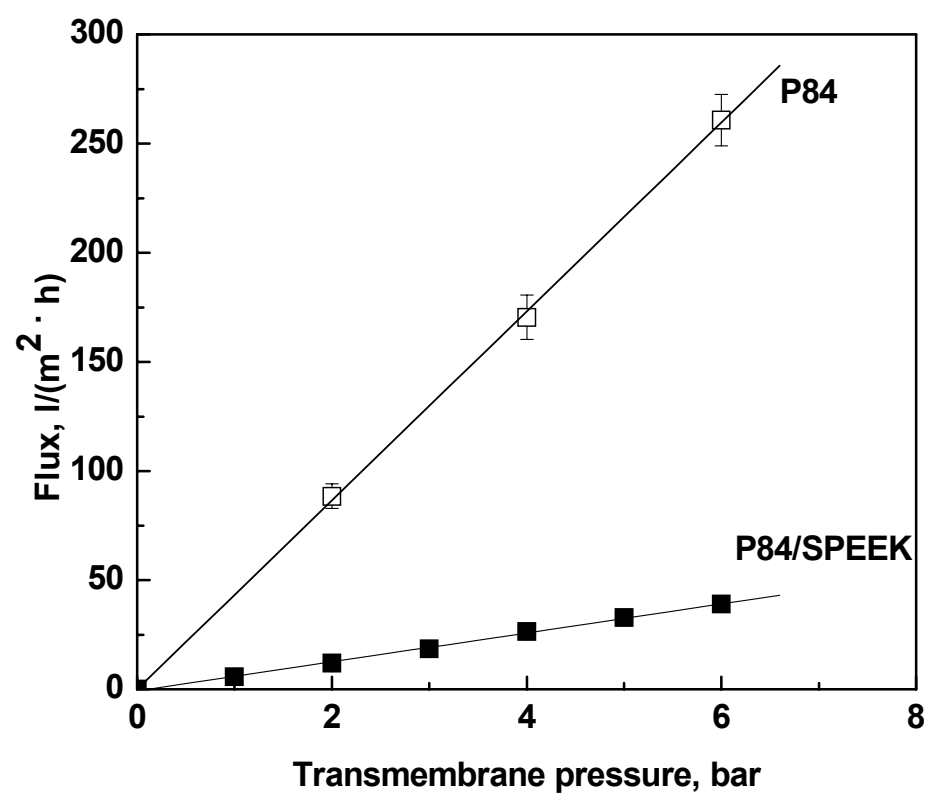

Figure 5 Clean water flux vs. pressure for P84 and P84/SPEEK membrane 


\subsection{Membrane charge}

Figure 6 shows the zeta-potential results of the two membranes. The P84 membrane has an isoelectric point (the $\mathrm{pH}$ where the measured zeta-potential is zero) at $\mathrm{pH} 3.75$ and it is negatively charged above this $\mathrm{pH}$ with the maximum negative charge of $-21.5 \mathrm{mV}$ at $\mathrm{pH} 6.5$. The P84/SPEEK is negatively charged through the entire $\mathrm{pH}$ range and its zeta-potential is on average 3 times higher than that of the $\mathrm{P} 84$ membrane, reaching -58.0 between $\mathrm{pH} 4.9$ and 9.0. The zeta-potential is an indirect proof of the existence of SPEEK layer on the lumen surface of the P84/SPEEK membrane. We propose two hypothetical mechanisms of incorporating the polyelectrolyte to the membrane by this technique. One tentative explanation is that the polyelectrolyte is physically bound in the inner separation layer of the membrane forming polymer. The polyelectrolyte maybe anchored by interlocking and entanglements between the chains of the membrane forming polymer and the polyelectrolyte. The second possible explanation is that there exists a bond between the polyimide P84 and SPEEK since they are acid-base pair. In any case (physical/chemical bound) the SPEEK layer seems to be stable and is not removed during the spinning nor during the subsequent washing step. The results of protein separation experiments suggest that the P84/SPEEK has higher negative charge than for P84 membrane. The long term stability of the SPEEK layer could be the subject of a future study.

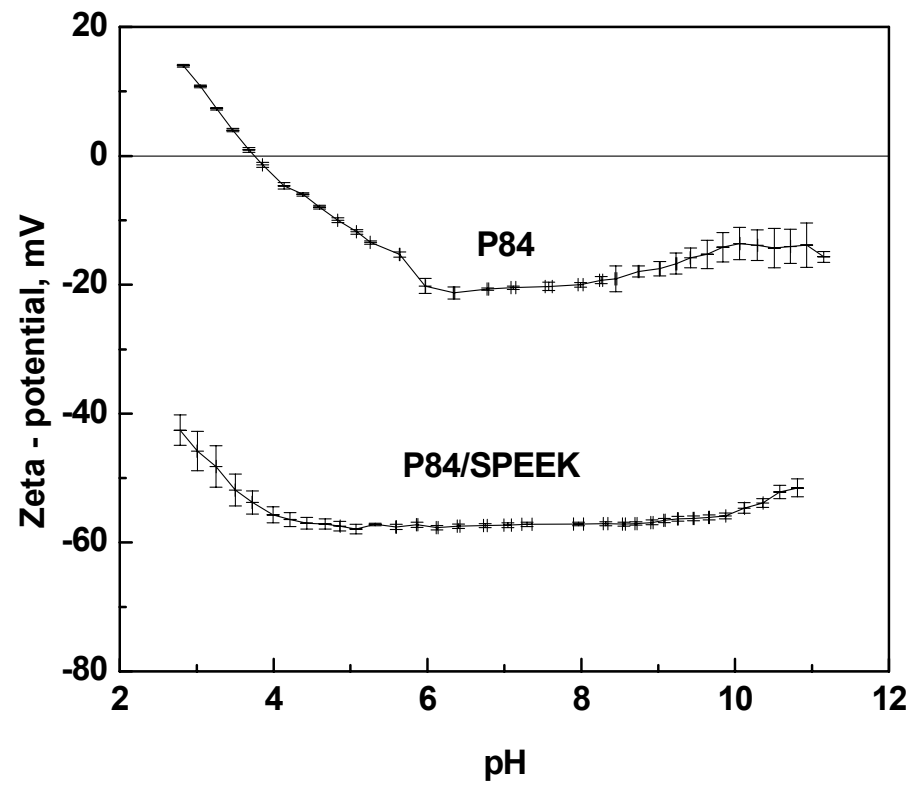

Figure 6 Zeta-potential as a function of $\mathrm{pH}$ for the P84 and P84/SPEEK membranes

The constant charge throughout a wide $\mathrm{pH}$ range permits a more controllable protein separation, where the charge of the proteins can be adjusted by changing the buffer $\mathrm{pH}$ without exceeding the limitations of the electrical properties of the membrane itself. It is important to note that tests were made to investigate the chemistry of the P84/SPEEK membranes by other analytical techniques such as Fourier Transform Infrared Spectroscopy (FTIR), Scanning Electron Microscopy Combined with Energy-Dispersive X-ray 
Spectroscopy (SEM/EDX) without success. It seems that the sensitivity of these techniques is not sufficient to detect the very small amount of SPEEK in the membrane.

\subsection{Protein separation}

Protein ultrafiltration of a binary mixture (BSA and $\mathrm{Hb}$ ) was performed with the two types of membranes, pure P84 and P84/SPEEK. Sieving coefficients for each protein, the selectivity with respect to the two proteins and the filtrate flux, were determined and the values shown are the average for three membrane modules tested at each pH (Fig. 7-10); lines connecting the symbols are there to guide the eye). The average standard deviation of the BSA sieving coefficient is $5 \%$ and of $\mathrm{Hb}$ sieving coefficient is $1 \%$. Hence, the fluctuations of the sieving coefficients do not represent changes in SC, but fall within the experimental error (maxima and minima in Fig.7a and Fig.7b). Higher SC of BSA and lower SC of Hb mean better separation performance of the membrane (higher selectivity). At all $\mathrm{pH}$ the ionic

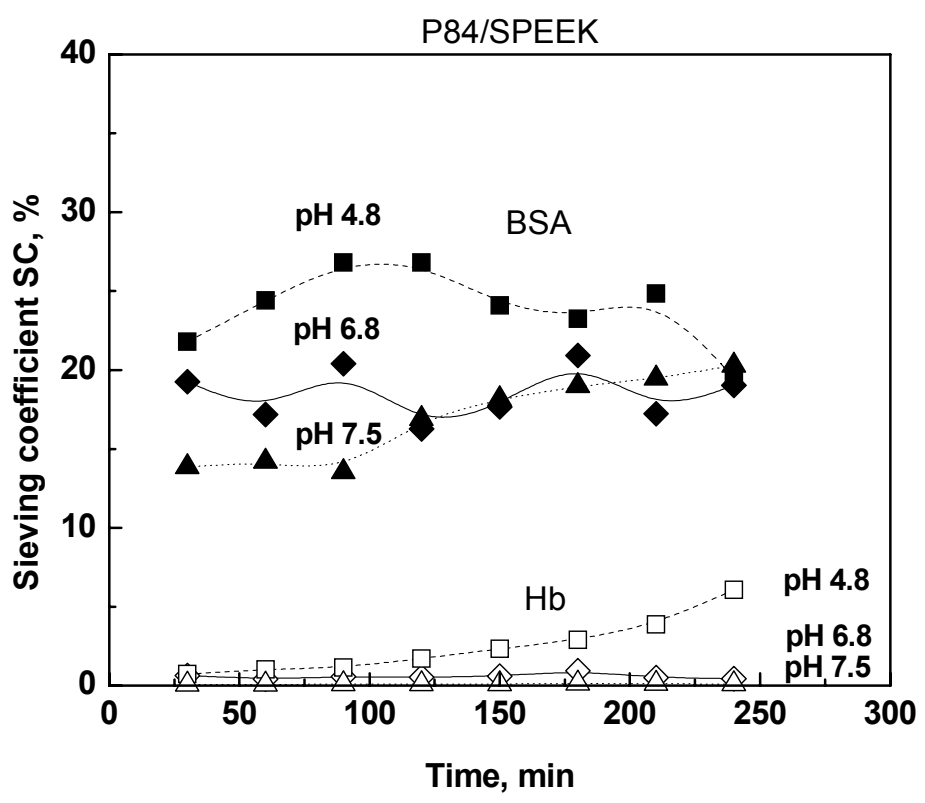

Figure 7a Sieving coefficient of BSA (full symbols) and $\mathrm{Hb}$ (open symbols) in time at different $\mathrm{pH}$ for P84/SPEEK membrane. The lines connecting the points are used to guide the eye

strength of the buffers was low concentration $(15 \mathrm{mM})$ to avoid shielding of the electrostatic interactions between the proteins and the membrane. At a sufficiently high salt concentration (typically above $200 \mathrm{mM}$ ) the salt will screen all the charged sites and the protein will not experience the surface charge of the membrane [28].

Figure $7 \mathrm{a}$ shows the evolution of sieving coefficient of BSA and $\mathrm{Hb}$ in time at different $\mathrm{pH}$ for P84/SPEEK membrane. Almost through the entire experiment, the $\mathrm{SC}_{\mathrm{BSA}}$ is the highest at its isoelectric point of $\mathrm{pH}$ 4.8. This is in agreement with literature [33]: the highest sieving coefficient is observed when a protein is uncharged (in case there are no strong electrostatic interactions with highly charged membrane). When a protein is charged (either has a positive or negative charge) an electrostatic double layer is formed around the 
protein molecule by the counter-ions and co-ions present in the solution. This double layer increases the effective size of the biomolecules, which can decrease the transmission of the protein through the porous membrane. When a protein carries zero net charge, the electrical double layer is absent and the protein size is the smallest. At higher $\mathrm{pH}$ the sieving coefficient of BSA decreases, because the protein becomes more negative (Fig. 2) and it is rejected by the negatively charged P84/SPEEK membrane (intrinsic electrostatic rejection).

In contrast to BSA, at $\mathrm{pH} 4.8, \mathrm{Hb}$ is positively charged (Fig.2) and it is attracted by the P84/SPEEK membrane. In fact, the $\mathrm{Hb}$ does not pass through the membrane, but it is adsorbed on the membrane and its sieving coefficient is low. The adsorption of $\mathrm{Hb}$ can be seen during the experiment with a bare eye - the hollow fiber membrane changes color and becomes red due to $\mathrm{Hb}$. After about $100 \mathrm{~min}$, when all the charged adsorption sites are covered by $\mathrm{Hb}$, a "dynamic membrane" is formed due to the selective (reversible) adsorption of the protein molecules on the membrane. This "dynamic membrane" shields the negative charge of the P84/SPEEK membrane and the $\mathrm{Hb}$ goes to the permeate side. Although the sign of the "dynamic membrane" should be positive as the sign of $\mathrm{Hb}$ (see Fig. 2), it seems that the electrostatic protein-protein interactions are less pronounced than the interactions membraneprotein. The adsorption of $\mathrm{Hb}$ at $\mathrm{pH} 4.8$ to the P84/SPEEK membrane can also be traced by the dramatic decline of the filtrate flux in time (Fig. 8a; the flux was normalized by the initial filtrate flux $\left(\mathrm{J}_{0}\right)$, which was evaluated within the first $4 \mathrm{~min}$ after start of the filtration). For the P84/SPEEK membrane, at $\mathrm{pH} 4.8$ the flux decreases to less than $20 \%$ of its initial value reaching a quasi-steady value after $150 \mathrm{~min}$. The $\mathrm{Hb}$ adsorption at the membrane surface at this $\mathrm{pH}$ seems to be responsible for the slight decrease of the BSA sieving coefficient in the later stage of the experiment, too (see Fig. 7a). At higher $\mathrm{pH}$, when $\mathrm{Hb}$ and membrane are both negatively charged, the flux decline is lower $\left(\sim 75 \%\right.$ of $\left.\mathrm{J}_{0}\right)$. The repulsion between membrane and protein at $\mathrm{pH} 6.8$ and 7.5 results in reduction of protein adsorption.

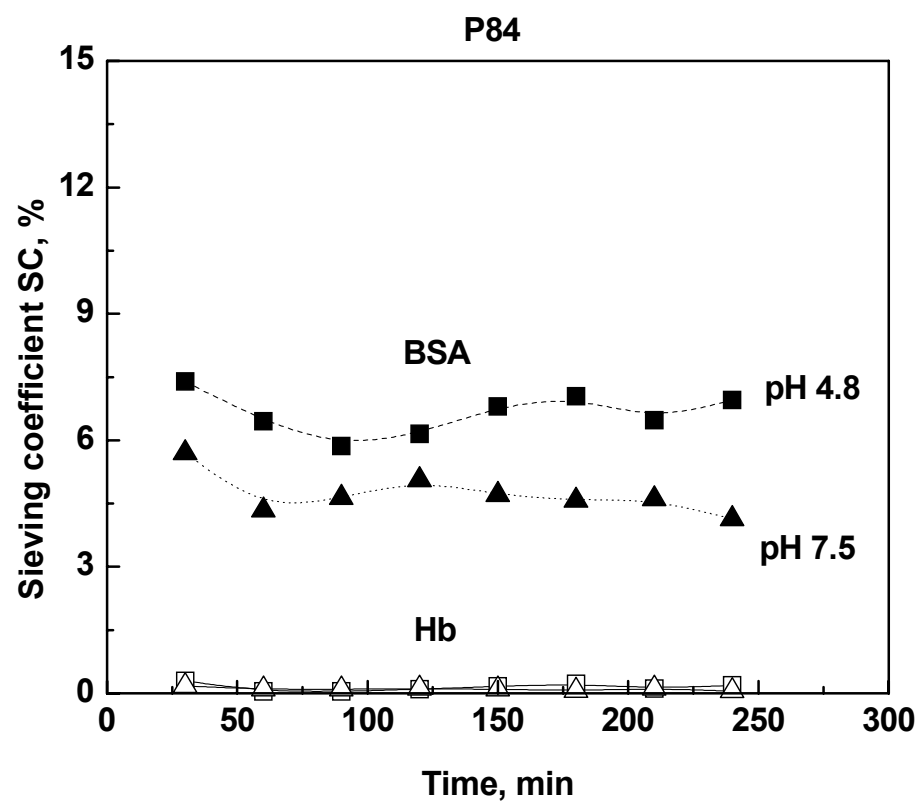

Figure 7b Sieving coefficient of BSA (full symbols) and $\mathrm{Hb}$ (open symbols) in time at different $\mathrm{pH}$ for P84 membrane. The lines connecting the points are used to guide the eye 


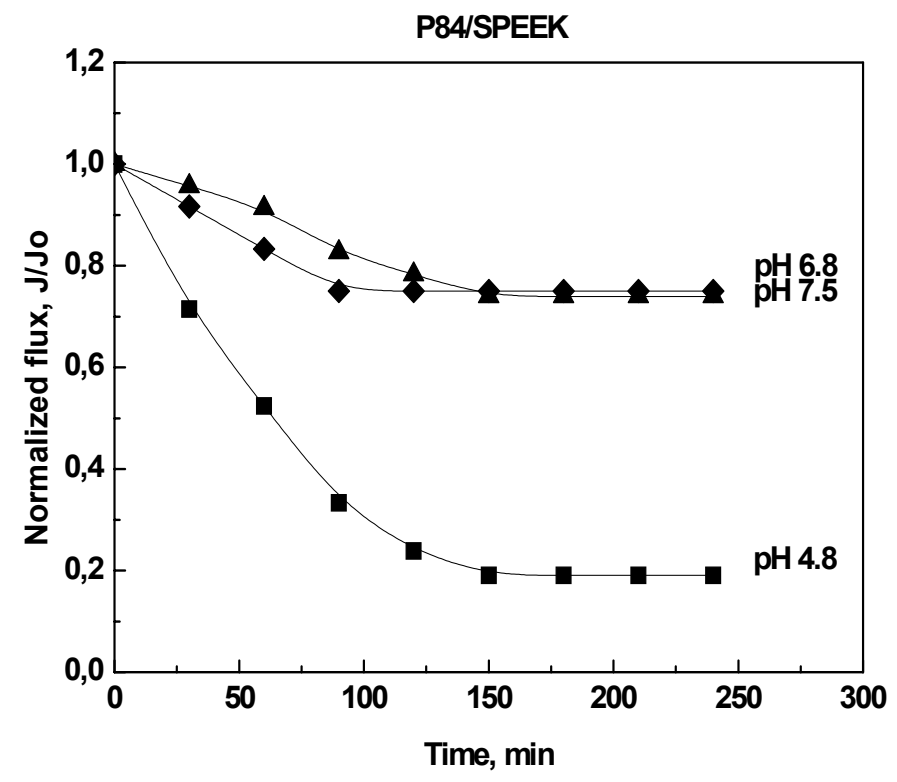

Figure 8a Normalized filtrate flux for the filtration of BSA/Hb solutions in time through the P84/SPEEK membranes

At $\mathrm{pH}$ 6.8, although it is the isoelectric point of $\mathrm{Hb}$, its transport through the membrane stays lower than at $\mathrm{pH} \mathrm{4.8,} \mathrm{where} \mathrm{after} \mathrm{the} \mathrm{"dynamic} \mathrm{membrane"} \mathrm{was} \mathrm{formed,} \mathrm{Hb}$ started "leaking" to the permeate, $\left(\mathrm{SC}_{\mathrm{Hb}}\right.$ increased and $\alpha_{\mathrm{BSA} / \mathrm{Hb}}$ decreased). $\mathrm{Hb}$ sieving coefficient becomes even lower at higher $\mathrm{pH}$, where $\mathrm{Hb}$ gains the negative charge and it is rejected by the negatively charged membrane.

Figure $7 \mathrm{~b}$ shows the sieving coefficient of BSA and $\mathrm{Hb}$ in time at two different $\mathrm{pHs}$ for the P84 hollow fiber membrane. For both proteins the sieving coefficients are lower than the ones obtained with membrane P84/SPEEK. In fact, $\mathrm{Hb}$ is almost completely retained by

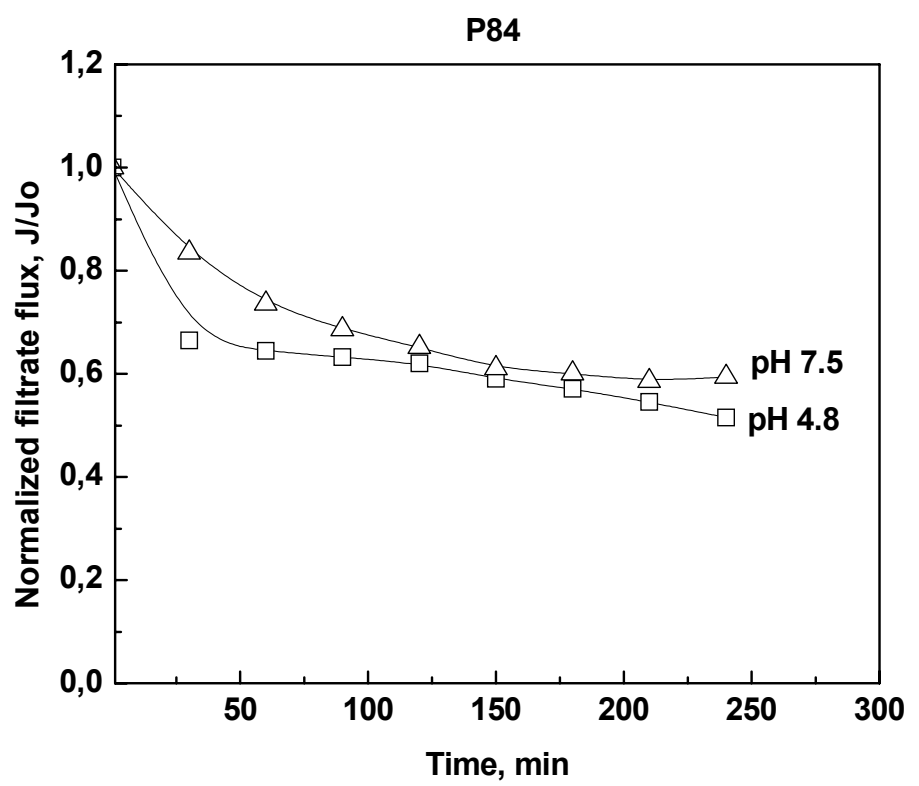

Figure 8b Normalized filtrate flux for the filtration of BSA/Hb solutions in time through the P84 membranes 
P84 membrane. This is most likely due to the higher hydrophobicity of the P84 membranes which causes higher non specific adsorption of the proteins on the membrane, than for the P84/SPEEK membrane, which is more hydrophilic due to SPEEK. The difference in the $\mathrm{SC}_{\mathrm{BSA}}$ and $\mathrm{SC}_{\mathrm{Hb}}$ between $\mathrm{pH} 4.8$ and 7.5 is not significant and within the experimental error.

In contrast to the P84/SPEEK membrane, the flux decline measured for P84 membrane (Fig. 8b) is much less dependent on the $\mathrm{pH}$, which indicates less electrostatic interactions membrane - protein than for P84/SPEEK membrane. At $\mathrm{pH} 4.8$ higher membrane fouling is observed for P84/SPEEK membrane due to the adsorption of positively charged $\mathrm{Hb}$ on the highly negatively charged membrane. At this $\mathrm{pH}$ the electrostatic interactions deteriorate the performance of the membrane. The effect of the charge seems to be dominant at this $\mathrm{pH}$ over the increased hydrophilicity of the membrane, which should lower the protein adsorption to the membrane. At pH 6.8 and 7.5 the situation is reversed and the P84/SPEEK membrane shows less fouling than P84 membrane. Here, the electrostatic repulsion of negative proteins by the negative membrane and the hydrophilicity act together against specific and non-specific adsorption and both these properties are more pronounced for the P84/SPEEK membrane. It seems that the slight negative charge of P84 is not as effective in fouling reduction as the charge obtained by introduction of SPEEK into the membrane.

Figure 9 presents the overall selectivities of $\mathrm{BSA} / \mathrm{Hb}$ obtained with $\mathrm{P} 84$ and P84/SPEEK membranes. The $\alpha_{\mathrm{BSA} / \mathrm{Hb}}$ increases with $\mathrm{pH}$ for both membranes; however for the P84/SPEEK membrane the increase is more dramatic. There, at $\mathrm{pH} 4.8$ the selectivity decreases in time tending to zero due to the increase of $\mathrm{SC}_{\mathrm{Hb}}$ in time (see Fig.9). The hemoglobin probably "leaks" to the permeate after formation of the "dynamic membrane". At $\mathrm{pH} 7.5$ the average $\alpha_{\mathrm{BSA} / \mathrm{Hb}}$ of the P84/SPEEK membrane is about 200 mainly due to the very low $\mathrm{Hb}$ sieving coefficient (at this $\mathrm{pH}$ the $\mathrm{Hb}$ is almost completely rejected by the membrane). As expected, for pure P84 membrane the dependence of BSA/Hb selectivity on $\mathrm{pH}$ is less pronounced due to the lower charge on the membrane surface and the high non specific interaction with the membrane.

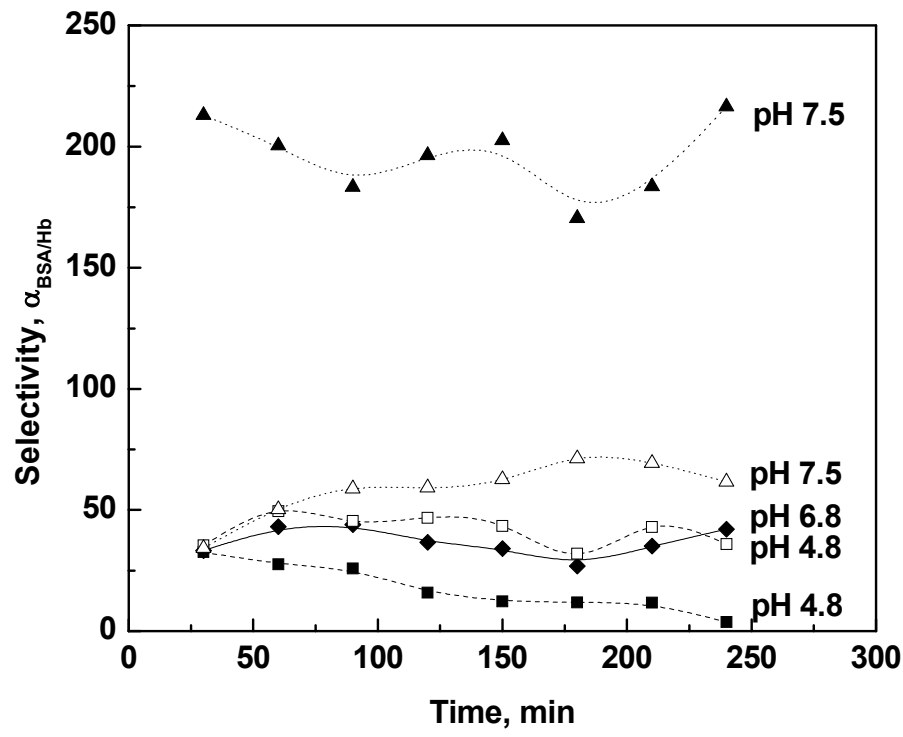

Figure 9 Selectivity $\mathrm{BSA} / \mathrm{Hb}$ in time at various $\mathrm{pH}$ for P84/SPEEK (full symbols) and P84 (open symbols) membrane. The lines connecting the points are used to guide the eye 
The higher transmission of BSA over $\mathrm{Hb}$ found in our work is consistent with the results reported by Li and Chung [4] who studied mixture of the same proteins through a dual layer hollow fiber composed of a polyethersulphone (PES) layer and a layer made of blend of sulphonated polyethersulphone and PES. There the separation was performed at $\mathrm{pH} 6.8$ and the obtained $\mathrm{BSA} / \mathrm{Hb}$ selectivity was less than 30 (in this work, it is 42 at the same $\mathrm{pH}$ ). In other work [34], a binary mixture of cytochrome c (isoelectric point at $\mathrm{pH}$ 9) and myoglobin (isoelectric point at $\mathrm{pH} 7$ ) with the ratio of MW 1.3 was separated using negatively charged hydrolyzed polyacrylonitrile membrane with the highest selectivity 40 at $\mathrm{pH} 5$. Similar selectivity to the one found in this work was obtained by Van Reis et al. [35]. There a separation of BSA and antigen binding fragment Fab (isoelectric point 8.5) with a ratio of MW 1.5 through commercial Biomax ${ }^{\mathrm{TM}} 100$ negative membrane was found to have the selectivity of 200 at $\mathrm{pH} 8.4$. The $\mathrm{BSA} / \mathrm{Hb}$ selectivity of 216 obtained in this work with P84/SPEEK membrane is higher than the selectivities reported so far for the separation of proteins with similar molecular weights.

It is also important to note that generally the transport behavior of a protein is altered by the presence of other proteins in the solution. Due to the protein-protein interactions, protein coupling often occurs which is more pronounced when proteins with opposite charge are present in the solution. This results in lowering of transport of both proteins through the membrane in the mixture solution in comparison to single protein solution [33, 36, 37]. All the results of this work were obtained using binary mixture of $\mathrm{BSA} / \mathrm{Hb}$. We anticipate that $\mathrm{SC}$ of the single BSA and single $\mathrm{Hb}$ through the membranes would be higher than those reported here for the binary mixture.

An explanation should be made why BSA permeates through the membrane while $\mathrm{Hb}$ is retained, even though they have similar molecular weight and at $\mathrm{pH}$ when they both are negatively charged. Molecular weight and the net charge of a protein are not the only factors which determine the protein permeation through a porous membrane. The other parameters are shape, the binding charge and the ratio of hydrophilic to hydrophobic aminoacids. Neither BSA nor $\mathrm{Hb}$ is a regular sphere (see Table 1). Although BSA has a slightly higher molecular weight and larger total surface area, it is hemoglobin which possesses larger contact surface area (calculated as the $\%$ of the total surface area which can interact with the solid surface, in this case, a membrane). Moreover, $\mathrm{Hb}$ has more hydrophobic than hydrophilic aminoacids (unlike BSA), which can contribute as the non-selective adsorption to the overall membrane performance. As the result one can expect that, the $\mathrm{Hb}$ transport through the membrane is lower than for BSA and this effect should be more pronounced in the case of P84 membrane because of its higher hydrophobicity in comparison to the P84/SPEEK membrane.

Figure 10 presents the final protein selectivities determined after 4 hours of experiment at various $\mathrm{pH}$ for both membranes. The final selectivities are chosen (and not the average values within the time of experiment), because the influence of the membrane charge on the separation efficiency is changing in time and the effects are most pronounced at the end of the experiment. The P84 membrane shows a slight increase in selectivity from 36 at $\mathrm{pH}$ 


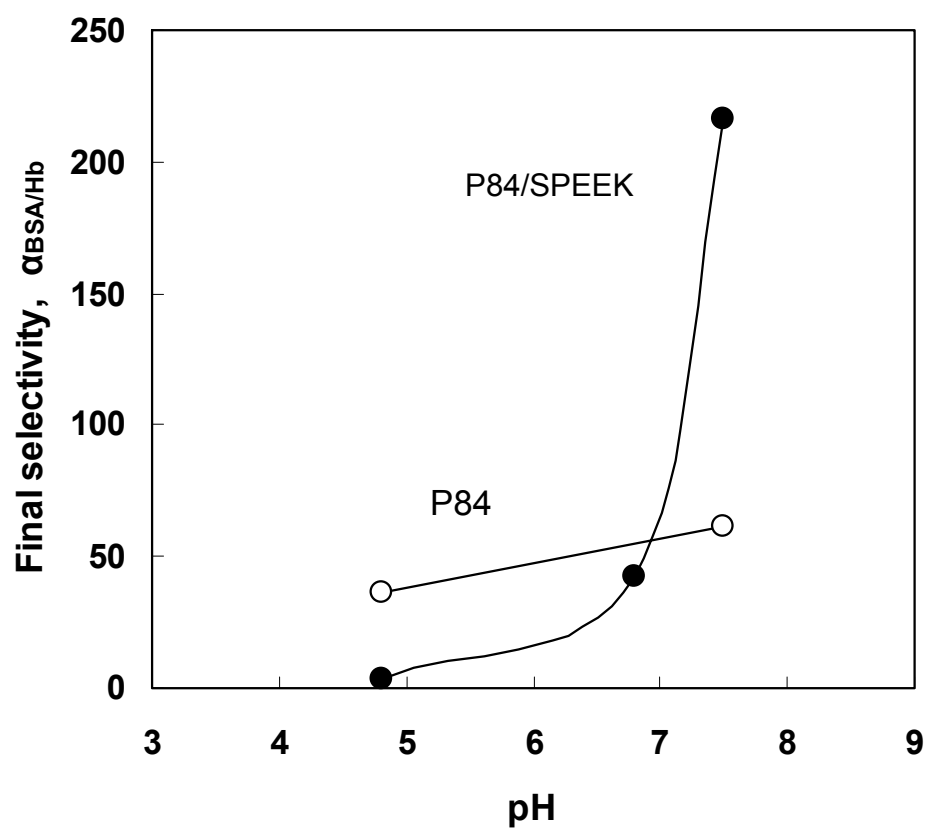

Figure 10 Comparison of final selectivities $\alpha_{\mathrm{BSA} / \mathrm{Hb}}$ (after 4 hours of filtration) at various $\mathrm{pH}$ for the P84 and P84/SPEEK membranes. The lines connecting the points are used to guide the eye

4.8 to 62 at $\mathrm{pH} 7.5$, while the P84/SPEEK membrane demonstrates an improvement in protein selectivity from 4 to 216 in the same $\mathrm{pH}$ range. These results clearly show the effect of the membrane charge and its influence on the separation performance.

\section{Conclusions}

This work presented a novel one-step technique to produce highly charged hollow fiber membranes by dissolving a polyelectrolyte in the bore liquid. This technique might be a new alternative for blending or co-extrusion, because it offers the advantage of the reduced amount of the required polyelectrolyte with the simplicity of fabrication.

The produced P84/SPEEK hollow fiber membrane is negatively charged at the wide $\mathrm{pH}$ range with the maximum zeta-potential of $-58 \mathrm{mV}(\mathrm{pH} 4.9$ to 9.0). In comparison, pure P84 membrane has isoelectric point at $\mathrm{pH} 3.75$ and the highest zeta-potential of $-21.5 \mathrm{mV}$. The P84/SPEEK membrane has a uniform sponge-like pore structure with no macrovoids and pure water permeance of $6.5 \mathrm{l} /\left(\mathrm{m}^{2} \cdot \mathrm{h} \cdot \mathrm{bar}\right)$.

The P84/SPEEK membrane produced by addition of SPEEK to the bore liquid shows an improved performance concerning protein separation in comparison to the pure P84 membrane. While varying the $\mathrm{pH}$, the selectivity of $\mathrm{BSA} / \mathrm{Hb}$ for the P84/SPEEK membrane increases from 4 to 216. At the same time fouling is notably reduced. Two properties of the P84/SPEEK play a role in the improvement of the membrane performance: higher charge (in comparison to the P84 membrane) and increased hydrophilicity. The P84/SPEEK membranes might find application not only for protein separation, but also for salt rejection and other fields of membrane technology where charged solutes need to be separated. 


\section{References}

[1] S. Nakao, H. Osada, H. Kurata, T. Tsuru, S. Kimura, Separation of proteins by charged ultrafiltration membranes, Desalination, 70 (1988) 191-205.

[2] C. Manea, M. Mulder, Characterization of polymer blends of polyethersulfone/sulfonated polysulfone and polyethersulfone/sulfonated polyetheretherketone for direct methanol fuel cell applications, Journal of Membrane Science, 206 (2002) 443-453.

[3] T. He, M.H.V. Mulder, H. Strathmann, M. Wessling, Preparation of composite hollow fiber membranes: co-extrusion of hydrophilic coatings onto porous hydrophobic support structures, Journal of Membrane Science, 207 (2002) 143-156.

[4] Y. Li, T.-S. Chung, Exploration of highly sulfonated polyethersulfone (SPES) as a membrane material with the aid of dual-layer hollow fiber fabrication technology for protein separation, Journal of Membrane Science, 309 (2008) 45-55.

[5] L. Yi, S. Sim Chuan, C. Tai-Shung, C. Sui Yung, Exploration of ionic modification in dual-layer hollow fiber membranes for long-term high-performance protein separation, AIChE Journal, 55 (2009) 321-330.

[6] M.J. Peer, Sulphonated Polyetherether Ketone Membranes, in: P.M.S. LTD (Ed.), Great Britain, 1989.

[7] W. Richard Bowen, T.A. Doneva, H.B. Yin, Polysulfone -- sulfonated poly(ether ether) ketone blend membranes: systematic synthesis and characterisation, Journal of Membrane Science, 181 (2001) 253-263.

[8] F.G. Wilhelm, I.G.M. Pünt, N.F.A. van der Vegt, H. Strathmann, M. Wessling, Cation permeable membranes from blends of sulfonated poly(ether ether ketone) and poly(ether sulfone), Journal of Membrane Science, 199 (2002) 167-176.

[9] W.R. Bowen, T.A. Doneva, H. Yin, The effect of sulfonated poly(ether ether ketone) additives on membrane formation and performance, Desalination, 145 (2002) 39-45.

[10] W.R. Bowen, T.A. Doneva, H.-B. Yin, Separation of humic acid from a model surface water with PSU/SPEEK blend UF/NF membranes, Journal of Membrane Science, 206 (2002) 417-429.

[11] S. Kaliaguine, S.D. Mikhailenko, K.P. Wang, P. Xing, G. Robertson, M. Guiver, Properties of SPEEK based PEMs for fuel cell application, Catalysis Today, 82 (2003) 213-222.

[12] K. Nymeijer, T. Visser, R. Assen, M. Wessling, Super selective membranes in gas-liquid membrane contactors for olefin/paraffin separation, Journal of Membrane Science, 232 (2004) 107-114.

[13] W.R. Bowen, S.Y. Cheng, T.A. Doneva, D.L. Oatley, Manufacture and characterisation of polyetherimide/sulfonated poly(ether ether ketone) blend membranes, Journal of Membrane Science, 250 (2005) 1-10.

[14] J. Balster, O. Krupenko, I. Punt, D.F. Stamatialis, M. Wessling, Preparation and characterisation of monovalent ion selective cation exchange membranes based on sulphonated poly(ether ether ketone), Journal of Membrane Science, 263 (2005) 137.

[15] G. Arthanareeswaran, P. Thanikaivelan, N. Jaya, D. Mohan, M. Raajenthiren, Removal of chromium from aqueous solution using cellulose acetate and sulfonated poly(ether 
ether ketone) blend ultrafiltration membranes, Journal of Hazardous Materials, 139 (2007) 44-49.

[16] G. Arthanareeswaran, D. Mohan, M. Raajenthiren, Preparation and performance of polysulfone-sulfonated poly(ether ether ketone) blend ultrafiltration membranes. Part I, Applied Surface Science, 253 (2007) 8705-8712.

[17] X. Li, S. De Feyter, I.F.J. Vankelecom, Poly(sulfone)/sulfonated poly(ether ether ketone) blend membranes: Morphology study and application in the filtration of alcohol based feeds, Journal of Membrane Science, 324 (2008) 67-75.

[18] T. He, M. Frank, M.H.V. Mulder, M. Wessling, Preparation and characterization of nanofiltration membranes by coating polyethersulfone hollow fibers with sulfonated poly(ether ether ketone) (SPEEK), Journal of Membrane Science, 307 (2008) 62-72.

[19] G. Arthanareeswaran, P. Thanikaivelan, M. Raajenthiren, Preparation and characterization of poly (methyl methacrylate) and sulfonated poly (ether ether ketone) blend ultrafiltration membranes for protein separation applications, Materials Science and Engineering: C, 29 (2009) 246-252.

[20] H. Maab, M. Schieda, W. Yave, S. Shishatskiy, S.P. Nunes, SPEEK/Polyimide Blends for Proton Conductive MembranesPresented at the 1st CARISMA Conference, Progress MEA 2008, La Grande Motte, 21st-24th September 2008, Fuel Cells, 9 (2009) 401-409.

[21] W.J. Lau, A.F. Ismail, Theoretical studies on the morphological and electrical properties of blended PES/SPEEK nanofiltration membranes using different sulfonation degree of SPEEK, Journal of Membrane Science, 334 (2009) 30-42.

[22] G. Arthanareeswaran, P. Thanikaivelan, M. Raajenthiren, Sulfonated poly(ether ether ketone)-induced porous poly(ether sulfone) blend membranes for the separation of proteins and metal ions, Journal of Applied Polymer Science, 116 (2009) 995-1004.

[23] H. Maab, S.P. Nunes, Modified SPEEK membranes for direct ethanol fuel cell, Journal of Power Sources, 195 (2010) 4036-4042.

[24] H. Sijbesma, K. Nymeijer, R. van Marwijk, R. Heijboer, J. Potreck, M. Wessling, Flue gas dehydration using polymer membranes, Journal of Membrane Science, 313 (2008) 263-276.

[25] T. He, Towards stabilization of supported liquid membranes: preparation and characterization of polysulfone support and sulfonated poly (ether ether ketone) coated composite hollow fiber membranes, Desalination, 225 (2008) 82-94.

[26] J. Kochan, T. Wintgens, J.E. Wong, T. Melin, Properties of polyethersulfone ultrafiltration membranes modified by polyelectrolytes, Desalination, 250 (2010) 10081010 .

[27] A.N. Cherkasov, A.E. Polotsky, The resolving power of ultrafiltration, Journal of Membrane Science, 110 (1996) 79-82.

[28] M.R. Ladisch, Bioseparations Engineering: Principles, Practice, and Economics, A John Wiley and Sons, Inc., 2001.

[29] Saiful, Mixed Matrix Membrane Adsorbers for Protein and Blood Purification, PhD Thesis, University of Twente, 2007.

[30] R. Shukla, M. Balakrishnan, G.P. Agarwal, Bovine serum albumin-hemoglobin fractionation: Significance of ultrafiltration system and feed solution characteristics, Bioseparation, 9 (2000) 7-19. 
[31] D. Möckel, E. Staude, M. Dal-Cin, K. Darcovich, M. Guiver, Tangential flow streaming potential measurements: Hydrodynamic cell characterization and zeta potentials of carboxylated polysulfone membranes, Journal of Membrane Science, 145 (1998) 211-222.

[32] M.-E. Avramescu, Z. Borneman, M. Wessling, Mixed-matrix membrane adsorbers for protein separation, Journal of Chromatography A, 1006 (2003) 171-183.

[33] R. Ghosh, Protein bioseparation using ultrafiltration: theory, applications and new developments, Imperial College Press, London, 2003.

[34] M.C. Yang, J.H. Tong, Loose ultrafiltration of proteins using hydrolyzed polyacrylonitrile hollow fiber, Journal of Membrane Science, 132 (1997) 63-71.

[35] R. van Reis, J.M. Brake, J. Charkoudian, D.B. Burns, A.L. Zydney, High-performance tangential flow filtration using charged membranes, Journal of Membrane Science, 159 (1999) 133-142.

[36] S. Saksena, A.L. Zydney, Influence of protein-protein interactions on bulk mass transport during ultrafiltration, Journal of Membrane Science, 125 (1997) 93-108.

[37] N.N. Sudareva, O.I. Kurenbin, B.G. Belenkii, Increase in the efficiency of membrane fractionation, Journal of Membrane Science, 68 (1992) 263-270. 


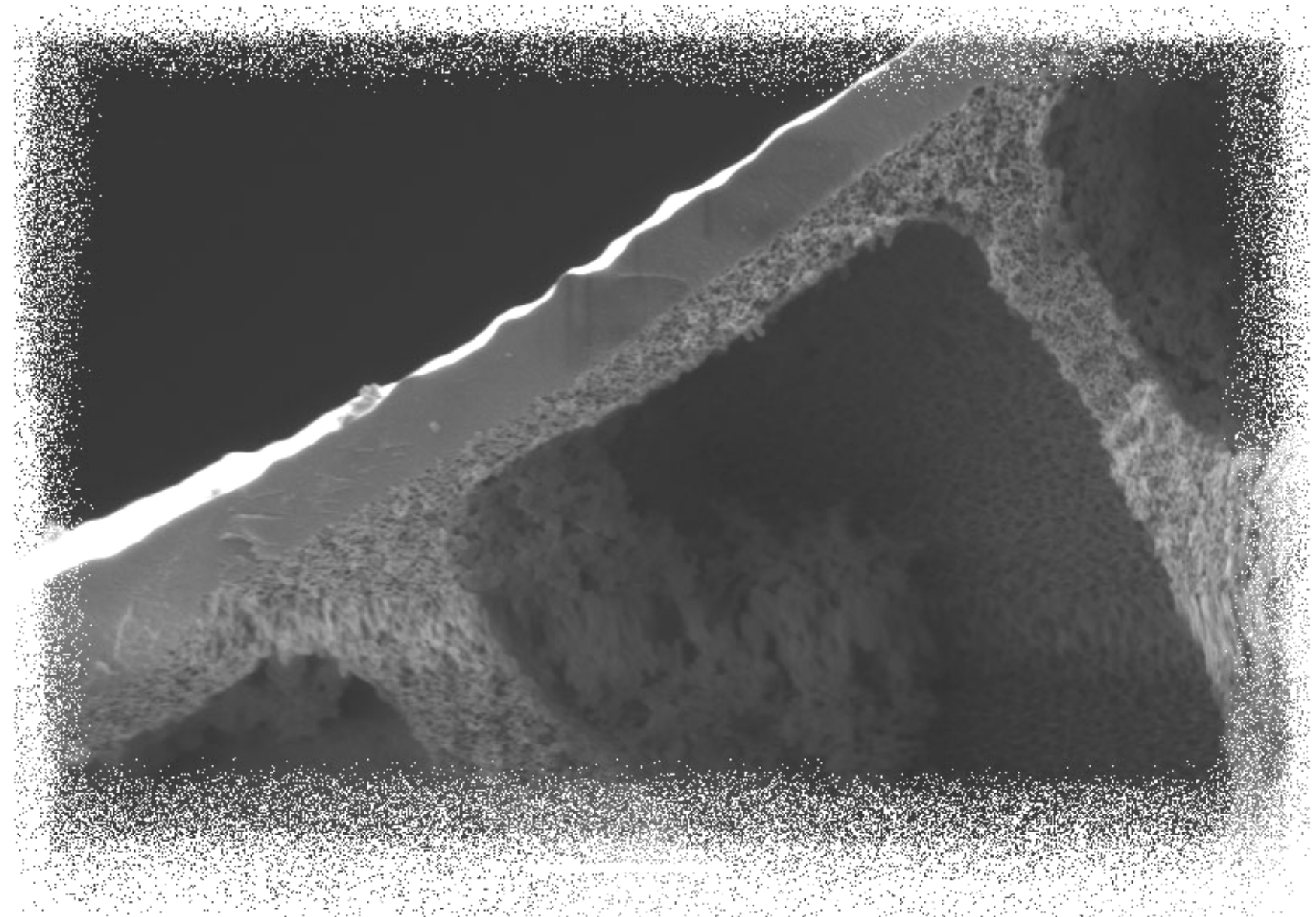

Chapter 3

Chemistry in a spinneret

- On the interplay of crosslinking and phase inversion during spinning of novel hollow fiber membranes 


\begin{abstract}
This work explores a new method of simultaneous membrane formation and chemical modification in a spinning process for fabricating asymmetric composite hollow fiber membranes. This method is based on controlled crosslinking reaction between the membrane forming polyimide P84 and the chemically modifying poly(ethylene imine) (PEI) dissolved in the bore liquid. We study the interplay between phase inversion and crosslinking, which determines the final morphology and chemistry of the hollow fiber membrane.

Depending on the composition of chemically active bore liquid, two different types of membranes can be fabricated. The first type is a membrane with a dense, crosslinked, gas selective inner layer (thickness in the range 1.4-6.1 $\mu \mathrm{m}$ ) having a mixed gas $\mathrm{CO}_{2} / \mathrm{N}_{2}$ selectivity $\sim 12$ in presence of water vapor. The second type is an entirely crosslinked membrane which is not soluble in NMP; it is porous (pure water flux $44.4 \pm 1.2 \mathrm{l} /\left(\mathrm{m}^{2} \cdot \mathrm{bar} \cdot \mathrm{h}\right)$ ) and selective for the separation of similar size proteins, bovine serum albumin (BSA) and hemoglobin $(\mathrm{Hb})$, due to the charge of the membrane. The isoelectric point of the new membrane is basic ( $\mathrm{pH} 9.3$ ), much higher than that of the $\mathrm{P} 84$ membrane ( $\mathrm{pH} 3.75)$.

The ease of process operation (only the bore composition needs to be modified) opens new perspectives towards applications in the area of gas separation and/or liquid filtration, the latter especially in harsh solvent environments.
\end{abstract}




\section{Introduction}

A major breakthrough in the history of membrane technology was the development of an asymmetric membrane obtained by phase inversion by Loeb and Sourirajan in the beginning of 1960s [1]. Another breakthrough was the development of asymmetric composite membrane where an ultrathin different material layer is applied on top of a supporting porous layer. In fact, several techniques to fabricate such composite membranes were explored over the last decades. They can be classified in three groups [2, 3]:

(i) Solution coating, first used by Forester and Francis [4] and Ward and Browall [5]. Currently, this technique is used as a dip coating, spray coating or spin coating for reverse osmosis, pervaporation and gas separation membranes. The dense selective layer produced with this technique has a thickness in range of 0.5-2 $\mu \mathrm{m}$ [2].

(ii) Polymerization reactions include interfacial polymerization and plasma polymerization methods. The interfacial polymerization membranes are widely used in reverse osmosis and nanofiltration, but not for gas separation because of the waterswollen hydrogel that fills the pores of the support membrane. The method was developed by Cadotte [6] and refined by Riley [7] and Kamiyama [8]. Plasma polymerization was first used to produce electrical insulation and protective coating, but selective membranes were prepared as well $[9,10]$. Both polymerization techniques result in an extremely thin dense film of thickness within the $50 \mathrm{~nm}$ range [3].

(iii) Dynamical coating, technique developed by Johnson and Kraus [11, 12], in which the selective layer is formed on the surface of a microporous support membrane by filtering a solution containing suspended colloid. Membranes produced by this technique found an application in reverse osmosis but proved to be unstable and difficult to reproduce due to the loss of the colloidal surface in time [2].

The advantage of the composite membrane over integrally asymmetric membrane is that each layer can be optimized independently to obtain the optimal properties with regard to the membrane selectivity, permeation and chemical and mechanical stability. However, the drawbacks are also obvious - these membranes have to be fabricated in many steps, which are time and energy consuming. In some cases, the membranes have also poor stability $[2,3]$.

In this work, we describe a novel method to fabricate a composite hollow fiber membrane in a one-step regular immersion precipitation dry-wet spinning by controlling the interplay between phase inversion and crosslinking. The crosslinking takes place between the amine groups of the poly(ethylene imine) (PEI) (Fig. 1) that is present in the bore liquid, and the carbonyl groups of the imide rings of polyimide P84 (Fig. 1), the membrane forming polymer. In contrast to the existing polyimide crosslinking as a post-treatment method [1321], and thus a second additional step of membrane modification, our method includes the crosslinking in the spinning process.

We demonstrate that the interplay between crosslinking and phase inversion can be controlled to obtain either porous completely crosslinked, solvent resistant hollow fiber membranes, or membranes with a dense, gas selective crosslinked inner layer. The crosslinking and phase inversion can take place simultaneously or one after each other. The 
thickness of the dense selective inner layer can be easily controlled by changing the concentration of PEI in the bore liquid and/or the ratio of solvent/nonsolvent in the bore liquid, shell liquid or polymer dope. Not only the crosslinking and formation of a dense layer takes place, but also the membrane surface charge is altered and a new positively charged membrane is obtained.
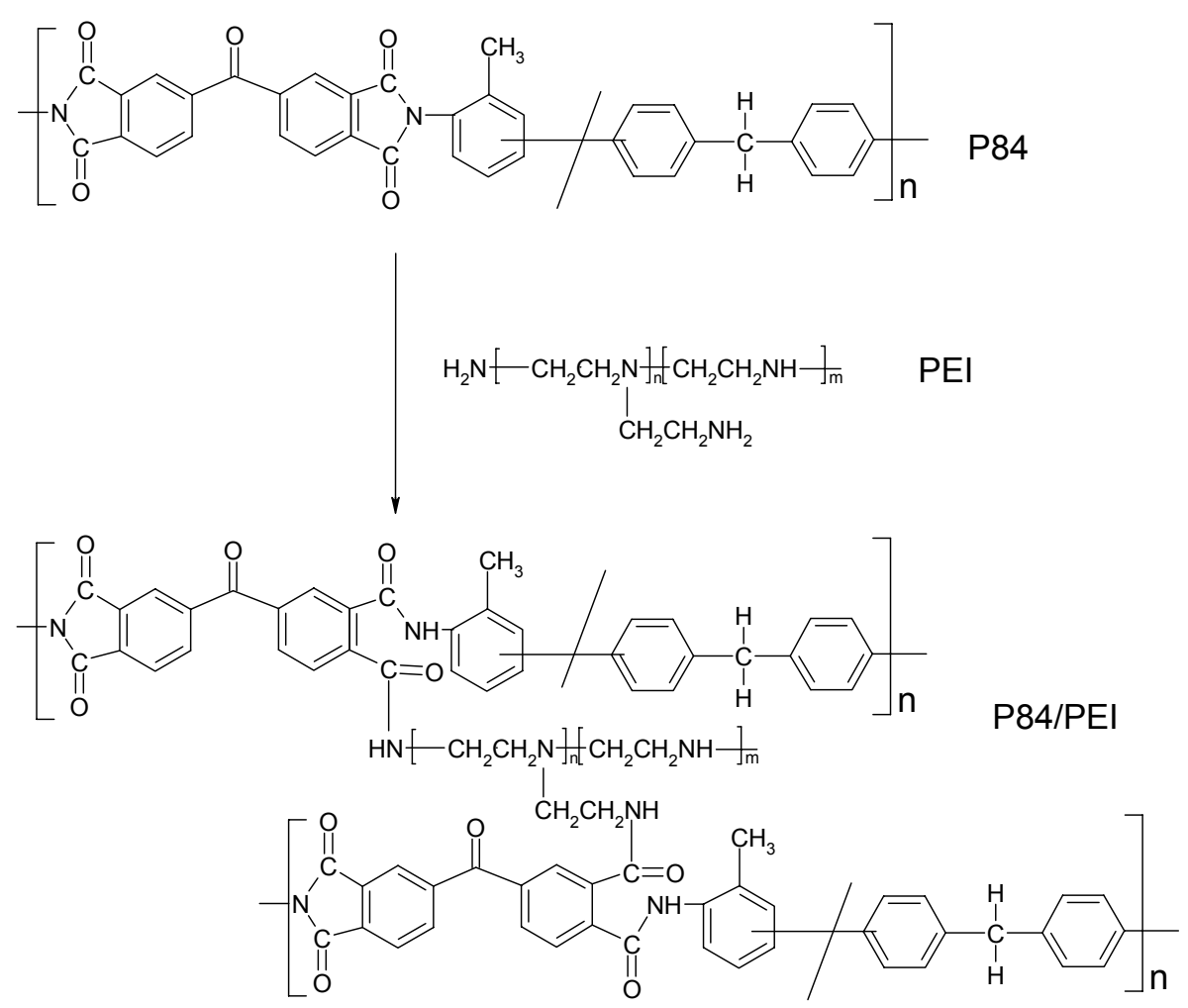

Figure 1 Proposed crosslinking reaction between polyimide P84 and polyethyleneimine

\section{Experimental}

\subsection{Materials}

\section{Hollow fiber fabrication}

Polyimide, type P84 was purchased from HP Polymer GmbH (325 mesh, STD) and poly(ethylene imine) PEI, high molecular weight (MW 25 000; Mn 10 000; containing 34\% primary amines, $40 \%$ secondary amines, and $26 \%$ tertiary amines), water-free, was obtained from Aldrich. Glycerol, ethanol, both of analytical grade and 1-methyl-pyrrolidone (NMP), extra pure, was purchased from Across Organics. 


\section{Hollow fiber characterization}

The transport of mixture of proteins through the membranes was studied with buffered solutions of BSA, fraction $\mathrm{V}$ from Fluka, and $\mathrm{Hb}$ from bovine blood, a lyophilized powder from Sigma-Aldrich. The properties of these two proteins are listed in Table 1 [22]. The experiments were performed at $\mathrm{pH} 4.8$ and 7.5 with a binary mixture of BSA and $\mathrm{Hb}$ (concentration $0.5 \mathrm{~g} / 1$ each protein) in $10 \mathrm{mM}$ buffers. The ionic strength of the buffers was adjusted to $15 \mathrm{mM}$ with sodium chloride, 99.5\%, purchased from Across Organics. The protein solution was filtered through the filtration paper (Rotilabo Faltenfilter, Roth) prior to

Table 1 Characteristics of albumin (BSA) and hemoglobin (Hb) [22]

\begin{tabular}{lcc}
\hline Property & BSA & $\mathrm{Hb}$ \\
\hline Molecular Weight, kDa & 66.4 & 64.5 \\
Number of aminoacids & 583 & 574 \\
Ratio of aminoacids & $1: 1.27$ & $1: 0.80$ \\
Hydrophobic : hydrophilic & 4.8 & 6.8 \\
Isoelectric point & $140 \times 40 \times 40$ & $70 \times 55 \times 55$ \\
Dimensions, $\AA$ & & \\
\hline
\end{tabular}

use in the filtration set-up. For $\mathrm{pH} 4.8$ the acetate buffer was used, obtained by dissolving in water: acetic acid (glacial 100\%, anhydrous, from Merck) and sodium acetate (anhydrous from Across Organics). Phosphate buffer was used for $\mathrm{pH}$ 7.5, prepared by dissolving in water monobasic sodium phosphate, monohydrate and dibasic sodium phosphate, anhydrous, both obtained from Across Organics. Potassium chloride and nitric acid $0.1 \mathrm{~mol} / \mathrm{L}$, volumetric solutions, for the zeta-potential measurements were purchased from Fluka. Sodium hydroxide $0.1 \mathrm{~mol} / \mathrm{L}$ in ampoules (Titrisol) was obtained from Merck. All these chemicals were of analytical grade and used as received. Water for pure water flux experiments and for preparing the buffers was obtained from Millipore water purification unit.

\subsection{Fabrication of a hollow fiber membrane}

The polyimide P84 was used as received after drying in the vacuum oven at $30^{\circ} \mathrm{C}$ for $24 \mathrm{~h}$. The polymer dope solution was stirred at room temperature for $48 \mathrm{~h}$; next it was filtrated through a metal filter with a $25 \mu \mathrm{m}$ mesh and left for degassing for $48 \mathrm{~h}$. Bore liquid and shell liquid were left for degassing for at least $16 \mathrm{~h}$.

All membranes were obtained by dry-wet immersion precipitation spinning. The dope solution along with the bore liquid, and optionally with the shell liquid, were simultaneously pumped through a triple orifice spinneret and, after short residence time in the air, immersed into the water coagulation bath. The take-up velocity was controlled by a pulling wheel, which enabled also stretching of the fiber. All prepared membranes were washed out for $48 \mathrm{~h}$ in water to remove the additives and solvent. Membranes for pure water flux measurements and protein filtration were impregnated with glycerol (by placing in the $20 \%(\mathrm{w} / \mathrm{w})$ glycerol in water) to prevent the porous structure from collapsing upon drying. 
Afterwards, the hollow fiber membranes were dried in the air. Membranes for gas transport experiments were directly dried in the air without impregnation.

The stability of membranes in NMP was evaluated by immersing pieces of hollow fibers in NMP for $48 \mathrm{~h}$ and visual inspection of the fibers appearance afterwards.

Sixteen batches of hollow fiber membranes were produced by varying the composition of polymer dope, bore liquid (mainly concentration of PEI from $0 \%$ to $20 \%$ ) and shell liquid. Ten representative batches were chosen and are presented in this work to show the proof of concept and trends in the membrane fabrication. In each batch several meters of fibers were produced (see Table 2). The categories of membranes designated as I and II were

Table 2 Parameters of the spun fibers

\begin{tabular}{|c|c|c|c|c|c|}
\hline No. & Batch & $\begin{array}{c}\text { Shell liquid, } \\
\%\end{array}$ & $\begin{array}{c}\text { Bore liquid, } \\
\%\end{array}$ & $\begin{array}{l}\text { Inner layer } \\
\text { density, } \mu \mathrm{m}\end{array}$ & $\begin{array}{l}\text { Stability } \\
\text { in NMP* }\end{array}$ \\
\hline \multicolumn{6}{|c|}{ Polymer dope: $22 \%$ P84, 12 \% glycerol, $66 \%$ NMP } \\
\hline Ref. & $\mathrm{I}-0$ & - & $100 \%$ ethanol & - & $\mathrm{D}$ \\
\hline 1 & $\mathrm{I}-1$ & - & $\begin{array}{l}20 \text { PEI } \\
70 \mathrm{NMP}^{2} \\
10 \mathrm{H}_{2} \mathrm{O}\end{array}$ & $\begin{array}{c}\text { Dense } \\
2.6 \pm 0.2\end{array}$ & LND \\
\hline 2 & $\mathrm{I}-2$ & - & $\begin{array}{l}10 \mathrm{PEI} \\
80 \mathrm{NMP} \\
10 \mathrm{H}_{2} \mathrm{O}\end{array}$ & $\begin{array}{c}\text { Dense } \\
1.4 \pm 0.1\end{array}$ & LND \\
\hline 3 & $\mathrm{I}-3$ & - & $\begin{array}{l}10 \text { PEI } \\
10 \mathrm{NMP} \\
80 \mathrm{H}_{2} \mathrm{O}\end{array}$ & - & ND \\
\hline 4 & $\mathrm{I}-4$ & - & $\begin{array}{l}10 \text { PEI } \\
45 \text { Glyc } \\
45 \text { EtOH }\end{array}$ & - & ND \\
\hline 5 & II-1 & $\begin{array}{l}75 \mathrm{NMP} \\
25 \mathrm{H}_{2} \mathrm{O}\end{array}$ & $\begin{array}{l}20 \mathrm{PEI} \\
70 \mathrm{NMP} \\
10 \mathrm{H}_{2} \mathrm{O}\end{array}$ & $\begin{array}{c}\text { Dense } \\
4.1 \pm 0.2\end{array}$ & LND \\
\hline 6 & II-2 & $\begin{array}{l}75 \mathrm{NMP} \\
25 \mathrm{H}_{2} \mathrm{O}\end{array}$ & $\begin{array}{l}10 \mathrm{PEI} \\
79 \mathrm{NMP} \\
11 \mathrm{H}_{2} \mathrm{O}\end{array}$ & $\begin{array}{c}\text { Dense } \\
2.3 \pm 0.2\end{array}$ & LND \\
\hline 7 & II-3 & $\begin{array}{l}75 \mathrm{NMP}^{\mathrm{NMP}} 25 \mathrm{H}_{2} \mathrm{O}\end{array}$ & $\begin{array}{l}10 \text { PEI } \\
90 \text { NMP }\end{array}$ & $\begin{array}{c}\text { Dense } \\
3.6 \pm 0.2\end{array}$ & LND \\
\hline
\end{tabular}

Polymer dope: $30 \%$ P84, 70 \% NMP

$\begin{array}{ccclcc}8 & & & & & \\ & \text { III-1 } & 75 \mathrm{NMP} & 20 \mathrm{PEI} & \text { Dense } & \text { LND } \\ & & 25 \mathrm{H}_{2} \mathrm{O} & 70 \mathrm{NMP} & 6.1 \pm 0.4 \mu \mathrm{m} & \\ & & & 10 \mathrm{H}_{2} \mathrm{O} & & \\ 9 & & & 10 \mathrm{PEI} & \text { Dense } & \text { LND } \\ & \text { III-2 } & 75 \mathrm{NMP} & 79 \mathrm{NMP} & 4.6 \pm 0.3 \mu \mathrm{m} & \\ & & 25 \mathrm{H}_{2} \mathrm{O} & 11 \mathrm{H}_{2} \mathrm{O} & & \end{array}$

D: Dissolved

ND: Not dissolved

LND: Layer not dissolved 
spun from a solution containing $22 \%$ of P84, 66\% NMP and $12 \%$ glycerol, while for the fabrication of membranes marked as III a polymer solution of 30\% P84 in NMP, without glycerol, was used. Shell liquid was only used in preparation of fibers II and III.

Figure 2 presents schematic of the spinnerets which represent the three main categories (I-III) of spun fibers together with the compositions of the dope solution, bore liquid and shell liquid. Fiber I-0 was spun as a reference, with bore liquid containing no PEI. The fibers spun with addition of PEI in the bore liquid will be referred as P84/PEI in the following sections of this paper.

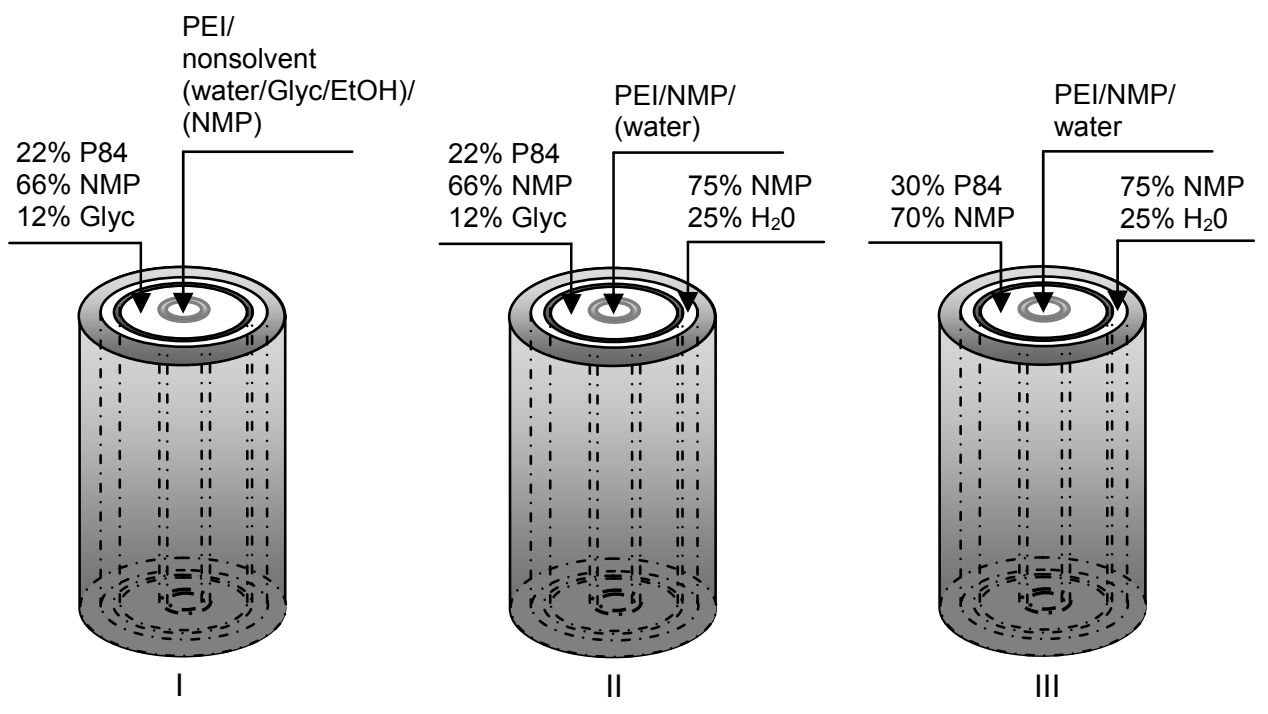

Figure 2 Schematic of triple orifice spinneret with the compositions of the polymer dope, bore liquid and shell liquid; (I) Fibers of category I, (II) Fibers of category II, (III) Fibers of category III

\subsection{Attenuated Total Reflectance Fourier Transform Infrared Spectroscopy (ATR- FTIR)}

PerkinElmer Spectrum 100 FTIR spectrometer equipped with universal ATR polarization accessory was used to identify the chemical changes of the fiber. For these measurements, the fiber I-1 was placed in NMP for $48 \mathrm{~h}$. The undissolved part of the fiber was rinsed for few times with fresh NMP and dried at $30^{\circ} \mathrm{C}$ in vacuum oven for 1 week. Afterwards it was ground to powder in liquid nitrogen. The fiber I-0 (used as a reference) was also ground and analyzed in the powder form. The typical imide bands and amide bands of the crosslinked imide were used to identify the changes of the polymer structure.

\subsection{Scanning Electron Microscopy}

Samples for scanning electron microscopy (SEM) were prepared by freezing the fibers in liquid nitrogen and breaking them in order to expose the cross-sectional area. Samples were dried under vacuum at $30^{\circ} \mathrm{C}$ overnight and afterwards coated with a thin layer of gold using Balzer Union SCD 040 sputtering device. Membranes were examined using Jeol JSM-5600 LV Scanning Electron Microscope with Semaphore software for the determination 
of fiber dimensions. The thickness of the dense inner layer was determined by evaluating three pieces of fiber from the same batch.

\subsection{Zeta-potential determination}

The zeta-potential of membranes was determined with a SurPAAS Electrokinetic Analyzer (Anton Paar GmbH, Austria) based on the measurement of streaming potential or streaming current. For this determination, we used modules having 1-3 fibers each, with length of around $4 \mathrm{~cm}$ and the space between the fibers completely filled with glue at the entire length of the module. $1 \mathrm{mM} \mathrm{KCl}$ was used as the electrolyte circulating through the measuring cell containing the membrane module. The $\mathrm{pH}$ was adjusted by automatic titration with $0.1 \mathrm{M}$ solution of nitric acid and $0.1 \mathrm{M}$ solution of sodium hydroxide in water. The electrolyte was flowing through the lumen of the fiber and the zeta-potential of the lumen surface was determined in the $\mathrm{pH}$ range 3-11, assuming that the electrolyte flows only in one direction along the fiber without entering the porous structure. The electrolyte conductivity, temperature and $\mathrm{pH}$ value were measured simultaneously.

\subsection{Mixed gas measurements}

The gas permeability of the hollow fiber membranes was measured with mixture of carbon dioxide/nitrogen and water vapor in the set-up described elsewhere [23] [24]. The modules containing 1-3 fibers with length of around $20 \mathrm{~cm}$ were tested in the inside-out mode with a mixture of $10 \% \mathrm{CO}_{2}$ and $90 \% \mathrm{~N}_{2}$ at $30^{\circ} \mathrm{C}$ with feed pressure 4 bar, first with dry gases (water vapor activity $\mathrm{a}_{\mathrm{W}}=0 \%$ ), and subsequently with addition of water vapor $\left(\mathrm{a}_{\mathrm{w}}=98 \%\right)$. The average permeance $(\mathrm{P})$ for three membranes was calculated and expressed in the gas permeation unit (GPU), $10^{-6} \mathrm{~cm}^{3}(\mathrm{STP}) /\left(\mathrm{cm}^{2} \cdot \mathrm{s} \cdot \mathrm{cm}_{\mathrm{Hg}}\right)$. The selectivity $\mathrm{CO}_{2} / \mathrm{N}_{2}\left(\alpha_{\mathrm{CO} 2 / \mathrm{N} 2}\right)$ was also determined. For the hollow fibers having the selective layer inside, sealing of the fiber cross-section at the inlets of the module is required otherwise the gases permeate through the porous wall of the fiber without selective separation. To avoid this, after potting and cutting the modules, pieces of $1 \mathrm{~cm}$ long silica capillaries were inserted into the fibers to the half of the capillary length and the cross-sections of the fibers were covered with glue fixing the capillary in place. After solidifying of the glue, the part of the capillary protruding of the fiber was cut off.

\subsection{Pure water flux measurements}

The modules for the pure water flux measurement contained one fiber with an effective length of about $16 \mathrm{~cm}$. The flux was determined using a dead-end ultrafiltration cell connected to a gas cylinder of compressed nitrogen to apply the feed pressure. The pure water

flux, $\mathrm{J}$ in $\mathrm{l} /\left(\mathrm{m}^{2} \cdot \mathrm{h}\right)$, was measured at different pressures up to 6 bar after the glycerol was removed from the membrane and the steady state conditions were reached. The membrane permeance $(\mathrm{P})$ was obtained from the slope of the flux $(\mathrm{J})$ vs. transmembrane pressure $(\Delta \mathrm{p})$.

\subsection{Protein filtration}

The experimental set-up for protein filtration is presented in Figure 3. Three modules with hollow fiber membrane were tested at each $\mathrm{pH}$. The hollow fiber was conditioned by flushing 
with pure water for $24 \mathrm{~h}$, and subsequently with the appropriate buffer for $2 \mathrm{~h}$. The feed (volume of $500 \mathrm{~mL}$ ), composed of a binary mixture of BSA and $\mathrm{Hb}$ in the buffer, was

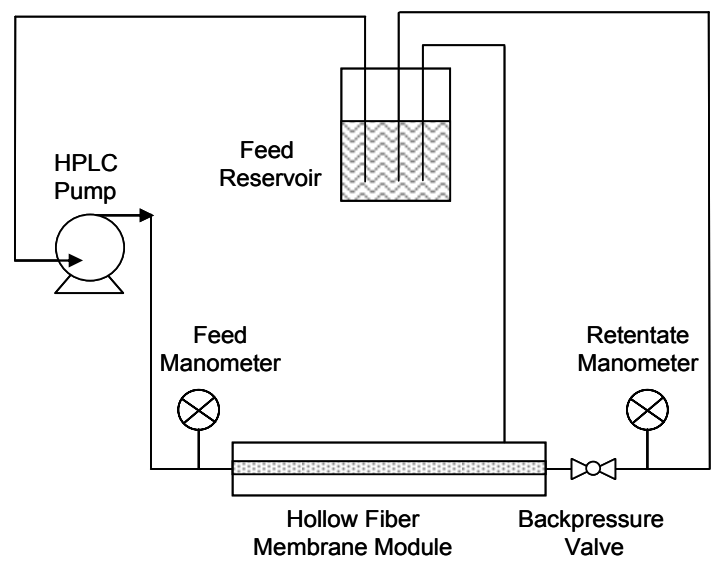

Figure 3 Scheme of the filtration set-up

pumped (Waters 590 Programmable HPLC Pump) into the lumen of the fiber and the permeate solution excited from the shell (inside-out system, cross-flow filtration mode). All the experiments were carried out in the laminar flow regime. Samples of feed, permeate and retentate were collected at various intervals for measuring the concentration. Both retentate and permeate were recycled back to the feed reservoir to keep the concentration of the feed solution constant during the entire experiment. Samples were taken every 30 min for $4 \mathrm{~h}$ (max. $3 \mathrm{~mL}$ per sample). The flow-rate of the feed was set at $14.0 \mathrm{ml} / \mathrm{min}$ and the pressure was regulated manually with a ball valve at the retentate line to keep the feed pressure at $6.0 \pm 0.2$ bar. The transmembrane pressure was monitored by means of pressure manometers placed at the feed and retentate lines. The protein concentration in feed, retentate and permeate was verified by an UV-Visible Spectrophotometer Cary 300 Scan (Varian). Hemoglobin solution displays 2 absorbance maxima at $280 \mathrm{~nm}$ and $406 \mathrm{~nm}$, whereas the BSA solution exhibits only one absorbance maximum at $280 \mathrm{~nm}$. Hence, the Hb concentration in the protein mixture was calculated from the absorbance at $406 \mathrm{~nm}$ and the BSA concentration was assessed from the absorbance at $280 \mathrm{~nm}$ after subtracting the Hb contribution at this wavelength. The permeation of each protein was expressed as sieving coefficient (SC):

$$
\mathrm{SC}=\frac{2 \mathrm{c}_{\mathrm{P}}}{\mathrm{c}_{\mathrm{R}}+\mathrm{c}_{\mathrm{F}}} \times 100 \%
$$

where $\mathrm{c}$ is the protein concentration $(\mathrm{g} / \mathrm{L})$ and the subscripts $\mathrm{P}, \mathrm{R}$ and $\mathrm{F}$ denote permeate, retentate and feed, respectively.

The separation efficiency of a membrane is expressed by the separation factor $\alpha_{\mathrm{BSA} / \mathrm{Hb}}$ :

$$
\alpha_{\mathrm{BSA} / \mathrm{Hb}}=\frac{\mathrm{SC}_{\mathrm{BSA}}}{\mathrm{SC}_{\mathrm{Hb}}}
$$

where $\mathrm{SC}_{\mathrm{BSA}}$ is the sieving coefficient of $\mathrm{BSA}$ and $\mathrm{SC}_{\mathrm{Hb}}$ is the sieving coefficient of $\mathrm{Hb}$. 

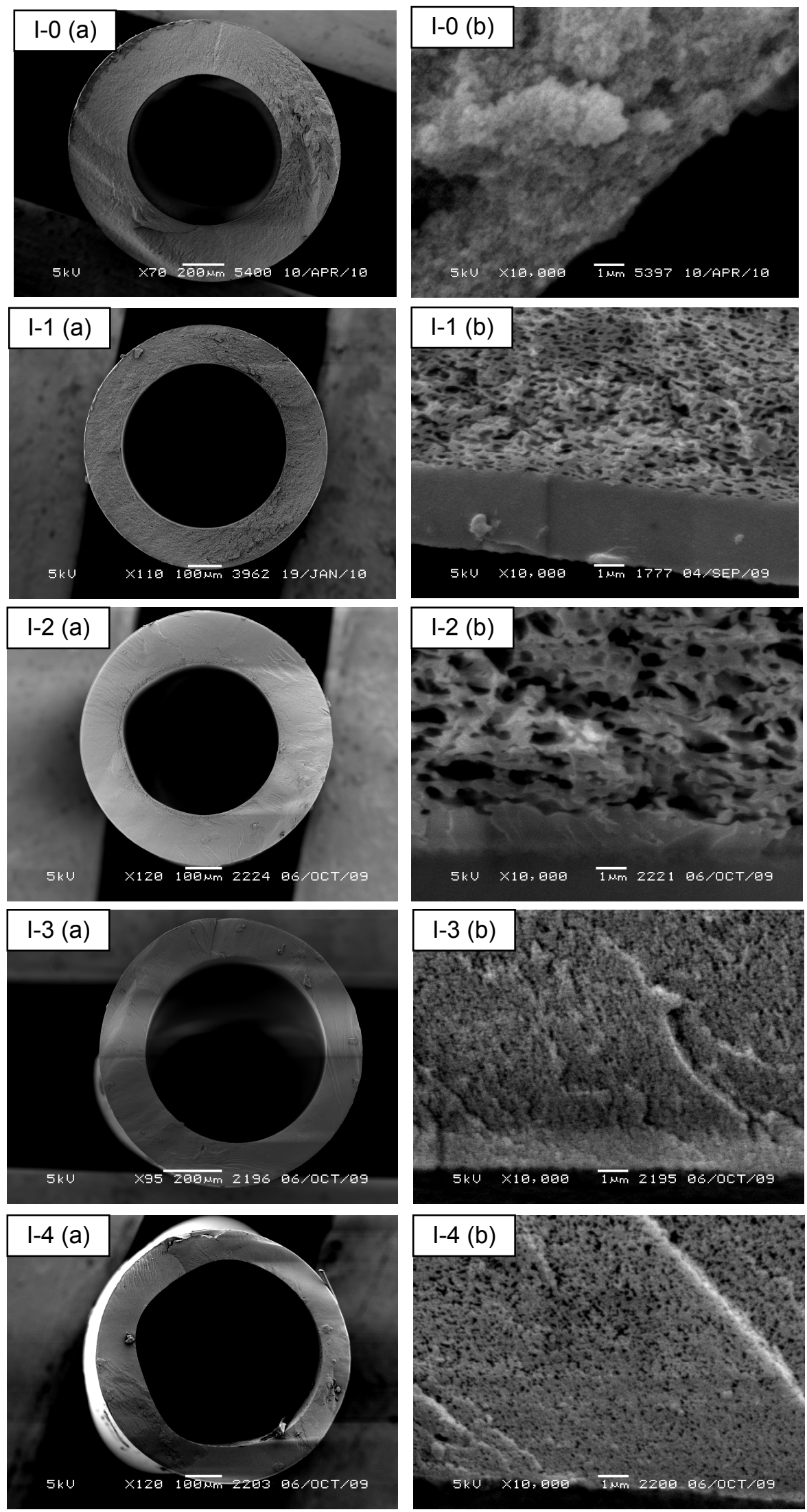

Figure 4 SEM images of the hollow fibers of category I (polymer dope: 22\% P84, 12\% glycerol, 66\% NMP; no shell liquid); composition of bore liquid: (I-0) 100\% ethanol; (I-1) 20\% PEI, 70\% NMP, $10 \% \mathrm{H}_{2} \mathrm{O}$; (I-2) 10\% PEI, 80\% NMP, 10\% $\mathrm{H}_{2} \mathrm{O}$; (I-3) 10\% PEI, 10\% NMP, $80 \%$ $\mathrm{H}_{2} \mathrm{O}$; (I-4) 10\% PEI, 45\% Glyc, 45\% EtOH 


\section{Results and discussion}

\subsection{Effect of PEI in the bore liquid}

\section{Membrane morphology}

Figure 4 shows the SEM images of the reference pure P84 fiber (I-0) and the P84/PEI (I-1) fiber spun with 20\% PEI in the bore liquid (for the exact compositions of spinning solutions see Table 2). The bore side of the pure P84 fiber has a porous structure, while for the fiber I-1, there is no gradient in porosity, but a dense layer of $\sim 2.6 \mu \mathrm{m}$ is obtained. When this fiber is placed in NMP, the outer porous layer is dissolved, while the inner layer stays intact and remains as a green, flexible gel-like capillary.

\section{Membrane chemistry}

The inner dense layer of the P84/PEI (I-1) hollow fiber was further investigated by ATR-FTIR analysis. Figure 5 compares its spectra with the P84 (I-0) reference membrane fabricated without PEI. For the pure P84 membrane, characteristic absorption bands for the imide groups are observed: at $1779 \mathrm{~cm}^{-1}$ (symmetric $\mathrm{C}=\mathrm{O}$ stretching), $1721 \mathrm{~cm}^{-1}$ (asymmetric $\mathrm{C}=\mathrm{O}$ stretching) and $1357 \mathrm{~cm}^{-1}$ (C-N stretching). For the dense layer of the P84/PEI fiber, peaks at the wavelengths characteristic for the imide groups are also detected, but of lower

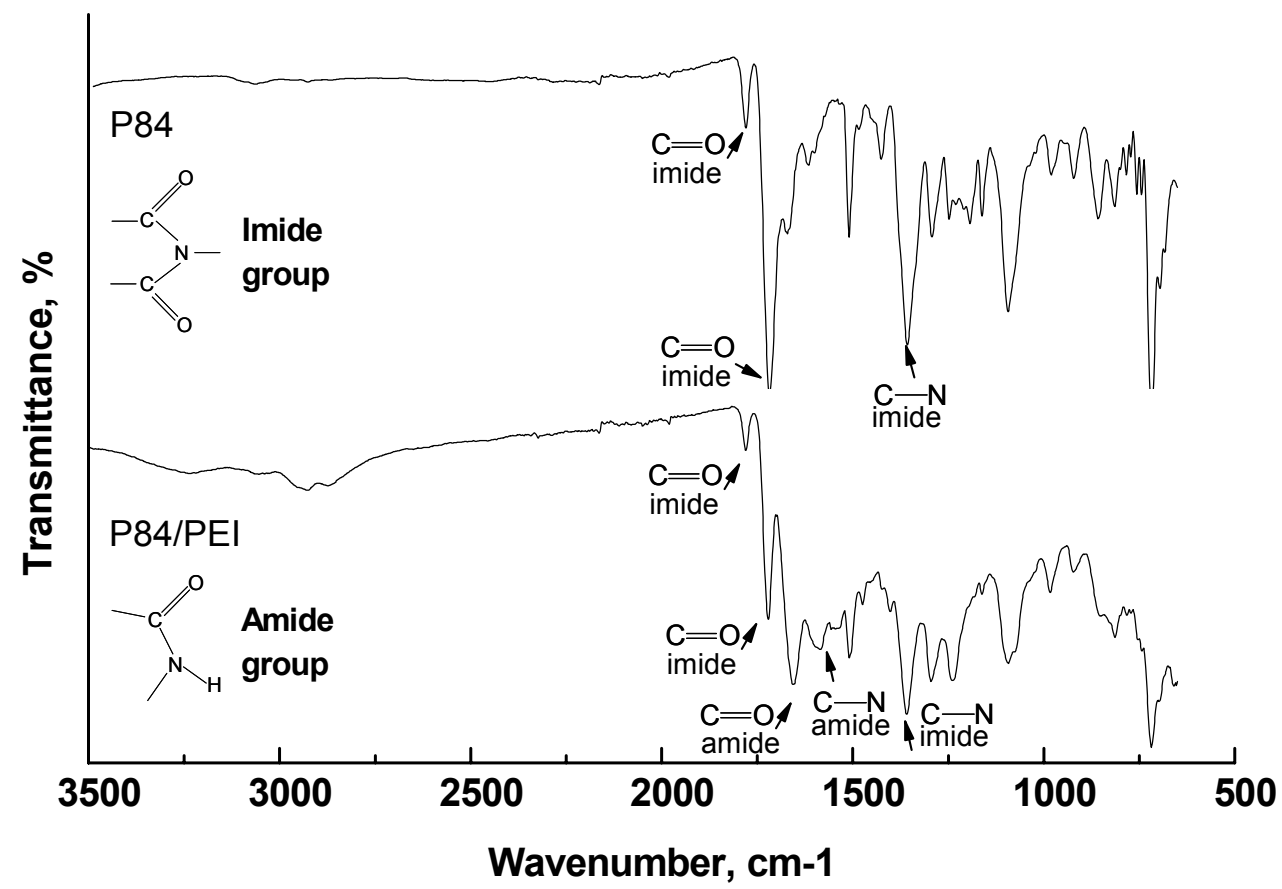

Figure 5 FTIR spectra of the P84 (I-0), fiber and the cross-linked layer of the P84/PEI (I-1) hollow fiber; (I-0): bore liquid: $100 \%$ ethanol, (I-1): bore liquid: $20 \%$ PEI, $70 \% \mathrm{NMP}, 10 \% \mathrm{H}_{2} \mathrm{O}$; both fibers have the same composition of dope solution (22\% P $84,12 \%$ glycerol, $66 \%$ NMP); shell liquid was not used

intensity. Furthermore, the typical peaks of amide groups, being a result of crosslinking between imide groups of P84 and amine groups of PEI are visible (Figure 5): at $1656 \mathrm{~cm}^{-1}$ 
( $\mathrm{C}=\mathrm{O}$ stretching) and $1547 \mathrm{~cm}^{-1}$ (C-N stretching). The presence of imide groups suggests that degree of crosslinking is below $100 \%$. The multiply broad peaks between $2600 \mathrm{~cm}^{-1}$ and 3200 $\mathrm{cm}^{-1}$ (N-H stretching) indicate the existence of tertiary amine groups, while the weak bands above $3150 \mathrm{~cm}^{-1}$ of a very low intensity are a sign of residual free secondary and primary amines. This ATR-FTIR data of the inner layer of the P84/PEI (I-1) fiber together with the fact that this layer does not dissolve in NMP suggests that crosslinking of P84 with PEI occurs in this dense layer of the fiber.

\section{Zeta-potential}

Figure 6 shows the zeta-potential of the I-1 hollow fiber membrane with $20 \%$ of PEI in the bore liquid in comparison to the P84 membrane produced without PEI (I-0). The P84 membrane has the isoelectric point (IP, the $\mathrm{pH}$ where the zeta-potential is zero) at $\mathrm{pH} 3.75$ and it is negatively charged above this $\mathrm{pH}$ with the maximum negative charge of $-21.5 \mathrm{mV}$ at $\mathrm{pH}$ 6.5. The P84/PEI crosslinked membrane has IP at $\mathrm{pH}$ 9.3. These results are consistent with work done by Trimpert et al. [25] who modified the poly(ether imide) with two types of poly(ethylene imine): a linear low-molecular weight PEI $\mathrm{Mn}=600$ resulting in the IP of 8.3, and a branched high-molecular weight PEI Mn=60 000 resulting in the IP of 10.1. The positive charge at the membrane surface may be attributed to the free amine groups (detected also with the ATR-FTIR) remaining after the crosslinking reaction between P84 and PEI. Most of the work done on crosslinking polyimide membranes with amines aims at increasing the chemical resistance of membranes e.g. for the organic solvent filtration. Only recently, the efforts were done to show the possibility of influencing the membrane charge with amine

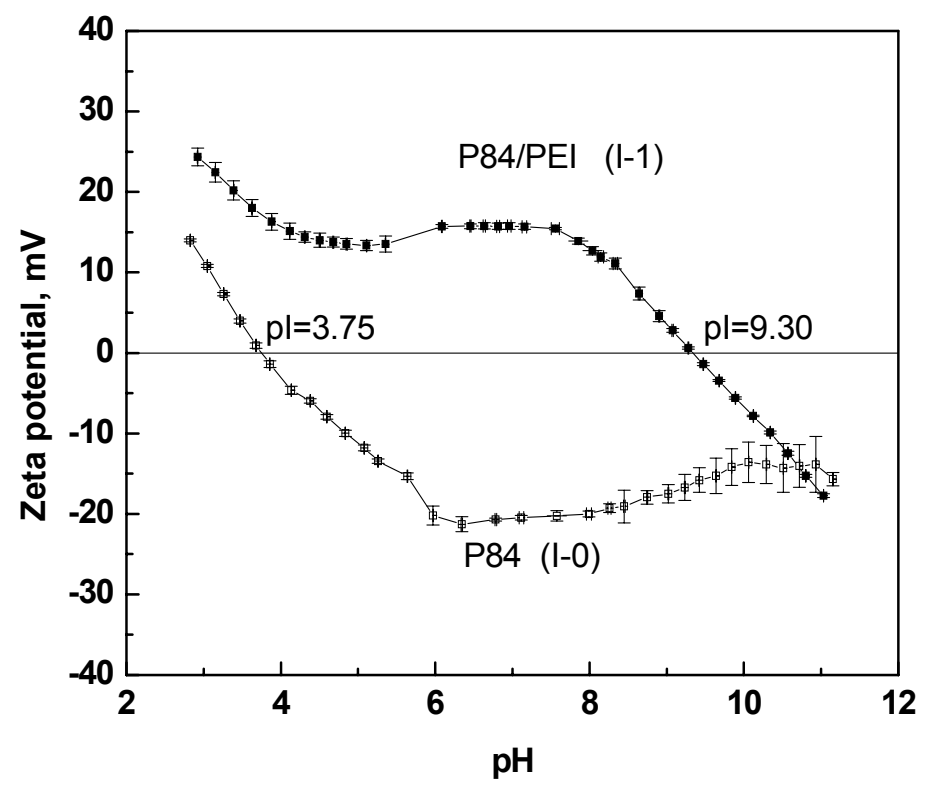

Figure 6 Zeta potential of the P84 (I-0) and the P84/PEI (I-1) hollow fiber membranes; (I-0): bore liquid: $100 \%$ ethanol, (I-1): bore liquid: $20 \%$ PEI, $70 \%$ NMP, $10 \% \mathrm{H}_{2} \mathrm{O}$; both fibers have the same composition of dope solution (22\% P84, 12\% glycerol, $66 \%$ NMP); shell liquid was not used 
crosslinking. Trimpert et al. [25] suggested the poly(ether imide) membranes modified with PEI as a promising material for in vitro cell culture for epidermal transplants and $\mathrm{Ba}$ et al. [21] reported the improved salt rejection for the positively charged P84 membrane crosslinked with PEI. The benefit of the method suggested here is to eliminate subsequent modification steps. Our chemistry-in-a-spinneret approach requires the tuning of a liquid flow in an already existing spinning process.

Gas vs liquid transport

The reference P84 (I-0) and P84/PEI (I-1) hollow fibers were tested using mixture of $\mathrm{CO}_{2}$ and $\mathrm{N}_{2}$ to determine the gas transport through the membranes and their selectivity. The tests with dry gases $\left(\mathrm{a}_{\mathrm{w}}=0\right)$ did not show a $\mathrm{CO}_{2} / \mathrm{N}_{2}$ selectivity for any of the membranes. However, introduction of water vapor into the system $\left(\mathrm{a}_{\mathrm{w}}=98 \%\right)$ revealed a $\mathrm{CO}_{2} / \mathrm{N}_{2}$ selectivity (the flux of $\mathrm{CO}_{2}$ increased compare to the dry state, the $\mathrm{N}_{2}$ flux did not change) for the P84/PEI membrane with dense inner layer. The $\alpha_{\mathrm{CO} / \mathrm{N} 2}$ up to 11.6 was obtained with the I1 hollow fiber membrane. Perhaps, in the presence of water vapor facilitated $\mathrm{CO}_{2}$ transport takes place in the crosslinked membranes due to the presence of PEI. As it is known [26-28], in presence of water vapour $\mathrm{CO}_{2}$ has high solubility in tertiary amines (here, the functional groups of PEI). The low gas permeance of the membrane (less than 2 GPU) may be attributed to the decrease in gas diffusivity due to the crosslinking (reduction in free volume, chains mobility and interstitial space among chains) $[15,17,29]$. Ideal selectivity $\mathrm{CO}_{2} / \mathrm{N}_{2}$ of around 40 and $\mathrm{CO}_{2}$ permeance of $4.9 \mathrm{GPU}$ (for skin layer average thickness of $0.45 \mu \mathrm{m}$ ) have been reported in the literature for P84 membrane at the same experimental conditions [30]. This verifies that in this work we prepared modified P84 membranes.

\subsection{Interplay of crosslinking and phase inversion}

Ten different batches with various compositions of dope solution, bore liquid and shell liquid were used to evaluate the spinning process. Figures 4,7,8 present SEM images of the fibers grouped in three categories, I, II, and III, respectively. Only one fiber, II-3, spun without addition of water in the bore liquid has finger-like macrovoids around the bore (for the proposed explanation see next sections). All the other fibers have no macrovoids and have centrally placed bore. Table 2 summarizes the results of the interplay between phase inversion and crosslinking for these fibers. The thickness of the dense inner layer (when visible) was estimated with help of the SEM software. Three different membrane structures are distinguished: Membranes that are completely dissolved in NMP (designated as D, dissolved), membranes that are intact in NMP (designated as ND, not dissolved), and membranes where the inner layer is not dissolved in NMP (designated as LND, layer not dissolved).

\section{Effect of PEI concentration in the bore liquid}

Fibers II-1 and II-2 were fabricated with the same ratio of NMP/water $(\sim 7: 1)$ in the bore liquid, but different PEI concentration. The fiber II-1 spun with 20\% PEI has a dense layer of $4.1 \mu \mathrm{m}$, while fiber II-2 spun with $10 \%$ PEI has a dense layer of $2.3 \mu \mathrm{m}$. When increasing the concentration of PEI in the bore liquid, the thickness of the dense layer increases, too. For both fibers, only the dense layer is crosslinked and it is not dissolved in NMP. 

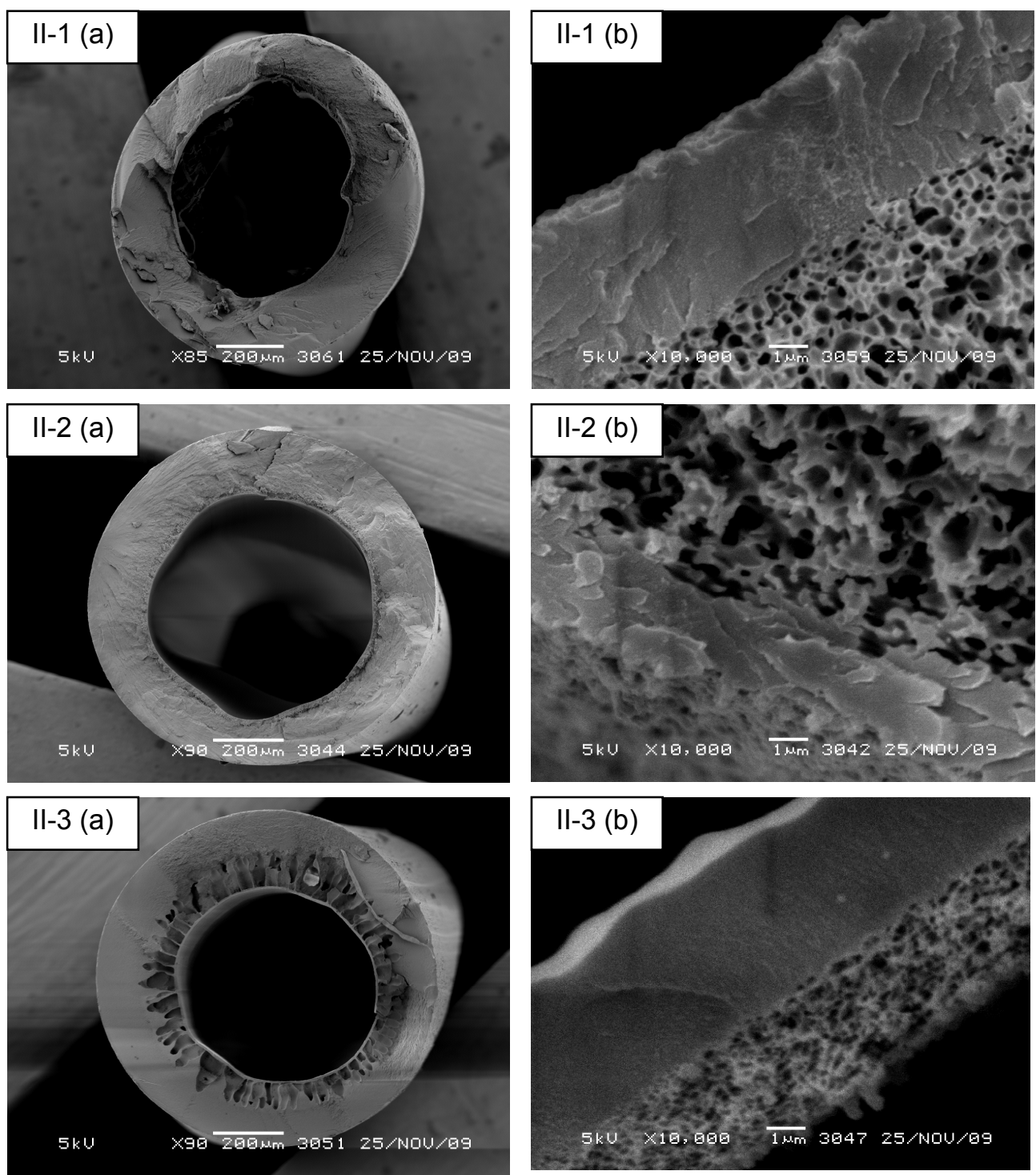

Figure 7 SEM images of hollow fibers of category II (polymer dope: 22\% P84, 12\% glycerol, 66\% NMP; shell liquid; $75 \% \mathrm{NMP}, 25 \% \mathrm{H}_{2} 0$ ); composition of bore liquid: (II-1) $20 \%$ PEI, $70 \%$ NMP, $10 \% \mathrm{H}_{2} \mathrm{O}$; (II-2) 10\% PEI, 79\% NMP, $11 \% \mathrm{H}_{2} \mathrm{O}$; (II-3) 10\% PEI, 90\% NMP

\section{Effect of solvent / nonsolvent ratio in the bore liquid}

The important aspect to study here is how the ratio solvent/nonsolvent in the bore liquid influences the final structure of the membrane. Fibers I-2 and I-3 were fabricated with the same concentration of PEI in the bore liquid, but different ratios of NMP/water. Fiber I-2 $(\mathrm{NMP} /$ water ratio $8: 1)$ has a dense inner layer of $1.4 \mu \mathrm{m}$, while fiber I-3 produced with $\mathrm{NMP} /$ water ratio 1:8 in bore liquid is fully porous. This suggests the existence of interplay between the phase inversion and crosslinking. Higher amount of NMP in the bore liquid delays phase inversion giving time for crosslinking with PEI. This results in the formation of dense crosslinked skin which hinders the flow of PEI further through the wall of the fiber. As 
a result, we obtain a hollow fiber having a crosslinked inner layer not soluble in NMP, whereas the rest of the membrane is basically P84 soluble in NMP.

When the ratio of NMP/water is low in the bore liquid (fiber I-3), the phase inversion happens fast and the membrane porous structure is formed before the crosslinking can occur. In this case, PEI transport across the wall takes place and the entire fiber is crosslinked (the entire fiber is not dissolved in NMP and there is no dense inner layer, see Table 2). When bore liquid without NMP is used (fiber I-4) but with glycerol and ethanol instead, no distinctive layer is noticed: the fiber is porous and entirely crosslinked. Glycerol and ethanol are soft nonsolvents for P84 and were used as water replacement for the practical reasons. $100 \%$ water in the bore liquid makes the spinning process very difficult (pulling and stretching of the fiber) as the phase inversion occurs very rapidly, while glycerol and ethanol slow down the coagulation process: they are soft coagulants.

One can also compare fibers II-2 and II-3. Both had the same concentration of PEI in the bore liquid (10\%), but fiber II-2 spun with addition of water in the bore liquid has a dense skin of $2.3 \mu \mathrm{m}$, while fiber II-3 spun with no water has a thicker skin of $3.6 \mu \mathrm{m}$. After placing these fibers in NMP, only the outer layer is dissolved.
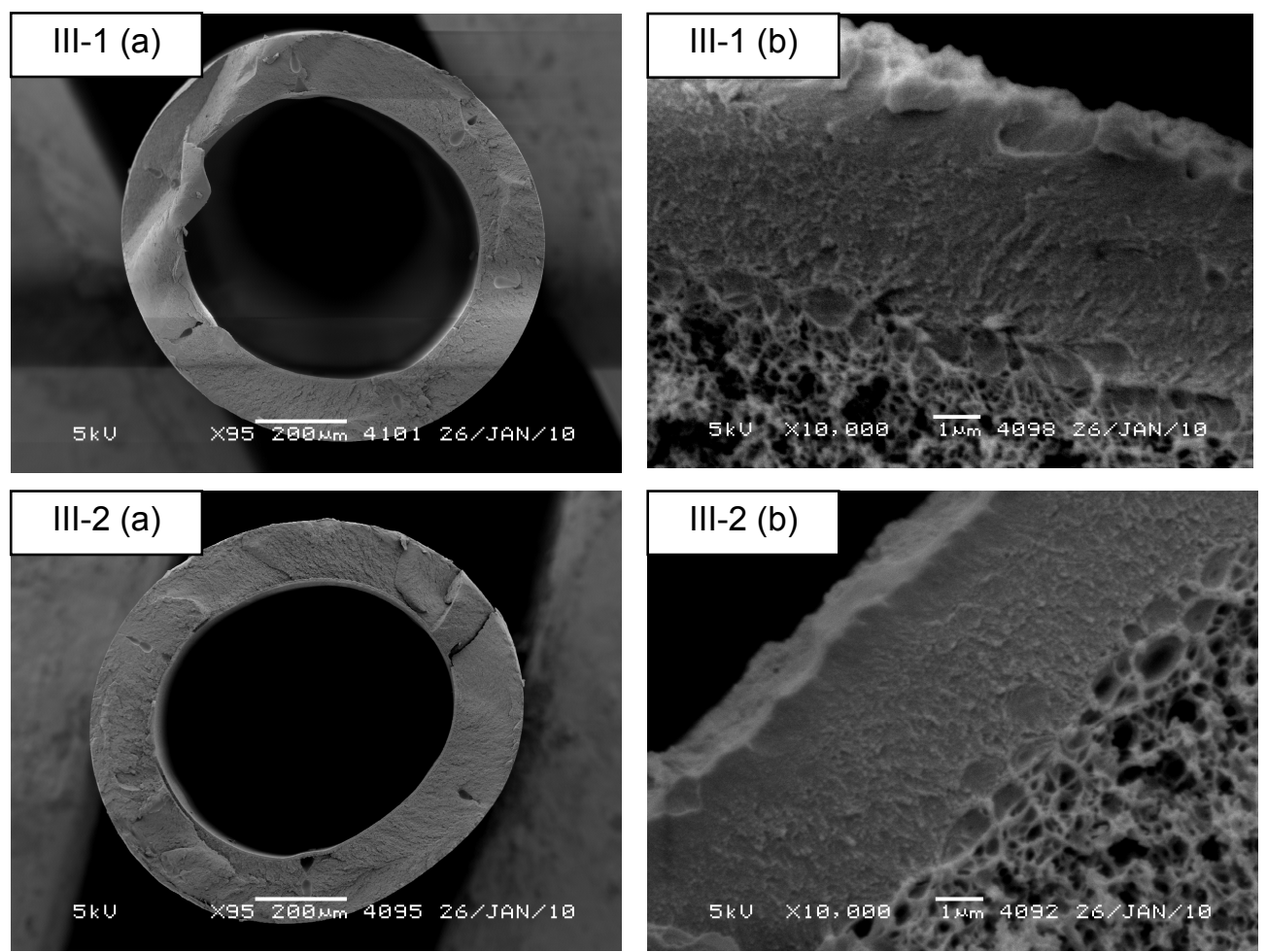

Figure 8 SEM images of hollow fibers of category III (polymer dope: 30\% P84, 70\% NMP; shell liquid: $75 \% \mathrm{NMP}, 25 \% \mathrm{H}_{2} \mathrm{O}$ ); composition of bore liquid: (III-1) $20 \% \mathrm{PEI}, 70 \% \mathrm{NMP}, 10 \%$ $\mathrm{H}_{2} \mathrm{O}$; (III-2) 10\% PEI, 79\% NMP, $11 \% \mathrm{H}_{2} \mathrm{O}$

Fiber II-3 spun without water in the bore liquid has macrovoids. Generally, macrovoids appear in polymer/solvent/nonsolvent systems when instantaneous demixing 
occurs. They are however absent in systems where delayed demixing occurs [3]. Since there is no water in the bore liquid, crosslinking happens most likely instantaneously and completely before the phase separation is completed. The dense crosslinked inner layer hinders diffusion of solvent out of the membrane resulting in growth of macrovoids close to the bore side. Generally, macrovoids are not favorable as they may lower the mechanical strength of the fiber and compromise the selectivity. However, the macrovoids in II-3 fiber do not traverse the dense inner layer (the selective layer) and no loss of mechanical strength of this fiber in comparison to the other fibers is noticed.

\section{Effect of solvent / nonsolvent ratio in shell liquid}

The thickness of the dense layer can be also controlled by the shell liquid. Fibers I-1 and II-1 were spun with the same composition of the polymer dope and bore liquid, but for the fabrication of fiber II-1 shell liquid consisted of 75\% NMP was used (dense skin of $4.1 \mu \mathrm{m}$ was obtained), while the fiber I-1 was spun without a shell liquid but directly into the water coagulation bath (dense skin of only $2.6 \mu \mathrm{m}$ ). It seems that NMP in the shell liquid delays the phase inversion and allows a deeper penetration of the PEI into phase separating polymer solution. As a result, thicker dense skin is formed.

\section{Effect of nonsolvent in the dope solution}

The morphology and chemistry of the fiber are influenced not only by the concentration of the nonsolvent in the bore and shell liquid, but also by the amount of nonsolvent in the polymer dope. This effect can be seen when comparing two pairs of fibers: II-1 with III-1 and II-2 with III-2, which were fabricated with the same compositions of bore liquid and shell liquid, but for fibers II the glycerol was added in the polymer dope. The fibers III prepared without the glycerol in the dope have a thicker dense layer than fibers II: 1.4 times for the 20\% PEI and 2.0 times for the 10\% PEI in the bore liquid. In this case (as also shown earlier), lowering the amount of nonsolvent in the dope solution (here removing the glycerol) causes delayed demixing. As a result crosslinking occurs and a thicker dense skin is formed. It should be mentioned that for fibers of category III the polymer concentration was increased, which can also have an effect on the final membrane structure, particularly by the increase of the dense layer thickness.

The above systematic study demonstrates that two different types of fibers can be fabricated in one step spinning depending on the composition of the bore liquid. When using no or very small amount of nonsolvent together with PEI as crosslinking agent, a fiber with a dense crosslinked inner layer is obtained. When using higher amount of nonsolvent in the bore liquid - porous and fully crosslinked porous fiber is obtained. Moreover, the thickness of the dense inner layer can be easily controlled and tuned by changing the ratio solvent/nonsolvent in the bore liquid, shell liquid and polymer dope. The difference between the two types of membranes can be seen with a naked eye - the fully crosslinked hollow fibers are entirely green, while the fibers with a dense layer have two colors: green on the inside (dense layer) and yellow (as pure P84) on the outside. 


\section{Gas vs liquid transport}

Four representative batches of fibers (out of the ten batches fabricated) were further investigated concerning gas and liquid transport. The results are presented in Table 3. Membranes with dense skin have gas selectivity and no water transport, while the porous membranes are permeable to water and have no gas selectivity.

The higher selectivity of I-1 membrane (11.6) than that of membrane I-2 (2.8) can be attributed to the lower nitrogen permeance through the I-1 membrane. This membrane was produced with higher concentration of PEI in the bore liquid and therefore has thicker dense skin of probably higher degree of crosslinking. Both factors may cause decrease of the nitrogen permeance (decrease of the diffusivity). However, permeance of carbon dioxide is not affected by the higher PEI concentration. Perhaps the decrease of $\mathrm{CO}_{2}$ diffusivity due to the crosslinking is balanced by the increase of its solubility.

Table 3 Characteristics of the hollow fiber membranes

\begin{tabular}{|c|c|c|c|c|c|}
\hline Batch & $\begin{array}{c}\text { Bore liquid, } \\
\%\end{array}$ & $\begin{array}{l}\text { Inner layer, } \\
\qquad \mu \mathrm{m}\end{array}$ & $\begin{array}{l}\text { Pure water } \\
\text { permeance } \\
1 /\left(\mathrm{m}^{2} \cdot h \cdot \text { bar }\right)\end{array}$ & $\begin{array}{c}\text { Mixed gases with } \\
\text { water vapor permeance } \\
\text { GPU }\end{array}$ & $\begin{array}{c}\alpha_{\mathrm{CO} 2 / \mathrm{N} 2} \\
\text { Mixed gases } \\
a_{\mathrm{w}}=98 \%\end{array}$ \\
\hline $\mathrm{I}-0$ & $100 \mathrm{EtOH}$ & - & $43.3 \pm 3.1$ & - & - \\
\hline I-1 & $\begin{array}{l}20 \mathrm{PEI} \\
70 \mathrm{NMP} \\
10 \mathrm{H}_{2} \mathrm{O}\end{array}$ & $\begin{array}{l}\text { Dense } \\
2.6\end{array}$ & $0 *$ & $\begin{array}{l}\left(\mathrm{N}_{2}\right)=0.08 \pm 0.01 \\
\left(\mathrm{CO}_{2}\right)=0.93 \pm 0.03\end{array}$ & 11.6 \\
\hline $\mathrm{I}-2$ & $\begin{array}{l}10 \mathrm{PEI} \\
80 \mathrm{NMP} \\
10 \mathrm{H}_{2} \mathrm{O}\end{array}$ & $\begin{array}{c}\text { Dense } \\
1.4\end{array}$ & $0 *$ & $\begin{array}{l}\left(\mathrm{N}_{2}\right)=0.35 \pm 0.01 \\
\left(\mathrm{CO}_{2}\right)=0.98 \pm 0.05\end{array}$ & 2.8 \\
\hline $\mathrm{I}-4$ & $\begin{array}{l}10 \text { PEI } \\
45 \text { Glyc } \\
45 \text { EtOH }\end{array}$ & - & $44.4 \pm 1.2$ & - & - \\
\hline
\end{tabular}

Up to TMP $=6$ bar no water transport was noticed over $12 \mathrm{~h}$

The porous fully crosslinked membrane P84/PEI (I-4) and the reference membrane P84 (I-0) without PEI have similar pure water flux $\left(44.4 \pm 1.2 \mathrm{l} /\left(\mathrm{m}^{2} \cdot \mathrm{h} \cdot \mathrm{bar}\right)\right.$ and $43.3 \pm 3.1$ $1 /\left(\mathrm{m}^{2} \cdot h \cdot\right.$ bar), respectively, Fig. 9). The ability of the porous P84/PEI (I-4) membrane to separate solutes in liquid system was tested with a binary mixture of similar size proteins BSA and $\mathrm{Hb}$ (see Table 1, [22]) and compared with the reference P84 (I-0) membrane (Fig. 10). As the zeta-potential measurements demonstrated, the P84/PEI membrane carries positive charge in the range of the investigated $\mathrm{pH}$ (4.8 and 7.5), while the pure P84 is slightly negatively charged. The interactions of charged membrane should vary with $\mathrm{pH}$ due to the change of the proteins charge (see Table 4). The ionic strength of the buffers was low (concentration $15 \mathrm{mM}$ ) to avoid shielding of the electrostatic interactions between the proteins and the membrane. Figure 10 presents the results of the proteins filtration at two different $\mathrm{pH}$ for both membranes (lines connect the symbols to guide the eye). For both $\mathrm{pH}$, the separation of proteins is due to the permeation of BSA and almost complete retention of $\mathrm{Hb}$, and 


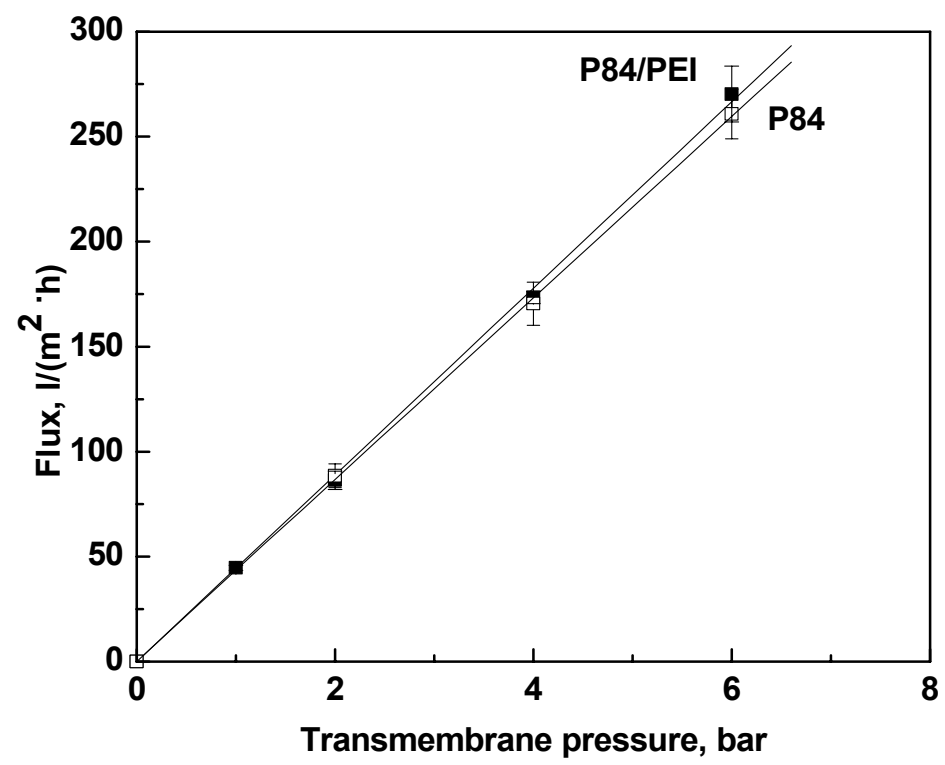

Figure 9 Pure water flux vs transmembrane pressure for P84 (I-0) and P84/PEI (I-4) hollow fiber membranes; (I-0): bore liquid: 100\% ethanol, (I-4): bore liquid: $10 \%$ PEI, $45 \%$ glycerol, $45 \%$ ethanol; both fibers have the same composition of dope solution $(22 \%$ P $84,12 \%$ glycerol, 66\% NMP); shell liquid was not used

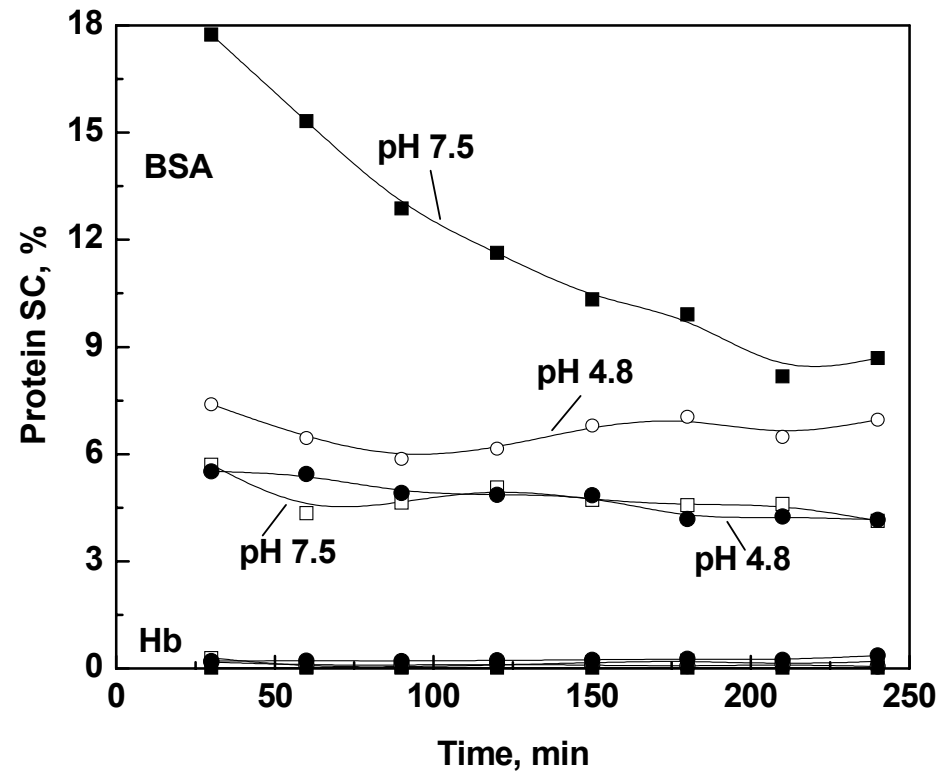

Figure 10 Sieving coefficient of BSA and $\mathrm{Hb}$ in time at various $\mathrm{pH}$ for P84/PEI (I-4) (full symbols) and P84 (I-0) (open symbols) hollow fiber membrane (lines connect the symbols to guide the eye); Reynolds number: for P84/PEI (I-4) fiber: 600 at the feed stream, 350 at the retentate stream; for P84 (I-0) fiber: 415 at the feed stream, 230 at the retentate stream

therefore only the BSA sieving coefficient is discussed further. For P84 membrane, $\mathrm{SC}_{\mathrm{BSA}}$ is

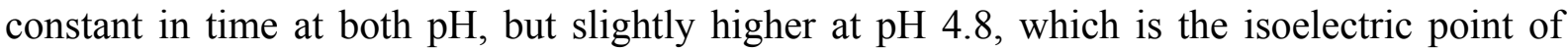
BSA and no electrostatic interactions membrane-protein are expected (see Table 4). At $\mathrm{pH}$ 7.5 , the membrane, as well as the BSA, carry negative charge and due to the repulsion, the $\mathrm{SC}_{\mathrm{BSA}}$ is lower. For the P84/PEI membrane, the situation is opposite: at $\mathrm{pH} 7.5$ the membrane 
carries positive charge, while the BSA is negatively charged and therefore attracted by the membrane resulting in higher sieving coefficient, in agreement with others [31]. At $\mathrm{pH} 4.8$, the $\mathrm{SC}_{\mathrm{BSA}}$ is rather constant in time (no electrostatic interactions between the positively charged membrane and neutral protein), while at $\mathrm{pH} 7.5, \mathrm{SC}_{\mathrm{BSA}}$ decreases, most probably due to the adsorption of the negatively charged BSA on the positively charged membrane.

Table 4 Charge of the membranes and proteins at investigated $\mathrm{pH}$

\begin{tabular}{ccccc}
\hline & \multicolumn{2}{c}{ Charge of membrane } & \multicolumn{2}{c}{ Charge of protein } \\
\cline { 2 - 5 } & P84 & P84/PEI & BSA & Hb \\
\hline 4.8 & - & + & 0 & + \\
7.5 & -- & + & -- & - \\
\hline
\end{tabular}

In conclusion, the results of the protein filtration experiments show that these proteins can be separated with the I-4 P84/PEI membrane. Moreover, there is an evidence of the positive charge carried by the membrane, which influences the protein separation.

It is finally worth to note that crosslinked P84 membranes have been reported in the literature for the use in liquid systems, mainly for the solvent resistant nanofiltration, as the crosslinking gives the chemical resistance against some organic solvents [18-21, 32]. This could be a potential application for the developed membranes, too.

\section{Conclusions and outlook}

This work presented a novel method to produce a composite hollow fiber membrane in a one-step immersion precipitation spinning, based on the crosslinking of the polyimide P84, the membrane forming polymer, with PEI dissolved in the bore liquid.

In fact, two different types of membranes were fabricated by the interplay of phase inversion and crosslinking. By increasing the concentration of solvent (here NMP) in the bore liquid, hollow fiber membrane with dense inner gas selective layer was produced. The thickness of the layer can be tuned by changing the ratio solvent/nonsolvent in the bore liquid, shell liquid and dope solution. By increasing the concentration of nonsolvent in the bore liquid, entirely crosslinked ultrafiltration membrane was produced with pure water flux of $40 \mathrm{l} /\left(\mathrm{m}^{2} \cdot \mathrm{bar} \cdot \mathrm{h}\right)$. The free tertiary amine groups of PEI, which are not used for crosslinking, induce a positive membrane charge which can be used for separation of similar size proteins $\mathrm{BSA}$ and $\mathrm{Hb}$. In case of the hollow fiber membranes with dense, crosslinked inner layer, a $\mathrm{CO}_{2} / \mathrm{N}_{2}$ selectivity up to 11.6 is observed in presence of water vapor.

Further research to improve the performance of the hollow fiber membranes prepared with this novel technique should focus on formation of very thin dense skin for the gas separation as well as tailoring the fiber crosslinking to achieve stability in various solvents. 
The new method of fabricating composite hollow fiber membrane via the interplay of phase inversion and crosslinking is simpler and less time consuming in comparison to other multi-step techniques. Moreover, it is less expensive and more environmental friendly as it does not require large amounts of solvents, normally involved in the post-treatment crosslinking. This new method may open the perspectives towards fabrication of novel gas separation membranes, nano- and ultrafiltration, as well as, solvent resistant membranes. 


\section{References}

[1] S. Loeb, S. Sourirajan, Sea Water Demineralization by Means of an Osmotic Membrane, in: Saline Water Conversion-II, American Chemical Society, Washington, D. C., 1963, pp. 117-132.

[2] R.W. Baker, Membrane Technology and Applications, Wiley, Chichester, 2004.

[3] M. Mulder, Basic Principles of Membrane Technology, Second edition ed., Kluwer Academic Publisher, Dordrecht, The Netherlands 1997, 1996.

[4] R.H. Forester, P.S. Francis, Method of Producing an Ultrathin Polymer Film Laminate, in: 3,551,244, US Patent, 1970.

[5] W.J. Ward Iii, W.R. Browall, R.M. Salemme, Ultrathin silicone/polycarbonate membranes for gas separation processes, J.MEMBR.SCI., 1 (1976) 99-108.

[6] J.E. Cadotte, R.J. Petersen, R.E. Larson, E.E. Erickson, A new thin-film composite seawater reverse osmosis membrane, Desalination, 32 (1980) 25-31.

[7] R.L. Riley, R.L. Fox, C.R. Lyons, C.E. Milstead, M.W. Seroy, M. Tagami, Spiralwound poly (ether/amide) thin-film composite membrane systems, Desalination, 19 (1976) 113-126.

[8] Y. Kamiyama, N. Yoshioka, K. Matsui, K. Nakagome, New thin-film composite reverse osmosis membranes and spiral wound modules, Desalination, 51 (1984) 79-92.

[9] H. Yasuda, Reverse osmosis membranes formed by plasma polimerization of organic compounds, Appl Polym Symp, (1973) 241-253.

[10] M. Kawakami, Y. Yamashita, M. Iwamoto, S. Kagawa, Modification of gas permeabilities of polymer membranes by plasma coating, Journal of Membrane Science, 19 (1984) 249-258.

[11] K.A. Kraus, A.J. Shor, J.S. Johnson Jr, Hyperfiltration studies x. Hyperfiltration with dynamically-formed membranes, Desalination, 2 (1967) 243-266.

[12] J.S. Johnson, K.A. Kraus, S.M. Fleming, H.D. Cochran, J.J. Perona, Hyperfiltration studies XIV Porous tubes precoated with filteraids as supports for dynamically formed membranes, Desalination, 5 (1968) 359-369.

[13] R.A. Hayes, Amine-modified polyimide membranes, in: EP0401005, US, 1990.

[14] Y. Liu, R. Wang, T.-S. Chung, Chemical cross-linking modification of polyimide membranes for gas separation, Journal of Membrane Science, 189 (2001) 231-239.

[15] P.S. Tin, T.S. Chung, Y. Liu, R. Wang, S.L. Liu, K.P. Pramoda, Effects of cross-linking modification on gas separation performance of Matrimid membranes, Journal of Membrane Science, 225 (2003) 77-90.

[16] T.-S. Chung, M.L. Chng, K.P. Pramoda, Y. Xiao, PAMAM Dendrimer-Induced CrossLinking Modification of Polyimide Membranes, Langmuir, 20 (2004) 2966-2969.

[17] L. Shao, L. Liu, S.-X. Cheng, Y.-D. Huang, J. Ma, Comparison of diamino cross-linking in different polyimide solutions and membranes by precipitation observation and gas transport, Journal of Membrane Science, 312 (2008) 174-185. 
[18] W. Albrecht, B. Seifert, T. Weigel, M. Schossig, A. Holländer, T. Groth, R. Hilke, Amination of Poly(ether imide) Membranes Using Di- and Multivalent Amines, Macromolecular Chemistry and Physics, 204 (2003) 510-521.

[19] Y.H. See Toh, F.W. Lim, A.G. Livingston, Polymeric membranes for nanofiltration in polar aprotic solvents, Journal of Membrane Science, 301 (2007) 3-10.

[20] K. Vanherck, P. Vandezande, S.O. Aldea, I.F.J. Vankelecom, Cross-linked polyimide membranes for solvent resistant nanofiltration in aprotic solvents, Journal of Membrane Science, 320 (2008) 468-476.

[21] C. Ba, J. Langer, J. Economy, Chemical modification of P84 copolyimide membranes by polyethylenimine for nanofiltration, Journal of Membrane Science, 327 (2009) 4958.

[22] R. Shukla, M. Balakrishnan, G.P. Agarwal, Bovine serum albumin-hemoglobin fractionation: Significance of ultrafiltration system and feed solution characteristics, Bioseparation, 9 (2000) 7-19.

[23] H. Sijbesma, K. Nymeijer, R. van Marwijk, R. Heijboer, J. Potreck, M. Wessling, Flue gas dehydration using polymer membranes, Journal of Membrane Science, 313 (2008) 263-276.

[24] S.J. Metz, W.J.C. van de Ven, J. Potreck, M.H.V. Mulder, M. Wessling, Transport of water vapor and inert gas mixtures through highly selective and highly permeable polymer membranes, Journal of Membrane Science, 251 (2005) 29-41.

[25] C. Trimpert, G. Boese, W. Albrecht, K. Richau, T. Weigel, A. Lendlein, T. Groth, Poly(ether imide) Membranes Modified with Poly(ethylene imine) as Potential Carriers for Epidermal Substitutes, Macromolecular Bioscience, 6 (2006) 274-284.

[26] J.G. Tajar, I.F. Miller, Permeation of carbon dioxide, oxygen, and nitrogen through weakly basic polymer membranes, AIChE Journal, 18 (1972) 78-83.

[27] H. Matsuyama, A. Terada, T. Nakagawara, Y. Kitamura, M. Teramoto, Facilitated transport of $\mathrm{CO} 2$ through polyethylenimine/poly(vinyl alcohol) blend membrane, Journal of Membrane Science, 163 (1999) 221-227.

[28] S. Shishatskiy, J.R. Pauls, S.P. Nunes, K.V. Peinemann, Quaternary ammonium membrane materials for CO2 separation, Journal of Membrane Science, 359 (2010) 4453.

[29] C.E. Powell, G.G. Qiao, Polymeric CO2/N2 gas separation membranes for the capture of carbon dioxide from power plant flue gases, Journal of Membrane Science, 279 (2006) 1-49.

[30] J.N. Barsema, G.C. Kapantaidakis, N.F.A. van der Vegt, G.H. Koops, M. Wessling, Preparation and characterization of highly selective dense and hollow fiber asymmetric membranes based on BTDA-TDI/MDI co-polyimide, Journal of Membrane Science, 216 (2003) 195-205.

[31] D.B. Burns, A.L. Zydney, Contributions to electrostatic interactions on protein transport in membrane systems, AIChE Journal, 47 (2001) 1101-1114.

[32] K. Vanherck, A. Cano-Odena, G. Koeckelberghs, T. Dedroog, I. Vankelecom, A simplified diamine crosslinking method for PI nanofiltration membranes, Journal of Membrane Science, 353 135-143. 


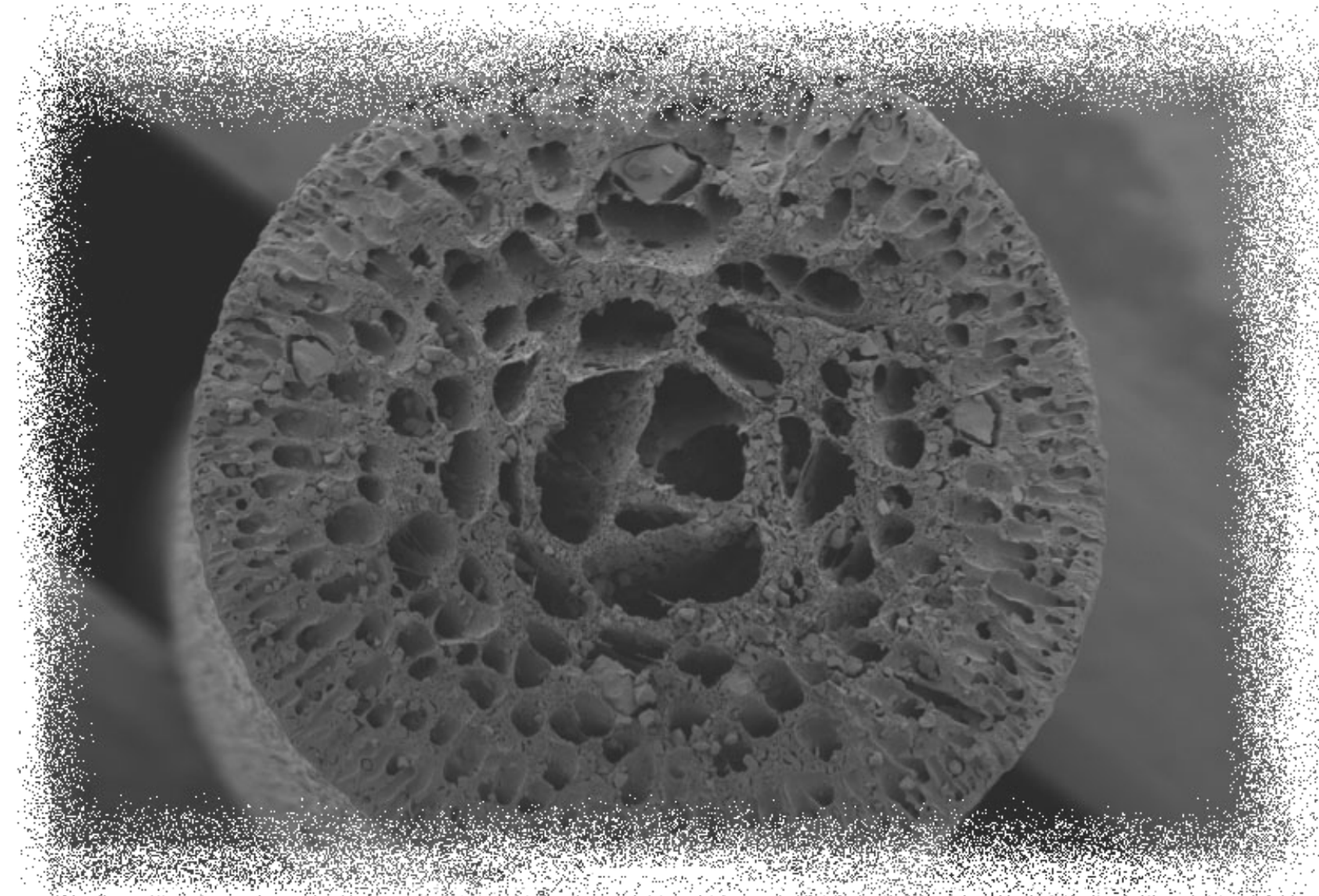

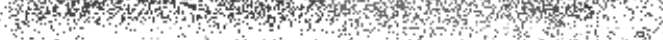

\section{Chapter 4}

Solvent-resistant mixed matrix membrane adsorbers 


\begin{abstract}
This work reports new mixed matrix hollow fiber membranes for adsorption of biomolecules from organic solvents. The membranes are composed of polyimide P84, the porous matrix forming polymer, and cation exchange particles incorporated in this matrix. These macroporous membranes, having a homogenous structure with a uniform distribution of particles, are crosslinked with ethylene diamine (EDA) and they are therefore resistant in organic solvents such as dimethyl sulphoxide (DMSO) and N-methyl pyrrolidone (NMP). The crosslinked mixed matrix membranes have very high water flux, but lower fluxes of the organic solvents, most likely due to the swelling.

In aqueous solutions, the membranes have high static adsorption capacity for bovine serum albumin (BSA) (125.3 mg BSA/ g particles) and lysosyme (Lys) (139.2 mg Lys/g particles) due to the electrostatic interactions between the positively charged proteins and negatively charged particles of the mixed matrix membrane. There is no loss of the adsorption capacity due to the membrane formation which suggests good accessibility of the adsorptive particles inside the mixed matrix membrane.
\end{abstract}

The static adsorption capacity of lysosyme in DMSO and cholesterol in NMP is lower than in the aqueous systems. Here, adsorption is due to the hydrophobic interactions and is also lowered by the membrane swelling. The advantage is, however, the better accessibility of the particles in the membrane in comparison to the suspension of particles, which undergo aggregation in organic solvents.

The ease of preparation of these membranes opens new perspectives in the field of biomolecules processed or isolated from non-aqueous media. 


\section{Introduction}

Proteins dissolved in neat organic solvents (as opposed to their natural aqueous environment) offer interesting biotechnological opportunities. They are an alternative approach to downstream processing, particularly for hydrophobic proteins [1,2] and a novel strategy for transdermal delivery of pharmaceutical proteins [3]. Enzymes can catalyze processes that are not possible in water but in organic solvents [4]. The area of industrial bioconversions, e.g. production of specialty chemicals and polymers is limited currently to aqueous media. However, most of the enzymes and biomolecules are not soluble in water, moreover water often promotes unwanted side reactions and degrades common organic reagents [4]. Furthermore, the thermodynamic equilibrium of many biological processes is not favorable in water. Thus, the catalysis in organic solvents as well as the mapping of protein surfaces with solvent crystal structures have been developing very fast over the last decades $[5,6]$.

Enzymes are often thermally labile in water which promotes the conformational mobility of protein molecules, as well as deleterious reactions as deamidation or hydrolysis of peptide bonds [7-9]. In organic solvents, however, the stability of enzymes seems to be improved as it was documented for ribonuclease [10] and lipase [11] with their half-lives of several hours in anhydrous solvents at $100^{\circ} \mathrm{C}$ in comparison to few seconds in water at this temperature. Moreover, in organic solvents enzymes are more stable against proteolysis, since most of the proteases (excreted by contaminating microorganisms) are insoluble in such media and thus cannot interact [12].

The employment of solids for the removal of specific (also solid) components from liquid mixtures based on their physical and chemical properties (known as solid phase extraction) has been widely used in the past [13-17]. The affinity of the adsorptive solid for specific molecules can be classified in terms of hydrophobic, hydrophilic or charged functionalities, in particular ion exchange effects, molecular (imprinted) recognition or other, specific interactions.

Recently, mixed matrix adsorber membranes entered the field of solid phase extraction, offering the advantages of the membrane technology: easy scale-up, high throughputs and low pressure drop [18-24]. This adsorption-based separation involves the preferential partitioning of the adsorbate molecules from the liquid phase onto the surface of substrate, here the ion exchange particles incorporated in the polymeric porous matrix, based on the electrostatic interactions between the charged biomolecules and particles. Mixed matrix adsorber membranes can be produced with any type/size of entrapped particles and many types of polymeric materials, all together shaped either in flat or fiber form. So far, however, the mixed matrix membranes were applied only in aqueous systems.

In this work, we demonstrate new solvent resistant mixed matrix membranes than can be applied for solid phase extraction of biomolecules from organic solvents. For this, a polyimide P84 is chosen as it can be easily crosslinked with amines and thus become resistant 
to some organic solvents. A solution of polyimide P84 with dispersed cation exchange particles is spun into microporous hollow fiber membranes in a dry-wet immersion precipitation spinning via a phase inversion process. As a post-treatment, the fibers (in fact, only the membrane forming polymer P84; the particles are composed of solvent resistant crosslinked polystyrene with sulphonic acid functionalities) are crosslinked with ethylenediamine (EDA). The reaction takes place between the amine groups of EDA and the carbonyl groups of the imide rings of polyimide P84 [25, 26]. The prepared hollow fiber membranes are tested with three biomolecules, bovine serum albumin (BSA), lysozyme (Lys) and cholesterol (Chol).

Bovine serum albumin is only used as a model protein in aqueous systems. The isoelectric point of BSA is 4.8 and to keep the positive charge in order to interact with negative particles, it is investigated at $\mathrm{pH}$ below its isoelectric point. Lysozyme (isoelectric point at $\mathrm{pH} 11.0$ ) is a hydrolase, an enzyme that damages bacterial cell walls. It dissolves well in DMSO (up to $50 \mathrm{mg} / \mathrm{ml}$ at $30^{\circ} \mathrm{C}$, [1]), a neat organic solvent with high stability, low toxicity and infinite miscibility with water. Lysozyme is extensively used in pharmaceutical and food industry, mainly for extraction of bacterial intracellular components, or as an antimicrobial or preservative agent. It possesses also antibiotic, anti-inflammatory, antihistaminic and antitumor effects [24]. Cholesterol is a biologically important steroid metabolite being a component of cell membranes and serum lipoproteins [27]. Investigation on cholesterol is done not only in terms of its fast and reliable detection in blood, but also in biotechnology for cell culturing [28], and as an intermediate for pharmaceutical and biotechnological synthesis [29]. As a hydrophobic and polar molecule, and thus not soluble in water, it has to be processed in organic solvents. These molecules, both playing important roles in the mammalian bodies and widely used in biotechnology, are used in this work to demonstrate the adsorption properties of the solvent resistant mixed matrix membranes which are characterized in terms of static adsorption capacity, adsorption and desorption kinetics, and adsorption isotherm. First, the behavior of BSA and Lys is tested in the aqueous systems, subsequently followed by investigation of Lys and Chol in organic solvents: dimethyl sulphoxide (DMSO) for Lys and N-methyl pyrrolidone (NMP) for Chol.

\section{Experimental}

\subsection{Materials}

\subsubsection{Hollow fiber fabrication}

Polyimide, type P84 was purchased from HP Polymer GmbH (325 mesh, STD) and used as membrane material without further modification. Glycerol of analytical grade and Nmethyl pyrrolidone (NMP), extra pure, were obtained from Across Organics. The strong cation exchange resins SCX Lewatit Monoplus112 WS with sulfonic acid group as the functional group (ion exchange capacity $1.75 \mathrm{eq} / \mathrm{L}$ ), and mean particle diameter $680 \mu \mathrm{m}$, were 
kindly supplied by Caldic Belgium. Methanol and n-hexane, both of analytical grade, were purchased from Merck and ethylenediamine (EDA) was obtained from Sigma-Aldrich.

\subsubsection{Hollow fiber characterization}

Dimethylsulfoxide (DMSO) and acetone, both of analytical grade, were purchased from Merck. Bovine serum albumin (BSA), fraction V (Fluka), lysozyme from chicken egg, (Sigma-Aldrich)), and cholesterol, 95\% (Sigma-Aldrich) were employed as adsorbates. For pH 4.5 acetate buffer was used, obtained by dissolving in water: acetic acid (glacial 100\%, anhydrous, from Merck) and sodium acetate (anhydrous from Across Organics). Phosphate buffer was used for $\mathrm{pH}$ 7.4, prepared by dissolving in water monobasic sodium phosphate, monohydrate and dibasic sodium phosphate, anhydrous, both obtained from Across Organics. Bradford reagent was prepared according to the procedure described elsewhere [30] using Coomassie Brilliant Blue G250, ethanol and orthophosphoric acid 85\%, all chemicals from Merck. Water for pure water flux experiments and for preparing the buffers was obtained from Millipore water purification unit.

\subsection{Membrane preparation}

\subsubsection{Adsorbent preparation}

The ion exchange particles were milled and sieved through a $20 \mu \mathrm{m}$ sieve. The particle size distribution was measured using a Microtrax X-100 from Leeds \& Northru, after ultrasonification treatment with Branson Sonifier 450 to break down the formed agglomerates. The average diameter of the particles used for the mixed matrix membrane preparation was estimated to be $7.9 \mu \mathrm{m}$. In fact $50 \%$ of particles are of this diameter.

\subsubsection{Membrane fabrication}

The polyimide P84 and ion exchange particles were dried in the vacuum oven at $30^{\circ} \mathrm{C}$ for $24 \mathrm{~h}$. The polymer dope solution was stirred at room temperature for $48 \mathrm{~h}$, then the ion exchange particles were added. The solution was stirred for another $12 \mathrm{~h}$ and left for degassing for $24 \mathrm{~h}$. Bore liquid was left for degassing for at least $12 \mathrm{~h}$. The compositions of dope solution and bore liquid are shown in Table 1. The particles loading was $60 \%$. All membranes were obtained by dry-wet immersion precipitation spinning. The dope solution along with bore liquid were simultaneously pumped through a double orifice spinneret and, after short residence time in the air, immersed into the water coagulation bath. The take-up velocity was controlled by a pulling wheel, which enabled also stretching of the fiber. All prepared membranes were washed out for $48 \mathrm{~h}$ in water to remove glycerol and solvent. As a reference, pure P84 hollow fiber membrane, without ion exchange particles, was spun in the same way as mixed matrix hollow fiber membranes (compositions of the spinning solutions are given in Table 1). 
Table 1 Composition of the spinning solutions

\begin{tabular}{cccc}
\hline \multirow{2}{*}{ Solution } & Component & $\begin{array}{c}\text { Mixed Matrix Membrane } \\
\%\end{array}$ & $\begin{array}{c}\text { Particle-free membrane } \\
\%\end{array}$ \\
\hline \multirow{3}{*}{ Dope } & P84 & 12.4 & 22 \\
& NMP & 77.6 & 66 \\
& Glycerol & 10.0 & 12 \\
\cline { 2 - 4 } & Lewatit particles & 60 (loading) & - \\
\hline \multirow{2}{*}{ Bore } & NMP & 90 & 90 \\
& water & 10 & 10 \\
\hline
\end{tabular}

\subsubsection{Fiber crosslinking procedure}

The spun hollow fiber membranes were taken from water washing bath and directly placed in methanol for $24 \mathrm{~h}$ to swell the polymer and make the chains more accessible to the crosslinking agent. Next, the fibers were immersed in the crosslinking solution: $10 \%(\mathrm{w} / \mathrm{w})$ EDA in methanol for $24 \mathrm{~h}$, and subsequently washed in methanol for another $48 \mathrm{~h}$ to remove the residues of the crosslinking agent. Finally, the fibers were soaked in n-hexane for $24 \mathrm{~h}$. The drying procedure was dependent on the fiber characterization method. Fibers for permeance measurements were impregnated with glycerol $(24 \mathrm{~h}$ in $20 \%(\mathrm{w} / \mathrm{w})$ glycerol in water) to improve the mechanical strength of the fibers, and afterwards dried in the air. Fibers for static adsorption and desorption were dried for $4 \mathrm{~h}$ in the air and for $12 \mathrm{~h}$ in the vacuum oven at $30^{\circ} \mathrm{C}$. The glycerol was not used for these fibers, since for these experiments the fiber mechanical strength was not of primal importance. Furthermore, we avoid the risk of having residues of glycerol in the fiber which would compromise the biomolecule adsorption to fiber.

\subsection{Membrane characterization}

\subsubsection{Scanning electron microscopy}

Samples for scanning electron microscopy (SEM) were prepared by freezing the fibers in liquid nitrogen and breaking them in order to expose the cross-sectional area. Samples were dried under vacuum at $30^{\circ} \mathrm{C}$ overnight and afterwards coated with a thin layer of gold using Balzer Union SCD 040 sputtering device. Membranes were examined using Jeol JSM-5600 LV Scanning Electron Microscope with Semaphore software for the determination of fiber dimensions.

\subsubsection{Stability in organic solvents}

The resistance of the crosslinked and uncrosslinked mixed matrix hollow fiber membranes against organic solvents was tested by immersing pieces of the fiber in NMP and DMSO for $24 \mathrm{~h}$, drying in the air for $12 \mathrm{~h}$ and vacuum oven at $60^{\circ} \mathrm{C}$ for 5 days, and comparing the mass of the fibers before and after immersion in the solvents. 


\subsubsection{Permeability}

The modules for pure water, NMP and DMSO flux measurements contained one crosslinked mixed matrix hollow fiber with an effective length of about $16 \mathrm{~cm}$. The flux was determined using a dead-end filtration cell connected to a gas cylinder of compressed nitrogen to apply the feed pressure. The flux, $\mathrm{J}$ in $1 /\left(\mathrm{m}^{2} \cdot \mathrm{h}\right)$, was measured at different pressures up to 3 bar after the glycerol was removed from the membrane and the steady state conditions were reached. The membrane permeance $(\mathrm{P})$ was obtained from the slope of the flux (J) vs transmembrane pressure $(\Delta \mathrm{p})$. The fluxes of various solvents were normalized for the solvent viscosity (see results later). Three membrane samples were tested to determine the average flux for each solvent.

\subsubsection{Static adsorption/desorption}

\section{Aqueous systems}

The adsorption capacity, adsorption kinetics and adsorption isotherms of the crosslinked mixed matrix membranes were determined with BSA in acetate buffer at $\mathrm{pH} 4.5$ and with lysozyme in phosphate buffer at $\mathrm{pH} 7.4$ (the physiological $\mathrm{pH}$ of blood). Both buffers had concentration of $50 \mathrm{mM}$ and the ionic strength adjusted to the physiological $154 \mathrm{mM}$. A known amount of membrane was first equilibrated for $24 \mathrm{~h}$ in an appropriate buffer, which was subsequently exchanged with the protein solution. The membrane samples were kept during the adsorption period in a shaking machine at constant temperature of $25^{\circ} \mathrm{C}$. The protein was adsorbed onto the mixed matrix membrane reducing the concentration in the bulk solution which was verified by an UV-Visible Spectrophotometer Cary 300 Scan (Varian) at $595 \mathrm{~nm}$ using the Bradford method [30]. For the adsorption capacity and kinetics experiments, protein solutions of $1 \mathrm{mg} / \mathrm{mL}$ were used, while for the determination of adsorption isotherms, concentrations between $0 \mathrm{mg} / \mathrm{mL}$ and $6 \mathrm{mg} / \mathrm{mL}$ were employed. The adsorption capacity of uncrosslinked mixed matrix membranes, crosslinked and uncrosslinked reference pure P84 membranes, and of ion exchange particles was tested, too.

\section{Non-aqueous systems}

The adsorption capacity, adsorption kinetics and adsorption isotherms of the crosslinked mixed matrix membranes were determined with lysozyme in DMSO and cholesterol in NMP. A known amount of membrane was first equilibrated for $24 \mathrm{~h}$ in an appropriate solvent, which was subsequently exchanged with the biomolecule solution. The membrane samples were kept during the adsorption period in a shaking machine at constant temperature of $25^{\circ} \mathrm{C}$. The biomolecule was adsorbed onto the mixed matrix membrane reducing the biomolecule concentration in the bulk solution which was verified by an UVVisible Spectrophotometer Cary 300 Scan (Varian). Lysozyme concentration in DMSO was measured at $595 \mathrm{~nm}$ with Bradford reagent. For the measurement of cholesterol concentration in NMP, the extraction method, using the fact that cholesterol is almost insoluble in water, was employed. Equal volumes of cholesterol/NMP solution and water were shaken out until a precipitate was extracted. The liquid above the precipitate, NMP/water mixture with dissolved 
Uncrosslinked

(a)

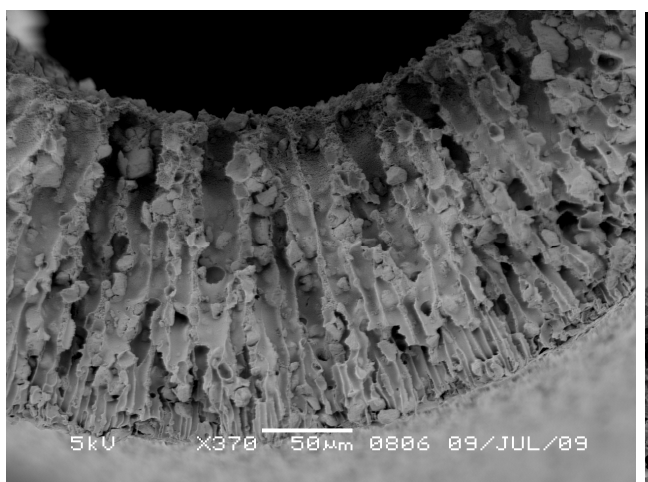

(b)

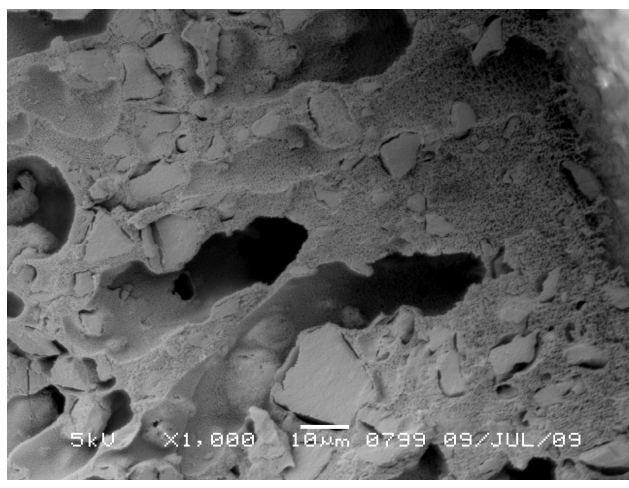

(c)

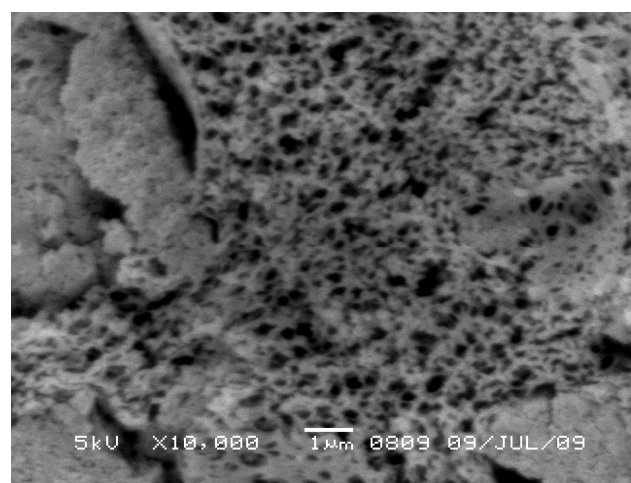

Crosslinked
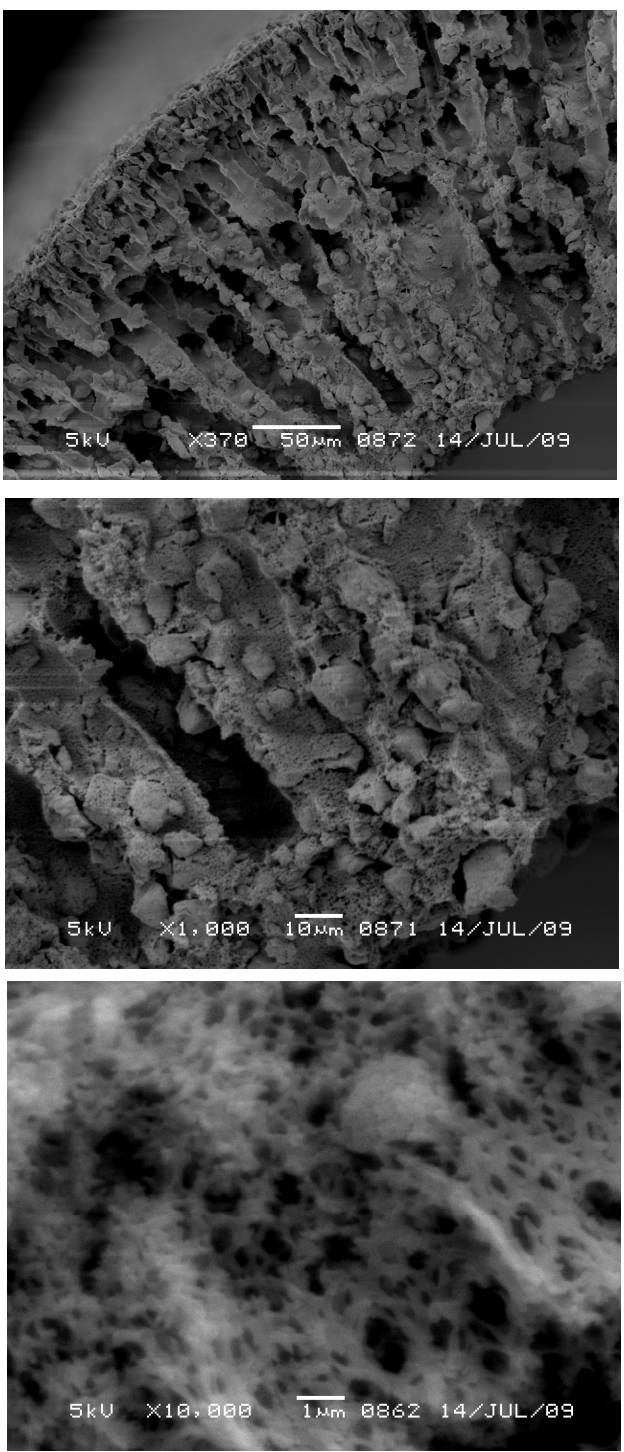

Figure 1 SEM images of the mixed matrix hollow fiber adsorber membranes; left: before crosslinking, right: after crosslinking

cholesterol (the amount that did not precipitate), was measured at $600 \mathrm{~nm}$. For the adsorption capacity and kinetics experiments, biomolecule solutions of $1 \mathrm{mg} / \mathrm{mL}$ were used, while for the determination of adsorption isotherms, concentrations between $0 \mathrm{mg} / \mathrm{mL}$ and $6 \mathrm{mg} / \mathrm{mL}$ were employed. The adsorption capacity of crosslinked mixed matrix membranes, crosslinked pure P84 membranes, and of ion exchange particles was tested, too.

\section{Results and discussion}

\subsection{Aqueous systems}

Morphology of the adsorber membrane 
Figure 1 presents the structure of P84 mixed matrix hollow fiber membranes prepared by incorporation of $60 \%$ Lewatit $112 \mathrm{WS}$ cation exchange particles. The hollow fibers are typically $900-1000 \mu \mathrm{m}$ in outer diameter with a wall thickness of approximately $300 \mu \mathrm{m}$. The fibers have an open, interconnected porous structure, with narrow and long finger-like macrovoids across the wall thickness. The ion exchange particles are tightly held together in the porous matrix. The loading of the particles was chosen as $60 \%$, based on earlier experiments in our group [18-21, 24]. In fact, for particles loading below 50\%, significantly larger macrovoids appear across the membrane structure, while for loading higher than $80 \%$ the mechanical strength of the fibers is poor. In this work, ion exchange particles with diameter below $20 \mu \mathrm{m}$ were used. Particles larger than $20 \mu \mathrm{m}$ cause formation of big macrovoids and have lower adhesion with the polymer matrix, resulting in falling out of the particles [18]. Our fibers have a homogenous porous structure and no significant loss of particles was observed during the membrane formation. There is no change in fiber dimensions (outer and inner diameter) between uncrosslinked and crosslinked fiber, but the particles and the membrane pores seem to be slightly larger for the crosslinked fiber (see Fig. $1)$.

\section{Membrane permeability}

Due to the very open structure, the prepared crosslinked mixed matrix hollow fiber membranes have very high pure water fluxes (Figure 2). At 0.1 bar the pure water flux is $1900 \mathrm{l} /\left(\mathrm{m}^{2} \cdot \mathrm{h}\right)$. The dependence of the flux on transmembrane pressure is, however, non-linear. The membranes seem to compact at transmembrane pressures above 0.2 bar.

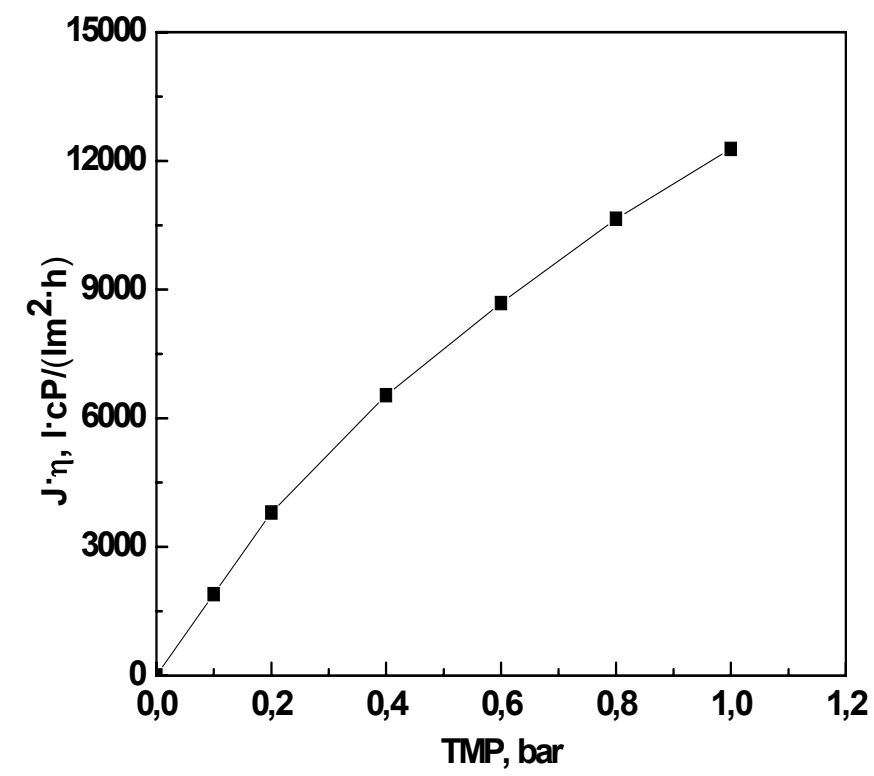

Figure 2 Pure water flux vs transmembrane pressure for the mixed matrix crosslinked hollow fiber membrane 


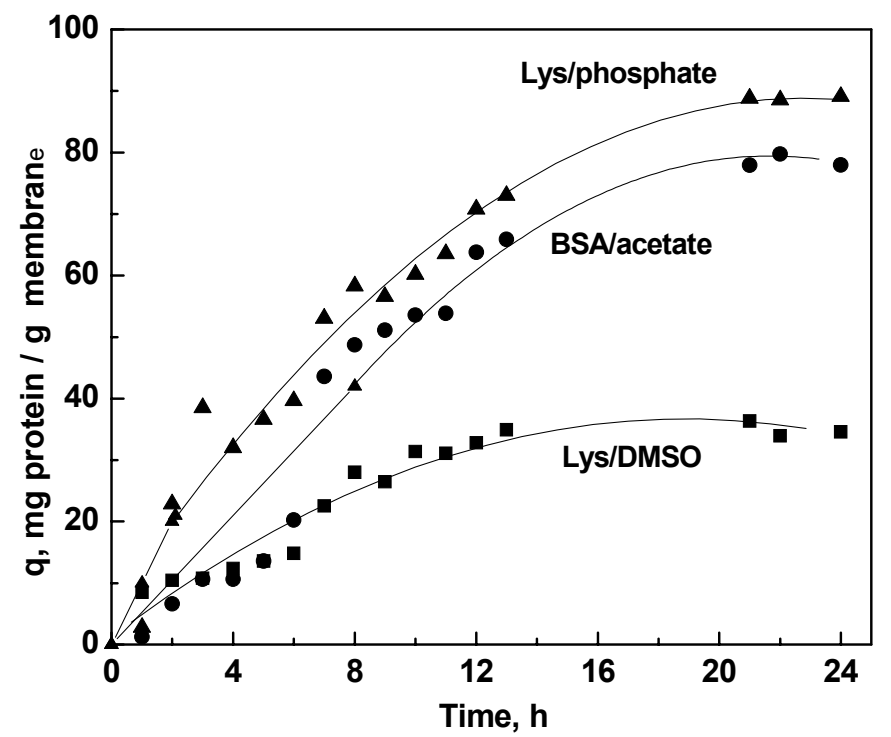

Figure 3 Adsorption kinetics of the proteins adsorbed on mixed matrix hollow fiber (the lines are there to guide the eye)

\section{Static adsorption capacity}

The static adsorption capacity of the adsorber membranes was studied batchwise in triplicate. The adsorption kinetics for a single incubation experiment of Lys in phosphate and BSA in acetate is shown in Figure 3. The adsorption reaches equilibrium at 24 hours, thus for all the screening experiments the adsorption capacity of the membranes/particles was determined after $24 \mathrm{~h}$.

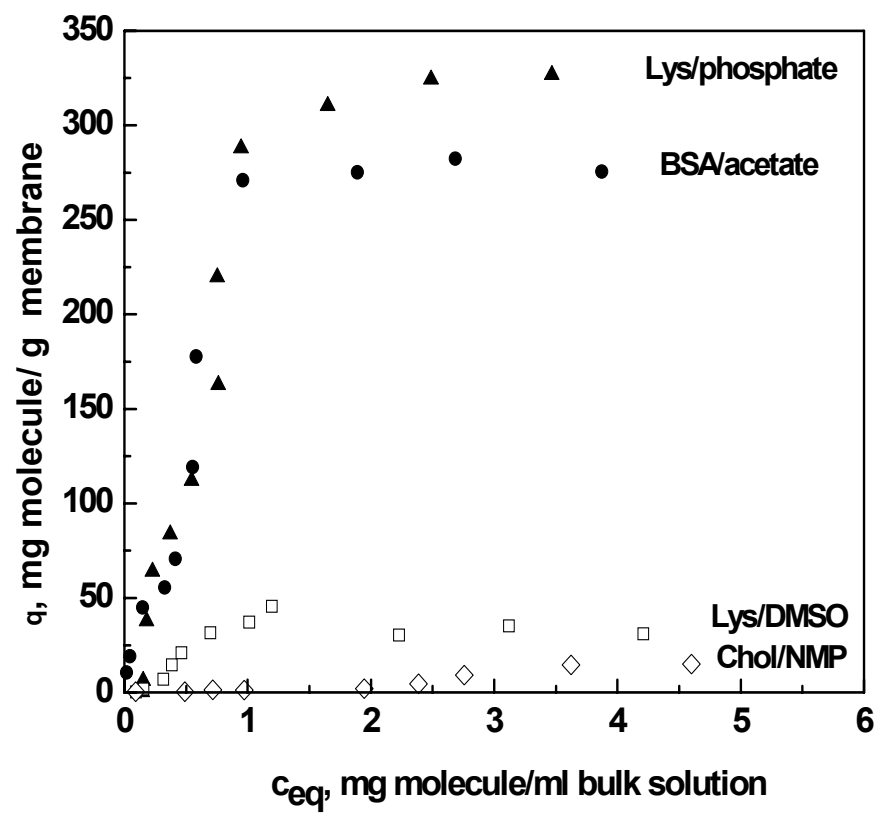

Figure 4 Experimental data of biomolecule adsorption from various solvents with different initial concentrations at $25^{\circ} \mathrm{C}$ (adsorption isotherms) 
Figure 4 presents the adsorption isotherms of Lys in phosphate and BSA in acetate buffer solutions at $25^{\circ} \mathrm{C}$. The maximum adsorption capacity of the adsorbent $\left(\mathrm{q}_{\mathrm{m}}\right)$ is reached at $\sim 330 \mathrm{mg}$ Lys/g membrane and $\sim 280 \mathrm{mg} \mathrm{BSA} / \mathrm{g}$ membrane. This compares well with results reported earlier by Avramescu et al for Lys [24] (210 mg Lys/g PES-based mixed matrix with 50\% loading of CNP80WS cation exchange particles) and by the same author et al [19] for BSA (160 mg BSA/g EVAL-based mixed matrix membrane with $65 \%$ loading of $112 \mathrm{WS}$ cation exchange particles).

The adsorption capacities of the membranes and particle suspensions were further investigated with protein solutions of concentration $1 \mathrm{mg} / \mathrm{mL}$. The BSA adsorption capacity of the crosslinked mixed matrix membrane is $77.0 \pm 0.9 \mathrm{mg} \mathrm{BSA} / \mathrm{g}$ membrane, slightly higher than for the same uncrosslinked membrane: $66.6 \pm 3.6 \mathrm{mg} \mathrm{BSA} / \mathrm{g}$ membrane (see Table 2). The higher adsorption capacity of the crosslinked membrane is most likely due to better accessibility of the particles in the crosslinked membrane. Since the P84 crosslinked membrane without particles has adsorption capacity of $4.5 \pm 0.2 \mathrm{mg} \mathrm{BSA} / \mathrm{g}$ membrane (which is $2.3 \%$ of the total BSA adsorption capacity, taking into account that the P84 occupies $40 \%$ $\mathrm{W} / \mathrm{w}$ of the membrane), we can conclude that the incorporated negatively charged particles are responsible for the high BSA adsorption capacity of the crosslinked mixed matrix membranes due to the electrostatic interactions with positively charged BSA ( $\mathrm{pH} 4.5$, below its isoelectric point). The adsorption of BSA on the particle-free P84 membrane can be attributed to hydrophobic interactions and dipole-dipole interactions.

Table 2 Static BSA adsorption capacity of the ion exchange particles and adsorber membranes; $1 \mathrm{mg} / \mathrm{mL}$ of protein in $50 \mathrm{mM}$ acetate buffer $\mathrm{pH}=4.5$

\begin{tabular}{cccc}
\hline \multirow{2}{*}{ Adsorber } & \multicolumn{2}{c}{ BSA adsorption capacity } \\
\cline { 3 - 4 } & & $\begin{array}{c}\text { mg BSA/ } \\
\text { g membrane }\end{array}$ & $\begin{array}{c}\text { mg BSA/ } \\
\text { g particles }\end{array}$ \\
\hline Membrane P84 & uncrosslinked & $6.4 \pm 0.9$ & - \\
& crosslinked & $4.5 \pm 0.2$ & - \\
\hline Membrane P84/Lewatit 112 WS particles & uncrosslinked & $66.6 \pm 3.6$ & $106.7 \pm 6.0^{*}$ \\
60\% loading & crosslinked & $77.0 \pm 0.9$ & $125.3 \pm 1.5^{*}$ \\
\hline Lewatit 112 WS particles & & - & $112.6 \pm 10.5$ \\
\hline
\end{tabular}

* Values are normalized for the adsorption of membrane P84

The accessibility of ion exchange particles inside the porous structure was evaluated after comparing with the adsorption capacity of the particle suspension investigated at the same experimental conditions. When normalizing the BSA adsorption capacity of the crosslinked mixed matrix membrane by the adsorption on the membrane and recalculating the adsorption capacity per gram of particles, a value of $125.3 \pm 1.5 \mathrm{mg} \mathrm{BSA} / \mathrm{g}$ particles is obtained (Table 2), while the adsorption capacity of the particle suspension is $112.6 \pm 10.5$ mg BSA/g particles. The close agreement between the two values suggests that the adsorber membrane possesses good accessibility for protein to the adsorptive sites, with no loss of ion exchange capacity due to the membrane formation. Results of BSA adsorption obtained in 
this work are in good agreement with data reported by Avramescu et al. [18] who found adsorption capacity of $110 \pm 20 \mathrm{mg}$ BSA/g particles for suspension of Lewatit CNP 80 cation exchange particles (particle diameter $<20 \mu \mathrm{m}$ ) and $131 \pm 11 \mathrm{mg} \mathrm{BSA} / \mathrm{g}$ particles for mixed matrix EVAL membrane with $65 \%$ loading (adsorption capacity of particle-free EVAL membrane was $3 \pm 2 \mathrm{mg} \mathrm{BSA} / \mathrm{g}$ membrane).

For adsorption of lysozyme from phosphate buffer at $\mathrm{pH} 7.4$, (below the isoelectric point of lysozyme), when the lysozyme is positively charged, the crosslinked mixed matrix membrane has the adsorption capacity of $85.1 \pm 4.1 \mathrm{mg}$ Lys $/ \mathrm{g}$ membrane (Table 3 ). The value of adsorption capacity for this mixed matrix membrane normalized by the adsorption on the membrane material alone ( $4.1 \pm 0.3 \mathrm{mg}$ Lys/g of pure P84 membrane) and recalculated per mass of the ion exchange particles is $139.2 \pm 6.8 \mathrm{mg}$ Lys/g particles. The adsorption capacity of the particles suspension is $169.6 \pm 1.2 \mathrm{mg}$ Lys/g particles, higher than for the crosslinked mixed matrix membrane. In this case, lysozyme adsorption is higher for the crosslinked membrane in comparison to the uncrosslinked, indicating some improved accessibility of the particles in the membrane or higher affinity of the lysozyme towards the crosslinked than to the uncrosslinked membrane. A similar trend of slightly lower adsorption capacity for the crosslinked mixed matrix membrane in comparison to the particle suspension was obtained by Saiful [22], who found a value of $\sim 230 \mathrm{mg}$ Lys/g particles and $\sim 211 \mathrm{mg}$ Lys/g particles for the mixed matrix membrane (EVAL polymer with Lewatit CNP80WS weak ion exchange particles, 65\% loading). The absolute values should not be compared to ours because the initial protein concentrations used are different. Pollio et al. [31] who used the same initial protein concentration as in our work, reported the adsorption of lysozyme onto resin Amberlite IRC-5 to be $\sim 137 \mathrm{mg}$ Lys/g particles, quite similar to the results obtained in this work.

Table 3 Static lysozyme adsorption capacity of the ion exchange particles and adsorber membranes; $1 \mathrm{mg} / \mathrm{mL}$ in $50 \mathrm{mM}$ phosphate buffer $\mathrm{pH}=7$

\begin{tabular}{cccc}
\hline \multirow{2}{*}{ Adsorber } & \multicolumn{2}{c}{ Lysozyme adsorption capacity } \\
\cline { 3 - 4 } & & $\begin{array}{c}\text { mg Lys/ } \\
\text { g membrane }\end{array}$ & $\begin{array}{c}\text { mg Lys/ } \\
\text { g particles }\end{array}$ \\
\hline Membrane P84 & uncrosslinked & $5.9 \pm 1.5$ & - \\
& crosslinked & $4.1 \pm 0.3$ & - \\
\hline Membrane P84/Lewatit 112WS particles 60\% & uncrosslinked & $70.3 \pm 6.3$ & $113.2 \pm 10.5^{*}$ \\
loading & crosslinked & $85.1 \pm 4.1$ & $139.2 \pm 6.8^{*}$ \\
\hline Lewatit 112WS particles & & - & $169.6 \pm 1.2$ \\
\hline
\end{tabular}

* Values are normalized for the adsorption of membrane P84

The ideal membrane adsorber possesses a low non-selective protein adsorption onto the polymer matrix and high reversible and selective (here, based on electrostatic interactions) adsorption onto resin particles. The mixed matrix membrane in this work demonstrates good performance for both proteins in aqueous solutions. 

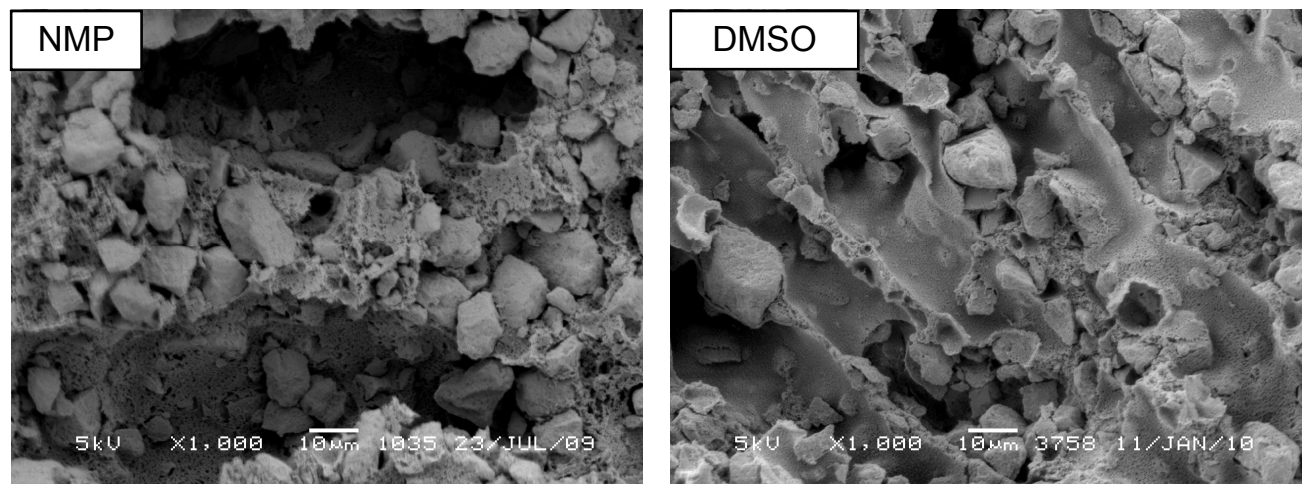

Figure 5 SEM images of the mixed matrix hollow fiber adsorber membranes after cross-linking and immersion in organic solvents; left: NMP, right: DMSO

\subsection{Non-aqueous systems}

\section{Membrane stability}

The stability of produced fibers towards strong organic solvents was tested by immersing them in DMSO and NMP which are good solvents for the uncrosslinked matrix polyimide. While the uncrosslinked fibers dissolved in both NMP and DMSO, the crosslinked fibers stayed intact showing that the crosslinking was successful and solvent-resistant mixed matrix membranes were produced. In fact, we found no change in the mass of the crosslinked fiber after immersion in both solvents, but the membrane morphology was slightly altered. The structure looks more nodular with particles exposed out of the polymer matrix (see Figure $5)$.

\section{Membrane permeability}

Figure 6 presents the fluxes of DMSO and NMP through the crosslinked membranes, normalized with the solvent viscosity. Both fluxes are much lower than for water: $19.1 \mathrm{l} /\left(\mathrm{m}^{2} \cdot \mathrm{h}\right)$ and $0.5 \mathrm{l} /\left(\mathrm{m}^{2} \cdot \mathrm{h}\right)$ at $0.1 \mathrm{bar}$, for DMSO and NMP, respectively (Figure 6), in comparison to $1900 \mathrm{l} /\left(\mathrm{m}^{2} \cdot \mathrm{h}\right.$ ) at 0.1 bar for water (Figure 2). In these solvents, membrane compaction occurs at transmembrane pressure higher than 0.2 bar, too. The crosslinked mixed matrix membranes although do not dissolve in organic solvents, may undergo swelling leading to decrease of porosity and therefore lower solvent flux. The previous work of Borneman [32] on the same type of cation exchange particles (Lewatit 112WS) reports negligible NMP uptake/ swelling. When these particles were exposed to water, the swelling was about $100 \%$. In a mixture of water and NMP (similar to the dope composition) water pre-swells the particles making them accessible to NMP. In our case, there was no water in the polymer dope and the hollow fiber membranes were not wetted with water before NMP or DMSO permeability experiments. We attribute the swelling not the particles, but to the matrix polymer. 


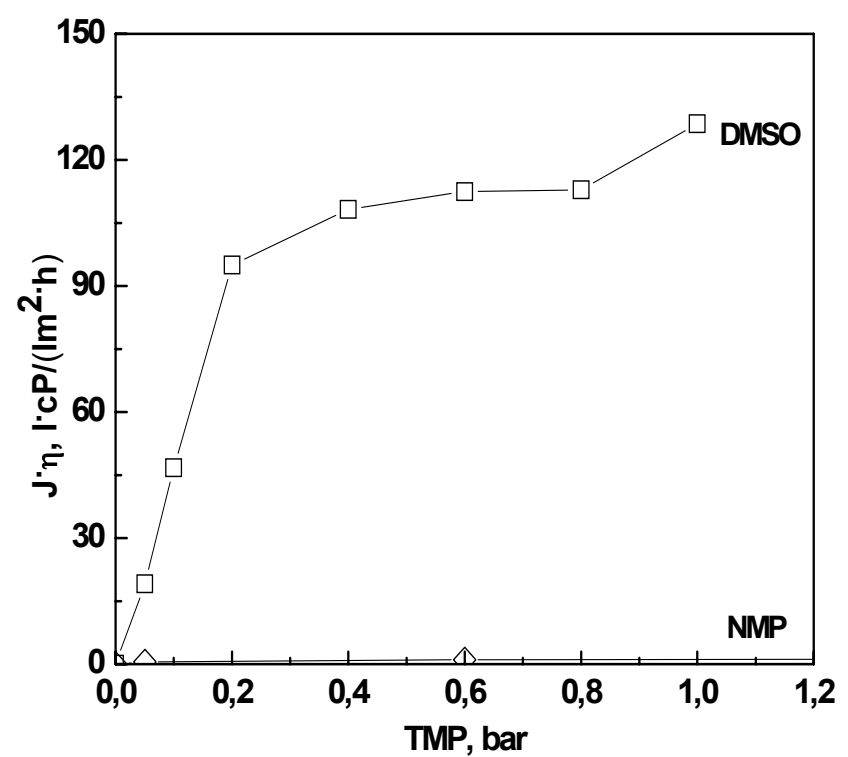

Figure 6 DMSO and NMP fluxes vs transmembrane pressure for the crosslinked mixed matrix hollow fiber membrane

\section{Static adsorption capacity}

The adsorption capacity of the crosslinked mixed matrix membrane and the particle suspension in organic solvents was screened after $24 \mathrm{~h}$ of incubation in the biomolecule solutions. In fact, the adsorption kinetics experiments (Fig. 3) reveal that in case of Lys in DMSO the saturation takes place already after around $13 \mathrm{~h}$, much earlier than for the same biomolecule in the aqueous solution.

Figure 4 compares the adsorption isotherms of Lys in DMSO and cholesterol in NMP at $25^{\circ} \mathrm{C}$. The membrane adsorber reaches maximum adsorption capacity $\left(\mathrm{q}_{\mathrm{m}}\right)$ for both biomolecules at higher initial concentrations (as it is for the proteins in aqueous systems): 40 $\mathrm{mg}$ Lys $/ \mathrm{mg}$ membrane and $\sim 15 \mathrm{mg} \mathrm{Chol} / \mathrm{g}$ membrane, meaning that the surface of adsorber membrane has a fixed number of adsorption sites.

The adsorption capacity for the particle suspension is much lower $(12.8 \pm 1.4 \mathrm{mg}$ Lys/g particles) than that obtained in the aqueous solution. DMSO is a polar aprotic solvent (dielectric constant is 47, for comparison: the dielectric constant of water is 80) and electrostatic interactions do not take place in this solvent. Besides, DMSO may compete strongly for hydrogen bonds between protein atoms leading to the unfolding of Lys and loosing of its tertiary structure [33]. It is also important to note that massive aggregation of particles occurs in DMSO (easily seen with a bare eye) which seems to be detrimental to the overall particle adsorption capacity.

The adsorption capacities of the membranes and particle suspensions were further investigated with biomolecule solutions of concentration $1 \mathrm{mg} / \mathrm{ml}$. The crosslinked mixed matrix membrane has adsorption capacity of $27.9 \pm 6.5 \mathrm{mg}$ Lys $/ \mathrm{g}$ membrane in DMSO. The adsorption capacity of the particle-free membrane is $16.4 \pm 0.8 \mathrm{mg}$ Lys/g membrane, almost $25 \%$ of the total adsorption (taking into account that the P84 occupies $40 \% \mathrm{w} / \mathrm{w}$ of the 
membrane) (Table 4), higher than in aqueous solution ( $4.1 \pm 0.3 \mathrm{mg}$ Lys/g membrane), which suggests that there are stronger interactions between lysozyme and membrane in DMSO than in water. The adsorption capacity of the particles in the mixed matrix membrane (35.5 $\pm 10.8 \mathrm{mg}$ Lys/g particles) is almost 3 fold higher than adsorption capacity of the particle suspension $(12.8 \pm 1.4 \mathrm{mg}$ Lys/g particles), showing that the particles are better accessible to Lys in the membrane, probably due to the avoidance of aggregation.

Tabela 4 Static lysozyme adsorption capacity of ion exchange particles suspension and adsorber membranes; $1 \mathrm{mg} / \mathrm{mL}$ in DMSO

\begin{tabular}{ccc}
\hline \multirow{2}{*}{ Adsorber } & \multicolumn{2}{c}{ Lysozyme adsorption capacity } \\
\cline { 2 - 3 } & mg Lys/g membrane & mg Lys/g particles \\
\hline Membrane crosslinked P84 & $16.4 \pm 0.8$ & - \\
Membrane crosslinked P84/Lewatit particles & $27.9 \pm 6.5$ & $35.5 \pm 10.8^{*}$ \\
Lewatit particles & - & $12.8 \pm 1.4$ \\
\hline
\end{tabular}

* Values are normalized for the adsorption of membrane P84

The adsorption of cholesterol from NMP (polar aprotic solvent, dielectric constant 32) reveals very low interaction of cholesterol with P84 $(0.1 \pm 0.1 \mathrm{mg}$ Chol/g membrane) (Table 5). In the Chol/NMP system the particle aggregation is very limited. As a result the cholesterol adsorption capacity of the particles in the membrane $(8.3 \pm 5.0 \mathrm{mg} \mathrm{Chol} / \mathrm{g}$ particles) is comparable with that in the suspension $(7.6 \pm 5.4 \mathrm{mg} \mathrm{Chol} / \mathrm{g}$ particles, see Table $5)$.

Tabela 5 Static cholesterol adsorption capacity of the ion exchange particles suspension and adsorber membranes; $1 \mathrm{mg} / \mathrm{mL}$ in NMP

\begin{tabular}{ccc}
\hline \multirow{2}{*}{ Adsorber } & \multicolumn{2}{c}{ Cholesterol adsorption capacity } \\
\cline { 2 - 3 } & $\mathrm{mg} \mathrm{chol} / \mathrm{g}$ & $\mathrm{mg}$ chol/g particles \\
\hline Membrane crosslinked P84 & $0.1 \pm 0.1$ & - \\
Membrane crosslinked P84/Lewatit particles & $5.0 \pm 3.0$ & $8.3 \pm 5.0$ \\
Lewatit particles & - & $7.6 \pm 5.4$ \\
\hline
\end{tabular}

* Values are normalized for the adsorption of membrane P84

In conclusion, the adsorption capacity of the membrane developed in this work is much lower than in organic solvents in the aqueous systems mainly due to the lack of electrostatic interactions between particles and biomolecules. In the polar aprotic solvents like DMSO and NMP, the adsorption takes place only due to the hydrophobic interactions. Nevertheless, the advantage of the mixed matrix membrane in some organic solvents is apparent (as shown here for DMSO) with the lack of aggregation. To increase the adsorption capacity of the crosslinked mixed matrix membranes, other types of particles with specific affinity to the target biomolecules could be used. 


\section{Conclusions - outlook}

Crosslinked mixed matrix adsorber membranes were developed for isolation of biomolecules from organic solvents such as NMP and DMSO. The produced membranes have a homogenous structure with uniform distribution of the incorporated ion exchange particles and have high clean water flux and high static adsorption capacity in aqueous systems: 125.3 $\mathrm{mg} \mathrm{BSA} / \mathrm{g}$ particles and $139.2 \mathrm{mg}$ Lys/g particles.

The flux of DMSO and NMP through the membrane is lower than water, probably due to the membrane swelling. In organic solvents the adsorption capacity of the mixed matrix membranes is lower: $35.5 \mathrm{mg}$ Lys/g particles and $8.3 \mathrm{mg} \mathrm{Chol} / \mathrm{g}$ particles, suggesting that the electrostatic interactions do not play a role in such systems. The particle-free P84 membrane has, however, higher adsorption capacity than in the aqueous systems, which is a sign of stronger hydrophobic interactions between the biomolecules and the polymer. In the case of Lys/DMSO, the accessibility of particles in the membrane is much higher than in particle suspension due to the avoidance of aggregation.

In this work we showed the proof of concept of solvent resistant mixed matrix adsorber membranes. For further improving the technologyy, various other types of particles as well as other target molecules / solvent systems should be considered in order to explore other types of interactions between the target molecules and the mixed matrix membrane. 


\section{References}

[1] N. Chang, S.J. Hen, A.M. Klibanov, Protein separation and purification in neat dimethyl sulfoxide, Biochemical and Biophysical Research Communications, 176 (1991) 14621468.

[2] N. Chang, A.M. Klibanov, Protein chromatography in neat organic solvents, Biotechnology and Bioengineering, 39 (1992) 575-578.

[3] L.E. Bromberg, A.M. Klibanov, Transport of proteins dissolved in organic solvents across biomimetic membranes, Proceedings of the National Academy of Sciences of the United States of America, 92 (1995) 1262-1266.

[4] A.M. Klibanov, Improving enzymes by using them in organic solvents, Nature, 409 (2001) 241.

[5] C. Mattos, D. Ringe, Proteins in organic solvents, Current Opinion in Structural Biology, 11 (2001) 761-764.

[6] C. Mattos, D. Ringe, Locating and characterizing binding sites on proteins, Nature Biotechnology, 14 (1996) 595-599.

[7] I.D. Kuntz Jr, W. Kauzmann, Hydration of proteins and polypeptides, Advances in Protein Chemistry, 28 (1974) 239-345.

[8] J.A. Rupley, G. Careri, Protein hydration and function, Advances in Protein Chemistry, 41 (1991) 37-172.

[9] T.J. Ahern, A.M. Klibanov, Analysis of processes causing thermal inactivation of enzymes, Methods of biochemical analysis, 33 (1988) 91-127.

[10] D.B. Volkin, A. Staubli, R. Langer, A.M. Klibanov, Enzyme thermoinactivation in anhydrous organic solvents, Biotechnology and Bioengineering, 37 (1991) 843-853.

[11] A. Zaks, A.M. Klibanov, Enzymatic Catalysis in Organic Media at $100^{\circ}$ C, Science, 224 (1984) 1249-1251.

[12] A. Zaks, A.M. Klibanov, Enzymatic catalysis in nonaqueous solvents, Journal of Biological Chemistry, 263 (1988) 3194-3201.

[13] G.L. Lensmeyer, C. Onsager, I.H. Carlson, D.A. Wiebe, Use of particle-loaded membranes to extract steroids for high-performance liquid chromatographic analyses improved analyte stability and detection, Journal of Chromatography A, 691 (1995) 239-246.

[14] J.L. Liao, C.M. Zeng, S. Hjerten, J. Pawliszyn, Solid Phase Micro Extraction of Biopolymers, Exemplified with Adsorption of Basic Proteins onto a Fiber Coated with Polyacrylic Acid, Journal of Microcolumn Separations, 8 (1996) 1-4.

[15] H. Lingeman, S.J.F. Hoekstra-Oussoren, Particle-loaded membranes for sample concentration and/or clean-up in bioanalysis, Journal of Chromatography B: Biomedical Sciences and Applications, 689 (1997) 221-237.

[16] G. Theodoridis, E.H.M. Koster, G.J. De Jong, Solid-phase microextraction for the analysis of biological samples, Journal of Chromatography B: Biomedical Sciences and Applications, 745 (2000) 49-82. 
[17] Y. Sun, S. Bai, L. Gu, S. Furusaki, Purification of lysozyme by affinity-based reversed micellar two-phase extraction, Bioprocess and Biosystems Engineering, 22 (2000) 1922.

[18] M.-E. Avramescu, M. Gironès, Z. Borneman, M. Wessling, Preparation of mixed matrix adsorber membranes for protein recovery, Journal of Membrane Science, 218 (2003) 219-233.

[19] Z.B.M.W. Maria-Elena Avramescu, Dynamic behavior of adsorber membranes for protein recovery, Biotechnology and Bioengineering, 84 (2003) 564-572.

[20] M.-E. Avramescu, Z. Borneman, M. Wessling, Mixed-matrix membrane adsorbers for protein separation, Journal of Chromatography A, 1006 (2003) 171-183.

[21] M.E. Avramescu, W.F.C. Sager, Z. Borneman, M. Wessling, Adsorptive membranes for bilirubin removal, Journal of Chromatography B, 803 (2004) 215-223.

[22] Saiful, Z. Borneman, M. Wessling, Enzyme capturing and concentration with mixed matrix membrane adsorbers, Journal of Membrane Science, 280 (2006) 406-417.

[23] Saiful, Mixed Matrix Membrane Adsorbers for Protein and Blood Purification, PhD Thesis University of Twente, 2007.

[24] M.-E. Avramescu, Z. Borneman, M. Wessling, Particle-loaded hollow-fiber membrane adsorbers for lysozyme separation, Journal of Membrane Science, 322 (2008) 306-313.

[25] Y.H. See Toh, F.W. Lim, A.G. Livingston, Polymeric membranes for nanofiltration in polar aprotic solvents, Journal of Membrane Science, 301 (2007) 3-10.

[26] K. Vanherck, A. Cano-Odena, G. Koeckelberghs, T. Dedroog, I. Vankelecom, A simplified diamine crosslinking method for PI nanofiltration membranes, Journal of Membrane Science, 353 135-143.

[27] D.B. Gilbert, C. Tanford, J.A. Reynolds, Cholesterol in aqueous solution: Hydrophobicity and self-association, Biochemistry, 14 (1975) 444-448.

[28] D. Talley, B. Cutak, E. Rathbone, T. Kolla, D. Allison, J. Blasberg, K. Kao, M. Caple, Synthechol $^{\mathrm{TM}}$ Synthetic Cholesterol for Cholesterol Dependent Cell Culture Development of Non-Animal Derived Chemically Defined NS0 Medium, in: Animal Cell Technology Meets Genomics, 2005, pp. 577-580.

[29] W.H. Liu, C.K. Lo, Production of testosterone from cholesterol using a single-step microbial transformation of Mycobacterium sp, Journal of Industrial Microbiology and Biotechnology, 19 (1997) 269-272.

[30] M.M. Bradford, A rapid and sensitive method for the quantitation of microgram quantities of protein utilizing the principle of protein-dye binding, Analytical Biochemistry, 72 (1976) 248-254.

[31] F.X. Pollio, R. Kunin, Use of macroreticular ion exchange resins for the fractionation and purification of enzymes and related proteins, Chem Eng Progr Symp Ser, 67 (1971) 66-74.

[32] Z. Borneman, Particle loaded membrane chromatography, $\mathrm{PhD}$ thesis, University of Twente, Enschede, 2006.

[33] T. Knubovets, J. J.Osterhout, A.M. Klibanov, Structure of lysozyme dissolved in neat organic solvents as assessed by NMR and CD spectroscopies, Biotechnology and Bioengineering, 63 (1999) 242-248. 


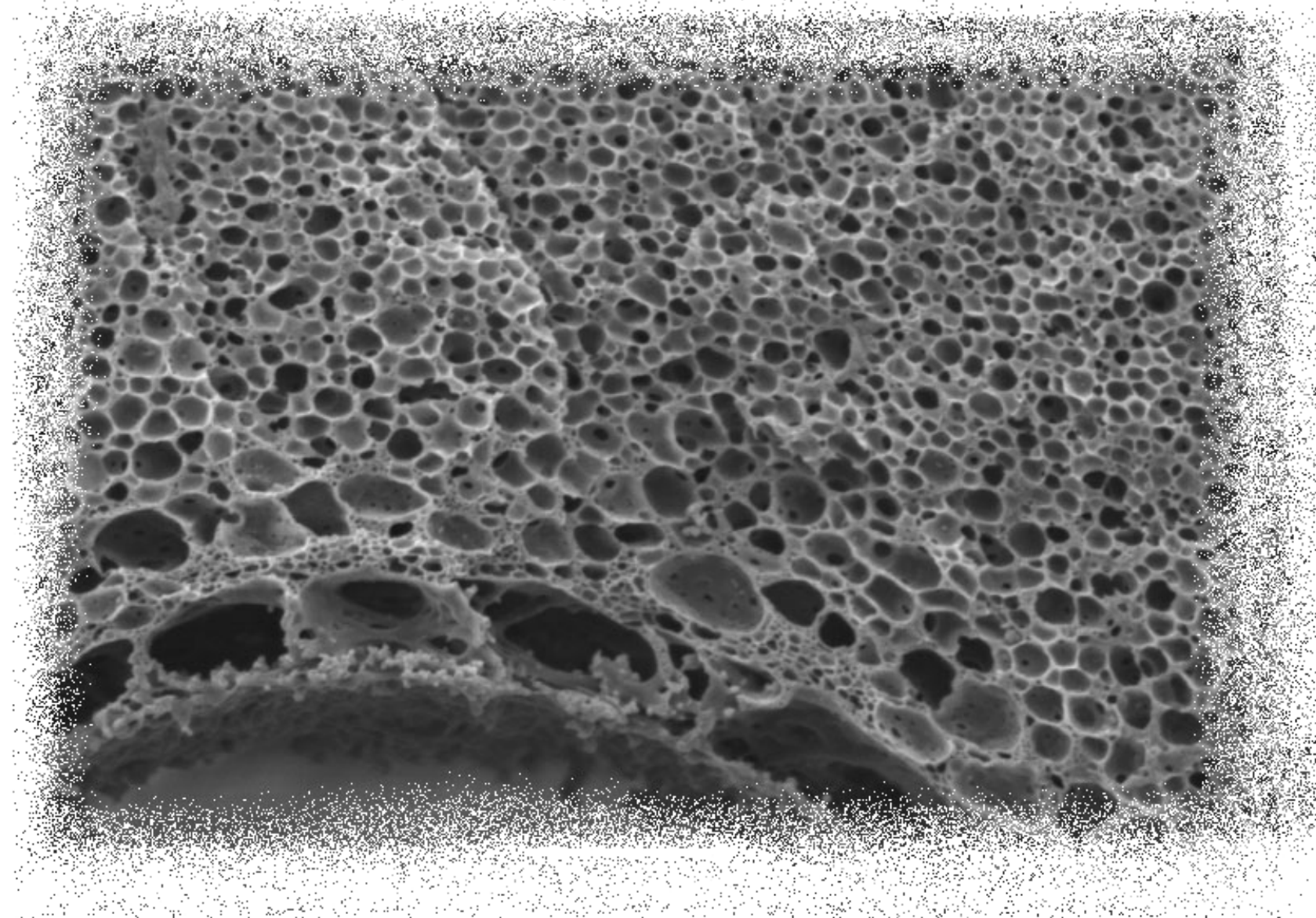

Chapter 5

Porous membrane structures as stationary phase for capillary electrochromatography 


\begin{abstract}
This chapter presents application of membrane formation processes for the fabrication of columns for capillary electrochromatography (CEC) separations using various techniques, all based on phase inversion of a polymer solution. Different polymers are processed via immersion precipitation dry-wet spinning into: (i) small-bore polyimide P84 fibers with sulphonated poly(ether ether ketone) (SPEEK) deposited on the bore side, (ii) small-bore fiber - a blend of P84 and SPEEK, (iii) mixed matrix full fiber poly(ether sulphone) (PES) with strong cation exchange particles, (iv) full fiber - a blend of P84 and SPEEK. The zeta-potential, morphology of the porous structure and performance in the CEC analysis are investigated. Neutral molecules (as markers of the electroosmotic flow) and proteins are injected into the column, driven under application of voltage, and detected in form of peaks on the electropherogram. The proof of concept is shown and possible optimization in order to reduce the low efficiency and selectivity is suggested.
\end{abstract}




\section{Introduction}

Capillary electrochromatography (CEC) is a relatively young separation technique, but it has the potential to become a high-performance chromatographic method. The interest in CEC is growing continuously, crossing the border between academia and industry. Since the publication of the two remarkable for the CEC field papers, first one of Pretorius [1] in 1974 reporting application of electroosmosis in column chromatography, and the second one of Jorgenson and Lukacs [2] in 1981, describing electroseparations in capillaries, a number of papers were published on CEC theory [3-6] and factors influencing performance [7-10]. All of them report the advantages of CEC over high performance liquid chromatography (HPLC) and capillary electrophoresis (CE), but emphasize that some aspects like the on-line detection or column technology still have to be improved.

\subsection{Background}

Capillary electrochromatography (CEC) is an analytical hybrid separation technique that combines the best features of capillary electrophoresis (CE) and high performance liquid chromatography (HPLC).

In $\mathrm{CE}$ the separation is carried out in a fused silica capillary with an inner diameter typically between $25-150 \mu \mathrm{m}$ (outer diameter varies between 150 and $520 \mu \mathrm{m}$ ) and length in the region of $20-100 \mathrm{~cm}$ [11]. Fused silica is the material of choice due to its UV transparency, durability (when polyimide coated), and zeta-potential. The capillary is filled with running buffer and the sample (typically $2-20 \mathrm{~nL}$ ) is introduced by dipping one end in the sample and applying voltage (electrokinetic injection), gas pressure (pressure injection) or lifting the sample vial above the height of the outlet vial (hydrostatic injection). Next, both ends of the capillary are immersed in the vials with buffer and high voltage of 10-30 kV (current up to $300 \mu \mathrm{A}$ ) is applied through the electrodes immersed in the same vials (Figure 1). Migration of the analytes through the capillary is driven by the electric field. The analytes are detected at the other end of the capillary as they pass through the on-line detector. Detection takes place on the capillary, normally by absorbance or, less frequently, by fluorescence, but techniques like mass spectrometry, conductivity, laser-induced fluorescence or nuclear magnetic resonance (NMR) have been applied, too [5, 11-13].

The migration of the analytes inside the capillary is caused by two phenomena: electrophoresis and electroosmotic flow.

\section{Electrophoresis}

Electrophoresis refers to the migration of charged molecules in the electrical field. The migration velocity of electrophoresis $u_{e p}(\mathrm{~cm} / \mathrm{s})$ is dependent on many factors, including the applied field strength $\mathrm{E}(\mathrm{V} / \mathrm{cm})$, the dielectric constant of the medium $\varepsilon$, the viscosity of the medium $\eta(\mathrm{Pa} \cdot \mathrm{s})$, and the zeta-potential of the capillary $\zeta(\mathrm{V})[12]$ :

$$
\mathrm{u}_{\mathrm{ep}}=\frac{E \varepsilon \zeta}{6 \pi \eta}=\frac{\mathrm{L}_{\mathrm{d}}}{\mathrm{t}_{\mathrm{m}}}
$$


where $L_{d}(\mathrm{~cm})$ is the capillary length from the inlet to the detector and $t_{m}(s)$ is the migration time of the peak.

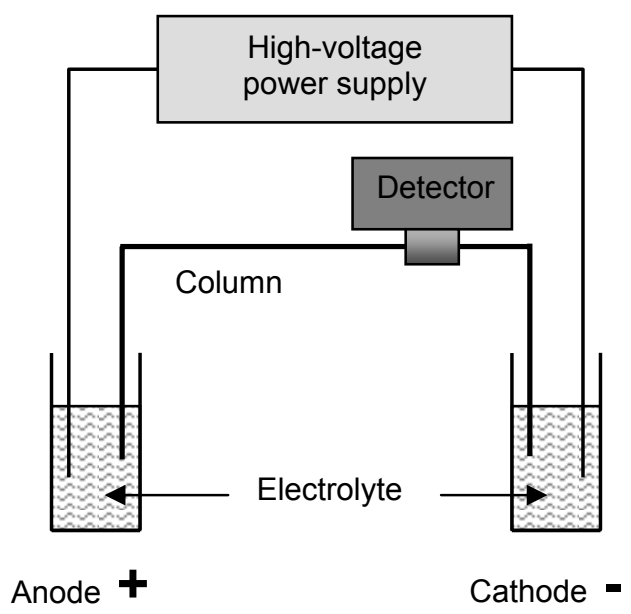

Figure 1 Principle of the CE/CEC separation

Another term, describing the flow of a molecule, is the electrophoretic mobility $\mu_{\mathrm{ep}}\left(\mathrm{cm}^{2} / \mathrm{V} \cdot \mathrm{s}\right)$ :

$\mu_{\text {ep }}=\frac{u_{\text {ep }}}{E}=\frac{L_{d} / t_{m}}{U / L_{t}}=\frac{q}{6 \pi \eta R_{S t}}$

where $L_{t}(\mathrm{~cm})$ is the total length of the capillary, $U$ is voltage $(V), q$ is the net charge and $R_{S t}$ (cm) is the Stokes radius of the ion, including the solvatation shell. The last part of the equation is the approximation of the Debeye-Huckel-Henry theory [14].

The electrophoretic mobility is highly dependent on the buffer composition and $\mathrm{pH}$, as well as temperature. The molecules move through the capillary at different rates because of differences in their charge and ionic radius. Small, highly charged ions move faster through the capillary than bigger and less charged molecules (Figure 2). The cations are attracted to the negatively charged cathode and the anions are attracted to the positively charged anode. The difference in the migration velocity is the basis of the CE separation. Here also comes the drawback of CE - the inability to separate noncharged molecules.

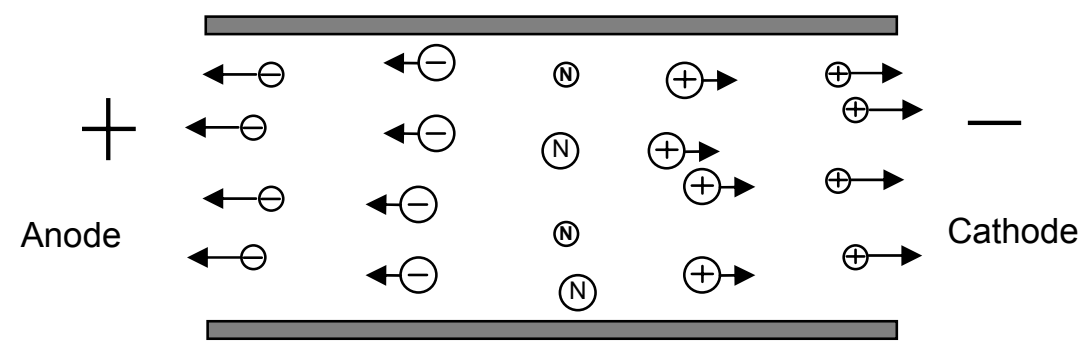

Figure 2 Electrophoresis phenomenon 


\section{Electroosmosis}

The other phenomenon, caused by the charged surface of the silica, is called electroosmotic flow (EOF). Many solids have fixed charges on their surface, in case of silica, the charged group is $\equiv \mathrm{Si}^{-} \mathrm{O}^{-}$. To preserve the charge neutrality, a layer of cations from the buffer is attracted by the negatively charged silica surface. These cations are immobilized in the close proximity of the silica due to the electrostatic attraction, but further from the silica the attraction is weaker, and in the bulk fluid the cations are free to move (the principle of electrical double layer and zeta-potential are described in details in Chapter 1: Introduction). In presence of external electrical field, the cations of the bulk buffer are attracted to the opposite charge - the cathode. As they move towards the cathode, they drag along water, generating an electroosmotic flow of the buffer solution. Because of this flow, not only the positive molecules, but also the neutral and negative ones are dragged towards the cathode and can be separated in one run together with the cations. The migration velocity of the EOF is described by the Helmholtz-Smoluchowski equation [11]:

$\mathrm{u}_{\mathrm{eof}}=\frac{\mathrm{E} \varepsilon \zeta}{4 \pi \eta}$

The EOF is influenced by composition of the electrolyte (the buffer) and depends strongly on the $\mathrm{pH}$. In case of silica, high $\mathrm{pH}$ increases the ionization of the silanol groups and therefore increases the electroosmotic flow (higher zeta-potential), while increasing the ionic strength decreases EOF [15]. Addition of organic solvents also affects the EOF, but less predictably [15].

In capillary electrophoresis, the separation principle is based on electrophoresis, while the process is driven by the electrical field (electroosmotic flow).

In HPLC, the separation principle is based on a different partitioning of the molecules between the stationary phase and the mobile phase [12]. Compounds that have higher affinity (physical or chemical) to the stationary phase migrate slower than those that "prefer" to stay in the mobile phase. Pressure is the driving force in HPLC which is always associated with the pressure drop due to the high resistance of the stationary phase. With the pumped flow, the flow velocity profile is parabolic (Figure 3). This reduces the efficiency of the column and induces band broadening, because the velocity in center of the channel is

A

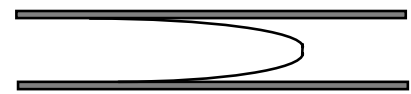

B

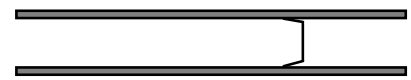

Figure 3 Representation of a pressure-generated parabolic flow profile (A) and an electroosmotic plug flow profile (B) 
much higher than velocity along the wall, which creates radial mixing and diffusion. In contrast, the flow velocity profile in the processes driven by electrical field is close to the ideal plug profile $[12,16]$.

Capillary electrochromatography (CEC) combines the efficiency of capillary electrophoresis, because the process uses electrical field rather than pressure to force the mobile phase, with the selectivity of high performance liquid chromatography, by using a column with the stationary phase, where also neutrals can be separated from each other.

Although HPLC is the most commercially successful technology in analytical chemistry, it is CEC which has the peak capacity about 10 times larger than HPLC and can reach up to 500000 theoretical plates (the quantity adapted from chromatography and calculated from the peak width and migration time), while with HPLC separations only up to 100000 plates were reported [12]. CEC uses also much less mobile phase/solvent than standard HPLC column and the CEC instrumentation is much simpler [12].

\subsection{CEC column technology}

\section{Types of CEC columns}

Fabrication of CEC columns became recently an independent branch in the CEC field, but it is still the weakest segment of the technique. Currently, three types of stationary phases used for CEC can be distinguished: packed capillary, monolith and open tubular capillary [12, 17-19].

Packed capillary was the first type of column exploited in CEC as it was simply adopted from the HLPC technology. So far, it is the most commonly used type [20-25]. The first CEC results were obtained with old HPLC columns packed with particles containing silanols, and it was found out that most of the electroosmotic flow was originated from the particles rather than from the silica wall [26]. The resistance to flow effectively limits the particle diameter in HPLC column to $1.5-3 \mu \mathrm{m}$, and below this size the column requires pressure that is higher than most HPLC pumps can deliver. In contrast, CEC uses electroosmosis which does not cause resistance, and particles smaller than $1 \mu \mathrm{m}$ can be used. Most of the available particles are porous (pore diameter 10-30 nm), but better results were reported for the nonporous particles [12]. As in HPLC, the reverse phase packing is the most common in CEC. To provide the electroosmotic flow, these packings need to have charge carrying groups. If silanols are used as charge carriers, the weak acid strength decreases the electroosmotic flow as the $\mathrm{pH}$ drops below 4.5. Inability to operate below this $\mathrm{pH}$ is a serious impediment to converting methods from reverse phase HPLC to CEC [16].

The two biggest drawbacks of the packed CEC columns are (i) the packing procedure itself (pressurized, ultrasonic or electrokinetic) which is very time consuming and costly, and (ii) the frit formation in order to keep the packing in place. In an HPLC column, sintered metal plugs are placed in the end fitting, but in fused silica capillaries there is no end fitting. There are several protocols for forming frits, but in all cases it is an additional step in column fabrication. Moreover, the frits are believed to cause bubble formation and band broadening by distorted electroosmotic flow at their spot. 
The second group of CEC columns are continuous beds, also called monoliths [2740]. Compare with packed capillaries, they are much easier to prepare. The capillary is filled with a polymer "cocktail" using a simple syringe, sealed and exposed to the polymerization initiators. The polymerization takes place in-situ and a porous phase is formed inside the capillary. After few hours, the capillary is washed to remove the solvent/additives. The morphology of the monolith can vary over a wide range, mainly the pore size which can be between $0.1 \mu \mathrm{m}$ and $10 \mu \mathrm{m}$, but in each case the monolith is made up of a globular structure. The disadvantage of a monolith is the reproducibility of the morphologies from column to column [12].

The third type, the least frequently investigated and applied, is an open tubular capillary (OTC) [41-45]. This column is produced starting with a small diameter capillary by etching the surface with caustic reagents and adding a bonded stationary phase, mostly a reverse phase. A variety of morphologies can be produced in this way ranging from ripples to coral like rods. These columns have shown to have smaller plate heights due to the lack of band broadening effects associated with the packing materials and end-column frits [12, 42]. Using small diameter columns brings advantages like high concentration sensitivity and possibility to use high voltage without significant Joule heating $[12,44]$.

Each approach (packed, monolith, open tubular) offers advantages along with certain problems. Monoliths have the lowest cost and high flexibility, since they can be cut to length. Packed capillaries probably offer the highest efficiencies (plates/meter), but are also the most expensive to manufacture. Open tubular capillaries have rather low retention and low sample capacities $[12,18,19]$.

\section{Materials for CEC columns}

Many polymeric materials have found biomedical use due to their biocompatibility, easy fabrication into many forms, and possibility of chemical modification, especially on the surface. Also in the field of CE and CEC the polymers gained much interest over the last years, mainly due to the better than of silica durability and inertness.

Polymeric capillaries first entered the area of capillary electrophoresis. The high zeta-potential and fast EOF of the fused silica capillaries is not desirable for some analytes. One group are the biological samples, especially peptides and proteins. Problems arise from electrostatic interactions between the positively charge proteins and negatively charged silanol groups of silica, resulting in the adsorption which leads to the loss of efficiency, poor reproducibility of migration times, low protein recovery and decreased sensitivity [46-48]. The second group are molecules with very similar electrophoretic mobilities which cannot be separated due to the very fast EOF. In contract to fused silica, the zeta-potential, and therefore the EOF of the polymeric materials is much lower, less dependent on $\mathrm{pH}$ and addition of organic solvents [49]. This offers better flexibility of the separation conditions leading to higher resolution. Various polymeric capillaries were investigated in the CE mode for separation of both biomolecules and inorganic analytes: ethylene/vinylacetate (EVA) [50], nylon [50], poly(methyl methacrylate) (PMMA) [47, 50], poly(butylene terephthalate) (PBTP) [48, 50], poly(ether ether ketone) [46]. The biggest interest was, however, in 
polypropylene, used in both the untreated hydrophobic form [48, 51], as well as hydrophilized by modification with cellulose [52], sulphonic acid, quaternary amine functionalities [53], dextran [49] or PMMA [54].

In CEC the polymeric materials have been used as stationary phase from the early stage, but they were always associated with a silica capillary in all the three types of CEC columns. There are only few papers which report other column technologies than packed, monolith or open tubular with silica capillary.

Fujimotto [55] explored a PEEK capillary with inner wall treated with a dilute chlorosulphonic acid solution, which increased a column surface area. He applied this column as an open tubular capillary for the electrochromatographic separation of neutral compounds obtaining very good resolution. Jinno et al. in a series of papers investigated silica capillaries filled with various fibrous materials such as textile cellulose acetate fibers [56, 57] for separation of mixtures of neutral compounds like parabens and natural alkaloids (theobromine and caffeine) with improved resolution in comparison to the CE separation without this stationary phase, and $\mathrm{Kevlar}^{\circledR}$ (para-type aramid) and Zylon ${ }^{\circledR}$ (poly(p-phenylene-2,6benzobisoxazole) PBO) fibers [58] for successful separation of parabens, naphthalene analogues and alkylphenones.

In this chapter we report the application of membranes as stationary phases for the CEC columns, which is a completely new approach in the current CEC column technology. The fabrication of polymeric porous morphologies via phase inversion process is much less time-consuming and less expensive compare to the manufacturing of the packed capillaries, monoliths or open-tubular columns. Moreover, it offers diversity of polymers to choose from and the easiness to tailor the porous structure by altering the pore size, tortuosity, pore connectivity, as well as the dimensions, in case of a hollow fiber - the inner and outer diameter, and length.

Various techniques and materials are investigated and discussed in view of the CEC column requirements. Figure 4 presents the types of fibers produced and applied as stationary phase for the CEC column in this work. The main two categories are:

a) small-bore fibers that resemble open tubular capillaries

b) full fibers that resemble monolithic columns.

As the polymeric fiber has a porous structure, it has to be „sealed” from outside - in case of a CEC column the fluid should not permeate across the fiber wall like in a traditional membrane filtration, but along the fiber. The sealing is accomplished by enclosing the fiber either in (i) a silica capillary, or in (ii) a polypropylene (PP) capillary (see Figure 4).

Three different techniques to introduce charge into fibers are presented: two of them are described in preceding chapters: (i) depositing a charged polymer on the bore surface of a hollow fiber by dissolving it in the bore liquid, and (ii) dispersing charged particles in a matrix polymer (mixed matrix membrane). The third technique used, not mentioned previously, is (iii) blending of the main - membrane forming polymer with a charged polymer.

The produced CEC columns are characterized with various techniques regarding their morphology, surface charge and chemistry, and finally tested with the laboratory-built 
CEC unit for the separation of proteins and inorganic ions, to prove the concept of application membrane technology for fabrication of CEC columns.

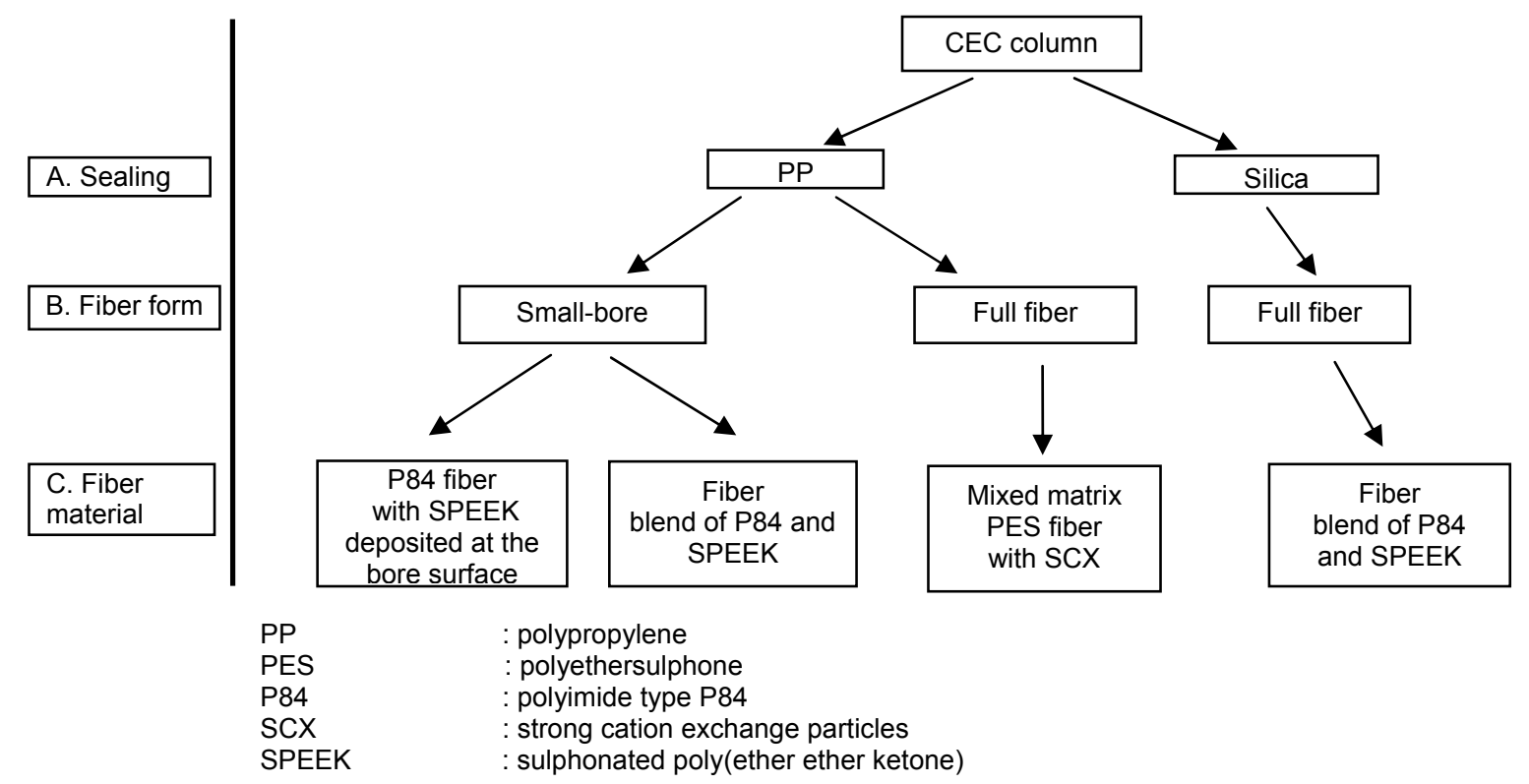

Figure 4 Scheme of the types of fabricated CEC columns 


\section{Experimental}

\subsection{Materials}

Polyimide, type P84 was purchased from HP Polymer GmbH (325 mesh, STD), poly(methyl methacrylate) (PMMA) MW 350,000 was obtained from Aldrich and poly(ether sulphone) (PES) Ultrason E6020P was supplied by BASF. Three types of poly(vinyl pyrrolidone): K15 (MW 10,000), K30 (MW 40,000), K90 (MW 36,000) were purchased from Fluka.

Table 1 Chemical structures of the polymers used for the fabrication of CEC columns

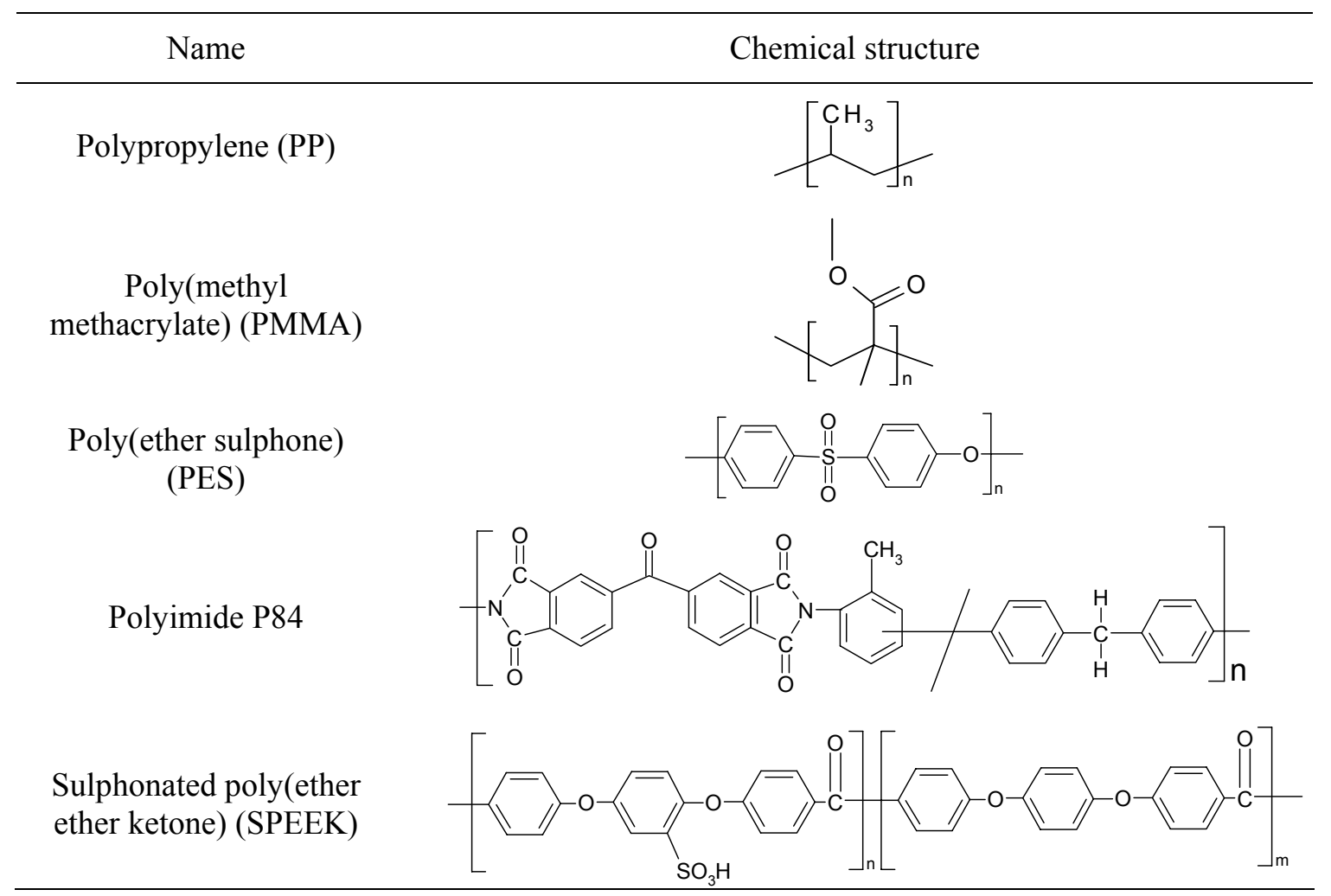

Poly(ether ether ketone) powder PEEK 450 PF was obtained from Victrex PLC. Polypropylene hollow fiber membranes ACCUREL with i.d. $\sim 580 \mu \mathrm{m}$, o.d $\sim 920 \mu \mathrm{m}$ and length of $50 \mathrm{~cm}$ were obtained from ENKA AG. The structures of the polymers used for fabrication of the CEC columns are presented in Table 1.

The strong cation exchange resins SCX Lewatit Monoplus112 WS with sulphonic acid functionalities (ion exchange capacity $1.75 \mathrm{eq} / \mathrm{L}$ ), and mean particle diameter $680 \mu \mathrm{m}$, were kindly supplied by Caldic Belgium. Glycerol, dimethylsulphoxide (DMSO), ethanol, all of analytical grade, and concentrated sulphuric acid (96-98\%, extra pure) were obtained from Merck. 1-methyl-pyrrolidone (NMP), extra pure, was purchased from Across Organics. Potassium chloride and nitric acid $0.1 \mathrm{~mol} / \mathrm{L}$, volumetric solutions, for the zeta-potential 
measurements were purchased from Fluka. Sodium hydroxide $0.1 \mathrm{~mol} / \mathrm{L}$ in ampoules (Titrisol) was obtained from Merck.

Buffers were obtained by dissolving the following chemicals in ultrapure water:

a) borate (for $\mathrm{pH} \sim 9.5$ ): sodium tetraborate decahydrate (ReagentPlus ${ }^{\circledR} \geq 99.5 \%$, SigmaAldrich)

b) acetate (for $\mathrm{pH} \sim 4.5$ ): acetic acid (glacial 100\%, anhydrous, Merck) and sodium acetate (anhydrous from Across Organics)

c) phosphate (for $\mathrm{pH} \sim 7.4$ ): monobasic sodium phosphate, monohydrate and dibasic sodium phosphate, anhydrous (both from Across Organics)

d) triethylammonium phosphate (TEAP): phosphoric acid, 99\% purris (Riedel-de Haën) and triethylamine (purris, Sigma-Aldrich).

Acetonitrile (LiChrosolv Merck), isocratic grade for liquid chromatography was used as the organic additive to the mobile phase.

For the separation, the following compounds were employed: trimethylphenylammonium bromide (Fluka), 4-aminoantypyrine (98\%, AcrosOrganics), benzyl alcohol (GR, Merck), phenol $(99 \%+$ for biochemistry, AcrosOrganics), benzoic acid (ACS reagent $\geq 99.5 \%$, Sigma Aldrich), vanilic acid (98.5\%, AcrosOrganics), thiourea (GR for analysis, Merck), bovine serum albumin (BSA), fraction $\mathrm{V}$ (Fluka). The structures of inorganic ions are presented in Table 2).

The mobile phase and the sample (mobile phase with the analytes) were filtered prior to use through a $0.45 \mu \mathrm{m}$ syringe filter Spartan 30/0.45 RC from Whatman ${ }^{\circledR}$.

\subsection{Fabrication of the fibrous CEC stationary phase}

\section{Mixed matrix PES full fiber with SCX particles (see also Chapter 4)}

The ion exchange particles Lewatit 112WS were milled and sieved through a $20 \mu \mathrm{m}$ sieve. The particle size distribution was measured using a Microtrax X-100 from Leeds \& Northru, after ultrasonification treatment with Branson Sonifier 450 to break down the formed agglomerates. The average diameter of the particles used for the mixed matrix membrane preparation was estimated as $7.9 \mu \mathrm{m}$. Poly(ether sulphone) and ion exchange particles were dried in the vacuum oven at $30^{\circ} \mathrm{C}$ for $24 \mathrm{~h}$. The polymer dope solution (composition given in Table 3) was stirred at room temperature for $48 \mathrm{~h}$, then the ion exchange particles were added. The solution was stirred for another $12 \mathrm{~h}$ and left for degassing for $24 \mathrm{~h}$. The particles loading was $60 \%$. The dope solution was pumped through a spinneret (without a needle) and, after short residence time in the air, immersed into the water coagulation bath. The take-up velocity was controlled by a pulling wheel, which enabled also stretching of the fiber. All prepared membranes were washed out for $48 \mathrm{~h}$ in water.

After spinning and coagulation, the fibers were rinsed with water at room temperature for 2 days to remove the solvent residues. All the fibers were stored in water with addition of boric acid $(0.5 \mathrm{~g} / \mathrm{L})$ to prevent formation of microorganisms. For the CEC experiments the fibers were dried at room temperature. 
Table 2 Analytes used for the evaluation and reproducibility study of the CE/CEC unit

\begin{tabular}{|c|c|c|c|c|c|}
\hline No. & Analyte & Regular name & $\begin{array}{l}\text { Molar } \\
\text { mass, } \\
\mathrm{g} / \mathrm{mol}\end{array}$ & Chemical structure & Charge \\
\hline 1 & $\begin{array}{l}\text { Trimethylphenyl } \\
\text { ammonium bromide }\end{array}$ & $\begin{array}{l}\text { Trimethylphenyl } \\
\text { ammonium } \\
\text { bromide }\end{array}$ & 216.12 & & Cation \\
\hline 2 & $\begin{array}{l}\text { 4-amino-2,3- } \\
\text { dimethyl-1-phenyl-3- } \\
\text { pyrazolin-5-one }\end{array}$ & 4-aminoantipyrine & 203.24 & & Cation \\
\hline 3 & Benzenemethanol & Benzyl alcohol & 108.14 & & Neutral \\
\hline 4 & Hydroxybenzene & $\begin{array}{c}\text { Phenol, carbolic } \\
\text { acid }\end{array}$ & 94.11 & & Neutral \\
\hline 5 & $\begin{array}{c}\text { Benzenecarboxylic } \\
\text { acid }\end{array}$ & Benzoic acid & 122.12 & & Anion \\
\hline 6 & Thiourea & Thiourea & 76.12 & & Neutral \\
\hline 7 & $\begin{array}{c}\text { 4-hydroxy-3- } \\
\text { methoxybenzoic acid }\end{array}$ & Vanilic acid & 168.15 & & Anion \\
\hline
\end{tabular}

Small-bore P84 fiber with SPEEK deposited at the bore surface (see also Chapter 2)

The polyimide P84 was used as received after drying in the vacuum oven at $30^{\circ} \mathrm{C}$. PEEK was sulphonated in our laboratory according to the procedure described elsewhere 
[59]. The sulphonation degree (SD) of sulphonated PEEK was estimated to be $\sim 65 \%$ from the ion exchange capacity measurements (IEC) corresponding to the IEC of around $1.88 \mathrm{meq} / \mathrm{g}$ $[59,60]$. The polymer solution with additives (composition given in Table 3 ) was stirred at room temperature for at least $48 \mathrm{~h}$; next it was filtrated through a metal filter with a $25 \mu \mathrm{m}$ and left for degassing for $24 \mathrm{~h}$. SPEEK was dissolved in a mixture of NMP and water and left for degassing for $24 \mathrm{~h}$ before it was used as a bore liquid in the spinning process.

The dope solution along with the bore liquid were simultaneously pumped through a double orifice spinneret and, after short residence time in the air, immersed into the water coagulation bath. The take-up velocity was controlled by a pulling wheel, which enabled also stretching of the fiber. All prepared membranes were washed out for $48 \mathrm{~h}$ in water.

\section{Small-bore fiber - blend of P84 and SPEEK}

This fiber was fabricated in the same way as the small-bore fiber with SPEEK deposited at the bore side, with the difference that SPEEK was not added to the bore liquid, but to the dope solution forming a blend with P84 (Table 3).

Table 3 Compositions of the spinning solutions of the fabricated membranes

\begin{tabular}{lccr}
\hline \multicolumn{3}{c}{ Dope solution } & Bore liquid \\
\hline \multicolumn{3}{c}{ Small-bore P84/SPEEK (3:1) blend fibers } \\
\hline P84 & $16.3 \%$ & $90 \%$ \\
SPEEK & $5.4 \%$ & NMP & $10 \%$ \\
Glycerol & $7.5 \%$ & Water & $3 \%$ \\
NMP & $70.8 \%$ & $87 \%$ \\
\hline \multicolumn{4}{c}{ Small-bore P84 fibers coated with SPEEK } \\
\hline P84 & $2.0 \%$ & SPEEK & $10 \%$ \\
Glycerol & $12.0 \%$ & NMP & \\
NMP & $66.0 \%$ & Water \\
\hline \multicolumn{5}{c}{} \\
\hline PES & Mixed matrix full fibers \\
NMP & $12.6 \%$ & \\
Water & $73.0 \%$ & \\
PVP K 15 & $4.2 \%$ & \\
PVP K 30 & $3.4 \%$ & \\
PVP K 90 & $3.4 \%$ & \\
\hline \multicolumn{5}{c}{} \\
\hline P84 & $3.4 \%$ & \\
Thin full P84/SPEEK & $19.5 \%$ & \\
Glycerol & $6.5 \%$ & \\
NMP & $9.0 \%$ & \\
\hline \multicolumn{5}{c}{} \\
\hline
\end{tabular}

\section{Full fiber - blend of P84 and SPEEK}

This fiber was fabricated in the same way as the small-bore fiber - blend of P84 and SPEEK (Table 3) with the difference that a spinneret without a needle was used (like in case of mixed matrix fiber - no bore liquid). 


\subsection{Sealing of the fibrous stationary phase}

Two types of CEC columns were prepared in regard to the sealing method: enclosed in a fused silica capillary or in a polypropylene capillary.

Column in a polypropylene capillary

A small-bore polymeric porous fiber with outer diameter 520-560 $\mu \mathrm{m}$ and length of around $30 \mathrm{~cm}$ was inserted into a hollow polypropylene fiber (i.d. $\sim 580 \mu \mathrm{m}$ ) of length $50 \mathrm{~cm}$. Thus so prepared fiber-in-fiber was hanged in the oven at $190^{\circ} \mathrm{C}$ for $10-15 \mathrm{~s}$ until the PP fiber melted (melting temperature of the ACCUREL PP $\sim 186^{\circ} \mathrm{C}$ ) sealing well around the smallbore fiber as a solid and transparent coating, and thus allowing the UV detection in the empty part of the column (Figure 5).

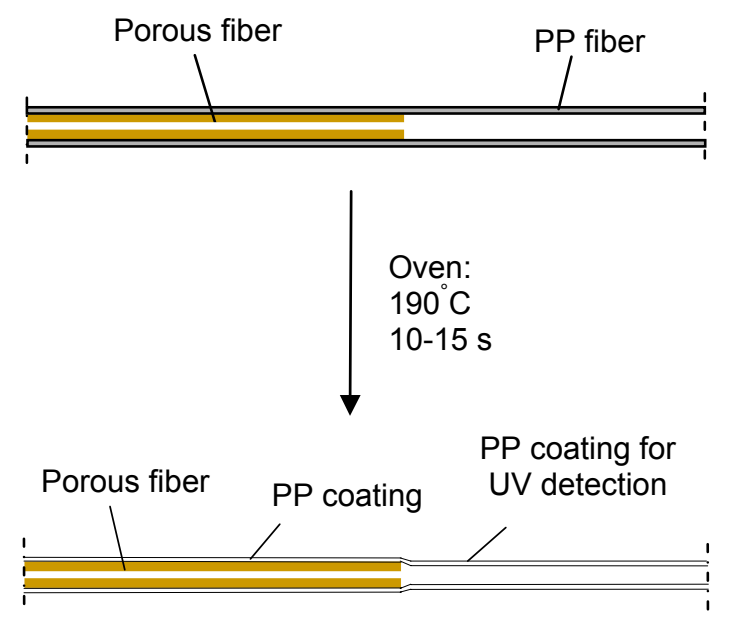

Figure 5 Schematic of the CEC column consisted of the small-bore polymeric porous fiber inside melted polypropylene fiber

\section{Column in a fused silica capillary}

Very thin, smaller than $180 \mu \mathrm{m}$ o.d., full fiber with length of around $30 \mathrm{~cm}$ was inserted into a fused silica capillary (i.d. $150 \mu \mathrm{m}$ or $200 \mu \mathrm{m}$ ) of length $\sim 47 \mathrm{~cm}$, leaving around $17 \mathrm{~cm}$ of empty capillary (from the UV detection window to the outlet end) (Figure 6).

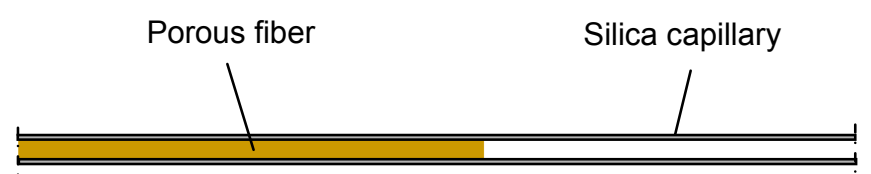

Figure 6 Schematic of the CEC column consisted of the polymeric porous full fiber inside a silica capillary 


\subsection{Characterizaction of the CEC column}

\section{SEM characterization}

The geometry and morphology of the fibers were studied using scanning electron microscope (SEM) Jeol JSM-5600 LV. Samples were prepared by freeze fracturing in liquid nitrogen and subsequently by covering with a thin layer of gold using a Balzer Union SCD 040 sputtering device.

\section{Zeta-potential measurement}

The zeta-potential of polymeric fibers and the fused silica capillary was determined with a SurPAAS Electrokinetic Analyzer (Anton Paar GmbH, Austria) based on the measurement of streaming potential or streaming current. For this determination, modules of 1-3 fibers/capillaries were used, with length of around $4 \mathrm{~cm}$ and space between the fibers/capillaries filled with glue at the entire length of the module. $1 \mathrm{mM} \mathrm{KCl}$ was used as the electrolyte circulating through the measuring cell containing the membrane module. The $\mathrm{pH}$ was adjusted by automatic titration with $0.1 \mathrm{M}$ solution of nitric acid and $0.1 \mathrm{M}$ solution of sodium hydroxide in water. The electrolyte was flowing through the lumen of the fiber/capillary and the zeta-potential of the lumen surface was determined in the $\mathrm{pH}$ range 311 (assuming that the electrolyte flows only in one direction, along the fiber, without entering the porous structure). The electrolyte conductivity, temperature and $\mathrm{pH}$ value were measured simultaneously.

The zeta-potential was determined taking into account the correction for the surface conductivity of the membrane [61]. When measuring the streaming potential of samples with significant surface conductivity (like in case of a polyelectrolyte), the overall specific electrical conductivity is comprised of the conductivity of the bulk electrolyte and the surface conductivity of the membrane. In such case the zeta-potential is measured based on the streaming potential with a $100 \mathrm{M} \mathrm{KCl}$ solution. Due to the high electrical conductivity of such concentrated solution, the surface conductivity can be neglected and zeta-potential can be determined with known resistance of the measuring cell with $1 \mathrm{mM}$ and $100 \mathrm{mM} \mathrm{KCl}$. Alternatively, the zeta-potential can be determined by measurement of the streaming current which is insensitive to the surface conductivity measurements. Here, the measurements were done with the streaming current method.

\section{UV absorption properties of the PP capillary}

The UV absorption of melted PP capillary and fused silica capillary (without the polyimide coating) were measured with the on-column $240 \mu \mathrm{m}$ path flow cell from Thermo Separation Products combined with the model Prostar 340 UV-Vis Detector from Varian (part of the laboratory-built CE/CEC unit). The absorbance of capillaries filled with air in the wavelength range of $190-290 \mathrm{~nm}$ is reported. 


\section{Diameter variation of the PP capillary}

The dimensions of the PP capillaries were measured with SEM combined with Semaphore software. The average i.d. was determined at five spots of a capillary (four capillaries were tested). The relative standard deviation (RSD, \%) was calculated for PP capillaries and compared with the silica capillary.

\section{CEC separation}

The CEC separations were performed on a laboratory-built instrument (Figure 7). Detailed description of the design and evaluation of this instrument can be found in the Appendix of this chapter.

The conditioning of the CEC column was based on the standard CEC procedure, but it was altered and adapted separately to each type of fabricated column, based on trial and error practice. The column was filled with the mobile phase and flushed for at least $2 \mathrm{~h}$. Subsequently, the column was exposed to voltage in few sessions, at least 10 min each, in the following order: $1 \mathrm{kV}, 4 \mathrm{kV}, 8 \mathrm{kV}, 12 \mathrm{kV}$ etc. until stable current was obtained. The injection was performed by applying voltage or pressure to the inlet vial. The voltage (and optionally equal pressures at both ends of the column) was applied for the separation to take place. The UV absorbance, voltage, current and pressure were continuously monitored during the analysis.

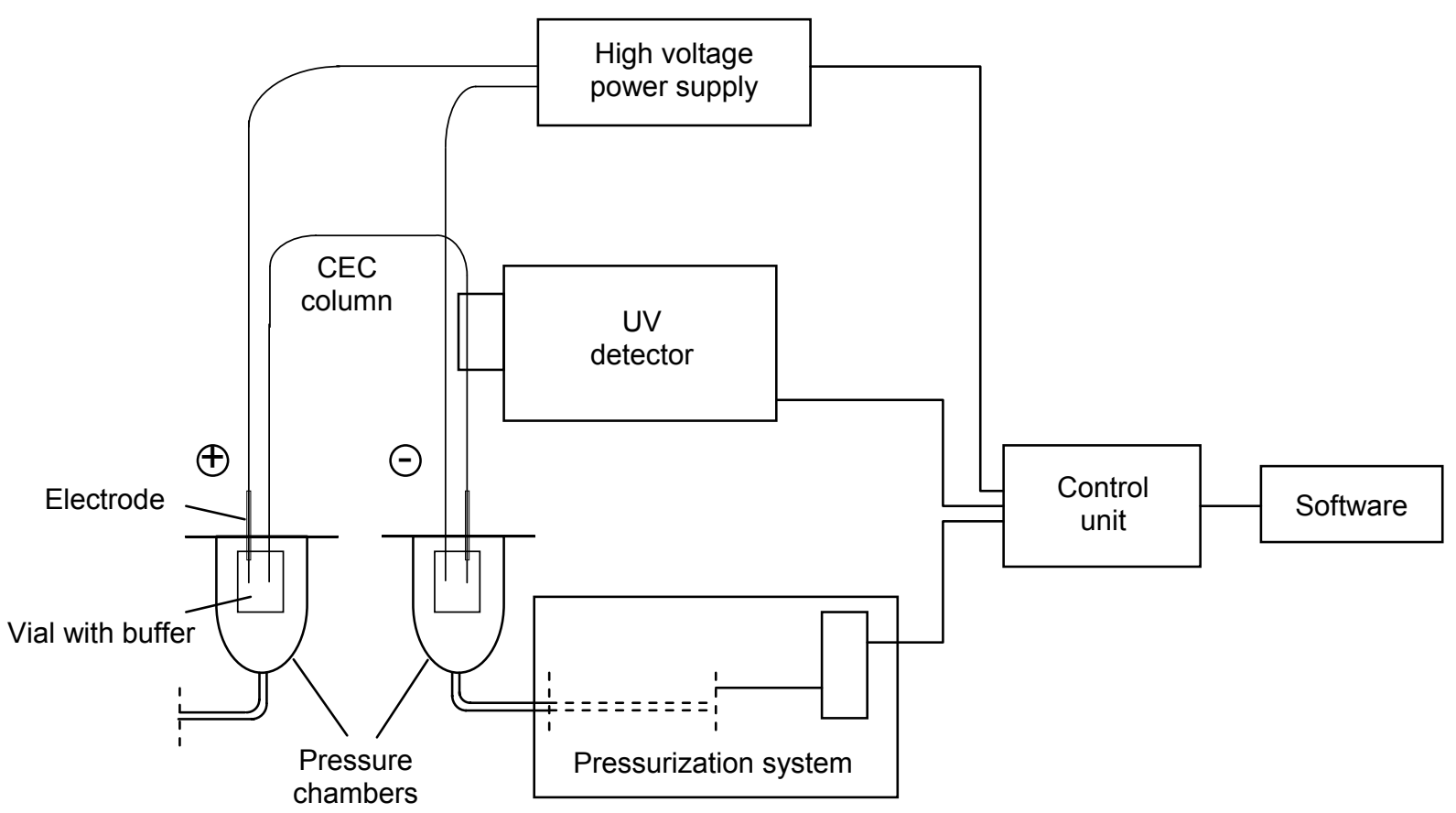

Figure 7 Schematic of the CEC set-up 


\section{Results and discussion}

\subsection{Zeta-potential}

Zeta-potential is a direct assessment of the surface charge of materials. The higher the negative value, the fastest the electroosmotic flow can be expected towards the cathode. Zeta-potential is strictly dependent on $\mathrm{pH}$. Negatively charged materials have negative zetapotential at $\mathrm{pH}$ higher than their isoelectric point and positive zeta-potential at low $\mathrm{pH}$ (weakly acidic or non-ionic) [61]. Choosing the operational $\mathrm{pH}$ for the CEC separation one should consider that at $\mathrm{pH}$ around the isoelectric point of the CE capillary or CEC stationary phase, the EOF is very low and the separation might take long time, while below the isoelectric point the EOF is reversed - towards the anode. Strongly acidic materials, e.g. containing the sulphonic acid groups $-\mathrm{SO}_{3} \mathrm{H}$, are ionized over a wide $\mathrm{pH}$ range, therefore

(a)

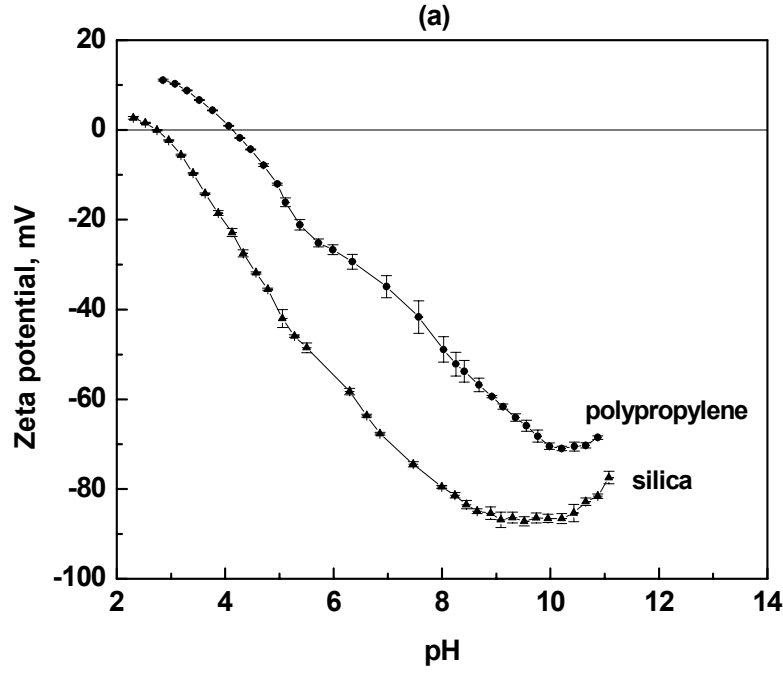

(b)

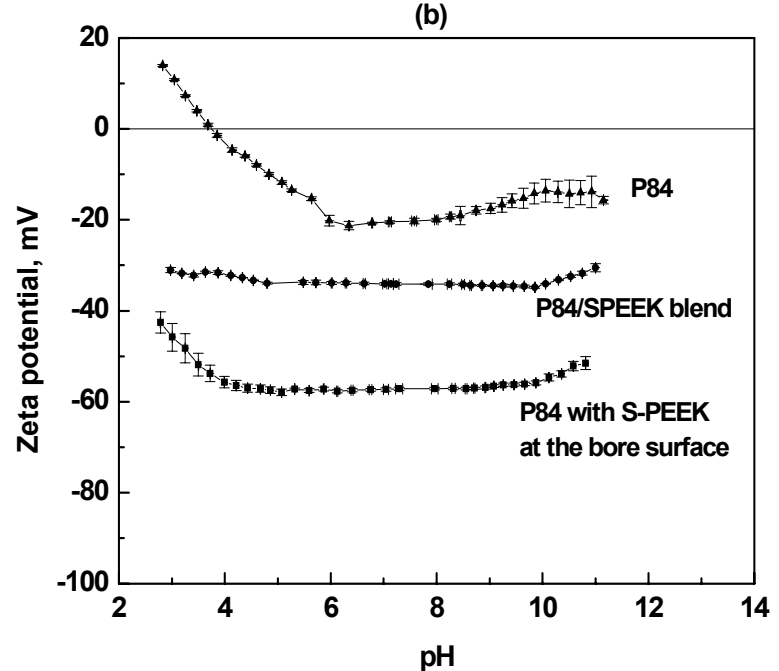

(c)

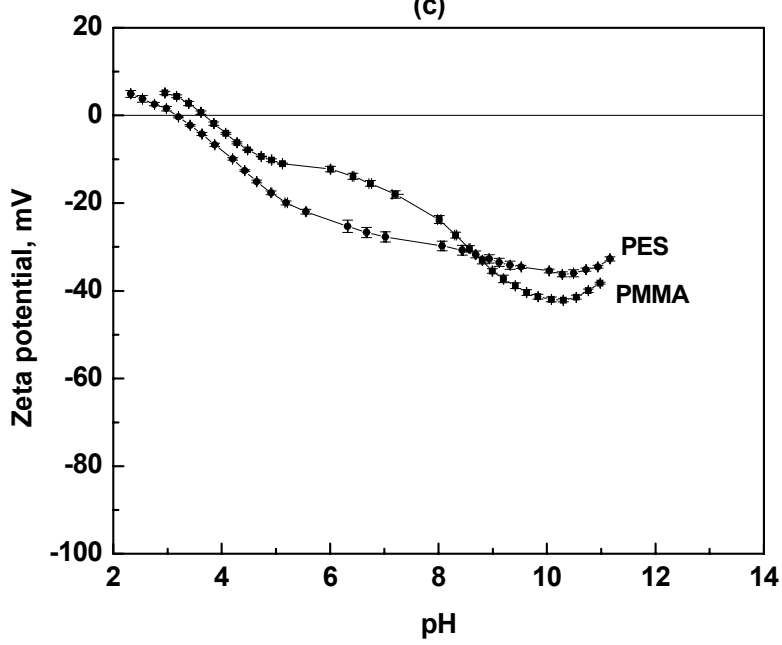

Figure 8 Zeta-potential of the materials used for fabrication of the CEC columns (measured in form of capillaries/hollow fibers) 
giving a significant contribution to the EOF even at low $\mathrm{pH}$. Operation with such materials is much more flexible, since they depend less on $\mathrm{pH}$ having stable EOF.

Figure 8 shows the zeta-potential measured at the bore surface of capillaries and fibers investigated for fabrication of CEC columns. Zeta-potential of P84, PMMA and PES materials (Figure $8 \mathrm{~b}$ and $8 \mathrm{c}$ ) is very similar, with the isoelectric point between $\mathrm{pH} 3.2$ and 3.8 and negative zeta-potential up to $-42 \mathrm{mV}$. Silica (Figure $8 \mathrm{a}$ ) has the most negative zetapotential (up to $-87 \mathrm{mV}$, result of the dissociation of silanol groups), but it varies significantly with $\mathrm{pH}$. The high negative zeta-potential of polypropylene is believed to come from the adsorption of hydroxyl and e.g. phosphate ions from the buffer solution [53]. Only the surface of P84/SPEEK blend fiber and P84 fiber coated with SPEEK (SPEEK dissolved in the bore liquid) (Figure 8b) does not have isoelectric point and is ionized over wide $\mathrm{pH}$ range. Application of SPEEK for the fabrication of membranes for CEC columns offers stable, $\mathrm{pH}$ independent EOF, which is particularly important for the separation of biomolecules like amino acids, peptides and proteins which are zwitterions and also change their net charge with the environmental $\mathrm{pH}$.

\subsection{Morphology and separation performance of CEC columns}

Before discussing the performance of CEC columns fabricated by incorporation of membranes as a stationary phase inside the polypropylene capillary, the performance of the polypropylene capillary alone is evaluated.

PP capillary

An important consideration with a polymeric column is its diameter variation. Because of the softness of the polypropylene capillary, the internal diameter might vary within one capillary, as well as between the capillaries. To investigate that, and also to confirm the accuracy of the newly developed melting procedure, the RSD of the internal diameter was estimated and it is shown in Table 3. The RSD of the PP capillary diameter, $4.5 \%$, is not quite as good as that of fused silica reported to be $1.0 \%[47,48]$ or $1.32 \%$ for polypropylene capillary [48], but it is close to the RSD of the PMMA capillary diameter 5.2\% [47].

Table 3 Variation of the internal diameter of the PP capillary

\begin{tabular}{clcc}
\hline Capillary No. & $\mathrm{n}$ & $\begin{array}{c}\text { Average i.d., } \\
\mu \mathrm{m}\end{array}$ & $\begin{array}{c}\text { RSD, } \\
\%\end{array}$ \\
\hline \multicolumn{4}{c}{ Within one capillary } \\
2 & 5 & 356.8 & 3.2 \\
3 & 5 & 325.3 & 5.8 \\
4 & 5 & 358.0 & 4.5 \\
\hline \multicolumn{5}{c}{ Total } & 5 & 340.0 & 7.6 \\
\hline \multicolumn{4}{l}{ Between capillaries } \\
\hline
\end{tabular}



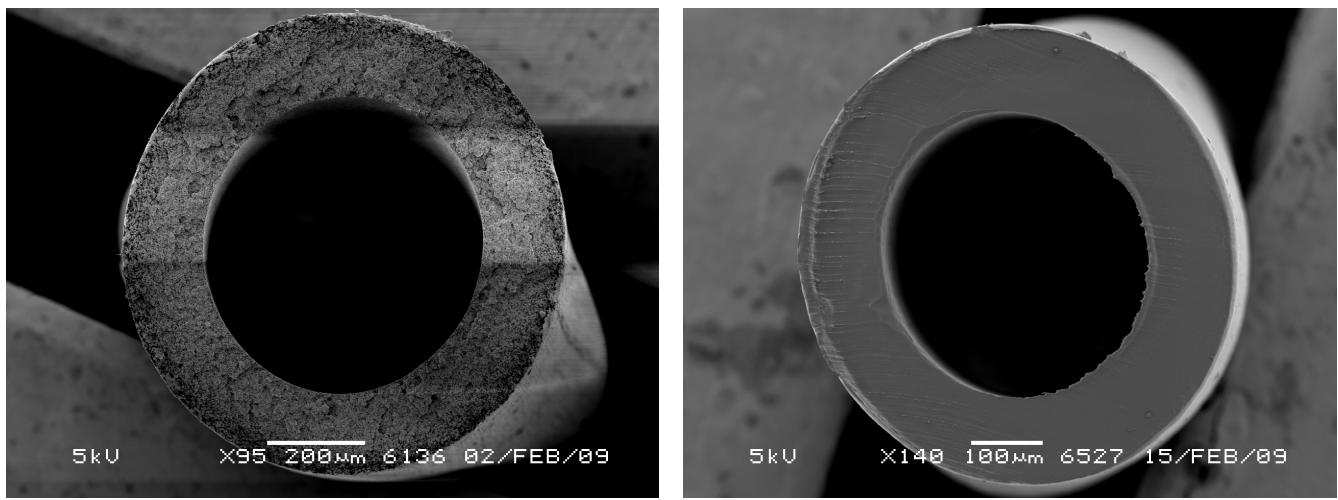

Figure 9 SEM pictures of the PP hollow fiber membrane (left) and the same fiber after melting (right)

The PP hollow fiber undergoes certain shrinkage during melting. Figure 9 compares the SEM pictures of as received porous hollow fiber membrane and that of melted, solid transparent PP capillary. The average shrinkage of the melted fiber was around $40 \%$.

Most polymeric materials absorb UV light to some extend, depending on their structure. The hydrophilic polymers contain carbonyl, ester or amide functional groups which absorb UV light at the same wavelengths as proteins and peptides. The polypropylene is however a hydrophobic material and has low light absorption in the UV range, being transparent for the visible light. The fabricated PP capillaries have a wall thickness of 110$115 \mu \mathrm{m}$, the same as fused silica capillary used in this work, and the magnitude of their absorbance can be compared (Figure 10). The absorbance of PP capillary below $250 \mathrm{~nm}$ is higher than that of silica, but it is still reasonable and allows reliable on-column detection as also proven by others $[47,48,51,63,64]$. The UV absorbance of PP capillary is assumed to be caused by residues of the additives used in the production process [51].

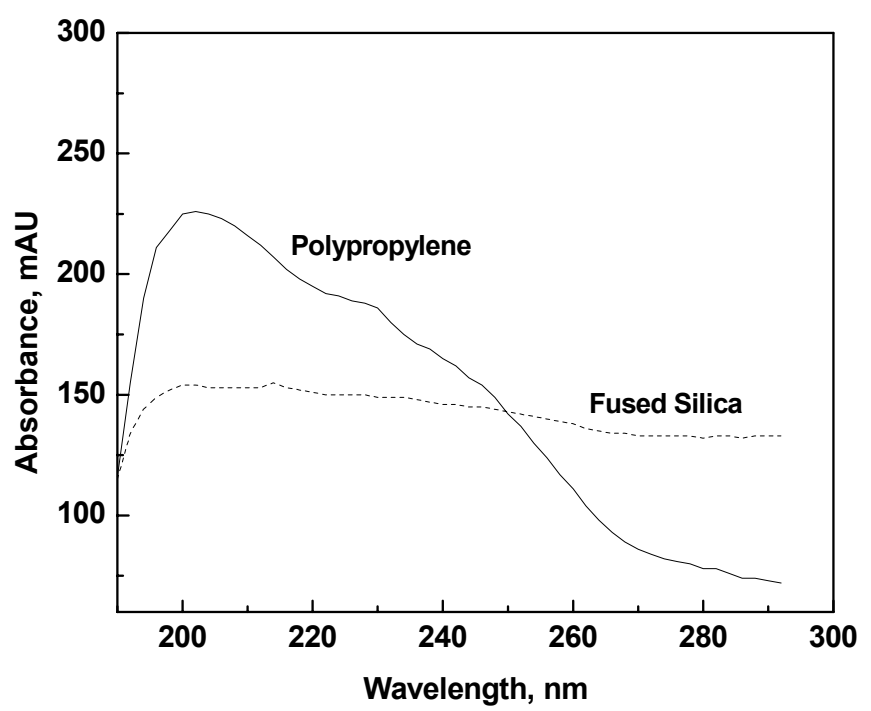

Figure $10 \mathrm{UV}$ absorption spectra of a polypropylene capillary and a fused silica capillary; wall thicknesses: PP capillary $111.4 \mu \mathrm{m}$, fused silica capillary $113.3 \mu \mathrm{m}$ 
Figure 11 shows the separation of neutral molecule benzyl alcohol, obtained with the PP capillary. The migration velocity of the electroosmotic flow estimated with benzyl alcohol has an average value of $13.4 \cdot 10^{-4} \mathrm{~cm}^{2} /(\mathrm{V} \cdot \mathrm{s})$ at $\mathrm{pH} 9.5$. This is in good agreement (order of magnitude) with values found for silica $\left(8.0 \cdot 10^{-4} \mathrm{~cm}^{2} /(\mathrm{V} \cdot \mathrm{s})\right)$ and values reported for polypropylene at the same $\mathrm{pH}$ by others: typically between $4.0-4.5 \cdot 10^{-4} \mathrm{~cm}^{2} /(\mathrm{V} \cdot \mathrm{s})[47,53,63]$ having in mind the differences in measuring conditions, eg. the ionic strentgh. The EOF of PP was measured here with low buffer concentration of $5 \mathrm{mM}$ (concentrations $20 \mathrm{mM}$ or higher were used for measurements which results are reported above) and it is well known that the EOF increases with decreasing ionic strength of the buffer [11]. The low buffer concentration for the CE analysis with PP capillary was used because of the high currents generated with the PP capillary, which has bigger internal diameter compare to the silica capillary. Big volume of the buffer produces more Joule heat and the dissipation of this heat is more difficult due to the worse surface/volume ratio and worse thermal conductivity of the PP, $3.3 \cdot 10^{-4}$ $\mathrm{cal} /\left(\mathrm{s} \cdot \mathrm{cm} \cdot{ }^{\circ} \mathrm{C}\right)$ compare to fused silica $33.3 \cdot 10^{-4} \mathrm{cal} /\left(\mathrm{s} \cdot \mathrm{cm} \cdot{ }^{\circ} \mathrm{C}\right)[48]$. These heat dissipation problems may also explain the significant peak broadening. Perhaps there is a radial

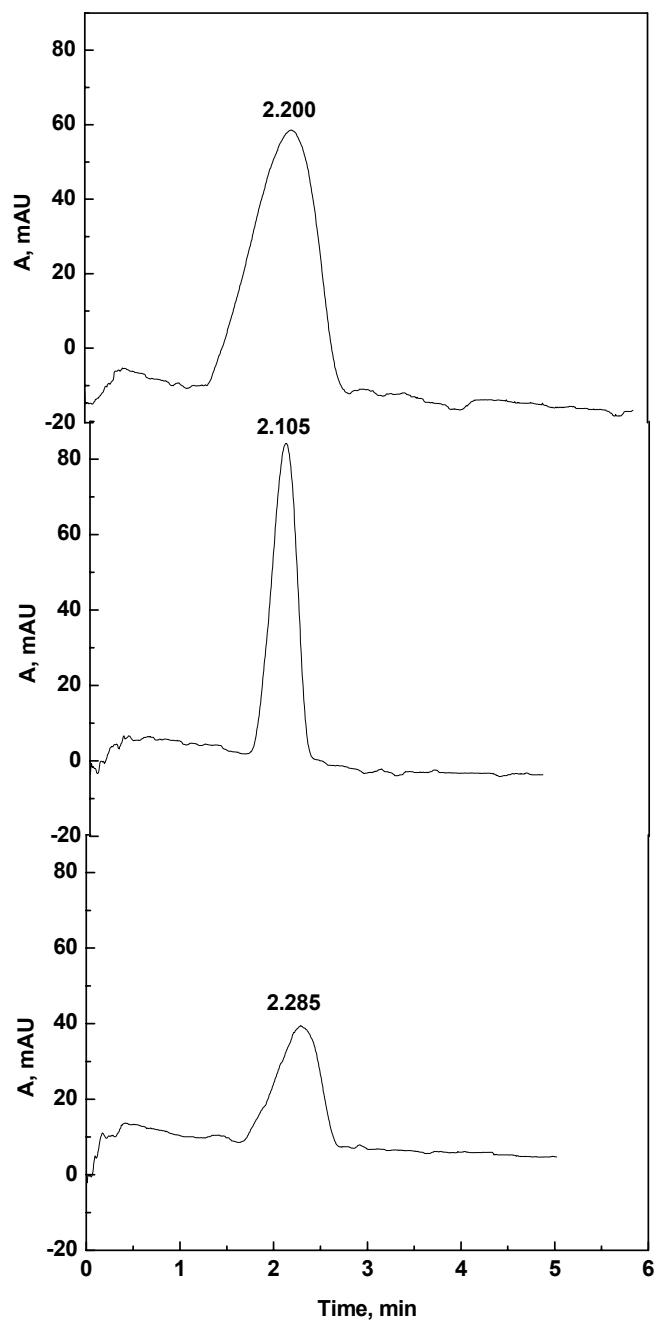

Figure 11 Three consecutive runs of benzyl alcohol with PP capillary; $L=31.5 / 47.5 \mathrm{~cm}$, separation: 8 $\mathrm{kV}(168 \mathrm{~V} / \mathrm{cm}) 5$ bar, UV detection at $214 \mathrm{~nm}$; mobile phase: $5 \mathrm{mM}$ borate $\mathrm{pH}=9.5$; injection: $5 \mathrm{kV} 2 \mathrm{~s}$ 
temperature gradient inside the capillary, which creates a viscosity gradient that affects the flow profile. As a result, the solute zone migrates slower in the regions of high viscosity (capillary wall) than in those of lower viscosity (capillary center). The formation of the temperature gradient depends strongly on the capillary dimensions, the buffer conductivity, and the cooling of the capillary. The RSD of the migration times of the three consecutive runs is $4.1 \%$.

Figure 12 shows three consecutive runs of BSA separation with a PP capillary. The peaks are broad and the migration times differ significantly between the runs. Moreover, the baseline becomes less constant with each run. Here, besides the Joule heat generation another problem arises, namely the adsorption of protein on the PP surface. Polypropylene is hydrophobic which leads to the strong interactions with biomolecules, and eventually to their adsorption. The noisy baseline might be due to the partial washing out of the BSA adsorbed during the previous runs.

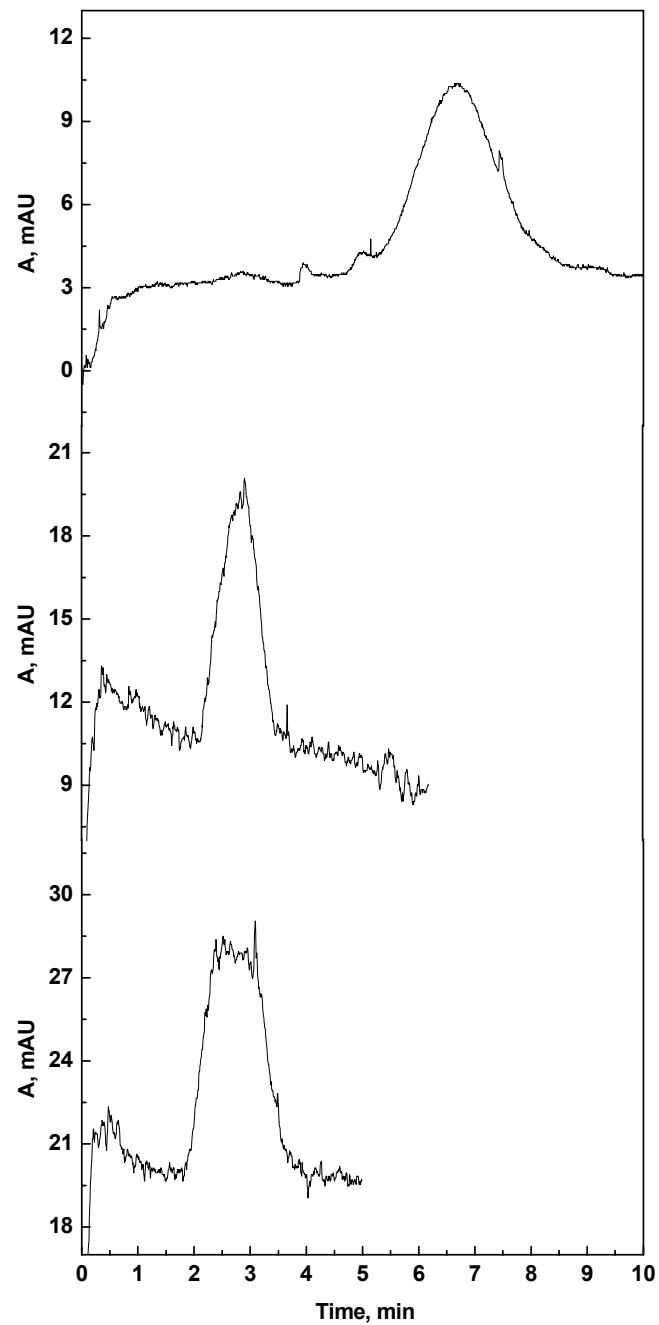

Figure 12 Three consecutive runs of BSA with PP capillary; L=31.5/47.5 cm, separation: $10 \mathrm{kV}(210$ $\mathrm{V} / \mathrm{cm}) 7$ bar, UV detection at $278 \mathrm{~nm}$; mobile phase: $5 \mathrm{mM}$ borate $\mathrm{pH}=9.5$; injection: $3 \mathrm{kV}$ $2 \mathrm{~s}$ 
The following modifications of the hydrophobic PP surface either by dynamic coating or with chemically bonded layers in order to hydrophilize the PP for the separation of peptides and proteins were reported: with acrylamide [48], cellulose [52], sulphonic acid and quaternary amine groups [53], dextran [49], PMMA [47] [54]. This seems to be a good solution when capillary electrophoresis is performed, but in this work, the PP capillary is used only to seal the outer surface of the membrane (the stationary phase) and as a window for UV detection, and there is no large surface area of PP to be in contact with the sample zone. The temperature problems are, unfortunately, not possible to solve with the investigated system. An improvement could be obtained by fabrication of thinner fibers which could be inserted in thinner PP capillaries.

Small-bore P84 fiber with SPEEK deposited at the bore surface and small-bore fiber - blend of P84 and SPEEK (fibers enclosed in PP capillary)

The concept of small-bore fiber aims to construct a CEC column that resembles an open-tubular column. Two types of small-bore fibers were fabricated. The first one was produced from blend of two polymers: polyimide P84 as the base - mechanically strong polymer and SPEEK, the polymer bringing charge and generating the electroosmotic flow. In fact, initially full fibers (no bore) were fabricated from the P84/SPEEK blend to resemble the structure of the monolithic columns. Those fibers were found to be impermeable and subsequently the small-bore fibers were produced. Figure 13 shows the morphology of the small-bore fibers. The difficulty was to fabricate a bore smaller than $30 \mu \mathrm{m}$ in diameter which is a typical dimension for the open tubular columns. The fiber was spun using the smallest available spinneret with dimensions i.d. $0.13 \mu \mathrm{m}$ and o.d. $0.5 \mu \mathrm{m}$. As the flow rate of the bore
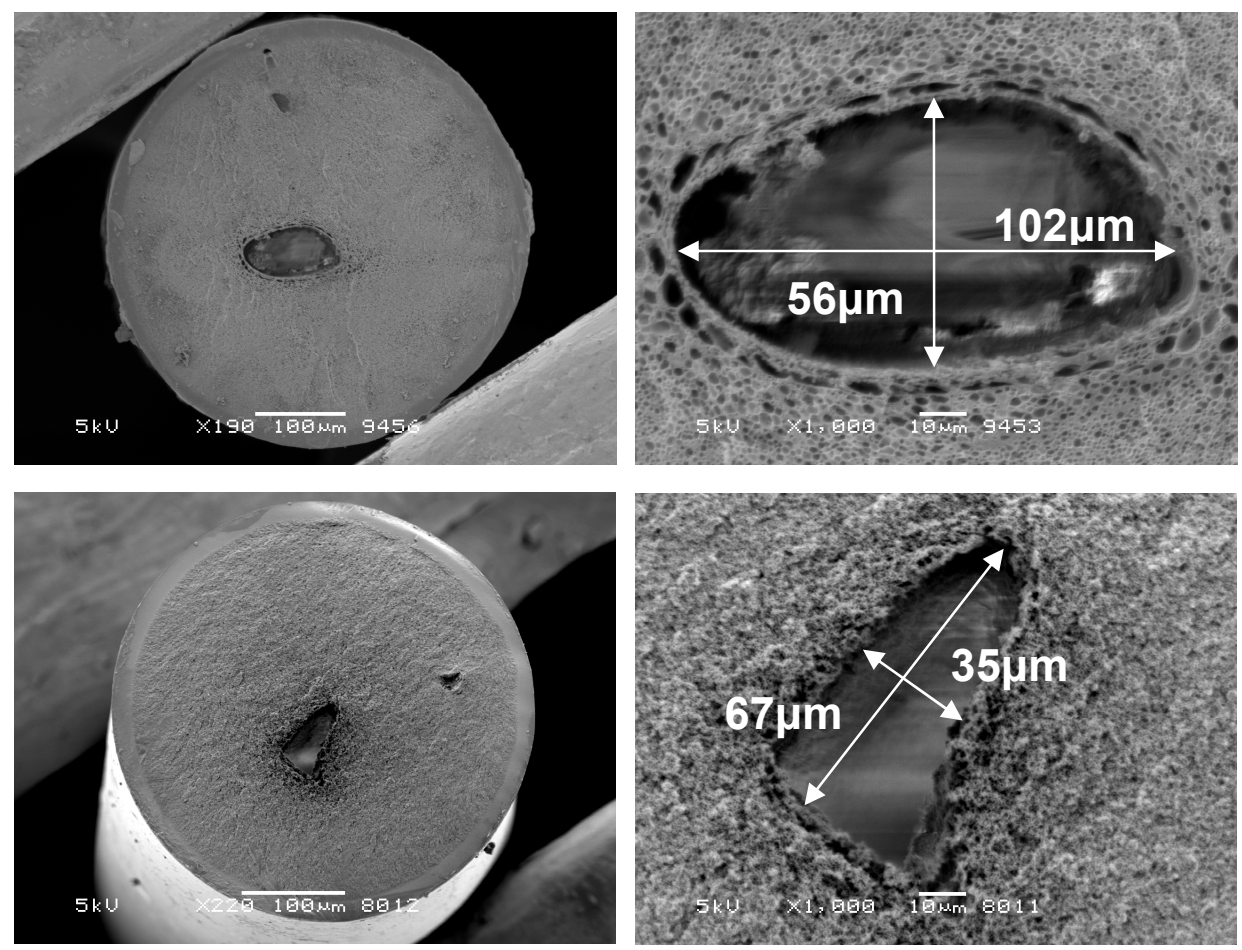

Figure 13 SEM pictures of the small-bore fibers: blend of P84 and SPEEK 
liquid was decreased to create a smaller bore, the fiber lost its cylindrical shape. Bore liquid consisted of $90 \%$ NMP and $10 \%$ water was used to create an open porous surface around the bore and increase the contact surface area.

Figure 14 shows the analysis of a neutral compound thiourea, used very often as a marker of the electroosmotic flow, performed at $\mathrm{pH} 4.0$ with the silica capillary and with the P84/SPEEK fiber enclosed in PP capillary. As expected, at this $\mathrm{pH}$ the EOF is faster with the P84/SPEEK fiber, since the zeta-potential of that fiber is higher at this $\mathrm{pH}$ compared to silica. The peak obtained with the fiber is quite narrow with slight tailing. The results were, however, of very poor reproducibility, both run-to-run for the same fiber (under the same conditions) and fiber-to-fiber. Similar results - unexpectedly high efficiency, but very low reproducibility were reported by others when using cation exchange stationary phase for CEC [64]. The mechanism producing the spectacular results is not understood yet. One of the possible explanations of the irreproducibility can be that the sulphonated materials are very hydrophilic and prone to swelling. The progressive swelling is responsible for creating dead volumes, which might lead to the irreproducibility.

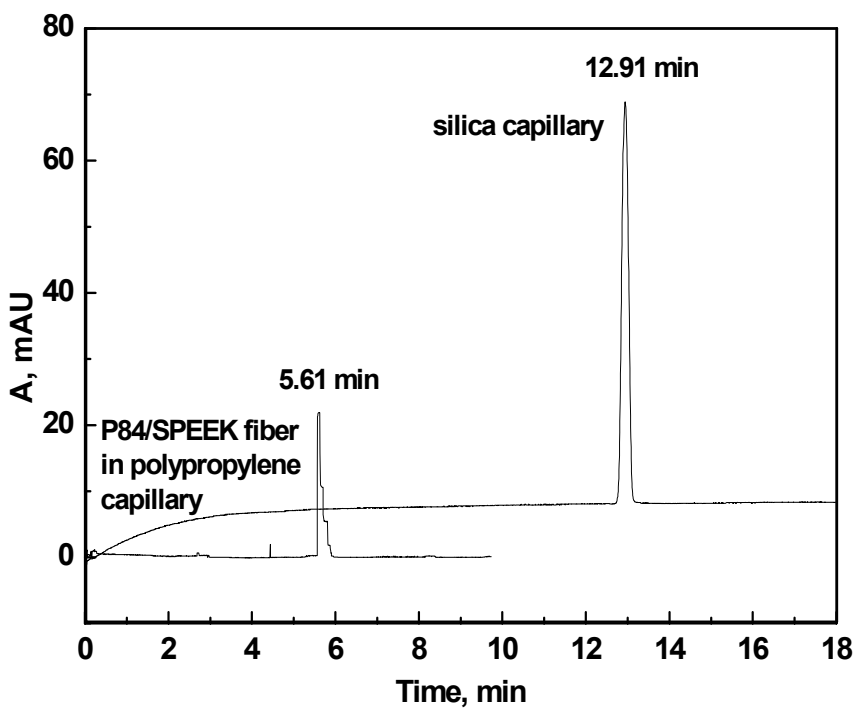

Figure 14 Separation of thiourea with silica capillary i.d. $75 \mu \mathrm{m}$ and polypropylene capillary packed with small-bore fiber i.d. $90 \mu \mathrm{m}$ P84/SPEEK blend; L=37/58 cm; separation: $10 \mathrm{kV}$ $(172 \mathrm{~V} / \mathrm{cm}), \mathrm{UV}$ detection at $250 \mathrm{~nm}$; mobile phase: $10 \mathrm{mM}$ acetate $\mathrm{pH}=4.0$; injection: 10 $\mathrm{kV} 10 \mathrm{~s}$

When a mixture of 6 analytes (trimethylphenyl ammonium bromide, 4aminoantypyrine, benzyl alcohol, phenol, benzoic acid, vanilic acid) was injected into the CEC column made of P84/SPEEK fiber (Figure 15), the separation was obtained only between anions, neutrals and cations, but a total separation was not achieved. The poor resolution and broadness of the peaks can be attributed to a large diameter of the bore. Big volume of the sample flows in the center of the bore without interacting with the porous stationary phase. Most probably this leads to formation of a zone that flows at different velocity that sample zone at the side where it can interact with the membrane. When fibers 

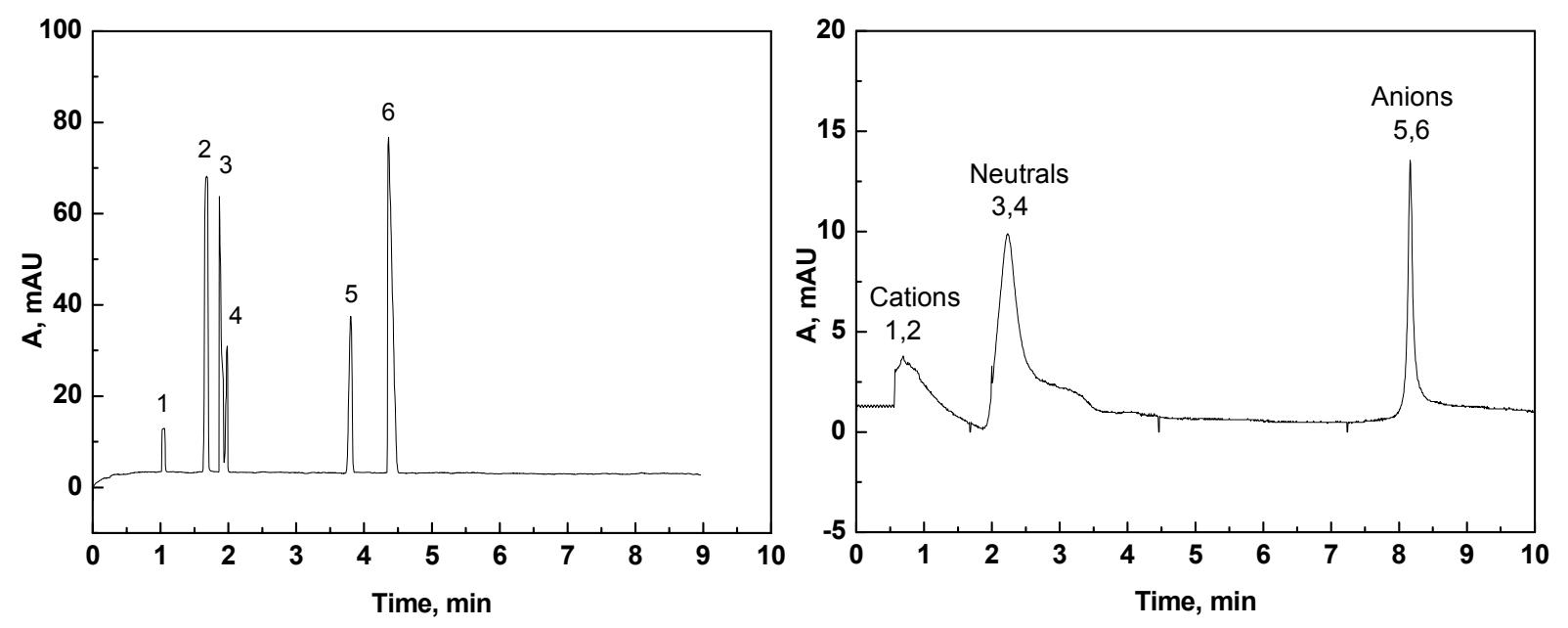

Figure 15 Separation of 6 compounds: trimethylphenylammonium bromide (1), 4-aminoantypyrine (2), benzyl alcohol (3), phenol (4), benzoic acid (5), vanilic acid (6) with silica capillary i.d. $75 \mu \mathrm{m}$ (left) and polypropylene capillary packed with small-bore fiber i.d. $90 \mu \mathrm{m}$ P84/SPEEK blend (right); Conditions: Left: L=32.5/48 cm; separation: $17 \mathrm{kV}(350 \mathrm{~V} / \mathrm{cm})$, UV detection at $214 \mathrm{~nm}$; mobile phase: $33 \mathrm{mM}$ borate $\mathrm{pH}=9.5$; injection: $10 \mathrm{kV} 10 \mathrm{~s}$; Right: $\mathrm{L}=30.0 / 50 \mathrm{~cm}$; separation: $5 \mathrm{kV}(100 \mathrm{~V} / \mathrm{cm})$, UV detection at $214 \mathrm{~nm}$; mobile phase: $4 \mathrm{mM}$ borate $\mathrm{pH}=9.5$; injection: $5 \mathrm{kV} 5 \mathrm{~s}$

with smaller bore were used (like the fiber shown in Figure 13 with a triangular shape bore), no flow through the fiber was observed, most probably due to fiber swelling.

The second type of the small-bore fibers was produced from a pure P84 dope solution and SPEEK was incorporated into the membrane by dissolving it in the bore liquid. The polyelectrolyte is believed to be physically bound at the bore surface to the P84, the membrane forming polymer. Most likely, the polyelectrolyte is securely anchored in the inner layer of the membrane by interlocking and entanglements between the chains of P84 and SPEEK (see also Chapter 2). Incorporation of SPEEK only as a thin layer rather than into the
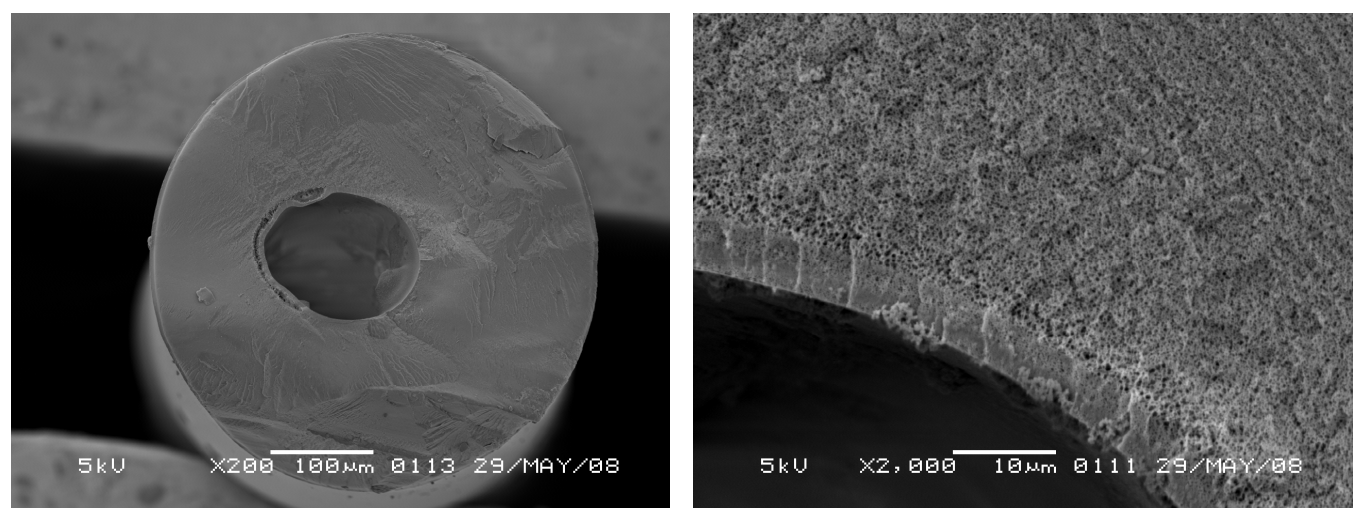

Figure 16 SEM pictures of the small-bore fiber: P84 with SPEEK at the bore surface

entire fiber may limit the swelling. Figure 16 shows the morphology of such a P84/SPEEK fiber produced by dissolving SPEEK in the bore liquid. The SEM/EDX analysis (SEM combined with Energy Dispersive X-ray Spectroscopy) of the inner layer (the bore surface) 
did not reveal presence of SPEEK. The zeta-potential measurements, however, prove the presence of SPEEK (Figure 8) - the zeta-potential of the P84 fiber with SPEEK at the bore surface is much higher than for pure P84 membrane. The SPEEK layer seems to be too thin to be detected (the sensitivity of the SEM/EDX technique is not sufficient).

The performance, mainly the reproducibility of the P84 fibers with SPEEK at the bore surface was slightly better than of the fibers made of P84/SPEEK blend. After each injection, response as a peak of the analyte was present on the electropherogram, which was not always a case for the P84/SPEEK blend fiber. The reproducibility of the migration time and peak shape, however, was poor. Figure 17 shows two consecutive runs of the BSA. The peaks are very broad and their area becomes smaller in time being a sign of protein remaining

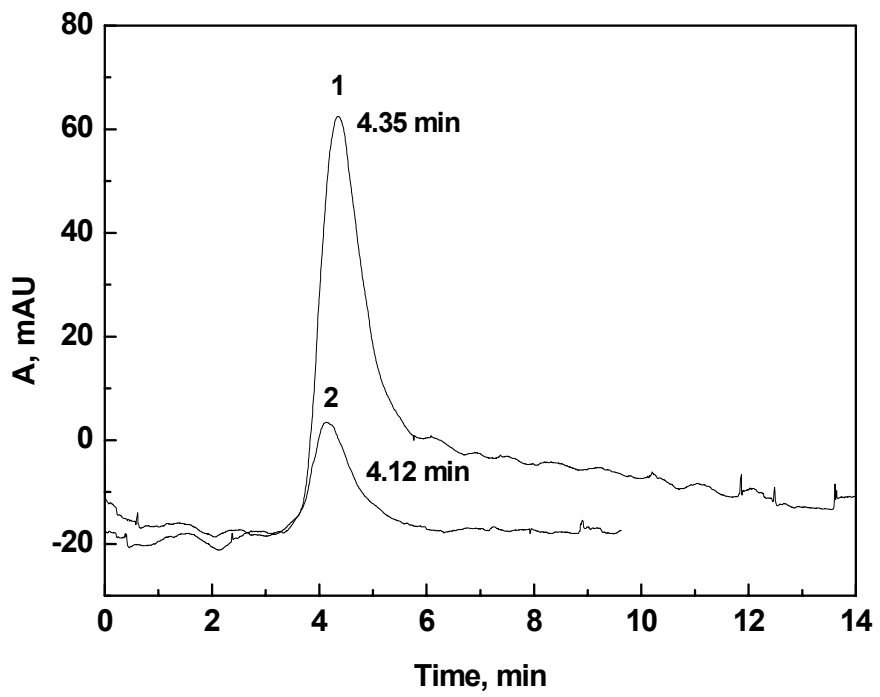

Figure 17 Two consecutive injections of BSA; P84 coated with SPEEK inside PP capillary; L=31/48 $\mathrm{cm}$; separation: $10 \mathrm{kV}(208 \mathrm{~V} / \mathrm{cm}), 5$ bar; UV detection at $278 \mathrm{~nm}$; mobile phase: $20 \mathrm{mM}$ TEAP $/ 60 \%$ acetonitrile $\mathrm{pH}=4.0$; injection: 2 bar $3 \mathrm{~s}$

inside the column. This is most probably due to the adsorption as the analysis was done at $\mathrm{pH}$ 4.0, while the protein is positively charged (isoelectric point of BSA is 4.8) and the fiber surface carries negative charges. The other reason might be swelling of the SPEEK layer and of a lesser extent swelling of the pure P84.

Further optimization in order to reduce swelling was done by post-spinning crosslinking. The fibers were placed for $24 \mathrm{~h}$ in a $10 \%(\mathrm{w} / \mathrm{w})$ ethylenediamine (EDA) solution in methanol. The crosslinking takes place between the carbonyl groups of the imide ring of the P84 polymer and the amine groups of EDA forming an amide group [65-68]. The crosslinking changes unfortunately also the chemistry of the porous morphology and produces a completely new complex structure. As the amine groups are positively charged, the charge net value and charge distribution on the bore surface are altered (see Chapter 3). In fact, the analysis was done with two types of sample injection: to the anode and to the cathode end of the column, but neither cathodic, nor anodic electroosmotic flow was noticed. 
Mixed matrix PES full fiber with SCX particles (fiber enclosed in PP capillary)

Neither the full fibers, nor the small-bore columns fulfill completely the requirements of the suitable column morphology. The addition of particles and production of
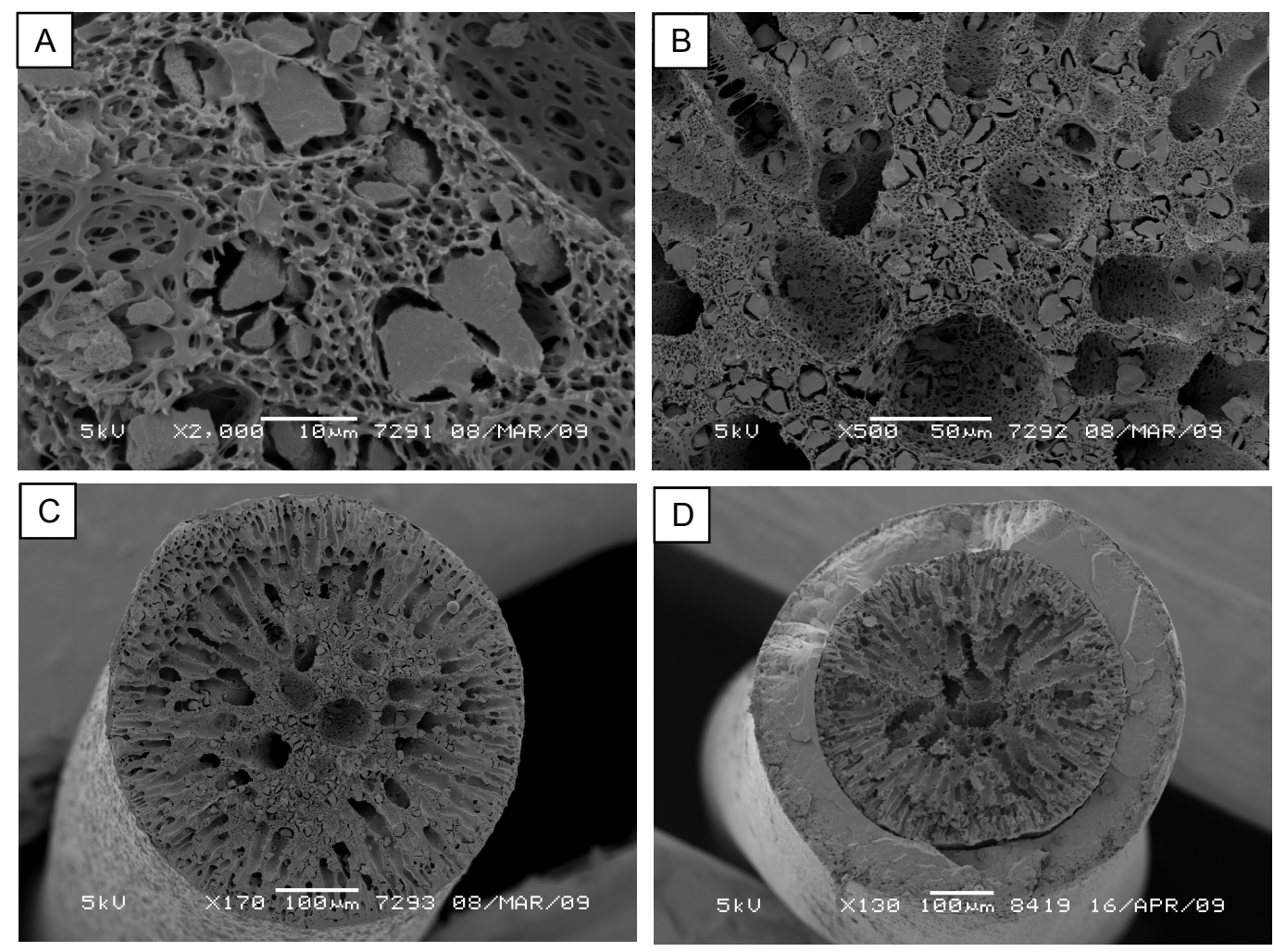

Figure 18 SEM pictures of the mixed matrix full fiber membranes: PES with SCX particles; (A,B) magnification of the mixed matrix structure, (C) cross-section of the fiber, (D) crosssection of the fiber enclosed in the PP capillary

mixed matrix membrane aimed to open the membrane structure and create a porous matrix with incorporated negatively charged particles (Figure 18). Although the SEM pictures show the presence of inter-polymer-particle voids, filling up and flushing the fiber with a mobile phase took up to $15 \mathrm{~h}$ at pressure of 20 bar even for short $10-15 \mathrm{~cm}$ columns.

Figure 19 shows a separation of neutral thiourea with a $13.5 \mathrm{~cm}$ long column (13.5 $\mathrm{cm}$ of the mixed matrix column to the detector). Even for such a short column the migration time of thiourea is very long with the $\mu_{\text {eof }}=0.44 \cdot 10^{-4} \mathrm{~cm}^{2} /(\mathrm{V} \cdot \mathrm{s})$, and severe peak fronting and tailing are present. It seems that the interactions of analytes with particles are significantly different than the interactions of analytes with polymer matrix, resulting in a very long sample zone. The particles incorporated to generate electroosmotic flow, in fact, do not create high EOF. In order to improve the performance of the mixed matrix membrane as a CEC column, smaller spherical particles should be used to create a uniform porous structure without big voids. To generate faster EOF the particles loading should be increased, too. 


\section{Full fiber - blend of P84 and SPEEK (fiber enclosed in silica capillary)}

Figure 20 shows the SEM pictures of the thin P84/SPEEK blend fiber before placing it in a silica capillary. The fiber inserted into the capillary was kept in place without a frit. Attaching the fiber to the capillary was necessary only at the beginning of flushing, and after swelling, the fiber filled up the capillary completely not being able to move anymore. Problems with

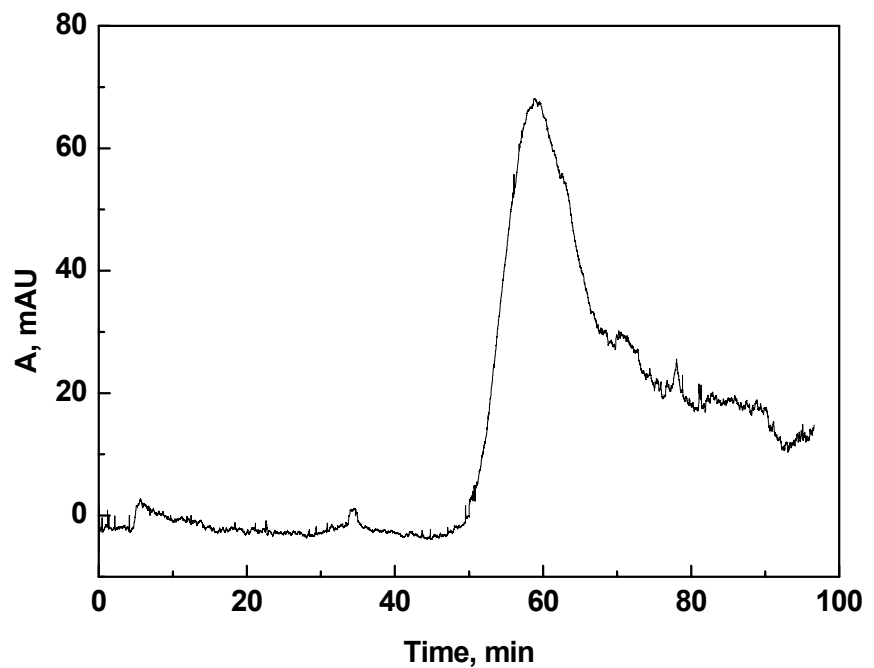

Figure 19 Separation of thiourea with PP capillary packed with mixed matrix membrane; L=13.5/46 $\mathrm{cm}$; separation: $4 \mathrm{kV}(87 \mathrm{~V} / \mathrm{cm}), 5$ bar; UV detection at $214 \mathrm{~nm}$; mobile phase: $5 \mathrm{mM}$ phosphate $\mathrm{pH}=6.8$; injection: $4 \mathrm{kV} 30 \mathrm{~s}$

current (breaking down or rising to the maximum) were experienced with these CEC columns. In cases were a separation was possible to perfrom, the run of a neutral EOF marker showed no influence of the fiber material, as the EOF was of the same order of magnitude as
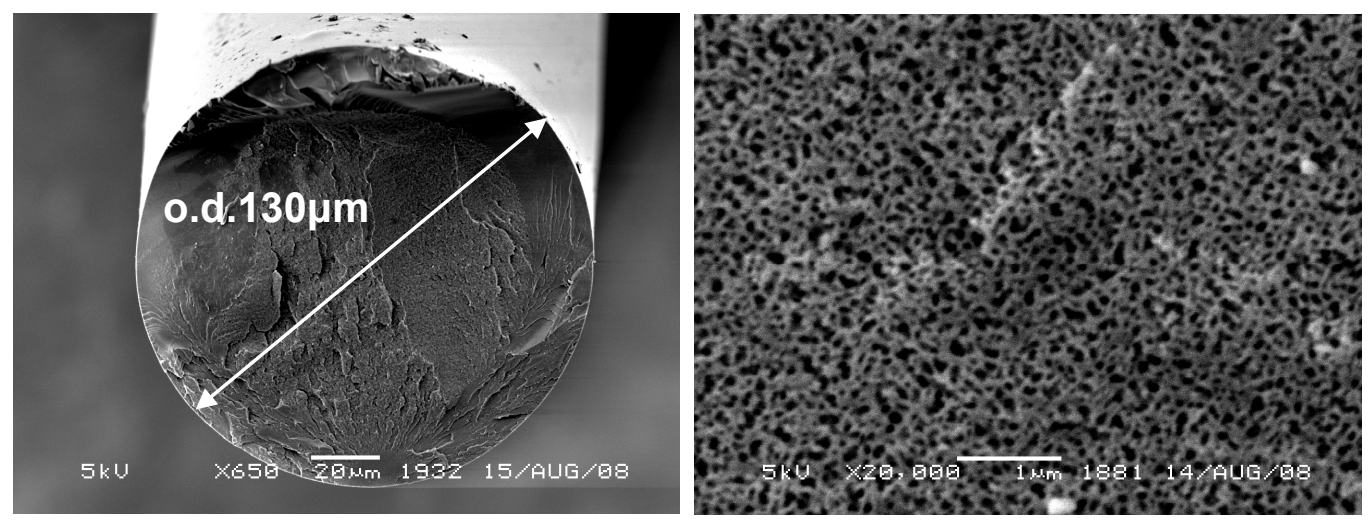

Figure 20 SEM pictures of the thin full fibers made of P84/SPEEK blend

for silica capillary. It was also not possible to separate a group of neutral compounds from each other as it is common for the silica capillary in the CE mode. It seems that the ratio of the surface area of P84/SPEEK fiber available for the interactions to the surface area of silica 
is too low and the mobile phase with analytes flows rather around the fiber without entering the porous structure since this path gives less resistance. It was not technically possible to insert more fibers into one silica capillary. Using capillaries with i.d. larger than $200 \mu \mathrm{m}$ created overheating which led even to the evaporation of mobile phase inside the capillary and drying it off.

\section{Conclusions}

Membrane technology offers advantages over the traditional fabrication techniques for CEC columns. Most of all, it is possible to fabricate meters of fibers within few hours in contrast to the current methods where hours or even days are required to prepare one single CEC column. Not of a less importance are also the costs of the production which are much lower when the membrane technology is applied. There are many polymers that can be processed into porous structures, moreover, they can be easily blended to form new materials with different chemical and physical properties or chemically modified after the spinning process.

The proof of principle is shown - inorganic compounds and large proteins like BSA pass through the porous membrane structures under application of an electrical field and are detected on-line as peaks on the electropherogram. The membrane morphologies require, however, further optimization, since the reproducibility, efficiency and selectivity are inferior compared to the current CEC columns. The optimization should be aimed at fabrication of more open structures with uniform porosity, smaller outer and inner (in case of small-bore fibers) diameter to reduce the Joule heat, which will result in more reproducible separation with narrower peaks. Other techniques should be investigated to seal the outer surface of the fiber and allow the on-line detection. 


\section{References}

[1] V. Pretorius, B.J. Hopkins, J.D. Schieke, Electro-osmosis: A new concept for high-speed liquid chromatography, Journal of Chromatography A, 99 (1974) 23.

[2] J.W. Jorgenson, K.D. Lukacs, High-resolution separations based on electrophoresis and electroosmosis, Journal of Chromatography, 218 (1981) 209.

[3] K.D. Bartle, P. Myers, Theory of capillary electrochromatography, Journal of Chromatography A, 916 (2001) 3-23.

[4] A.S. Rathore, C. Horvath, Capillary electrochromatography: theories on electroosmotic flow in porous media, Journal of Chromatography A, 781 (1997) 185.

[5] M.M. Robson, M.G. Cikalo, P. Myers, M.R. Euerby, K.D. Bartle, Capillary Electrochromatography: A Review, Journal of Microcolumn Separations, 9 (1997) 357372.

[6] M.G. Cikalo, K.D. Bartle, M.M. Robson, P. Myers, M.R. Euerby, Capillary electrochromatography, Analyst, 123 (1998).

[7] M.M. Dittmann, G.P. Rozing, Capillary electrochromatography -- a high-efficiency microseparation technique, Journal of Chromatography A, 744 (1996) 63.

[8] M.M. Dittmann, G.P. Rozinger, Capillary electrochromatography: investigations of the influence of mobile phase and stationary phase properties on electroosmotic velocity, retention, and selectivity, Journal of Microcolumn Separations, 9 (1997) 399.

[9] K.D. Altria, N.W. Smith, C.H. Turnbull, A review of the current-status of capillary electrochromatography technology and applications, Chromatographia, 46 (1997) 664674.

[10] K.D. Bartle, R.A. Carney, A. Cavazza, M.G. Cikalo, P. Myers, M.M. Robson, S.C.P. Roulin, K. Sealey, Capillary electrochromatography on silica columns: factors influencing performance, Journal of Chromatography A, 892 (2000) 279.

[11] F.F. P. Bocek, L. Krivankova, Capillary Zone Electrophoresis John Wiley \& Son Ltd, 1993.

[12] I.S. Krull, R.L. Stevenson, K. Mistry, M.e. Swartz, Capillary electrochromatography and Pressurized Flow Capillary Electrochromatography. An Introduction, HNB Publishing, New York, 2000.

[13] F. Steiner, B. Scherer, Instrumentation for capillary electrochromatography, Journal of Chromatography A, 887 (2000) 55-83.

[14] N. Smith, Introduction to Capillary Electrophoresis, Beckman, U.S.A., 1994.

[15] G. Kemp, Capillary electrophoresis: a versatile family of analytical techniques, Biotechnology and Applied Biochemistry, 27 (1998) (1998) 9-17.

[16] N. Smith, Capillary ElectroChromatography, Beckman Coulter, U.K., 1998.

[17] M. Pursch, L.C. Sander, Stationary phases for capillary electrochromatography, Journal of Chromatography A, 887 (2000) 313-326.

[18] L.A. Colon, G. Burgos, T.D. Maloney, J.M. Cintron, R.L. Rodriguez, Recent progress in capillary electrochromatography, Electrophoresis, 21 (2000) 3965-3993. 
[19] Q. Tang, M.L. Lee, Column technology for capillary electrochromatography, TrAC Trends in Analytical Chemistry, 19 648-663.

[20] J.H. Knox, I.H. Grant, Electrochromatography in packed tubes using 1.5 to 50mikrom silica gels and ODS bonded silica gels, Chromatographia, 32 (1991) 317.

[21] T.M. Zimina, R.M. Smith, P. Myers, Comparison of ODS-modified silica gels as stationary phases for electrochromatography in packed capillaries, Journal of Chromatography A, 758 (1997) 191.

[22] L.A. Colon, T.D. Maloney, A.M. Fermier, Packing columns for capillary electrochromatography, Journal of Chromatography A, 887 (2000) 43.

[23] R. Boughtflower, T. Underwood, C. Paterson, Capillary electrochromatography - Some important considerations in the preparation of packed capillaries and the choice of mobile phase buffers, Chromatographia, 40 (1995) 329-335.

[24] C. Yan, D. Schaufelberger, F. Erni, Electrochromatography and micro high-performance liquid chromatography with $320 \quad[\mathrm{mu}] \mathrm{m}$ I.D. packed columns, Journal of Chromatography A, 670 (1994) 15.

[25] H. Yamamoto, J. Baumann, F. Erni, Electrokinetic reversed-phase chromatography with packed capillaries, Journal of Chromatography A, 593 (1992) 313.

[26] G. Choudhary, C. Horvath, Dynamics of capillary electrochromatography experimental study on the electrosmotic flow and conductance in open and packed capillaries, Journal of Chromatography A, 781 (1997) 161.

[27] C. Ericson, J.-L. Liao, K. Nakazato, S. Hjerten, Preparation of continuous beds for electrochromatography and reversed-phase liquid chromatography of low-molecularmass compounds, Journal of Chromatography A, 767 (1997) 33.

[28] E.C. Peters, M. Petro, F. Svec, J.M.J. Frechet, Molded Rigid Polymer Monoliths as Separation Media for Capillary Electrochromatography. 1. Fine Control of Porous Properties and Surface Chemistry, Anal. Chem., 70 (1998) 2288-2295.

[29] I. Gusev, X. Huang, C. Horvath, Capillary columns with in situ formed porous monolithic packing for micro high-performance liquid chromatography and capillary electrochromatography, Journal of Chromatography A, 855 (1999) 273.

[30] F. Svec, E.C. Peters, D. Sýkora, C.Y. Jean, M.J. Fréchet, Monolithic Stationary Phases for Capillary Electrochromatography Based on Synthetic Polymers: Designs and Applications, Journal of High Resolution Chromatography, 23 (2000) 3-18.

[31] E.F. Hilder, F. Svec, J.M.J. Frechet, Polymeric monolithic stationary phases for capillary eletrochromatography, ELECTROPHORESIS, 23 (2002) 3934-3953.

[32] H. Zou, X. Huang, M. Ye, Q. Luo, Monolithic stationary phases for liquid chromatography and capillary electrochromatography, Journal of Chromatography A, 954 (2002) 5-32.

[33] M. Bedair, Z. El Rassi, Recent advances in polymeric monolithic stationary phases for electrochromatography in capillaries and chips, ELECTROPHORESIS, 25 (2004) 41104119.

[34] S. Frantisek, Recent developments in the field of monolithic stationary phases for capillary electrochromatography, Journal of Separation Science, 28 (2005) 729-745. 
[35] K. Stulik, V. Pacakova, J. Suchankova, P. Coufal, Monolithic organic polymeric columns for capillary liquid chromatography and electrochromatography, Journal of Chromatography B: Analytical Technologies in the Biomedical and Life Sciences, 841 (2006) 79-87.

[36] D. Schaller, E.F. Hilder, P.R. Haddad, Monolithic stationary phases for fast ion chromatography and capillary electrochromatography of inorganic ions, Journal of Separation Science, 29 (2006) 1705-1719.

[37] S. Eeltink, F. Svec, Recent advances in the control of morphology and surface chemistry of porous polymer-based monolithic stationary phases and their application in CEC, ELECTROPHORESIS, 28 (2007) 137-147.

[38] S. Zhang, X. Huang, J. Zhang, C. Horvath, Capillary electrochromatography of proteins and peptides with a cationic acrylic monolith, Journal of Chromatography A, 887 (2000) 465.

[39] R. Wu, H. Zou, M. Ye, Z. Lei, J. Ni, Capillary Electrochromatography for Separation of Peptides Driven with Electrophoretic Mobility on Monolithic Column, Anal. Chem., 73 (2001) 4918-4923.

[40] T. Jiang, J. Jiskra, H.A. Claessens, C.A. Cramers, Preparation and characterization of monolithic polymer columns for capillary electrochromatography, Journal of Chromatography A, 923 (2001) 215-227.

[41] X. Huang, J. Zhang, C. HorvA $\tilde{A}_{i}$ th, Capillary electrochromatography of proteins and peptides with porous-layer open-tubular columns, Journal of Chromatography A, 858 (1999) 91-101.

[42] Z. Ji, R.E. Majors, E.J. Guthrie, Porous layer open-tubular capillary columns: Preparations, applications and future directions, Journal of Chromatography A, 842 (1999) 115-142.

[43] C.P. Kapnissi-Christodoulou, X. Zhu, I.M. Warner, Analytical separations in opentubular capillary electrochromatography, ELECTROPHORESIS, 24 (2003) 3917-3934.

[44] E. Guihen, J.D. Glennon, Recent highlights in stationary phase design for open-tubular capillary electrochromatography, Journal of Chromatography A, 1044 (2004) 67-81.

[45] S. Eeltink, F. Svec, J.M.J. Fréchet, Open-tubular capillary columns with a porous layer of monolithic polymer for highly efficient and fast separations in electrochromatography, Electrophoresis, 27 (2006) 4249-4256.

[46] T. Knjazeva, M. Kulp, M. Kaljurand, CE separation of various analytes of biological origin using polyether ether ketone capillaries and contactless conductivity detection, Electrophoresis, 30 (2009) 424-430.

[47] S. Chen, M.L. Lee, Hydrophilic polymethylmethacrylate hollow fibers for capillary electrophoresis of biomolecules, Journal of Microcolumn Separations, 9 (1997) 57-62.

[48] P.Z. Liu, A. Malik, M.C.J. Kuchar, W.P. Vorkink, M.L. Lee, Polymeric Hollow Fibers for Capillary Electrophoresis, Journal of Microcolumn Separations, 5 (1993) 245-253.

[49] A. Fridstrom, N. Lundell, B. Ekstrom, K.E. Markides, Dextran-Modified Polypropylene Hollow Fibers for Use in Capillary Electrophoresis, Journal of Microcolumn Separations, 9 (1997) 1-7.

[50] H. Bayer, H. Engelhardt, Capillary electrophoresis in organic polymer capillaries, Journal of Microcolumn Separations, 8 (1996) 479-484. 
[51] M.W.F. Nielen, Capillary zone electrophoresis using a hollow polypropylene fiber, Journal of High Resolution Chromatography, 16 (1993) 62-64.

[52] X. Ren, P.Z. Liu, M.L. Lee, Cellulose Modified Polypropylene Hollow Fibers for Capillary Electrophoresis, Journal of Microcolumn Separations, 8 (1996) 529-534.

[53] X. Ren, P.Z. Liu, A. Malik, M.L. Lee, Hydrophilic polymer-modified polypropylene hollow fibers with controllable electroosmotic flow for capillary electrophoresis, Journal of Microcolumn Separations, 8 (1996) 535-540.

[54] S. Qi, M.L. Lee, Polypropylene hollow fibers modified with PMMA for capillary electrophoresis, Journal of Microcolumn Separations, 10 (1998) 605-609.

[55] C. Fujimoto, M. Sakurai, Y. Muranaka, PEEK columns for open-tubular liquid chromatography with electroosmotic flow, Journal of Microcolumn Separations, 11 (1999) 693-700.

[56] K. Jinno, J. Wu, H. Sawada, Y. Kiso, Cellulose acetate fiber as stationary phase in capillary electrochromatography, HRC Journal of High Resolution Chromatography, 21 (1998) 617-619.

[57] K. Jinno, H. Watanabe, Y. Kiso, Fibrous stationary phase in capillary electrochromatography, Journal of Biochemical and Biophysical Methods, 48 (2001) 209-218.

[58] K. Jinno, H. Watanabe, Y. Saito, T. Takeichi, Capillary electrochromatography using fibers as stationary phases, ELECTROPHORESIS, 22 (2001) 3371-3376.

[59] J. Balster, O. Krupenko, I. Punt, D.F. Stamatialis, M. Wessling, Preparation and characterisation of monovalent ion selective cation exchange membranes based on sulphonated poly(ether ether ketone), Journal of Membrane Science, 263 (2005) 137.

[60] F.G. Wilhelm, I.G.M. Pünt, N.F.A. van der Vegt, H. Strathmann, M. Wessling, Cation permeable membranes from blends of sulfonated poly(ether ether ketone) and poly(ether sulfone), Journal of Membrane Science, 199 (2002) 167-176.

[61] D. Möckel, E. Staude, M. Dal-Cin, K. Darcovich, M. Guiver, Tangential flow streaming potential measurements: Hydrodynamic cell characterization and zeta potentials of carboxylated polysulfone membranes, Journal of Membrane Science, 145 (1998) 211222.

[62] A. Fridstrom, K.E. Markides, M.L. Lee, Micellar electrokinetic capillary chromatography using polymeric hollow fibers, Chromatographia, 41 (1995) 295-300.

[63] J.D. Lamb, T.L. Huxford, K.B. Czirr, Capillary electrophoresis of anions in an untreated polypropylene hollow fiber, Journal of Chromatography A, 739 (1996) 373-378.

[64] N.W. Smith, M.B. Evans, The efficient analysis of neutral and highly polar pharmaceutical compounds using reversed-phase and ion-exchange electrochromatography, Chromatographia, 41 (1995) 197.

[65] R.A. Hayes, Amine-modified polyimide membranes; Patent EP 0401005, in: D. Pont (Ed.), US, 1990.

[66] Y. Liu, R. Wang, T.-S. Chung, Chemical cross-linking modification of polyimide membranes for gas separation, Journal of Membrane Science, 189 (2001) 231-239.

[67] Y.H. See Toh, F.W. Lim, A.G. Livingston, Polymeric membranes for nanofiltration in polar aprotic solvents, Journal of Membrane Science, 301 (2007) 3-10. 
[68] L. Shao, L. Liu, S.-X. Cheng, Y.-D. Huang, J. Ma, Comparison of diamino cross-linking in different polyimide solutions and membranes by precipitation observation and gas transport, Journal of Membrane Science, 312 (2008) 174-185. 
Appendix to Chapter 5

Design and evaluation of the CE/CEC unit 


\section{Design of the capillary electrophoresis/capillary electrochromatography unit}

Figures 1 and 2 show a picture and a schematic diagram of the laboratory-built capillary electrochromatography unit (without the pressurization system). High voltage power supply (10), type CZE30PN 2000 from Spellman (Hauppauge, NY, USA) with maximal output voltage of $30 \mathrm{kV}$, maximum current $300 \mu \mathrm{A}$ and reversible polarity, combined with platinum electrodes (5) (platinum wire $0.5 \mathrm{~mm}$ o.d. from Sigma-Aldrich, Zwijndrecht, The Netherlands) were used as a voltage source. Model Prostar 340 UV-Vis Detector (12) from Varian (Walnut Creek, CA, USA) together with a $240 \mu \mathrm{m}$ path flow cell (11) from Thermo Separation Products (Fremont, CA, USA) were used for on-column detection. An instrument control unit (14), also home built, equipped with National Instruments (Austin, TX, USA) data acquisition cards was used as an interface for LabVIEW data analysis software. The glass vials (2) of the total volume $10 \mathrm{~mL}$ for the running buffer or sample were kept inside the stainless steel chambers (1), which are modified double-end $300 \mathrm{~mL}$ cylinders 304-SS-LHDF4-300 from Swagelok (Waddinxveen, The Netherlands). The chambers were pressurized at the bottom and in order to prevent the glass vials from moving during the pressurization, the vials were kept in place by bottom and top PTFE holding rings (3). The stainless steel lids (8) of the chambers were modified with threaded ports to introduce and seal in place the $\mathrm{CE} / \mathrm{CEC}$ column and the electrode by means of PEEK nuts (6) and PEEK tubings (7), both from Upchurch Scientific (Oak Harbor, WA, USA). The lids were tightened to the chambers with clamping rings (9). High voltage power supply, UV detector and the entire pressurization system (shown in Figures 1 and 2) were controlled via computer (15) using a software designed in LabVIEW.

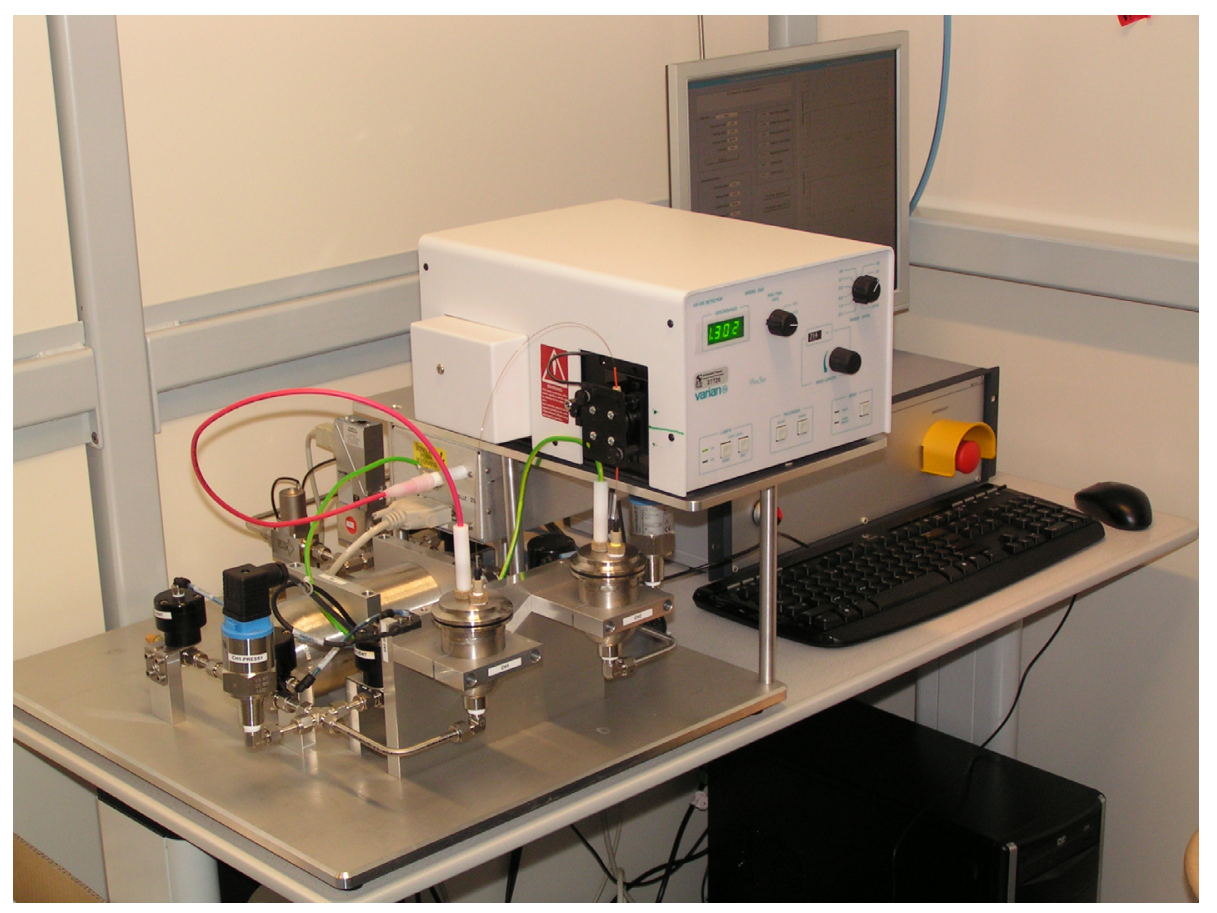

Figure 1 Laboratory-built CE/CEC unit 


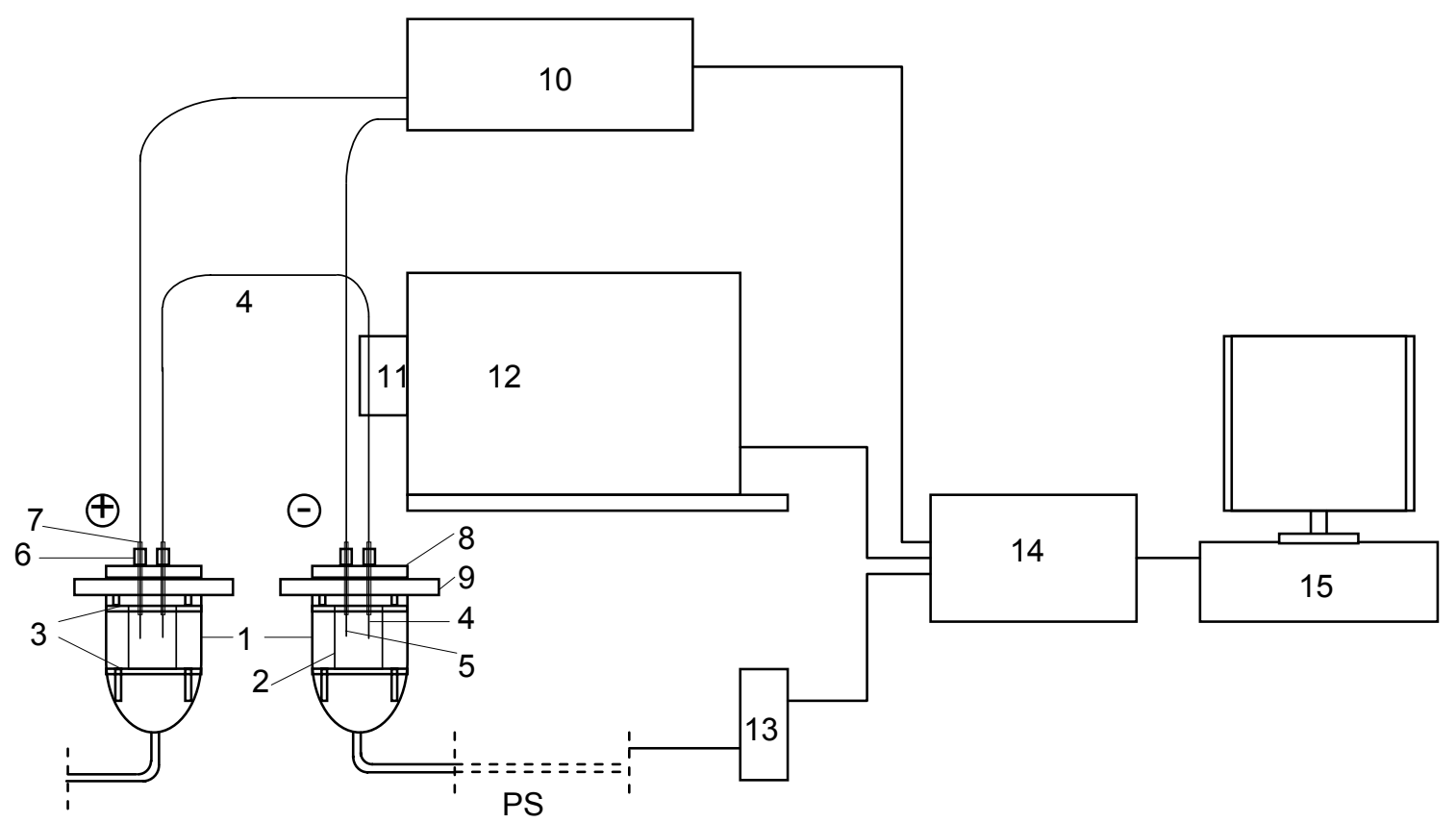

Figure 2 Schematic of the CEC set-up: (1) stainless steel chamber, (2) glass vial (3) PTFE holding ring, (4) CE/CEC column, (5) platinum electrode, (6) PEEK nut, (7) PEEK tubing, (8) chamber lid, (9) clamping ring, (10) high voltage power supply, (11) flow cell, (12) UV detector, (13) digital pressure controller, (14) instrument control unit, (15) computer, (PS) pressurization system (shown in details in Fig.2.)

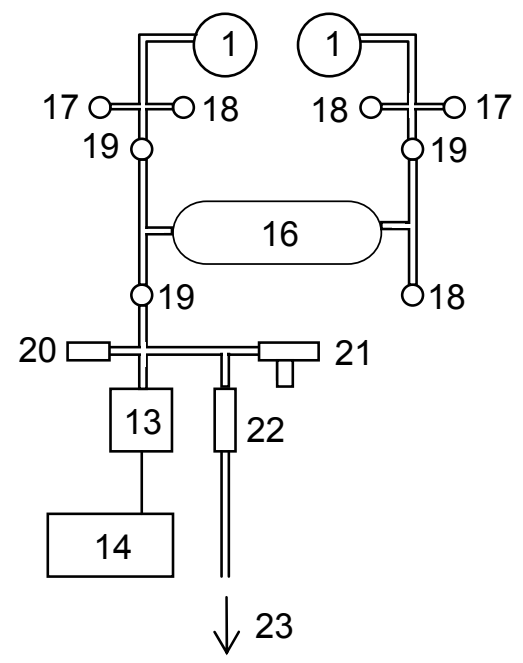

Figure 3 Schematic diagram (top view) of the pressurization system: (13) digital pressure controller, (14) instrument control unit, (16) pressure barrel, (17) pressure transducer, (18) vent valve, (19) supply valve, (20) leak valve, (21) relief valve, (22) main valve to the nitrogen source, (23) nitrogen cylinder

The fully automated pressurization system (Figure 3) allows the pressurization with nitrogen or helium of both chambers simultaneously, as well as each of them separately, to a maximum pressure of 20 bar. The very precised performance of the pressurization system (reaching 5 bar inside the chamber from atmospheric pressure within $0.3 \mathrm{~s}$ ) was obtained by use of a "buffer" pressure barrel (16), which was first filled with gas and when the adequate 
pressure was reached, an "injection" of gas to the chambers followed. The simultaneous equal pressurization of both vials during the separation was performed to suppress the bubble formation in the buffer due to the degassing, which takes place because of the temperature increase as an effect of the Joule heating.

\section{Reproducibility study}

Flexible fused silica capillary tubing (TSP 075375, Polymicro Technologies), i.d. $75 \mu \mathrm{m}$, o.d. $360 \mu \mathrm{m}$, coated with polyimide, was used for the evaluation of the CE/CEC unit, which was tested in the capillary electrophoresis mode. The window for UV detection was made by burning off the layer of the polyimide. The length of the capillary was $48 \mathrm{~cm}$, with $32.5 \mathrm{~cm}$ from inlet to the detection window. The conditions of the separation and the mixture of analytes were chosen from the reference paper by Engelhardt [1]. The control mixture consisted of six analytes: trimethylphenyl ammonium bromide (Fluka), 4-aminoantypyrine (98\%, Acros Organics), benzyl alcohol (GR, Merck), phenol $(99 \%+$ for biochemistry, Acros Organics), benzoic acid (ACS reagent $\geq 99.5 \%$, Sigma-Aldrich), vanilic acid (98.5\%, Acros Organics) (see Table 2 in Chapter 5). All the analytes, apart from phenol with concentration 3 $\mathrm{mM}$, were used with concentration $1.5 \mathrm{mM}$ in a buffer. The running buffer was $33 \mathrm{mM}$ borate pH 9.5 obtained by dissolving sodium tetraborate decahydrate (ReagentPlus ${ }^{\circledR} \geq 99.5 \%$, SigmaAldrich) in milipure water. The buffer and the sample were filtered prior to use through 0.45 $\mu \mathrm{m}$ syringe filter Spartan 30/0.45 RC from Whatman ${ }^{\circledR}$.

The mixture of analytes was injected by application of voltage $10 \mathrm{kV}$ for $10 \mathrm{~s}$. The detection was performed at $214 \mathrm{~nm}$. The separation was done at $17 \mathrm{kV}$ (electrical field $350 \mathrm{~V} / \mathrm{cm}$ of capillary) with pressurization of both ends of the capillary at 5 bar against bubble formation.

Separation and current-voltage experiments were performed in constant voltage mode. Two types of silica capillaries (i.d. $90 \mu \mathrm{m}$ and $200 \mu \mathrm{m}$ ), and borate buffers with concentrations $4 \mathrm{mM}$ and $33 \mathrm{mM}$ were tested to determine the current-voltage plots of the Ohm's law.

\section{Evaluation of the $\mathrm{CE} / \mathrm{CEC}$ unit}

Figure 4 shows five consecutive separation runs. In all the runs the analytes were separated within less than $5 \mathrm{~min}$ in the following order: two cations, trimethylphenyl ammonium bromide (1), 4-aminoantipyrine (2), two neutrals, benzyl alcohol (3), phenol (4), two anions, benzoic acid (5), vanilic acid (6). Only the neutrals were not baseline separated which was also the case in the reference separation [1]. Under these conditions the uncharged molecules migrate with the same velocity (that of EOF) and cannot be separated from each other, whereas the ions can be separated because their electrophoretic mobilities differ.

The reproducibility was conformed by repeating the separation in five consecutive runs with the same injection and separation conditions. Between the runs, the capillary was flushed with fresh buffer for $200 \mathrm{~s}$ by application of pressure of 1.5 bar to the inlet vial. The calculated relative standard deviation (RSD) of the migration times for all the analytes is lower than $2 \%$ (see Table 2 ), which proves good precision and reliability of the CE/CEC unit 
$[2,3]$. When concentrations of the analytes were doubled, there was an adequate response on the electropherogram (Figure 5), although the peaks, especially of the slower anions, showed slight broadening. This overloading phenomena is a very often observed effect, which takes place when high volumes and/or high concentrations of sample are injected [4]. Since there is no stationary phase in $\mathrm{CE}$, the overloading effects appear easily.

The velocity of the EOF measured at $\mathrm{pH} 9.5$ with neutral benzyl alcohol was $\mathrm{u}_{\mathrm{eof}}=0.28 \mathrm{~cm} / \mathrm{s}$ and the electrophoretic mobility was $\mu_{\mathrm{eof}}=8.0 \cdot 10^{-4} \mathrm{~cm}^{2} /(\mathrm{V} \cdot \mathrm{s})$, which are in the range reported by others for a fused silica capillary [5-9].

The laboratory-built CE/CEC instrument used in this study had no facilities for thermostating the column. The production of heat in CE and CEC is the inevitable result of the application of high field strength. Two major problems arise from heat production: temperature gradients across the capillary and temperature changes with time due to ineffective heat dissipation. Operating with narrow-diameter capillaries improves the situation for two reasons: the current passed through the capillary is reduced by the square of the capillary radius, and the heat is more readily dissipated across the narrower radial path. Figure 6 shows the increase in the current as a function of the voltage (the Ohm's plot) for different inner diameters of fused silica capillaries and different concentrations of an electrolyte (a buffer). The magnitude of the current depends on the capillary diameter and the specific conductance of a buffer, which increases with increasing concentration. Equation (1) describes this relationship [4]:

$$
\mathrm{P}=\mathrm{U} \cdot \mathrm{I}=\mathrm{R} \cdot \mathrm{I}^{2}=\mathrm{U}^{2} \cdot \mathrm{d}^{2} \cdot \frac{\pi \cdot \kappa}{2 \mathrm{~L}_{\mathrm{t}}}
$$

where $\mathrm{P}$ is power, $\mathrm{I}$ is current, $\mathrm{R}$ is resistance, $\mathrm{d}$ is inner capillary diameter, and $\kappa$ is specific conductance of a buffer.

The conductivity of the buffer in the capillary increases with rising temperature and causes the current to alter (at constant voltage) at the beginning of an analysis until a steady state of the temperature gradient is established. In this stationary state the generated Joule heat is dissipated through the capillary wall. With inefficient cooling, the buffer temperature continues to rise and the current increases disproportionally with the applied voltage (the system works outside the range of validity of Ohm's law). This can be seen at higher voltages in Figure 6 which, however, does not contribute to the peak broadening at the conditions of the evaluation and reproducibility tests (Figures 4 and 5). To avoid a destructive temperature gradient, electric field strengths not higher than $400 \mathrm{~V} / \mathrm{cm}$ were used in the experiments. 


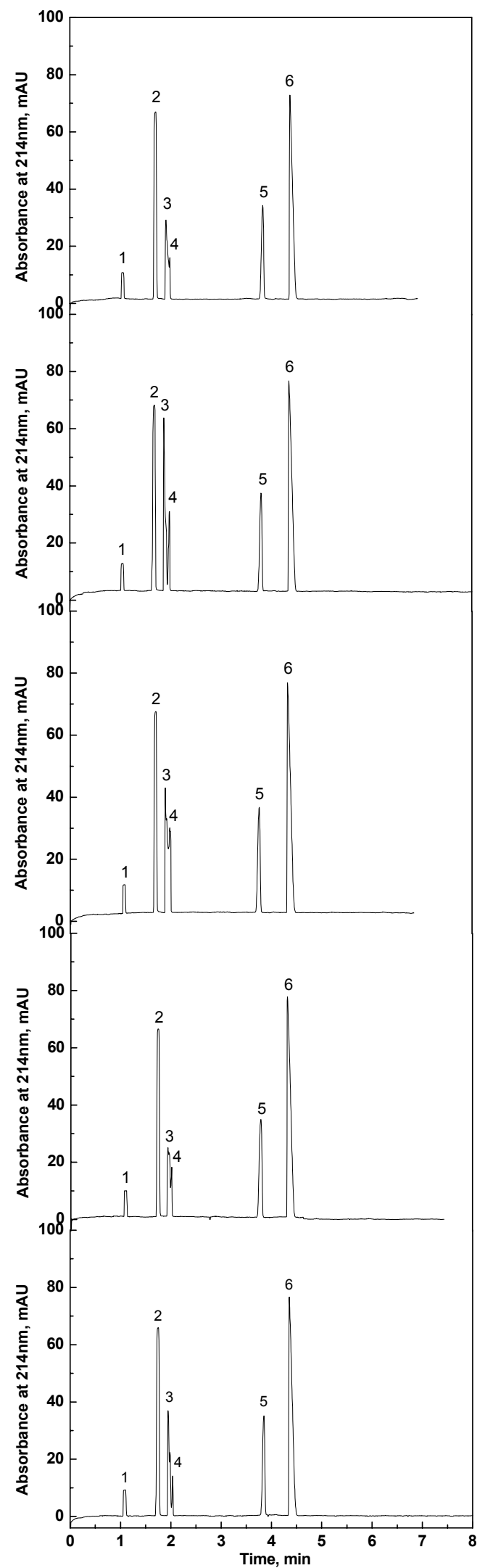

Figure 4 Reproducibility study: five consecutive separation runs of the control mixture (concentration of analytes: phenol $3 \mathrm{mM}$, other analytes $1.5 \mathrm{mM}$ ); for the separation conditions: see text 


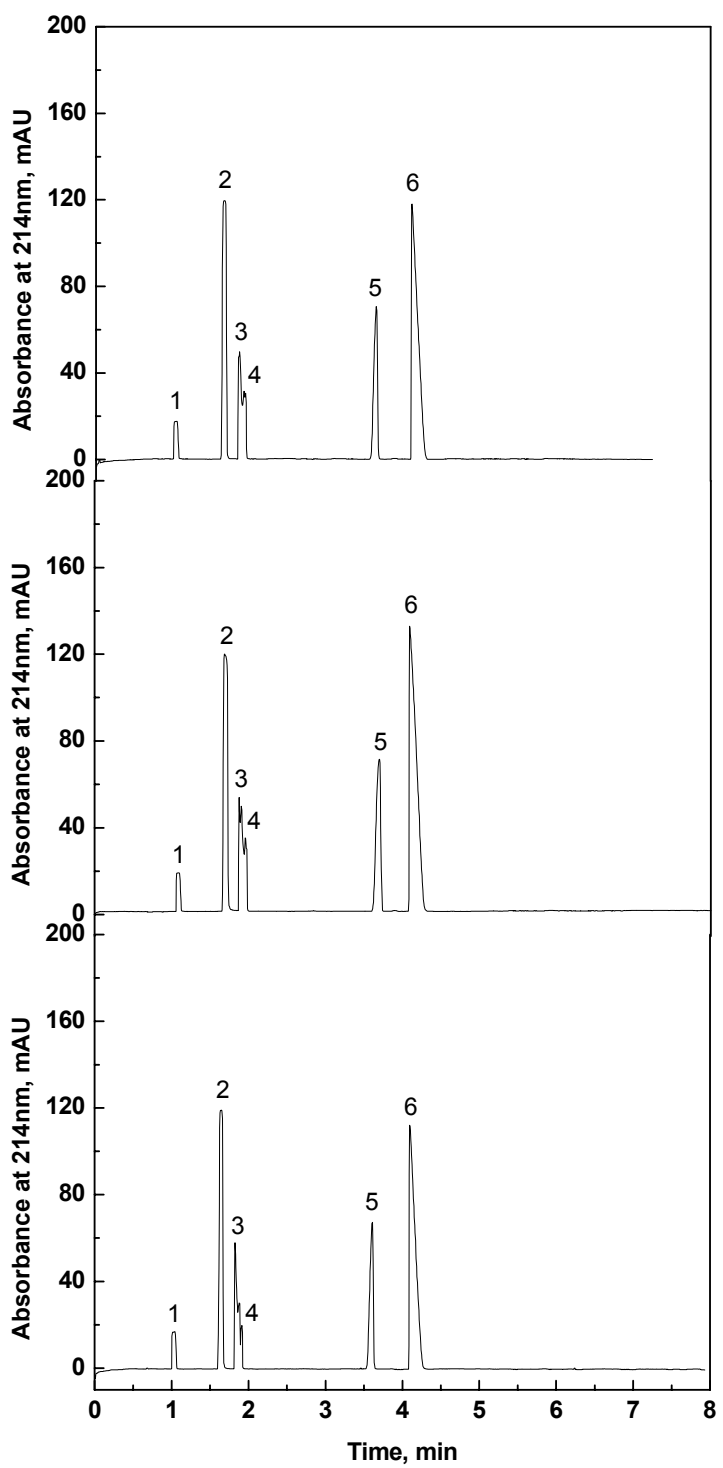

Figure 5 Reproducibility study: response of the unit to doubled concentrations

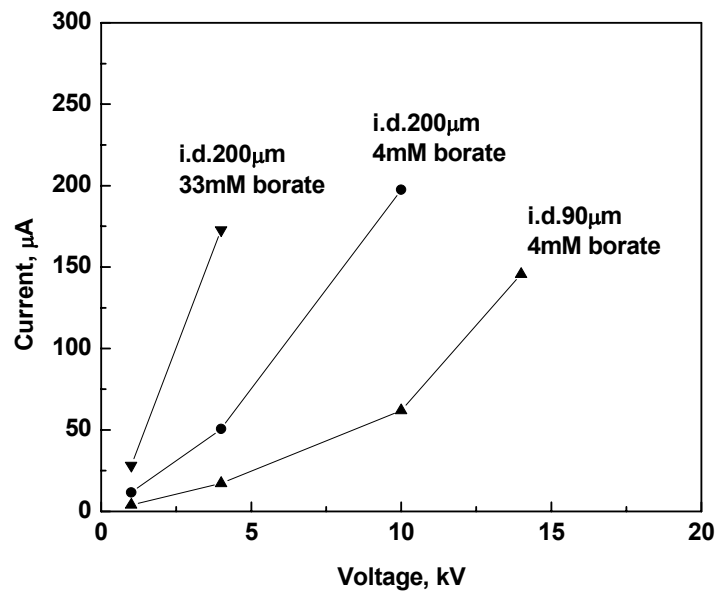

Figure 6 Current as a function of voltage for different inner diameters of the silica capillary and different electrolyte concentrations; o.d. $360 \mu \mathrm{m}$ 
Table 2 Relative standard deviation of the migration times for the analytes of the control mixture (for the separation conditions: see text)

\begin{tabular}{ccc}
\hline No. & Analyte & RSD, \% \\
\hline 1 & Trimethylphenyl & 1.85 \\
2 & ammonium bromide & 1.47 \\
3 & 4-aminoantipyrine & 1.46 \\
4 & Benzyl alcohol & 0.96 \\
5 & Phenol, carbolic acid & 0.88 \\
6 & Benzoic acid & 0.55 \\
\hline
\end{tabular}

\section{Conclusions}

The laboratory-built set-up for electrically driven separation processes was verified with the control mixture of six analytes. The compounds were separated with similar resolution and efficiency as in the reference source. The consecutive analysis runs at the same conditions proved the reproducibility of the separation and of the operation technique. The lack of the cooling system was manifested at higher voltages as shown by the nonlinearity of the Ohm's plot, but it could be avoided by working at lower voltages and/or lower buffer concentrations, and/or narrower capillaries. The formation of air-bubbles (degassing of the buffer due to the raising temperature) was successfully prevented by application of equal pressures to the inlet and outlet vials. 


\section{References}

[1] H. Engelhardt, W. Beck, J. Kohr, T. Schmitt, Capillary electrophoresis: Methods and Scope, Angewandte Chemie - International Edition, 32 (5) (1993) 629-649.

[2] I.S. Krull, R.L. Stevenson, K. Mistry, M.e. Swartz, Capillary electrochromatography and Pressurized Flow Capillary Electrochromatography. An Introduction, HNB Publishing, New York, 2000.

[3] K.D. Altria, N.W. Smith, C.H. Turnbull, A review of the current-status of capillary electrochromatography technology and applications, Chromatographia, 46 (1997) 664674.

[4] F.F. P. Bocek, L. Krivankova, Capillary Zone Electrophoresis John Wiley \& Son Ltd, 1993.

[5] S. Qi, M.L. Lee, Polypropylene hollow fibers modified with PMMA for capillary electrophoresis, Journal of Microcolumn Separations, 10 (1998) 605-609.

[6] S. Chen, M.L. Lee, Hydrophilic polymethylmethacrylate hollow fibers for capillary electrophoresis of biomolecules, Journal of Microcolumn Separations, 9 (1997) 57-62.

[7] P.Z. Liu, A. Malik, M.C.J. Kuchar, W.P. Vorkink, M.L. Lee, Polymeric Hollow Fibers for Capillary Electrophoresis, Journal of Microcolumn Separations, 5 (1993) 245-253.

[8] H. Bayer, H. Engelhardt, Capillary electrophoresis in organic polymer capillaries, Journal of Microcolumn Separations, 8 (1996) 479-484.

[9] J.D. Lamb, T.L. Huxford, K.B. Czirr, Capillary electrophoresis of anions in an untreated polypropylene hollow fiber, Journal of Chromatography A, 739 (1996) 373-378. 


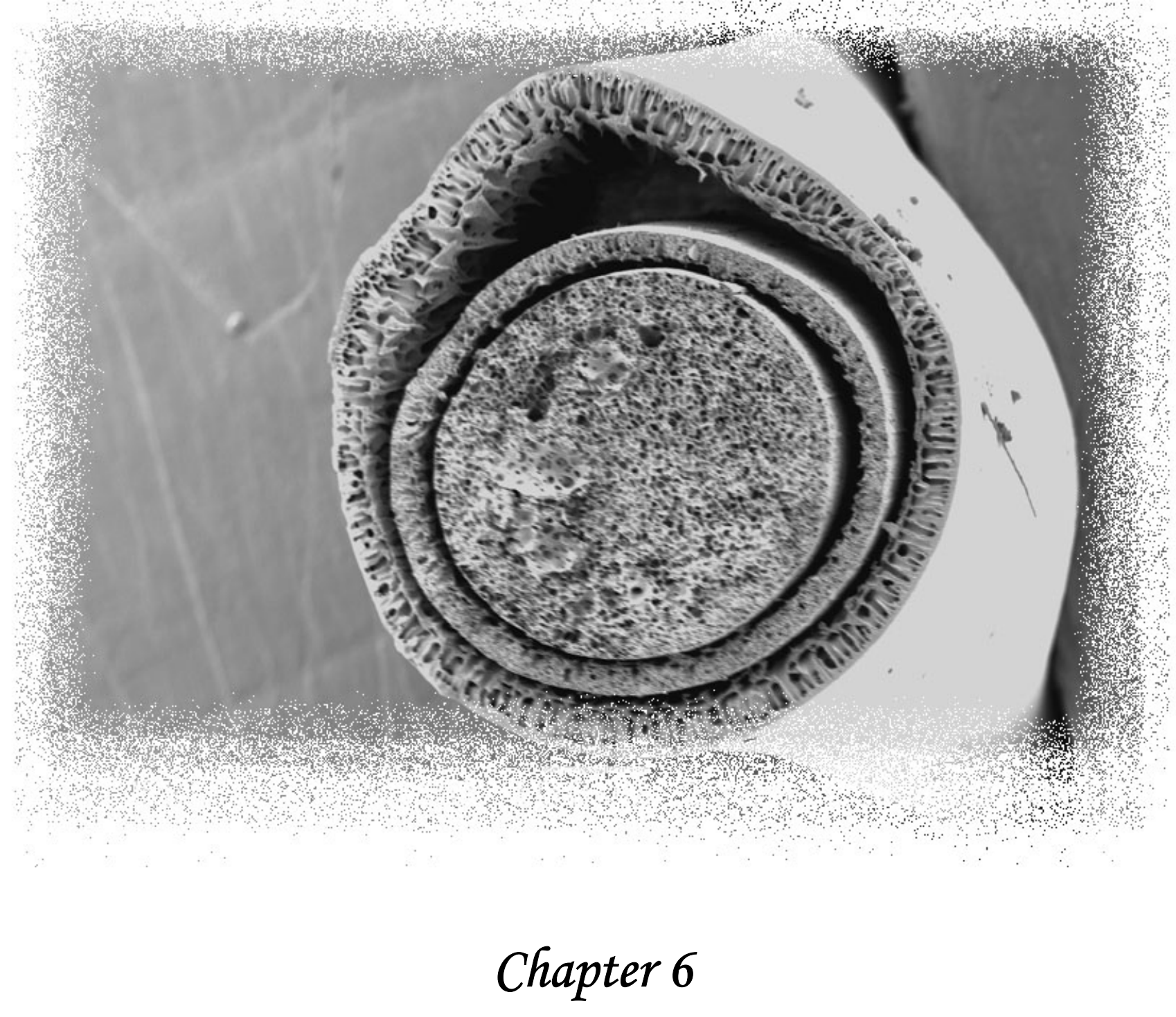

\section{Evaluation and Outlook}




\section{Development of charged membranes for biomolecule separation}

This thesis investigates the potential of membrane technology for separation of biologically active compounds. It demonstrates that separation of the same biomolecules can be accomplished by distinctively different membrane processes, like ultrafiltration, membrane adsorption or capillary electrochromatography, all involving application of charged membranes. The immersion precipitation spinning was the main membrane fabrication technique exploited in this thesis. This is a rather complicated procedure with many variables. It is not possible to become skilled in spinning within one day or one week. Learning the spinning "tricks" requires months or even years of practice often by trial and error. Figure 1 and Figure 2 present the variables of spinning and membrane post-treatment that can influence the final morphology and performance of the fiber membrane. Often changing one of these variables (certainly, the list is not complete yet) might entirely alter the fiber structure. In this thesis we used some of those variables to create various types of fiber membranes (hollow, small bore or full fiber membranes) for separation of biomolecules.

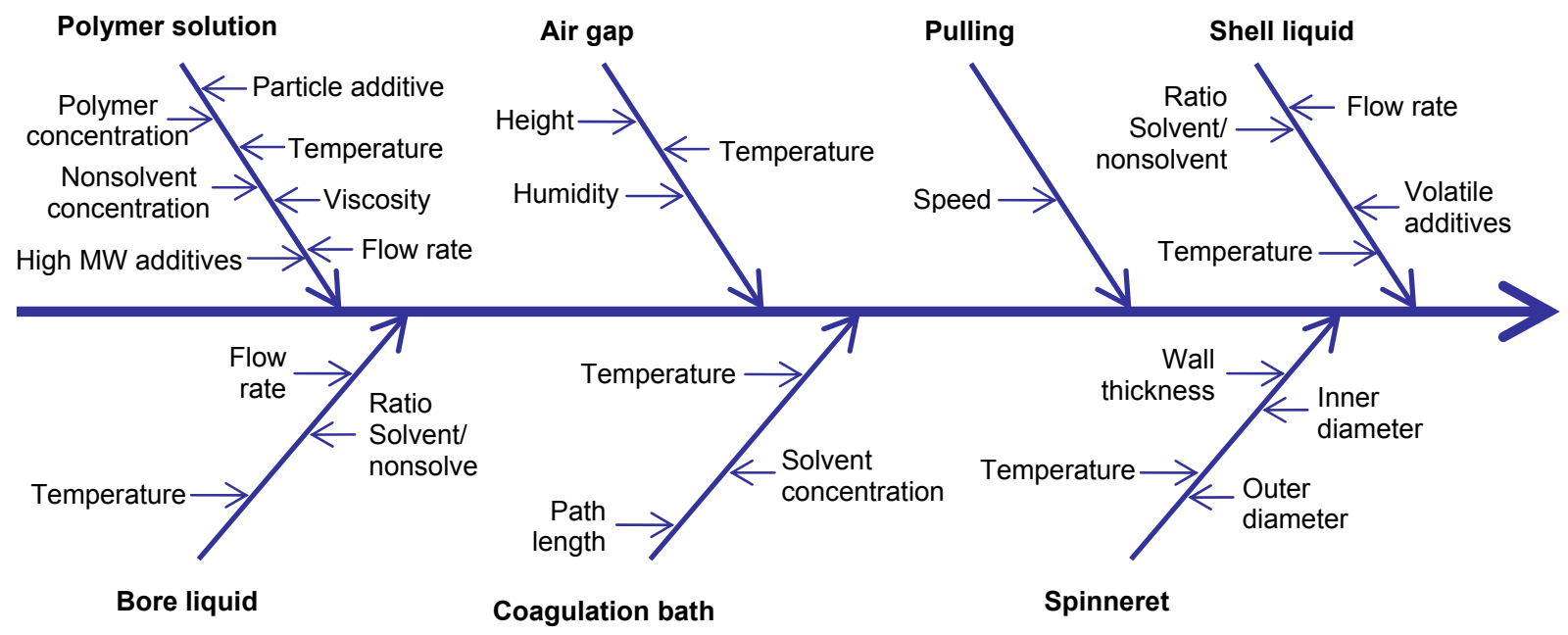

Figure 1 Spinning variables

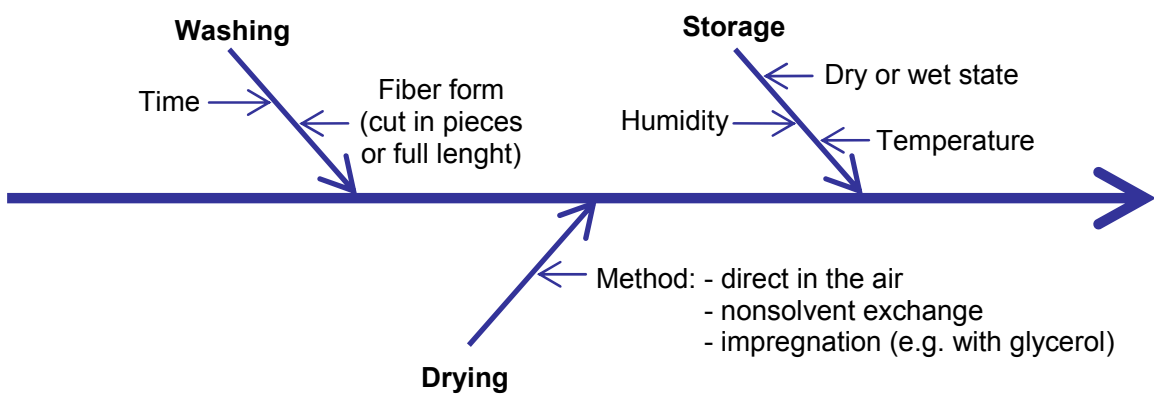

Figure 2 Post treatment variables 
The following sections describe the novelty and main achievements of each membrane fabrication technique. Moreover, ideas for future work and some preliminary experimental results are presented.

\subsection{Polyelectrolyte in the bore liquid}

This one-step spinning method is an alternative for blending or co-extrusion and has two main advantages: reduced amount of the required polyelectrolyte and the possibility to tailor only the surface of the membrane. This method can be used not only to tailor the membrane charge, but also the hydrophilicity, especially in membrane applications where there is no need or it is not desired to modify the entire membrane. Introducing only a thin hydrophilic layer might significantly reduce the overall membrane swelling. This membrane fabrication technique can be used not only for separation of charged biomolecules, but for all the fields of membrane technology where charged solutes need to be separated, e.g. in salt rejection.

The next research step should be, certainly, in direction of investigating the exact mechanism of polyelectrolyte deposition and measuring the thickness of the charged layer. Using 3\% SPEEK in the bore liquid results in a polyelectrolyte layer that cannot be detected with FTIR and SEM/EDX (the X-ray photoelectron spectroscopy, XPS, was also considered, but it is not meant for such porous structures). Increasing the concentration of SPEEK and/or the sulphonation degree should be carried on. It would be interesting to see how the zetapotential is influenced when changing the concentration and properties of the polyelectrolyte. Another important aspect for the commercialization of this technique is evaluation of the long term stability of the deposited electrolyte. A systematic study should be done on measuring the content (or thickness) of the polyelectrolyte after the sequential steps: directly after the membrane formation, after membrane washing and after the permeation through the membrane. Such tests could give also better insight into the mechanism of the polyelectrolyte attachment to the membrane forming polymer.

\subsection{Polyelectrolyte/crosslinker in the bore liquid (gas and liquid/solute separation)}

The breakthrough of this method is that not only the fiber morphology and charge, but also the membrane material chemistry can be tuned already during the spinning - inside the spinneret. The possibility of crosslinking the entire fiber during one-step spinning could open a new era of the solvent resistant membranes: no more post-treatment steps that require large amounts of solvents like methanol or isopropanol (when a ready membrane has to be crosslinked, a membrane preswelling is required to ensure full crosslinking of all the polymer

chains) [1, 2], large amounts of expensive crosslinker, and no time-consuming extensive membrane washing to remove the residual solvent and crosslinker. These aspects make the new method less expensive and more environmental benign. Theoretically, other membrane forming polymers that contain imide rings, like polyimide Matrimid or polyetherimide could be used instead of P84.

Fabrication of a composite hollow fiber membrane with dense inner layer may open new perspectives in the field of gas separation. The dense layer on the bore side of the fiber is 
an advantage in case of flue gas treatment where the outer dense selective layer is subject to damage due to the particles carried on by the feed flue gas (the gas separations are generally done in the outside-in mode) [3,4]. Further optimization of this technique for gas separation membranes should aim at formation of a thinner dense layer to ensure higher permeability and investigation of different crosslinking degrees.

Studying the degree of crosslinking with FTIR technique for all the membranes presented in Chapter 3 should be the next step: systematic determination of the membrane structure-property relations in context of the bore liquid composition should give more accurate approach of the control between the crosslinking and phase inversion. For the specific fiber of known crosslinking degree of the dense inner layer, the intrinsic permeance of the gas of interest could be determined, which would allow evaluation of the exact thickness of the dense layer via the gas permeation experiments. The degree of crosslinking should directly influence the zeta-potential (valid for both: dense crosslinked layer and the entirely crosslinked porous membrane) since the shift of the zeta-potential from negative to positive is due to the free amines of PEI which did not take part in the crosslinking (determination of free amine content e.g. by acid orange II assay is another possibility). Higher degree of crosslinking should result in less positive charge or lower isoelectric point. As the tertiary amines are not involved in crosslinking, it would be very interesting to use other types of polyethyleneimine with different ratio of primary, secondary and tertiary amines, and monitor the structure-property relations of the membranes. Using a linear PEI which contains only secondary amines, should hypothetically result in no change of zetapotential if $100 \%$ degree of crosslinking is ensured. The membrane structure-property relations could be also investigated in terms of molecular weight of PEI: lower MW PEI as a smaller molecule will have higher diffusion coefficient which should result in faster crosslinking.

All the above mentioned suggestions about the direction of future research are part of the study on the complex kinetics of the crosslinking reaction that takes place next to the phase inversion process.

\section{Comparison of the ultrafiltration membranes}

Two chapters of this thesis are dedicated to the ultrafiltration of biomolecules. The comparison of various membranes, although meant for separation of the same protein mixture, is not straightforward when membranes are made of different materials. Very often ultrafiltration membranes are characterized by their molecular weight cut-off, which is defined as the molecular weight of a solute that has a rejection coefficient of $90 \%$. However, this value of $90 \%$ is not standardized, because it comes as a result of measurement with different solutes and at different operational conditions [5]. Two membranes rated with the same molecular weight cut-off can have very different pore size and performance characteristics.

In the field of gas separation membranes, Robeson [6] developed simple approach for comparing membranes made of different materials and by different manufacturers. 
Analogous Robeson Plot for ultrafiltration membranes was developed by Mehta and Zydney [5].

Theoretical calculations were performed for an idealized ultrafiltration membrane according to Mehta and Zydney to get a „critical line” - an upper limit of the membrane performance (see Figure 3) based on its selectivity and permeability with BSA as the model protein. This upper limit (the solid line in Figure 3) was obtained from a set of equations (1)(4).

The hydraulic permeability $L_{p}$ of the memebrane was calculated assuming that the fluid flow through each pore is described by the Hagen-Poiseuille equation:

$L_{p}=\frac{\varepsilon}{8 \mu \delta_{m}} \frac{\int_{0}^{\infty} n(r) r^{4} d r}{\int_{0}^{\infty} n(r) r^{2} d r}$

where $\varepsilon$ is the membrane porosity, $\delta_{m}$ is the membrane thickness, $\mu$ is the solvent viscosity and $n(r)$ is the pore size distribution.

The selectivity $\alpha$ was asumed to be equal to the ratio of the sieving coeffcients of the small impurities and of BSA:

$\alpha=\frac{S C_{\text {impurities }}}{S C_{B S A}}$

Since the small impurities pass freely through the membrane $\left(S_{\text {impurities }}\right) \approx 1$, the selectivity factor would be equal to the reciprocal of the BSA sieving coefficient.

The actual protein sieving coefficient was evaluted using equation (3):

$S C=\frac{\int_{0}^{\infty} S C(r) n(r) r^{4} d r}{\int_{0}^{\infty} n(r) r^{4} d r}$

and equation (4)

$S C(r)=(1-\lambda)^{2}\left[2-(1-\lambda)^{2} \exp \left(-0.7146 \lambda^{2}\right)\right.$

where $\lambda=a / r$ with $a$ being the protein radius.

The calcuations were performed using a log-normal pore size distribution:

$n(r)=\frac{n_{0}}{r \sqrt{2 \pi}}\left[\ln \left(1+(\sigma / \bar{r})^{2}\right]^{-1 / 2} \times \exp \left\{-\frac{\left(\ln (r / \bar{r})\left[1+(\sigma / \bar{r})^{2}\right]^{1 / 2}\right)^{2}}{2 \ln \left[1+(\sigma / \bar{r})^{2}\right.}\right\}\right.$ 

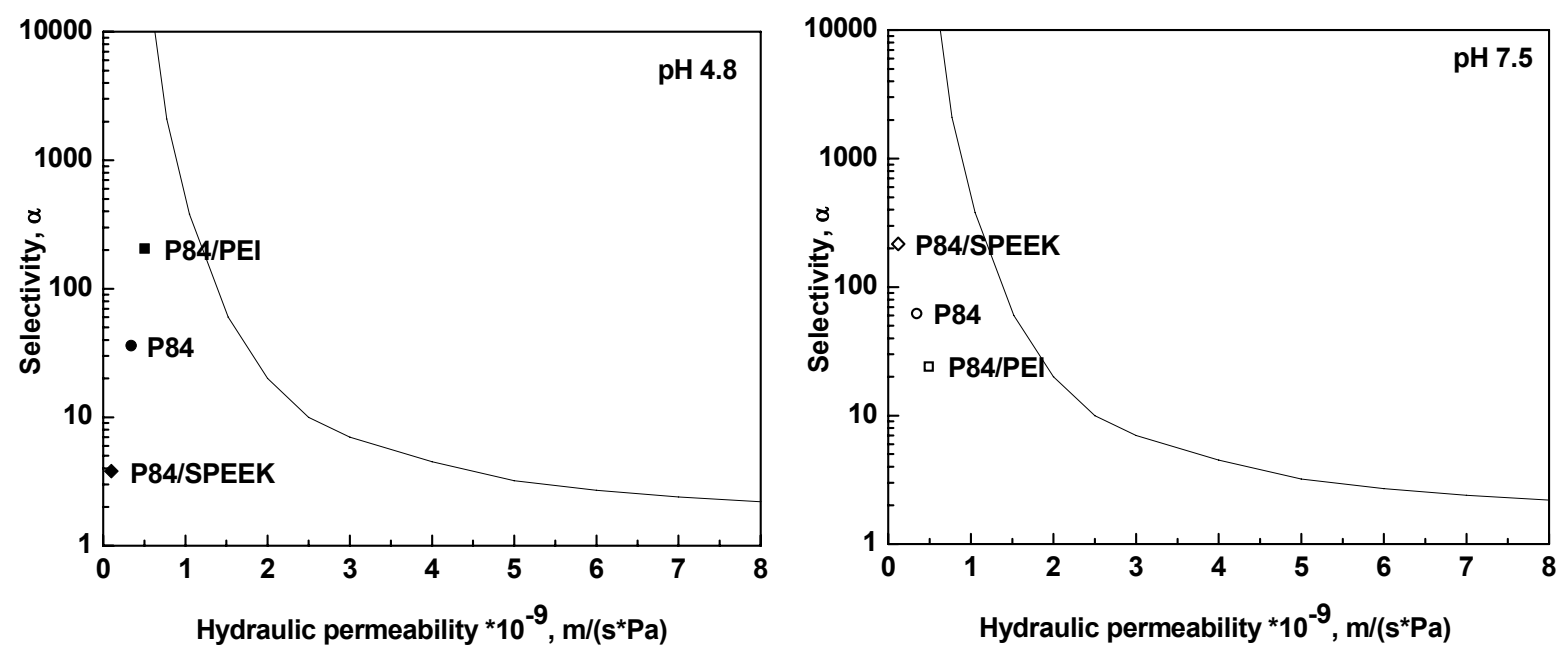

Figure 3 Selectivity - permeability trade off for ultrafiltration membranes investigated in the thesis using BSA as the model protein; solid curve represents model calculations using lognormal pore size distribution; left: $\mathrm{pH} 4.8$; right: $\mathrm{pH} 7.5$

where $\bar{r}$ is the mean distribution and $\sigma^{2}$ is the variance of ditribution.

The coefficient of variation was kept at constant value of $\sigma / \bar{r}=0.2$. Calculations were performed by varying the mean pore size (with $\sigma / \bar{r}$ and $\varepsilon / \delta_{m}$ fixed) with the separation factor and the permeability for each value of $\bar{r}$. Membranes with large mean pore radius have low separation factor, but high permeability, while membranes with small mean pore radius tend to have low permeability, but high separation factor. This is the reason why the currently available ultrafiltration membranes cluster along and below the line being the upper limit. The ideal ultrafiltration membrane will have high separation factor and high permeability. Such a membrane would be located in the upper right corner of the plot - a region that is inaccessible by existing ultrafiltration membranes.

The performance of different membranes can be marked in the selectivitypermeability diagram and compared to each other using the upper limit refrence.

The hydraulic permeability of various membranes is calculated according to equation (6):

$L_{p}=\frac{J_{v}}{\Delta P}$

where $J_{v}$ is the volumetric filtrate flux (volume flow rate per membrane area) and $\Delta P$ is the transmembrane pressure.

The actual sieving coefficient (that accounts for differences in concentration polarization within various modules) which is the intrinsic sieving coefficient is evaluated from equation (7):

$S C_{B S A}=\frac{S C_{0 B S A}}{\left(1-S_{0}\right) \exp \left(J_{V} / k\right)+S_{0}}$

where $S C_{O B S A}=C_{\text {filtrate }} / C_{\text {feed }}$ is the sieving coefficient and $k$ is the mass transfer coefficient in a module. 
Figure 3 shows the model calculations together with the characteristics of the ultrafiltration membranes investigated in this work: the P84/SPEEK membrane, the P84/PEI membrane and the reference $\mathrm{P} 84$ membrane, presented in two graphs (different $\mathrm{pH}$ ). All the membranes are situated below the "critical line". The higher selectivities of the charged membranes are not the effect of higher permeabilities which is particularly evident at $\mathrm{pH} 4.8$ (the P84/PEI membrane has the highest selectivity and the highest permeability). The effect of charge is apparent: the selectivities of the charged membranes with PEI and SPEEK are greatly affected when changing $\mathrm{pH}$ becoming reversed in a reference to the P84 membrane. If more open membranes could be produced with the same surface chemistry and charge, the membrane performance on the diagram should move to the right while still having the same selectivities due to the charge. This should result in crossing the upper limit line.

\subsection{Mixed matrix membranes (solid phase extraction)}

This thesis presents for the first time application of mixed matrix membrane adsorbers in non-aqueous solutions. By crosslinking the P84 matrix polymer, solvent resistant adsorber membranes are produced that can be used in solvents like $\mathrm{N}$-methylpyrrolidone and dimethyl sulphoxide. The investigated adsorber, strong cation exchange particles, show lower static adsorption capacity of lysozyme from DMSO and cholesterol from NMP than for the same biomolecules in aqueous solutions (DMSO and NMP are aprotic solvents), however the adsorption of particles in the mixed matrix membranes is higher than for particles suspension due to the better accessibility of the particles (particles in loose suspension undergo aggregation in the investigated organic solvents).

In order to increase the values of biomolecule adsorption, other combinations: adsorbing particles - biomolecule - solvent should be investigated to explore other types of reactions between the target molecule and the mixed matrix membrane.

Some preliminary research was carried on the adsorption capacity of the activated carbon particles for isolation of lysozyme from DMSO. The value of $9.8 \pm 0.4 \mathrm{mg} \mathrm{Lys} / \mathrm{g}$ particles was obtained which is slightly lower than for suspension of strong cation exchange particles $(12.8 \pm 1.4 \mathrm{mg}$ Lys/g particles). The problem here might be the high solvent adsorption by the activated carbon particles which lowers their selectivity for lysozyme. Further research on the activated carbon particles, e.g. formation of mixed matrix membrane with these particles, was therefore discontinued. A promising class of particles for this application could be silica which can be used in the natural hydrophilic and modified hydrophobic form. When finding the right combination, the next research step should be evaluation of the dynamic adsorption capacity of the membranes as done by Avramescu for aqueous solutions $[7,8]$.

\subsection{Capillary electrochromatography}

The proof of concept of application membrane technology for fabrication of stationary phase as capillary electrochromatography (CEC) column is shown in Chapter 5. The advantages of membranes and advantages of CEC can be merged, but reliable analytical 
separations using porous membrane structure can be obtained only after further optimization. The membrane structure should be improved in such a way that more open morphology with interconnected pores and uniform porosity are created, and the fiber itself has smaller dimensions to enhance the effective heat dissipation.

Other polymers should be investigated for membrane fabrication that have sufficient zeta-potential and do not undergo swelling. Some research has been done on the poly (methyl methacrylate) as this polymer has quite high negative zeta-potential (see Chapter 5). Full fiber membranes were spun using thermally induced phase separation (TIPS). Although the fibers had homogenous structure (Figure 4), they were not permeable for liquids (water, ethanol).
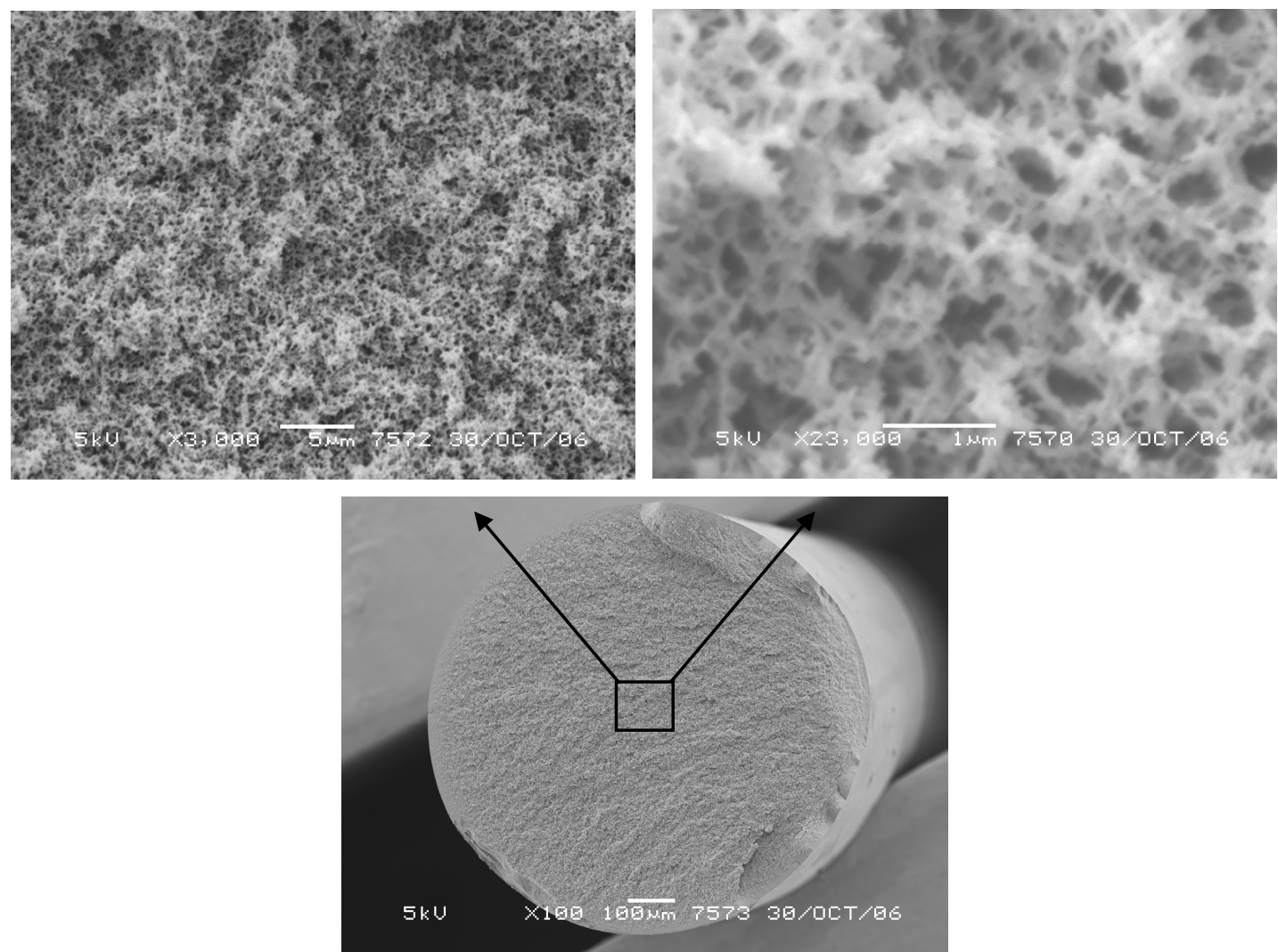

Figure 4 SEM pictures of the PMMA hollow fiber membranes spun with the TIPS technique

Apart from the immersion precipitation spinning and the above mentioned thermally induced spinning of fiber membranes, two other, recently developed membrane fabrication techniques were preliminary tested for the fabrication of porous stationary phases as CEC columns: phase inversion in-situ and polymer foaming.

\section{Phase inversion in-situ}

This method of fabricating polymeric porous monoliths was first described by de Jong [9]. It consists of two main steps: first, the porous PP fiber is filled with the polymer solution, second, it is placed in the water coagulation bath, where phase inversion occurs as a result of the solvent/nonsolvent exchange through the pores of the PP fiber. Here, to improve 
the water transport through the hydrophobic PP, the fiber was first prewetted by sequential immersion in three liquids, in each for $24 \mathrm{~h}$ : ethanol, mixture $50 \%(\mathrm{w} / \mathrm{w})$ ethanol/water, pure water. Thus prewetted fiber was filled using a syringe with a P84 or PMMA solution (see compositions in Table 1) to certain length, and immediately placed in a water bath (Figure 5). The polymer solution inside the PP fiber solidified forming a porous structure. After $12 \mathrm{~h}$ of washing, the fiber was dried in the air for $2 \mathrm{~h}$ and subsequently in the vacuum oven at $30^{\circ} \mathrm{C}$ for another $12 \mathrm{~h}$.

Table 1 Compositions of the solutions used for the preparation of monoliths via phase separation insitu

\begin{tabular}{lccr}
\hline \multicolumn{4}{c}{ Continuous beds phase separated in-situ } \\
\hline P84 & $11.0 \%$ & PMMA & $11.0 \%$ \\
Glycerol & $12.0 \%$ & DMSO & $89.0 \%$ \\
NMP & $66.0 \%$ & & \\
\hline
\end{tabular}

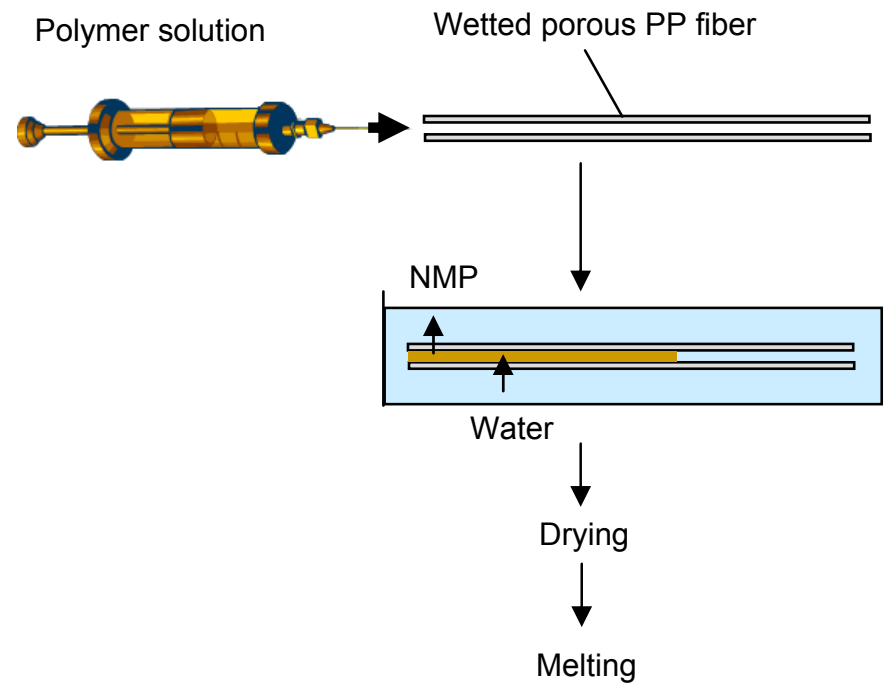

Figure 5 Schematic of the phase inversion in-situ process
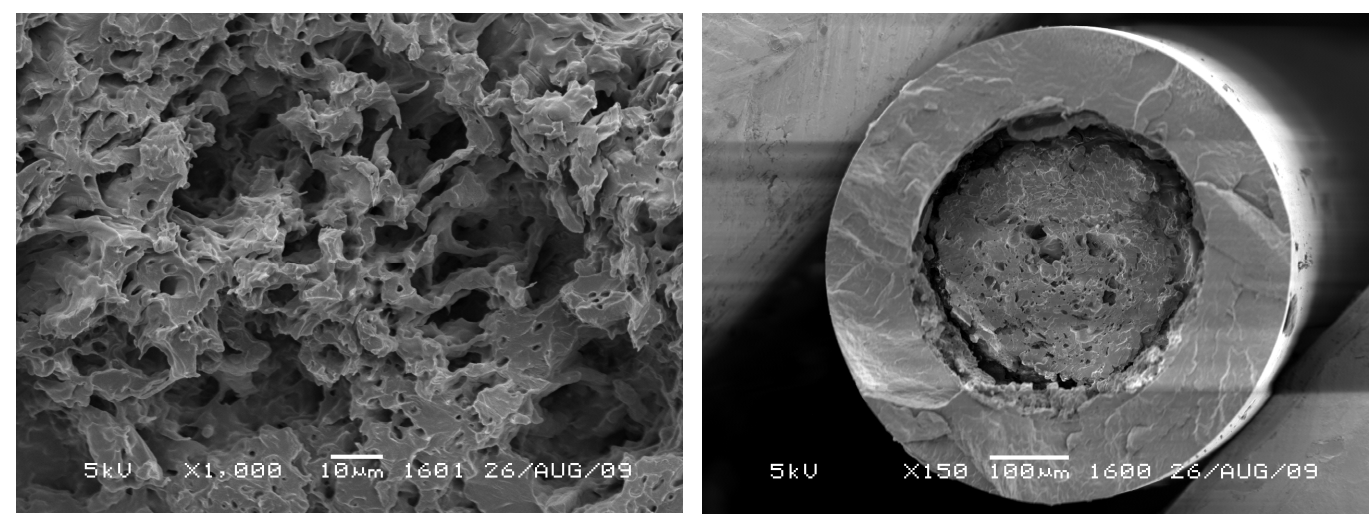

Figure 6 SEM pictures of a PMMA continuous bed (phase inversion in-situ) inside a PP capillary 
This method, altough very simple and fast, has unfortunately few drawbacks. The main shortcoming is the column-to-column reproducibility. There are many variables during the fabrication procedure that determine the final morphology of the column, but are difficult to control, the most important being injection rate of the polymer solution into the PP capillary, and the time of column transfer into the coagulation bath. The other problem is the adhesion of the polymer to the PP capillary. During the coagulation and the outflow of solvent, the porous structure shrinks until it completely solidifies and the solvent is washed out. Figure 6 shows an example of a fine PP capillary filled with the porous PMMA, while Figure 7 presents few examples of unsuccessful structures.
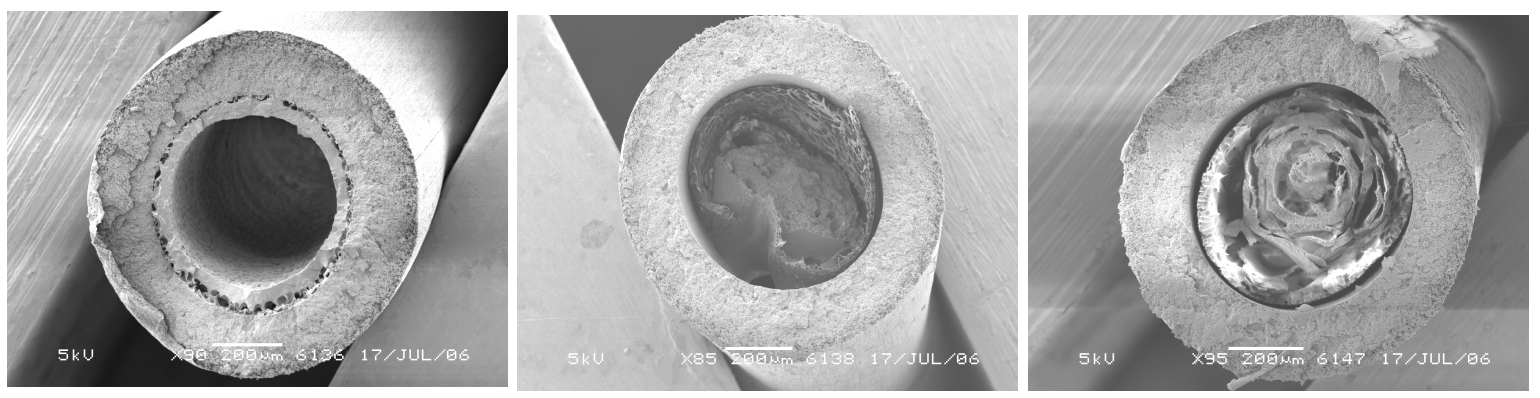

Figure 7 SEM pictures showing examples of unsuccessful columns fabricated via phase separation in-situ (pictures taken before melting the PP capillary)

The CEC performance of a monolithic column is presented in Figure 8. Two consecutive runs of thiourea were performed at different voltages. The system responds well to the voltage increase as the migration time is much shorter when doubling the voltage. The peaks are narrower and the EOF is faster $\left(6.4 \cdot 10^{-4} \mathrm{~cm}^{2} /(\mathrm{V} \cdot \mathrm{s})\right)$ than for the column packed with a mixed matrix membrane. The column-to-column reproducibility is however worse as certain columns did not give any response after sample injection. Moreover, the current during the analysis was not stable, either breaking down or rising to the maximum, most likely due to the nonuniformity of the structure along the column.

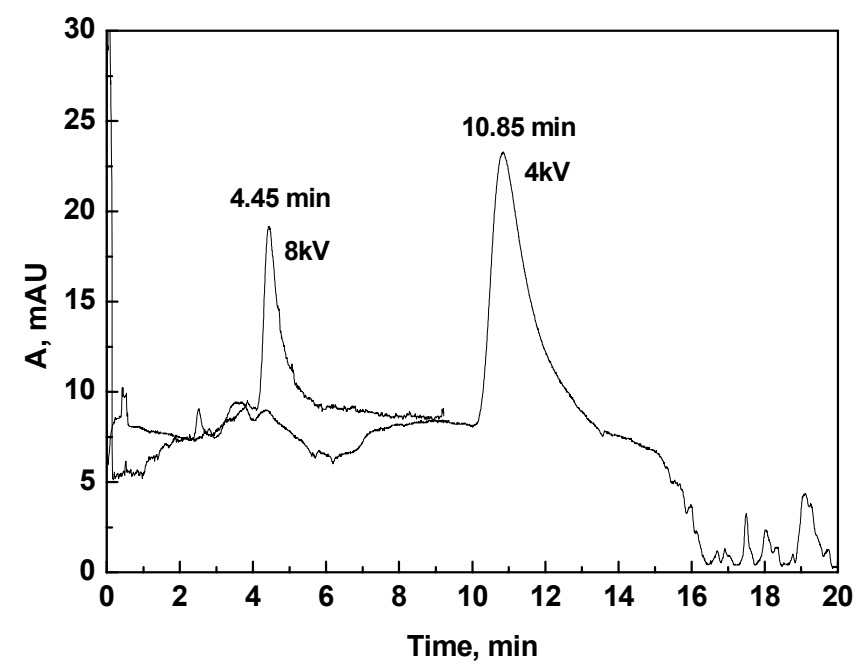

Figure 8 Analysis of thiourea at various voltages; P84 stationary phase by phase inversion in-situ; capillary; L=31/48 cm; separation: $4 \mathrm{kV} / 8 \mathrm{kV}$, UV detection at $214 \mathrm{~nm}$; mobile phase: $5 \mathrm{mM}$ phosphate $\mathrm{pH}=7.0$; injection: $8 \mathrm{kV} 10 \mathrm{~s}$ 


\section{Polymer foaming}

All the techniques of membrane fabrication described so far in this thesis were based on a phase inversion process. A drawback of this process is the presence of organic solvent during the preparation procedure. In addition to not being environmental friendly, the solvent contaminates the porous material and even an extensive post treatment membrane washing does not ensure complete removal of the solvent which is required for some pharmaceutical and medical applications.

Table 2 Process variables of the foaming technique [11]

\begin{tabular}{ll}
\hline \multicolumn{1}{c}{ Process variable } & \multicolumn{1}{c}{ Description } \\
\hline $\begin{array}{l}\text { Saturation time } \\
\text { Saturation pressure } \\
\text { Saturation temperature }\end{array}$ & $\begin{array}{l}\text { Residence time in the } \mathrm{CO}_{2} \text { pressure vessel } \\
\text { The } \mathrm{CO}_{2} \text { pressure in the saturation vessel } \\
\text { Temperature in the } \mathrm{CO}_{2} \text { pressure vessel } \\
\text { The time elapsed between removing the saturated } \\
\text { polymer sample from the pressure vessel and the } \\
\text { heating step } \\
\text { Transfer time }\end{array}$ \\
$\begin{array}{l}\text { Residence time of the gas saturated sample in the } \\
\text { heating bath }\end{array}$ \\
Foaming time & The temperature of the foaming bath \\
\hline
\end{tabular}

Polymer foaming is a solvent free method for membrane fabrication that was investigated to produce a stationary phase for capillary electrochromatography. It consists of three sequential steps: (1) saturation of polymer with a gaseous penetrant (blowing agent) at high pressure, (2) quenching the polymer/gas mixture into a supersaturated state by reducing the pressure and increasing the temperature, (3) nucleation and growth of gas cells dispersed throughout the polymer until the thermodynamic forces which drive the mass transport vanish.

Foaming of high- $\mathrm{T}_{\mathrm{g}}$ polymers ( $\mathrm{T}_{\mathrm{g}}$, glass transition temperature) was investigated by Krause et al. [10-14], who specified the process conditions at which foamed high- $\mathrm{T}_{\mathrm{g}}$ polymers with interconnected pores, required for membrane applications, could be obtained. The disadvantage of foaming in view of the membrane application is the presence of dense unfoamed skin which hinders the mass transport across the membrane. The polymer flat membranes and fibers are, however, permeable to gas in the longitudinal direction. The dense skin is the obstacle for application of foamed polymers in ultrafiltration, but it does not hamper in case of the membrane chromatography when the transport takes place along the membrane column, and it may be a real advantage in case of the stationary phase for capillary electrochromatography column where transport occurs along the column which has to be sealed from outside.

Preliminary research has been done on the foaming of poly(methyl methacrylate) thin films, since as already mentioned, this glassy polymer has quite high negative zetapotential, transmits visible and UV light up to $300 \mathrm{~nm}$ (advantage in case of CEC for the oncolumn detection), and foaming of this polymer [15-19] as well as data of carbon dioxide 

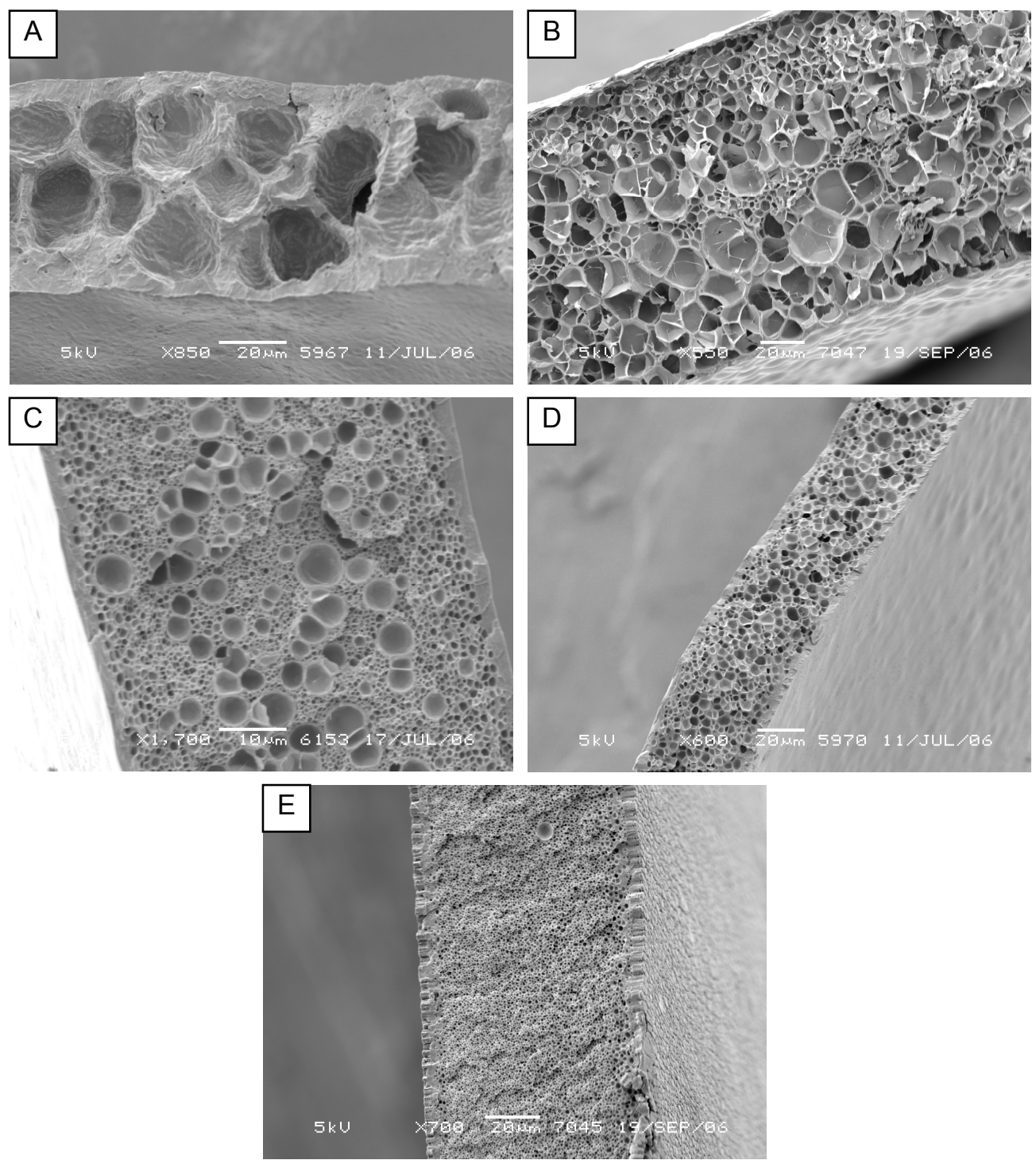

Figure 9 SEM pictures of the foamed PMMA (MW=100 000) thin films casted from acetone; (A) saturation: 35 bar, $3^{\circ} \mathrm{C}, 24 \mathrm{~h}$; (B) saturation: 35 bar, $0^{\circ} \mathrm{C}, 24 \mathrm{~h}$; (C), saturation: 35 bar, $0^{\circ} \mathrm{C}$, $41 \mathrm{~h}$; (D) saturation: $35 \mathrm{bar}, 0^{\circ} \mathrm{C}, 48 \mathrm{~h}$; (E) saturation: $35 \mathrm{bar},-5^{\circ} \mathrm{C}, 48 \mathrm{~h}$; all films foamed at $85^{\circ} \mathrm{C}$ for $30 \mathrm{~s}$; transfer time $30 \mathrm{~s}$; Tg of PMMA $\approx 90^{\circ} \mathrm{C}$

sorption $[20,21]$ have been reported. Dense PMMA films of thickness 45-140 $\mu \mathrm{m}$ were prepared by casting of PMMA solutions on a glass plate (3 different solvents were used: dimethyl sulphoxide, acetone and toluene) and then evaporating the solvent. Following the procedure proposed by Krause et al [10-13], thin polymer films were placed in a pressure vessel and saturated with carbon dioxide at elevated pressures. Subsequently, the carbon dioxide was quickly released from the pressure vessel (within $1 \mathrm{~s}$ ) and the gas-saturated polymer was immersed in a glycerol bath at the desired foaming temperature. The process parameters as listed in Table 2 were varied based on the work of Handa [16] and his diagram of glass transition temperature of the PMMA- $\mathrm{CO}_{2}$ mixture vs. $\mathrm{CO}_{2}$ pressure. Figure 9 presents SEM pictures of some PMMA films saturated at various conditions. No pore connectivity was found for these PMMA films (tested with nitrogen). Further modifications of saturation as well as of foaming conditions did not change the PMMA morphology in direction of 

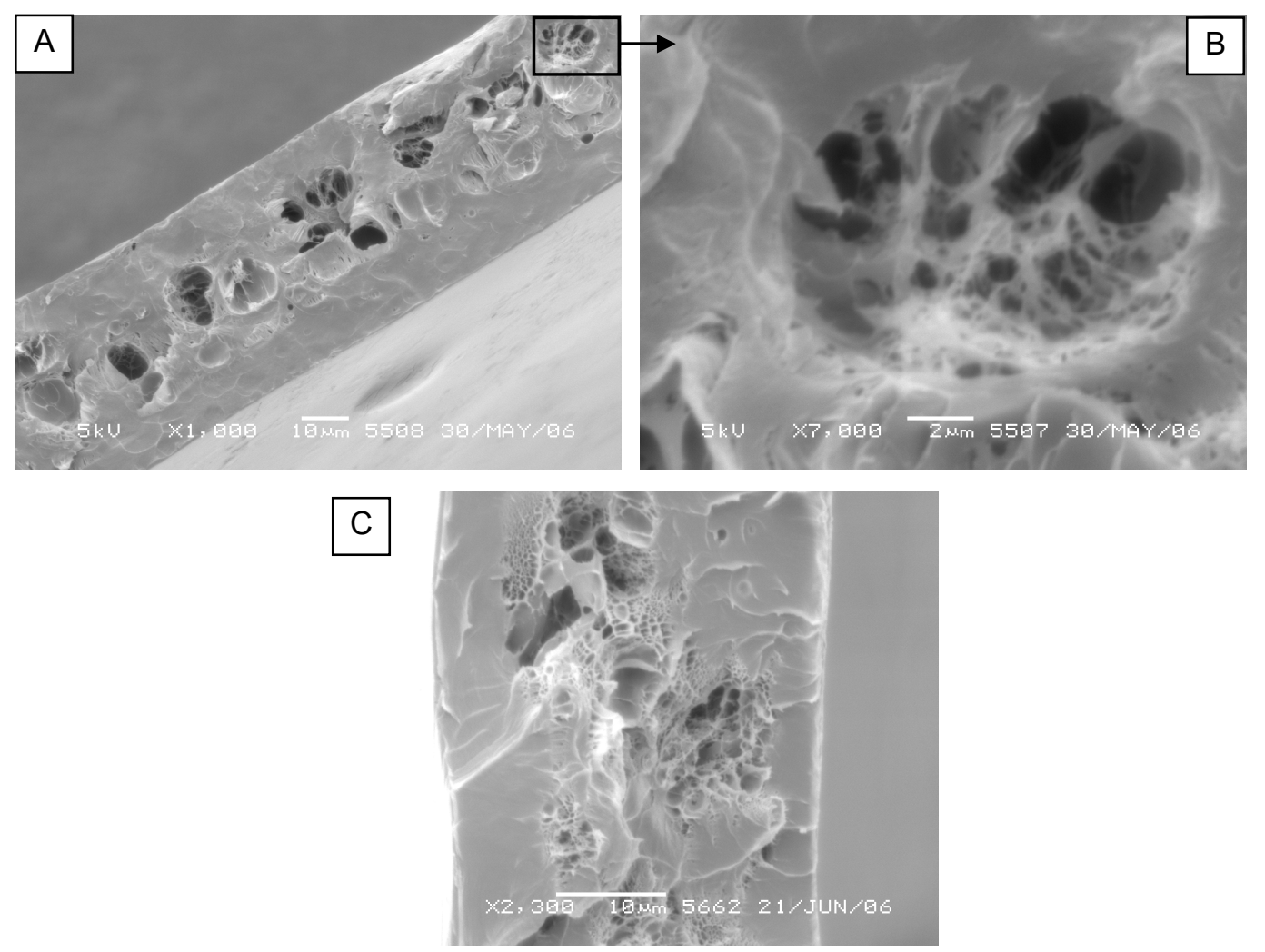

Figure 10 SEM pictures of the foamed PMMA (MW=350 000) thin films casted from acetone; $(\mathrm{A}, \mathrm{B})$ saturation: $35 \mathrm{bar}, 2^{\circ} \mathrm{C}, 24 \mathrm{~h}$; foaming $80^{\circ} \mathrm{C}$; (C) ) saturation: 35 bar, $4^{\circ} \mathrm{C}, 24 \mathrm{~h}$; foaming $85^{\circ} \mathrm{C}$; both samples foamed for $30 \mathrm{~s}$, transfer time $30 \mathrm{~s}$

interconnected pores. Saturation at higher pressures (up to 54 bar) did not bring any improvement, however better results were obtained when increasing the $\mathrm{CO}_{2}$ sorption by decreasing the temperature of the saturation and increasing the saturation time. Better results were obtained when using higher molecular weight MW=350000 PMMA (Figure 10). Regions of open cells smaller than $0.1 \mu \mathrm{m}$ were found in between completely dense unfoamed areas. The results obtained with higher molecular weight PMMA foamed at the same temperature as the lower molecular weight PMMA suggest that the region of bicontinuous structure might be somewhere in between the foaming temperature of $80^{\circ} \mathrm{C}$ and $24^{\circ} \mathrm{C}$ mentioned by Handa [16], and further research should be focused on investigating this range of temperature for the pressures of around 35 bar.

Work of Krause et al. [13] on foaming polyetherimide fibers was also repeated, and indeed the fibers were found to be permeable for nitrogen, however no liquid transport (water, ethanol) was detected through the fibers (pieces of $4 \mathrm{~cm}$ long fibers were tested) in the longitudinal direction (Figure 11). 

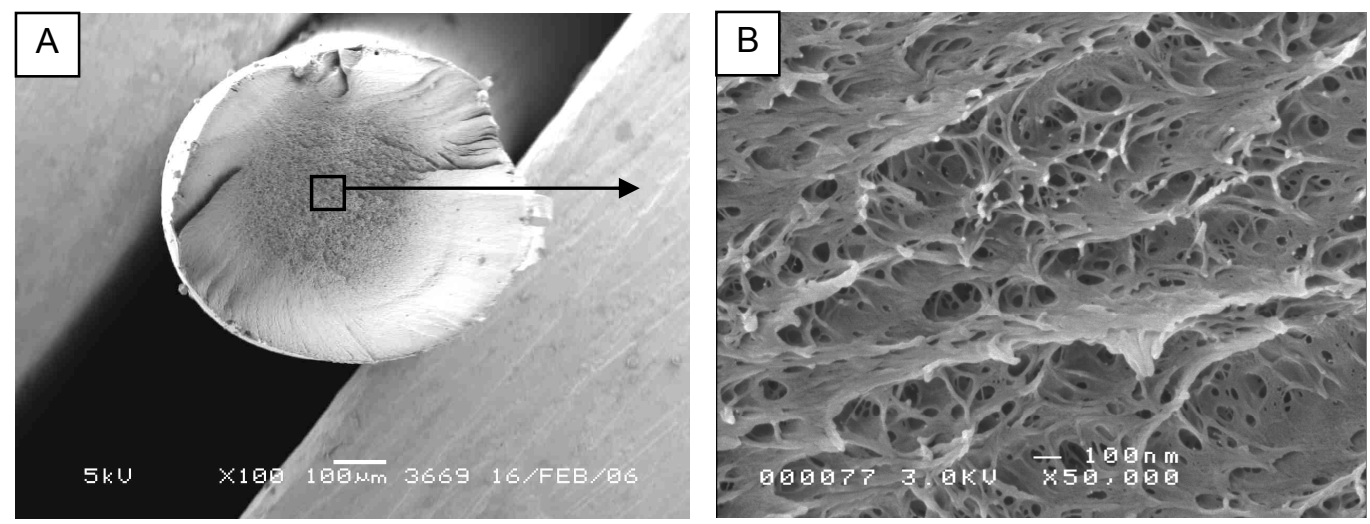

Figure 11 SEM pictures of the PEI fibers saturated at 52 bar for $8 \mathrm{~h}$ and foamed at $200^{\circ} \mathrm{C}$ for $30 \mathrm{~s}$ with transfering time of $30 \mathrm{~s}$

\section{Reflections and Directions}

This thesis, although revolves around biomolecules, presents three very different techniques for their separation: ultrafiltration, membrane adsorption (also referred as a solid phase extraction) and capillary electrochromatography.

The application of mixed matrix membranes in solid phase extraction is promising. The research in this field has been actively going on for the last decade creating new directions and new applications. The contribution of this work into the subject is reflected in the application of mixed matrix membrane adsorbers for the first time in non-aqueous, organic solvents. The developed membranes, successfully made as solvent resistant require however further optimization, mainly concerning the adsorptive particles.

Capillary electrochromatography, although a very efficient and selective technique for separation of biomolecules, seems "challenging" in combination with a membrane stationary phase. Many problems, which have been addressed in this work, have to be solved before capillary electrochromatography and membrane technology can successfully "work together".

Ultrafiltration, being a well established technique, let us focus more on membrane development. Two novel methods to introduce charge into hollow fiber membranes are described in this thesis. Both of them are based on dissolving a modifying chemical agent in the bore liquid, a completely new concept in membrane technology. This opens new perspectives in the world of charged membranes which can now be produced in a one-step spinning with a small amount of the polyelectrolyte, and what is the most innovative - with a charged selective layer on the bore surface, in contrast with all other techniques which involve modification of the outer layer of the hollow fiber membrane.

The most promising research is related to the concept of "chemistry in a spinneret". Dissolving a nucleophilic agent in the bore liquid which crosslinks the membrane forming polymer already in the spinneret, in parallel with the phase inversion process, can be the future not only of the filtrations that are based on charged membranes, but it can offer a great 
potential for many types of membrane processes, such as gas separation or solvent resistant nanofiltration. Using the "chemistry in a spinneret" concept, it becomes possible to hydrophilize a membrane, introduce a charge into it, make the membrane solvent resistant or create a dense gas selective layer, only by playing with the concentration of the crosslinking agent and solvent/nonsolvent ratio in the bore liquid. Moreover, these properties can be introduced into the hollow fiber membrane either only as a thin modified inner layer or an entirely crosslinked membrane can be obtained by changing the ratio solvent/nonsolvent in the bore liquid, shell liquid and polymer solution. No more membrane post-treatment: large volumes of wasted solvent, time consuming modification and washing step; everything can happen now during the spinning, inside a small spinneret - the fiber creator. 


\section{References}

[1] Y.H. See Toh, F.W. Lim, A.G. Livingston, Polymeric membranes for nanofiltration in polar aprotic solvents, Journal of Membrane Science, 301 (2007) 3-10.

[2] K. Vanherck, P. Vandezande, S.O. Aldea, I.F.J. Vankelecom, Cross-linked polyimide membranes for solvent resistant nanofiltration in aprotic solvents, Journal of Membrane Science, 320 (2008) 468-476.

[3] H. Sijbesma, K. Nymeijer, R. van Marwijk, R. Heijboer, J. Potreck, M. Wessling, Flue gas dehydration using polymer membranes, Journal of Membrane Science, 313 (2008) 263276.

[4] J. Potreck, K. Nijmeijer, T. Kosinski, M. Wessling, Mixed water vapor/gas transport through the rubbery polymer PEBAX® 1074, Journal of Membrane Science, 338 (2009) 11-16.

[5] A. Mehta, A.L. Zydney, Permeability and selectivity analysis for ultrafiltration membranes, Journal of Membrane Science, 249 (2005) 245-249.

[6] L.M. Robeson, Correlation of separation factor versus permeability for polymeric membranes, Journal of Membrane Science, 62 (1991) 165-185.

[7] M.-E. Avramescu, M. Girončs, Z. Borneman, M. Wessling, Preparation of mixed matrix adsorber membranes for protein recovery, Journal of Membrane Science, 218 (2003) 219-233.

[8] M.-E. Avramescu, Z. Borneman, M. Wessling, Particle-loaded hollow-fiber membrane adsorbers for lysozyme separation, Journal of Membrane Science, 322 (2008) 306-313.

[9] J.d. Jong, Application of Membrane Technology in Microfluidic Devices, $\mathrm{PhD}$ Thesis, University of Twente, Enschede, 2008.

[10] B. Krause, R. Mettinkhof, N.F.A. Vegt van der, M. Wessling, Microcellular Foaming of Amorphous High- $\mathrm{T}_{\mathrm{g}}$ Polymers Using Carbon Dioxide, Macromolecules, 24-4 (2001) (2001) 874-884.

[11] B. Krause, H.J.P. Sijbesma, P. Munuklu, N.F.A. Vegt van der, M. Wessling, Bicontinous nanoporous polymers by carbon dioxide foaming, Macromolecules, 34 (2001) (2001) 8792-8801.

[12] B. Krause, K. Diekmann, N.F.A. Vegt van der, M. Wessling, Open Nanoporous Morphologies from Polymeric Blends by Carbon Dioxide Foaming, Macromolecules, 35 (2002) (2002) 1738-1745.

[13] B. Krause, M. Kloth, N.F.A. Vegt van der, M. Wessling, Porous Monofilaments by Continous Solid-state Foaming, Industrial and Engineering Chemistry Research, 41 (2002) (2002) 1195-1204.

[14] B. Krause, N.F.A. Vegt van der, M. Wessling, New ways to produce porous porous polymeric membranes by carbon dioxide foaming, Desalination, 144 (2002) (2002) 5-7.

[15] S.K. Goel, E.J. Beckman, Plasticization of poly(methyl methacrylate) (PMMA) networks by supercritical carbon dioxide, Polymer, 34 (1993) 1410-1417.

[16] P.Y. Handa, Z. Zhang, A new technique for measuring retrograde vitrification in polymer-gas systems and for making ultramicrocellular foams from the retrograde phase, Journal of Polymer Science: Part B: Polymer Physics, 38 (2000) 716-725. 
[17] C. Zeng, X. Han, L. Lee, K. Koelling, D. Tomasko, Polymer-Clay Nanocomposite Foams Prepared Using Carbon Dioxide, Advanced Materials, 15 (2003) 1743-1747.

[18] S. Siripurapu, J. DeSimone, S. Khan, R. Spontak, Low-Temperature, Surface-Mediated Foaming of Polymer Films, Advanced Materials, 16 (2004) 989-994.

[19] S.P. Nalawade, F. Picchioni, L.P.B.M. Janssen, Supercritical carbon dioxide as a green solvent for processing polymer melts: Processing aspects and applications, Progress in Polymer Science, 31 (2006) 19.

[20] C. Zhang, J. Wyatt, D.H. Weinkauf, Carbon dioxide sorption in conventional and plasma polymerized methyl methacrylate thin films, Polymer, 45 (2004) 7665.

[21] M. Pantoula, C. Panayiotou, Sorption and swelling in glassy polymer/carbon dioxide systems: Part I. Sorption, The Journal of Supercritical Fluids, 37 (2006) 254-262. 


\section{Summary}

Bioseparations require different techniques than those used in traditional chemical industries. Biomolecules, the organic molecules produced by a living organism are labile and are generally being processed at mild conditions. When heated or placed in environment of extreme $\mathrm{pH}$ for example, they change their structure, lose their function and are eventually destroyed.

Some of the advantages of membrane processes over other traditional techniques are the efficient transport, high throughput, no need of additives, low energy consumption due to operation at low temperatures, the possibility to upscale or downscale, as well as to integrate into other process lines. Current research and development on membranes in order to become techniques of choice for biotechnology, focuses on improvement of selectivity while maintaining the high throughput.

As most of the biomolecules are charged, using a charged membrane for the separation provides improvement of the separation selectivity. A positively charged membrane gives higher retention of a positively charged biomolecule than a neutral or negatively charged membrane of the same pore size. The most applicable group of biomolecules to be used with charged membranes are proteins and this thesis is focused on them. The net charge of a protein depends on the sum of positive and negative charged amino acids, which is a function of the solvent $\mathrm{pH}$. Charged proteins can be fractionated based on charge, even though they have similar sizes. The separation of biomolecules with charged membranes requires optimization of various process parameters like $\mathrm{pH}$, ionic strength of the buffer solution as well as, if possible, tailoring the membrane and protein charge.

This thesis presents various techniques to produce charged membranes. In all cases polymeric porous fiber membranes are produced via the immersion precipitation dry-wet spinning and tested for separation of biomolecules.

Chapter 2 and 3 focus on development of ultrafiltration membranes. In both of them a novel technique of introduction a charge onto the membrane surface by dissolving a polyelectrolyte in the bore liquid is applied. In Chapter 2, a negatively charged, polyimide P84-based membrane is produced by dissolving a sulphonated poly (ether ether ketone) (SPEEK) in the bore liquid, which is deposited on the bore surface of the hollow fiber during the membrane formation. The zeta-potential of the lumen surface of such a membrane is almost three times higher than of the pure P84 membrane. Filtration of a mixture of proteins with similar molecular weights, bovine serum albumin and hemoglobin, but differing in the electrostatic properties, through a P84/SPEEK membrane results in selectivity of over 210 in comparison to selectivity of 60 obtained with the pure P84 membrane at the same $\mathrm{pH}$. Such a 
high selectivity is due to the electrostatic interactions membrane - protein which can be tuned with $\mathrm{pH}$. This in-line one-step spinning method for introduction charge into the membrane can be an alternative for blending or co-extrusion, because it has the advantages of reduced amount of the required polyelectrolyte and the simplicity of fabrication. The P84/SPEEK membranes might find application not only for the separation of biomolecules, but also for salt rejection and other areas of membrane technology where charged solutes need to be separated.

Chapter 3 also explores the technique of dissolving a polyelectrolyte in the bore liquid, but here, this polyelectrolyte (polyethyleneimine, PEI) is at the same time a crosslinking agent for the P84 membrane forming polymer. During the spinning process, an interplay of membrane formation by phase separation and crosslinking occur. It is demonstrated that this interplay can be controlled by the ratio solvent/nonsolvent in the bore liquid, shell liquid, and/or in the polymer solution. Depending on the composition of the bore liquid, two different types of membranes can be produced: either a completely crosslinked, not soluble in N-methylpyrrolidone and porous ultrafiltration fiber, or a porous fiber with a crosslinked dense inner layer selective for gases. In fact, by adding PEI into the bore liquid the membrane morphology, chemistry, charge and hydrophilicity can be tailored. The free tertiary amine groups of PEI, which are not used for crosslinking, induce a positive charge. The porous charged P84/PEI membrane has higher selectivity for the separation of the protein mixture, bovine serum albumin and hemoglobin in comparison to pure P84 membrane. This new method of fabricating composite hollow fiber membrane is simpler, less time consuming, less expensive and more environmental friendly in comparison to other multi-step techniques. It may give perspectives towards fabrication of novel membranes not only in the area of bioseparations, but also in gas separation and nano- and ultrafiltration, especially in harsh solvent environments.

The next membrane separation technique presented here is the membrane chromatography (referred also as a solid phase extraction) that is based on the adsorption of biomolecules onto the mixed matrix hollow fiber membranes (Chapter 4). The charge is introduced into these membranes by dispersing negatively charged particles in the P84 matrix polymer. The novelty is that the membranes are made solvent resistant by crosslinking them with ethylenediamine and for the first time applied for the adsorption of biomolecules from organic solvents. In aqueous solutions, the membranes have high adsorption capacity of bovine serum albumin and lysozyme due to the electrostatic interactions between the positively charged protein and negatively charged membrane. However, the adsorption of lysozyme from dimethyl sulphoxide and cholesterol from N-methylpyrrolidone is significantly lower. In these systems, the adsorption is due to the hydrophobic interactions (rather than the electrostatic interactions) and is lowered by the membrane swelling. The advantage is, however, the better accessibility of the particles in the membrane in comparison to the suspension of particles, which undergo aggregation in organic solvents. In chapter 4, we show the proof of concept of the solvent resistant mixed matrix adsorber membranes and we suggest that for further improving this technology, various other types of particles as well as other target molecule/solvent systems should be considered. 
Capillary electrochromatography (CEC) is the last technique presented in this thesis as a method for biomolecule separation. In fact, Chapter 5 describes application of membrane technology for fabrication of a stationary phase as a column for this hybrid analytical separation technique. Different polymers are processed either via immersion precipitation spinning into: (i) full fibers being a blend of polyimide P84 and SPEEK, (ii) small-bore P84 fibers with SPEEK by dissolving it in the bore liquid (technique developed in Chapter 2), (iii) mixed matrix full fibers made by incorporating negatively charged particles into poly(ether sulphone) matrix, or via phase inversion in-situ as (iv) monoliths of P84 or poly(methyl methacrylate). All produced membranes are evaluated in terms of the morphology, zetapotential and performance in the CEC mode to estimate the electroosmotic flow, selectivity and efficiency. The proof of concept is shown - inorganic compounds as well as large proteins like bovine serum albumin pass through the porous charged membrane structure under application of external electrical field and are detected on-line in form of peaks on the electropherogram. The separations have, unfortunately, poor reproducibility, selectivity and efficiency due to the inhomogeneous membrane morphology, membrane swelling and rather large column dimensions resulting in overheating. Further optimization of these membrane stationary phases should result in improvement of the column characteristics.

The thesis finishes with the evaluation and outlook (Chapter 6). In this part we present the main highlights of the research described in the preceding chapters. We suggest further improvements and directions to explore, and describe some preliminary research. 


\section{Samenvatting}

Het scheiden van biomoleculen vraagt andere technieken dan die zoals gebruikt worden in de traditionele chemische industrie. Biomoleculen, de organische moleculen geproduceerd door een levend organisme, zijn labiel en dienen daarom te worden verwerkt onder milde procescondities. Bij verhitting of blootstelling aan extreme $\mathrm{pH}$ condities veranderen ze van structuur, verliezen hun functionaliteit en worden uiteindelijk vernietigd.

Enkele voordelen van membraanprocessen ten opzichte van andere, meer traditionele technieken, zijn efficiënt transport, hoge doorzet, geen behoefte aan additieven, laag energieverbruik door verwerking op lage temperaturen, modulair, waardoor opschalen of afschalen eenvoudig is, evenals de mogelijkheid tot integratie in andere proceslijnen. Onderzoek en ontwikkelingen in de membraantechnologie richten zich tegenwoordig op het verhogen van de selectiviteit met behoud van de hoge doorzet om zodoende een preferentiële techniek in de biotechnologie te worden. Omdat de meeste biomoleculen een lading bezitten kan, door gebruik te maken van geladen membranen, een hogere scheidingselectiviteit worden behaald. Een positief geladen membraan heeft een hogere retentie voor een positief geladen biomolecule dan een neutraal of negatief geladen membraan met dezelfde poriegrootte. De grootste klasse van biomoleculen, die wordt gebruikt in combinatie met geladen membranen zijn eiwitten, in dit proefschrift wordt hierop dieper ingegaan. De netto lading van een eiwit is afhankelijk af van de som van de positieve en negatieve ladingen in de aminozuren, deze zijn een functie van de $\mathrm{pH}$ van het oplosmiddel. Daarom kunnen eiwitten, ook al bezitten ze een vergelijkbare grootte, toch worden gefractioneerd op basis van hun lading. De scheiding van biomoleculen met geladen membranen vereist optimalisatie van verschillende procesparameters zoals $\mathrm{pH}$, ionsterkte van de bufferoplossing alsook, wanneer mogelijk, het instellen van de membraan- en eiwitlading.

In dit proefschrift worden verschillende technieken beschreven voor de productie van geladen membranen. In alle gevallen gaat het om polymeer gebaseerde poreuze vezel membranen, die worden geproduceerd door een polymeeroplossing via een droog-nat spinproces te extruderen in een waterbad. De vezels worden vervolgens getest op de toepasbaarheid in het scheiden van biomoleculen.

De hoofdstukken 2 en 3 richten zich op de ontwikkeling van ultrafiltratiemembranen. In deze hoofdstukken worden nieuwe technieken beschreven om een lading op een membraanoppervlak aan te brengen door het oplossen van een polyelektrolyt in de lumenvloeistof. In hoofdstuk 2 wordt een negatief geladen, op polyimide P84-gebaseerd, membraan gemaakt door het oplossen van gesulfoneerd polyetheretherketon (SPEEK) in de lumen vloeistof, het opgeloste SPEEK slaat tijdens de membraanvorming neer op het binnenoppervlak van de holle vezel. De zeta-potentiaal van het lumen oppervlak van een 
dergelijk membraan is bijna drie keer hoger dan van een zuiver P84 membraan. Filtratie van een mengsel proteïnen bij de dezelfde $\mathrm{pH}$ en met een gelijk molecuulgewicht, runderserumalbumine en hemoglobine, maar verschillend in de elektrostatische eigenschappen, door een P84/SPEEK membraan geeft een selectiviteit van meer dan 210 waar een selectiviteit van 60 wordt verkregen met een zuiver P84 membraan. Een dergelijk hoge selectiviteit wordt toegeschreven aan de elektrostatische interacties tussen het membraan en het eiwitmolecuul welke kunnen worden ingesteld met de $\mathrm{pH}$. Deze in-line éénstapspinmethode voor het inbouwen van lading in het membraan is vanwege een lager polyelektrolyt verbruik en door de eenvoudige fabricage, een alternatief voor het mengen of co-extruderen. De P84/SPEEK membranen zijn niet alleen toepasbaar voor de scheiding van biomoleculen, maar ook in ontzouting en andere gebieden binnen de membraantechnologie, waar opgeloste stoffen, die een lading bezitten, gescheiden moeten worden.

In hoofdstuk 3 wordt een techniek beschreven waarbij het polyelektrolyt (polyethyleenimine, PEI) dat wordt opgelost in de lumenvloeistof, een crosslinker is voor P84, het membraanvormende polymeer. Tijdens dit proces treedt er een samenspel van membraanvorming, door fasescheiding, en crosslinking plaats. Er wordt aangetoond dat dit samenspel kan worden beïnvloed door de verhouding oplosmiddel/niet-oplosmiddel in de lumenvloeistof, de externe vloeistof en/of in de polymeeroplossing. Afhankelijk van de samenstelling van de lumenvloeistof, kunnen twee verschillende soorten membranen worden geproduceerd: hetzij een volledig verknoopt, niet oplosbaar in N-methylpyrrolidone poreuze ultrafiltratievezel, of een poreuze vezel met een verknoopt, dichte binnenste laag die selectief is voor gassen. Door het toevoegen van PEI in de lumenvloeistof, kan in feite de gewenste membraanmorfologie, -chemie, -lading en hydrofiliciteit ingesteld worden. De vrije tertiaire amine groepen van PEI, die niet worden gebruikt voor het verknopen, geven het membraan een positieve lading. Het poreuze, geladen P84/PEI membraan bezit een hogere selectiviteit voor de scheiding van het eiwit mengsel runderserumalbumine/hemoglobine in vergelijking met het zuivere P84 membraan. Deze nieuwe methode voor het vervaardigen van samengestelde holle vezelmembranen is eenvoudiger, minder tijdrovend, minder kostbaar en meer milieuvriendelijk in vergelijking met andere meerstap technieken. De methode biedt perspectieven voor de fabricage van nieuwe membranen, niet alleen op het gebied van bioscheidingen, maar ook in de gasscheiding, nano- en ultrafiltratie en in het bijzonder voor filtraties onder extreme oplosmiddelcondities.

De membraanscheidingtechniek, die wordt beschreven in hoofdstuk 4, is membraanchromatografie, ook wel aangeduid als een vaste fase extractie, deze is gebaseerd op de adsorptie van biomoleculen op de gemengde matrix holle vezel membranen. De lading in deze membranen wordt geïntroduceerd door het dispergeren van negatief geladen deeltjes in een P84 matrix. De innovatie van dit onderzoek is, dat oplosmiddelresistente membranen gemaakt worden door verknoping met ethyleendiamine en vervolgens voor het eerst worden toegepast voor adsorptie van biomoleculen in organische oplosmiddelen. In waterige oplossingen, laten deze membranen een hoge adsorptiecapaciteit van runderserumalbumine en lysozyme zien als gevolg van de elektrostatische interacties tussen de positief geladen eiwitten en het negatief geladen membraan. Echter, de adsorptiecapaciteit van lysozyme in dimethylsulfoxide en die van cholesterol in N-methylpyrrolidone is aanzienlijk lager. In deze 
systemen wordt de adsorptie bewerkstelligd door hydrofobe interacties (in plaats van de elektrostatische interacties) en wordt verlaagd door de membraanzwelling. Het voordeel is echter de betere bereikbaarheid van de deeltjes in het membraan in vergelijking met de in de oplossing gedispergeerde deeltjes, welke onderhevig zijn aan aggregatie. Ook laten we in hoofdstuk 4 het concept van oplosmiddelbestendige gemengde matrix adsorber membranen zien en geven aan dat een verdere verbetering van deze technologie mogelijk is door gebruik te maken van een ander type deeltje, doelmolecuul of oplosmiddel.

Capillaire elektrochromatografie (CEC) is de laatste techniek die in dit proefschrift is beschreven als mogelijke methode voor biomolecuulscheiding. In feite wordt in hoofdstuk $\mathbf{5}$ de toepasbaarheid van de membraantechnologie voor de productie van een stationaire fase chromatografische kolom voor deze hybride analytische scheidingsmethode beschreven. Verschillende polymeren verwerkt met enerzijds het droog-nat spinproces in: (i) volle vezels op basis van een blend van polyimide P84 en SPEEK, (ii) P84 vezels met een klein lumen bekleed met SPEEK door het oplossen ervan in de lumenvloeistof (de techniek ontwikkeld in hoofdstuk 2), (iii) gemengde matrix volle vezels gemaakt door het dispergeren van negatief geladen deeltjes in een polyethersulfon matrix, of anderzijds via in-situ fase-inversieproces als (iv) monolieten van P84 of polymethylmethacrylaat. Alle gemaakte vezels zijn geëvalueerd op basis van morfologie, zeta-potentiaal en de prestaties in de CEC-modus om zo de elektroosmotische flow, selectiviteit en de efficiëntie te kunnen afschatten. De proeve van bewijs wordt geillustreerd door: anorganische verbindingen en grote eiwitten zoals runderserumalbumine door de poreuze structuur van geladen membraan te permeëren onder het aanleggen van een extern elektrisch veld waarna ze on-line in de vorm van pieken in een elektroferogram zichtbaar zijn gemaakt.

De scheidingen laten, helaas, een slechte reproduceerbaarheid, selectiviteit en efficiëntie zien, als gevolg van een inhomogene membraanmorfologie, membraanzwelling en de vrij grote membraanafmetingen, die resulteren in oververhitting. Verdere optimalisatie van deze stationaire fasen moet leiden tot verbetering van de kolomkarakteristieken.

Het proefschrift eindigt met de evaluatie en de vooruitblik (hoofdstuk 6). In dit deel presenteren we de belangrijkste hoogtepunten uit de voorgaande hoofdstukken. We geven suggesties voor verder onderzoek en procesverbeteringen en beschrijven enkele inleidende resultaten. 


\section{Podsumowanie}

Bioseparacje wymagają innych technik niż te używane w tradycjnym przemyśle chemicznym. Biomolekuły, organiczne substancje produkowane przez żywe organizmy, są nietrwałe i z reguły przetwarzane $\mathrm{w}$ łagodnych warunkach. Jeśli zostaną poddane wysokim temperaturom lub umieszczone w środowisku o wysokim $\mathrm{pH}$, mogą zmienić strukturę, stracić swoje funkcje i ostatecznie ulec degradacji.

Do zalet procesów membranowych, które są przewagą dla tradycyjnych technik, należą efektywny transport, wysoka wydajność, brak potrzeby używania dodatków, niskie zużycie energii dzięki eksploatacji w niskich temperaturach, mozliwość zwiększania i zmniejszenia skali procesu jak również integrowania z innymi operacjami jednostkowymi. Obecne badania i rozwój membran pod kątem zwiększenia ich roli w biotechnologii, muszą zmierzać w kierunku poprawy selektywności przy zachowaniu dotychczasowej wydajności.

Większość biomolekuł posiada ładunek elektryczny, dlatego zastosowanie membran również posiadających ładunek elektryczny zapewnia poprawę selektywności. Dodatnio naładowana membrana zapewnia wyższą retencję pozytywnie naładowanej biomolekuły niż membrana nie posiadająca ładunku lub naładowana ujemnie. Najodpowiedniejszą grupą biomolekuł do separacji przy użyciu membran posiadających ładunek elektryczny są proteiny, na których skupia się niniejsza dysertacja. Ładunek netto proteiny jest funkcja pH i zależy od sumy pozytywnie i negatywnie naładowanych aminokwasów. Naładowane proteiny mogą być frakcjonowane na zasadzie różnic $w$ ich ładunku, nawet jeśli mają podobne masy cząsteczkowe. Separacja biomolekuł przy pomocy naładowanych membran wymaga optymalizacji wielu parametrów, z których najważniejsze to $\mathrm{pH}$ i siła jonowa buforu oraz ładunek membrany i proteiny.

Dysertacja ta przedstawia różne techniki produkcji naładowanych membran. We wszystkich przypadkach polimerowe porowate membrany w kształcie pustych włókien produkowane są w procesie sucho-mokrego spinowania (ekstruzji) poprzez tzw. wytrącanie przez zanurzenie w koagulancie, i nastepnie używane do separcji biomolekuł.

Rozdziały 2. i 3. skupiają się na produkcji membran ultrafiltracyjnych. W obu przypadkach zastosowana jest nowatorska metoda wprowadzania ładunku na powierzchnię membrany poprzez rozpuszczenie polielektrolitu w cieczy tworzącej otwór włókna (cieczy wewnętrznej). W Rozdziale 2. ujemnie naładowana membrana poliimidowa (P84) produkowana jest przez rozpuszczenie sulfonowanego polietereterketonu (SPEEK) w cieczy wewnętrznej, który to polimer osadza się na wewnętrznej powierzchni włókna podczas formowania się membrany. Zeta-potencjał wewnętrznej powierzchni takiej membrany jest prawie trzy razy wyższy niz zeta-potencjał membrany poliimidowej bez SPEEK-u. Filtracja 
mieszaniny protein o podobnych masach molowych, surowiczej albuminy wołowej i hemoglobiny, ale różniących się właściwościami elektrostatycznymi, z użyciem membrany P84/SPEEK skutkuje $\mathrm{w}$ selektywności ponad 200, w porównaniu z selektywnością 60 otrzymaną z membraną P84 bez SPEEK-u w tym samym pH. Tak wysoka selektywność spowodowana jest elektrostatycznymi oddziaływaniami membrana-proteina, które mogą być łatwo modyfikowane poprzez zmiane $\mathrm{pH}$. Ta jedno-etapowa (ang. "in-line") metoda spinowania prowadząca do uzyskania naładowanej elektrostatycznie membrany, może być alternatywą dla mieszanek polimerowych lub dwuwarstwowej ekstruzji dzięki takim zaletom jak zredukowana ilość zużywanego polielektrolitu i prostota procesu fabrykacji. Membrany P84/SPEEK mogą znaleźć zastosowanie nie tylko w separacji biomolekuł, ale również w usuwaniu soli i innych dziedzinach technologii membranowej, gdzie separacji podlegają anality z ładunkiem elektrycznym.

Rozdzial 3. również poświęcony jest technice, w której polielektrolit rozpuszczany jest w cieczy wewnętrznej, ale w tym wypadku, polielektrolit (polietylenoimina, PEI), jest również czynnikiem sieciującym dla polimeru P84 tworzącego membranę. Podczas procesu spinowania dochodzi równocześnie do separacji faz jak i sieciowania polimeru, które to mechanizmy oddziaływują na siebie wzajemnie. Wykazano, że to wzajemne oddziaływanie może być kontrolowane poprzez proporcję rozpuszczalnik/nierozpuszczalnik w cieczy wewnętrznej, cieczy zewnętrznej i/lub w roztworze polimeru. W zależności od składu cieczy wewnętrznej wyprodukowane mogą być dwa różne rodzaje membran : całkowicie zsieciowane, nierozpuszczalne w N-metylpyrolidonie i porowate włókna ultrafiltracyjne lub porowate włókna z usieciowaną wewnętrzną nieporowatą i selektywną dla gazów warstwą. Poprzez dodanie PEI do cieczy wewnętrznej, możliwe jest zmienianie morfologii membrany, jej składu chemicznego, ładunku oraz hydrofilowości. Wolne aminy trzeciorzędowe od PEI, które nie są zużyte podczas sieciowania, indukują pozytywny ładunek na powierzchni membrany. Porowata naładowana membrana P84/PEI ma wyższą selektywność separacji mieszaniny protein, surowiczej albuminy wołowej i hemoglobiny, w porówaniu z membraną P84 bez PEI. Ta nowa metoda produkcji kompozytowych włókien membranowych jest łatwiejsza, mniej czasochłonna, mniej kosztowna i bardziej przyjazna dla środowiska w porównaniu z innymi wielo-etapowymi technikami. Metoda ta otwiera perspektywy w kierunku fabrykacji nowych membran nie tylko w zakresie bioseparacji, ale również w dziedzinie separacji gazów, nano- i ultrafiltracji, szczególnie w środowisku agresywnych rozpuszczalników.

Następną przedstawioną $\mathrm{w}$ tej dysertacji techniką separacji membranowej jest chromatografia membranowa (znana również jako ekstrakcja do fazy stałej) oparta na adsorpcji biomolekuł na membranach włóknowych o mieszanej matrycy (Rozdzial 4). Ładunek wprowadzany jest do tych membran poprzez rozprowadzenie negatywnie naładowanych cząstek w matrycy polimeru P84. Innowacją metody prezentowanej tutaj jest wyprodukowanie membran stabilnych $\mathrm{w}$ rozpuszczalnikach poprzez usieciowanie ich etylenodiaminą i po raz pierwszy zastosowanie tych membran do adsorpcji biomolekuł z rozpuszczalników organicznych. W roztworach wodnych, membrany te odznaczają się wysoką pojemnością adsorpcyjną surowiczej albuminy wołowej i lizosomu z powodu interakcji elektrostatycznych pomiędzy pozytywnie naładowaną proteiną i negatywnie 
naladowaną membraną. Jednakże adsorpcja lizosomu z dimetylosulfotlenku i cholesterolu z $\mathrm{N}$-metylpyrolidonu jest znacząco niższa. W takich systemach, adsorpcja odbywa się z powodu interakcji hydrofobowych (a nie elektrostatycznych) i jest redukowana dodatkowo przez puchnięcie membrany. Tym niemniej, zaletą jest lepsza dostepność cząstek w membranie w porównaniu do zawiesiny cząstek, które ulegają agregacji w rozpuszczalnikach organicznych. W rozdziale 4. pokazujemy dowód koncepcji membran o mieszanej matrycy stabilnych w rozpuszczalnikch i sugerujemy, że w celu dalszego udoskonalenia tej technologii, powinny być uwzględniane inne rodzaje cząstek jak równiez systemów docelowa biomolekuła/ rozpuszczalnik.

Kapilarna elektrochromatografia (KEC) jest ostatnią techniką separacji biomolekuł prezentowana $\mathrm{w}$ tej dysertacji. W Rozdziale 5. opisane jest zastosowanie technologii membranowej do fabrykacji fazy stacjonarnej jako kolumny dla tej hybrydowej analitycznej techniki separacyjnej. Różne polimery są przetwarzane albo w wyniku spinowania połączonego z wytrącaniem przez zanurzanie w koagulancie jako: (i) włókna pełne będące mieszanką poliimidu P84 i SPEEK-u, (ii) włókna o małej średnicy wewnętrznej, P84 ze SPEEK-iem osadzonym na powierzchni włókna poprzez rozpuszczenie SPEEK-u w cieczy wewnętrznej (technika opisana $\mathrm{w}$ rodziale 2.), (iii) membrany o mieszanej matrycy $\mathrm{w}$ kształcie pełnych włókien otrzymane przez rozprowadzenie negatywnie naładowanych cząstek w matrycy polietersulfonu, albo w wyniku inwersji faz in-situ jako (iv) monolity $\mathrm{z}$ P84 lub z poli(metakrylatu metylu). Wszystkie wyprodukowane rodzaje membran sa analizowane pod względem ich morfologii, zeta-potencjału i charakterystyki KEC w celu oszacowania przepływu elektroosmotycznego, selektywności i sprawności. Jest możliwe do wykazania, że nieorganiczne anality oraz duże proteiny jak surowicza albumina wołowa, przepływają przez porowatą naładowaną strukturę membrany pod wpływem przyłożenia zewnętrznego napięcia elektrycznego, i wykrywane są on-line w postaci pików na elektroferogramie. Separacje charakteryzują się niestety niską powtarzalnością, selektywnością i sprawnością, głównie z powodu niehomogenicznej struktury membrany, puchnięcia membrany i raczej dużych rozmiarów kolumny prowadzących do jej przegrzewania. Dalsza optymalizacja membranowych faz stacjonarnych powinna prowadzić do polepszenia charakterystyki kolumny.

Dysertacja kończy się Rozdziałem 6. zawierającym ocenę przeprowadzonych badań i perspektywy opisanych innowacji. W części tej prezentowane są najważniejsze dokonania z poprzedzających rozdziałów oraz rekomendowane są dalsze optymalizacje i kierunki badań. 


\section{Acknowledgment}

Four and a half years - it went like a second, and I still cannot believe when I look at this book. I would lie if I say I have been dreaming about doing a $\mathrm{PhD}$ since I started walking. The truth is that I never planned to do a $\mathrm{PhD}$, but now I know, it was one of the best decisions I have ever made. Many things happened in my life according to a chain reaction mechanism, I was pushed by some people and I pulled others behind me.

I will begin with the people who pushed me :-)

Everything started thanks to Prof. Korff who gave lectures called Membranes and Bioseparations at Fachhochschule Münster (I did quite well at the final exam :-) and who found a position for me for a Master Project at Gambro Dialysatoren $\mathrm{GmbH}$, and opened the Membrane World for me. Next, Bernd Krause, my supervisor at Gambro... and the most "responsible" person :-) Bernd, you said: "Have you ever thought about doing a PhD?" And here I am, 5 years later, and you are again "my supervisor" being a member of the committee of my $\mathrm{PhD}$ defense. Thank you for the "push"; I really needed it. You are a fundamental person on my course to reach this point, special thanks.

Matthias, you gave me the chance to come to Twente... and it seems you did not regret that! :-) Thank you for having faith in me and for giving me the opportunity to join your "New Team" in Aachen. It is a pleasure to work for you!

Dimitris, my daily supervisor, we spent hours on scientific discussions. Your question: "How do others do it?" still wakes me up at night. Dimitris, I don't care how others do it. You should know by now that I follow always my own way :-). Thank you for your patience and your criticism, both were required.

The person I pulled behind me - Szymon. It is actually quite difficult to make it clear who pulled/pushed whom. All I know is that without your help, your support, hundreds of hours of discussions, your ideas... (I could go like this forever), without your supervision, there wouldn't be this book. I cannot thank you enough... I could always count on you, in everything; I could laugh and cry on your shoulder. At the very last day of this way, you also stand next to me, dziekuję.

Ikenna, wierzę, że Twój polski jest już wyśmienity, ale dla ułatwienia, napiszę też po angielsku :-). You were the first person I saw when I started my $\mathrm{PhD}$, as we started it together on the very same day. Thanks to your support and your trust in me, I did not give up within the first six months. My friend, thank you for believing in me and for making me believe that things will get better. You were right (as always) - they got better, at all levels $\odot$. It might be that our ways will separate, but I will never forget you. Thanks for standing next to me on "that" day. 
The MTG group, you were my family! I had a great time during the working hours and all the events outside. Maybe sometimes I complained too much about the Netherlands, but the truth is, I love this country!

I will begin with my office mates.

My first office in Langezijds: Jörg, Dana, Jorrit and Hylke - you gave me a warm welcome and introduced me to the group, thanks guys! My second office in Meander: Hakan, Tymen and Joost - we talked a lot (when did we work then?), and the final composition (the best office ever): Olga, Wika and Nicolas - we rocked, guys!

The frame of the MTG, one by one:

Antoine, we had bad times and good times, but I think we finished well and the end is the one that matters.

Zandrie, I still cannot understand some of your jokes (it is better that way, for sure), thank you for translating the summary - you are now part of my thesis, can there be a better appreciation? :-)

Herman, Erik, Marcel - my spinning masters, I learned a lot from you, and you can be sure, it is not that easy to get rid of me, I will keep bugging you!

Harmen, you were always there to discuss any problem. I will never forget what you told me when I was leaving the group. Your words made me realized that I contributed to the group and that this input will not be forgotten.

Lydia, the experimental work of $1 / 4$ of this thesis was done by you and I deeply appreciate your efforts and dedication. It was a pleasure working with you, thank you!

De "sunshine" heeft Enschede verlaten, maar ik ben ervan overtuigd dat de zon voor jou nogsteeds genoeg licht zal geven om het fantastische werk te verrichten dat je niet alleen voor mij hebt gedaan, maar voor ons allemaal. Dank je wel, John.

Greet, you are the best secretary ever! You rock! You are the most organized person I have ever met, having time to arrange everything and answer questions from all around. In the last months of my presence in the group I used to pass by your office quite often and you were always there for me, listening, supporting and understanding what I felt. Greet, all this meant a lot to me, thank you...

I had only one student (but a good one!). Rogier, thanks for all the work you did and good luck!

I would like to say a big THANK YOU to all the people, who "rewound" during "my times" in Twente and who will always stay in my mind, especially: Maik, Hakan, Jens, João, Alisia, Matías, Sander, Çan, Katja, Olga, Anne Corine, Enver, Al-Hadidi, Zeynep, Jeroen, Marlon, Wojtek.

Special thanks should go to two ladies, Katja and Olga.

Katja, if I count all the hours we talked during all the conferences between the lectures and in the rooms, during all the stukjes we prepared together - it will end up in hundreds. You are a great listener and even a better adviser. I could always rely on you. Thank you.

Olga, there is one thing I regret about our friendship... that it started so late!!! Why didn't you join our group earlier? Olga, you have this special gift (similar to Ikenna) of making me believe that things are going to turn up better. I learned from you to look in a different way at things and situations happening around me. Your support during the last 
months was healing. You were right (as always) things get better. Olga, we will show them!!!!!!!!!!!!!!!!!!!!!!!!!!!!!!!!!!!!!!!!!!!!!!!!!!!!!!!!!!!!!!!!!!!!!!!!!!!!!!!!!!!!!!!!!!!!!!!!!!!!!!!!!!!!

There was a bunch of people whose support was very valuable to me in the last months of my PhD and I would like to appreciate them: Szymon, Agata, Olga, Wika, Greet, Wojtek, Çan and Laura.

Many thanks go to the Indian community, especially to Srivatsa, for the nice time we had together. I had so much fun during all the festivals and I learned a lot about your culture. One day I will go to India...

The Polish people, my solid rock abroad... Agata and Wilco (almost Polish by now), Szymon and Danka, Magda and Artur, Izabela and Alexis (almost Polish by now), Kasia and Tomek, Krzys and Kasia, Wojtek and Joasia, the entire Polish mafia from Steinfurt, Gosia, Kasia, Lidzia and Rafał, Edyta, Agata. Thanks to you I had a bit of Poland always with me, in my pocket...

Agata, last but not least, I found a wonderful friend in you. I cannot imagine going through this $\mathrm{PhD}$ without you. You were the first to listen about my ups and downs, we could laugh and cry together, get drunk and go for a crazy trip to Paris (not in this sequence, necessarily). I am sure that this friendship will last forever...

Now the time has come to close the Enschede stage and start the Aachen part. I received a warm welcome in my new group and I would like to say big THANKS for that to my new Aachener Kollegen. There are few people that I just must mention: Steffie, John, Kathrin and Murat. If I think how close we became in such a short time! Guys, thanks for the wonderful 18th birthday you arranged for me. You are great! Special thanks go to Steffie who helped me (read: did almost all the job) in formatting my thesis. João, you made "the slide in" much easier for me, I appreciate your help a lot.

To my family.

Artur i Sandra, dziekuję za Wasze wsparcie. Mogłam zawsze na Was liczyć, w każdej, nawet nadbramkowej sytuacji. Nieważne czego potrzebowałam - zawsze wyciagaliście pomocną dłon i slużyliście radą.

Mamo, Tato, byliście moją podpora, nigdy nie skarżyliście się, że wyjechałam tak daleko i widzicie mnie trzy razy do roku. Dziekuję za to, że wspieraliście mnie we wszystkim co robiłam i we wszystkich decyzjach, które podejmowałam. Nigdy nie przestaliście we mnie wierzyć. Dziekuję Wam za to.

\section{Karina}


